\title{
The Power-Knowledge to Move Mountains: Subaltern Discourses of Mountaintop Removal in Coal River Valley, West Virginia
}

Jen Osha

West Virginia University

Follow this and additional works at: https://researchrepository.wvu.edu/etd

\section{Recommended Citation}

Osha, Jen, "The Power-Knowledge to Move Mountains: Subaltern Discourses of Mountaintop Removal in Coal River Valley, West Virginia" (2010). Graduate Theses, Dissertations, and Problem Reports. 3259. https://researchrepository.wvu.edu/etd/3259

This Dissertation is protected by copyright and/or related rights. It has been brought to you by the The Research Repository @ WVU with permission from the rights-holder(s). You are free to use this Dissertation in any way that is permitted by the copyright and related rights legislation that applies to your use. For other uses you must obtain permission from the rights-holder(s) directly, unless additional rights are indicated by a Creative Commons license in the record and/ or on the work itself. This Dissertation has been accepted for inclusion in WVU Graduate Theses, Dissertations, and Problem Reports collection by an authorized administrator of The Research Repository @ WVU.

For more information, please contact researchrepository@mail.wvu.edu. 
The Power-Knowledge to Move Mountains:

Subaltern Discourses of Mountaintop Removal in Coal River Valley, West Virginia.

\author{
Jen Osha \\ Dissertation Submitted to the \\ Eberly College of Arts and Sciences \\ at West Virginia University \\ in partial fulfillment of the requirements \\ for the degree of \\ Doctor of Philosophy \\ in Geography
}

\author{
Ann Oberhauser, Ph.D., Chair \\ Brent McCusker, Ph.D. \\ Bradley Wilson, Ph.D. \\ Daniel Weiner, Ph.D. * \\ Harvard Ayers, Ph.D. ** \\ Department of Geology and Geography \\ * Ohio University, Athens, Ohio \\ ** Appalachian State University, Boone, NC
}

Morgantown, WV
2010

Keywords: Mountaintop removal, Coal River Mountain, West Virginia, coal communities, surface mining, strip mining, valley fill, power knowledge, Foucault, Participatory GIS, participatory mapping, slurry impoundment, Rock Creek, Brushy Fork, Whitesville.

Copyright 2010 Jen Osha 


\title{
ABstract \\ The Power-Knowledge to Move Mountains: Subaltern Discourses of Mountaintop Removal in Coal River Valley, West Virginia.
}

\author{
Jen Osha
}

This research investigates the perspectives of local residents within the Coal River Valley, WV, who are concerned about the impacts of mountaintop removal (MTR) on themselves, their families and communities, and their environment. In this dissertation, the term 'subaltern' represents a heterogeneous community of resistance to MTR with multiple perspectives around intersections of gender, age, and livelihood. The objectives of my study are twofold: to illuminate how dominant legal discourse continues to subjugate the discourse of resistance to MTR, and to identify possible spaces of resistance within which the subaltern discourse can challenge the power relations that continue to permit mountaintop removal in the case study area. The subaltern discourse is illustrated through 59 interviews with local residents and the construction of participatory maps showing specific concerns regarding MTR on Coal River Mountain.

This participatory GIS (PGIS) project of Coal River Valley is situated within a Foucauldian framework that locates my specific case study within the larger power dynamics controlling mountaintop removal within the valley. Literature from both critical cartography and critical GIS is drawn upon to explain the "particular, local, regional knowledge" referred to by Foucault as an "insurrection of subjugated knowledges" within the Coal River Valley. The use of a PGIS approach to construct the subaltern discourse allows for local residents in the case study area to provide "expert" data regarding their concerns and to play an active role in how their concerns and home place are represented. Data collected through the construction of a mini-archeology of the legal discourse of MTR and a PGIS of Coal River Valley is used to analyze the power relations that continue to subjugate the subaltern discourse. Specific analysis focuses on the discursive formations that are not privileged as "expert knowledge" by the dominant discourse. This dissertation illustrates the concerns of local residents regarding the impact of MTR on the physical and social landscapes of their homes and recommends "spaces of resistance” within which the subaltern discourse can alter power dynamics regarding the continued permitting of MTR. 


\section{Dedication}

To the people of Coal River

and to the mountains that sustain and enrich them 


\section{Acknowledgements}

This work is the culmination of a decade of relationships and four years of research in the Coal River Valley. First and foremost, I would like to express my heartfelt thanks to the families of Coal River who not only trusted me in their lives, but shared so many lessons with me about true connection to family and to the land. While I have received a fine formal education in my life, I am the most proud of the life education that I earned during my time in Coal River. I am a better mother and a better person for it, and I will pass it on as I promised.

I am very grateful have had an excellent, supportive committee throughout this arduous process. I would like to thank my committee: Ann Oberhauser, Brent McCusker, Bradley Wilson, Daniel Weiner, and Harvard Ayers, for your faith and support of me. I would also like to thank Trevor Harris and Ray Hicks, who served on my committee. Every person on my committee contributed in a meaningful way to this work of scholaractivism, which was a gift of time and faith. I would like to give particular thanks to my Chair, Dr Ann Oberhauser, who helped me to stay physically and emotionally headed in the right direction, and supported me in my struggle to balance motherhood and dissertation writing.

This dissertation involved a great deal of travel between Morgantown and Rock Creek, WV, where I conducted my fieldwork. I would like to thank the Eberly College of Arts and Sciences and the West Virginia University Graduate Office for my Dissertation Fellowship and for two travel grants, Arctic Voices for travel and fieldwork support, and Coal River Mountain Watch for lodging, food, and a decade of support and friendship. While the West Virginia Humanities Council did not support direct research costs, their generous support allowed for the creation of the participatory product of this research: the Journey Up Coal River website. I would also like to thank the Switzer Foundation, the Ohio Valley Environmental Coalition, Climate Ground Zero, Mountain Justice, Appalachian Voices, the Sierra Club, and our Aurora Lights crew for more than words can possibly express. To the Rock Creek crew, you know who you are, and you made the daily reality of this work possible. Much love and respect.

Many thanks to Charles Suggs, Dea Goblirsch, Sherman Stinson, Jen Smith, Laura von Dolen, Matt Finck, Will Wickham, Eric Blevins, Jason Johnson, Laura Merner, Jordan Freeman, EmmaKate Martin, Matt Noerpel and Rory Mcllmoil for help with editing, transcribing, and research. Fritz Boettner at Downstream Strategies provided essential help to me learning ArcMap, as well as creating the map of blasting on Cherry Pond Mountain. Thanks to Chad Stevens and Jordan Freeman for the use of their photographs documenting non violent direction protests on Coal River Mountain, and to Antrim Caskey for helping me figure out how to take at least a decent picture.

Closer to home, I want to thank my mother Judy Osha for her support and belief in me. I wouldn't have started this program without her, and she's one tough woman. She doesn't know it, but she's my hero. To my father Frank Osha, who isn't here to see me graduate, 
but I know he would have been really excited. Many thanks to my best friend Samatha McCreery for years of lunch breaks, GIS help, the best home-made canned chicken noodle soup ever, and her ability to make even the worst situation better! Above all, I would like to thank my husband Nick Buysse and my son, who supported me through extended periods of absence for my fieldwork and then endless hours in front of the computer. It's finally time for some family adventures! When I get my Ph.D., each one of us gets a letter. 


\section{TABLE OF CONTENTS}

ABSTRACT ii

DEDICATION

ACKNOWLEDGEMENTS iv

List of Tables $\quad$ ix

List of Figures $\quad \mathrm{X}$

List of Terms and Abbreviations $\quad$ xi

1) INTRODUCTION 1

2) CONCEPTUAL FRAMEWORK AND LITERATURE REVIEW 17

a) Foucauldian Framework

b) Critical Cartography/GIS and Participatory GIS

c) Appalachian Political Economy, Identity, and the Subaltern

d) Conclusion

3) RESOURCE EXTRACTION AND RESISTANCE IN THE CASE

STUDY AREA: COAL RIVER VALLEY OF SOUTHERN WEST VIRGINIA
a) Justification of Case Study Area
b) Overview of Physical and Social Geography
c) Coal River as Periphery: Natural Resource Extraction
d) Resistance in the Coal River Valley
e) Multiple Livelihood Strategies and Community Land Use
f) Conclusion

4) RESEARCH QUESTIONS, METHODOLOGY AND METHODS
a) Research Questions
b) Methodology
c) Research Methods
d) Conclusion

5) “HOW DO THEY GET A PERMIT FOR SUCH DEVESTATION?”: 
a) The Original Legal Definition of 'Mountain Top Removal' and 'Valley Fills'

b) Regulatory Rule-Making

c) Intersection with Case Study area

d) Analysis and Conclusion

6) “SO GO THE MOUNTAINS, SO GO THE MOUNTAINEER”:

SUBALTERN DISCOURSES OF MTR IN THE CASE STUDY AREA

a) Introduction to Participants

b) Overall Participant Concern Regarding the Impacts of Mountaintop Removal:

“They'll be nothing here left for anyone”

c) Participant Concern by Geographical Location

d) Intersections of Gender, Age, and Livelihood

e) Alternative Land Use

f) Conclusion

7) THE POWER-KNOWLEDGE TO MOVE MOUNTAINS

a) Legal Conditions of Possibility

b) “If West Virginia were a horse, we'd be the hind end:” The 'Situation' of the Subaltern

c) Spaces of Resistance

d) Conclusion

8) SUMMARY AND CONCLUSIONS

a) Situating the Discourse of Resistance

b) Locating the Discourse within the Communities around Coal River Mountain

c) Participatory Methods and Inclusive Research

d) Unpacking the Original Construction of Mountaintop Removal

e) The Mountaineer Meets Mountaintop Removal

f) Insurrections of Subjugated Knowledges

g) Contributions and Additional Research

h) Conclusion

REFERENCES 


\section{APPENDICES}

Appendix 1: Bee Tree Surface Mine Permit 208

Appendix 2: Eagle No. 2 Surface Mine Permit 210

Appendix 3: Leather Leaf Surface Mine Permit 212

$\begin{array}{ll}\text { Appendix 4: Interview Questions } & 214\end{array}$

Appendix 5: Quantitative Data of Participants 215 


\section{LIST OF TABLES:}

Table 2.1: Citizen Participation Ladder (Weidemann and Femer, 1993)

Table 3.1: Age Distribution

Table 5.1: Surface Mines on Coal River Mountain. Source: WVDEP

Table 6.1: Years of Residency for Participants

Table 6:2: Total and Gender Specific Employment Type for Participants

Table 6.3: Age Breakdown of Participants

Table 6.3: Age Breakdown of Participants

Table 6.4: Participant Concerns Regarding Impacts from Mountaintop Removal Coal Mining

Table 6.5: Descriptions of Mountaintop Removal as Completely Destructive of Associated Environmental and Social Impacts

Table 6.6: Gendered Perspectives on Impacts on Landscape and Perceived Social Impacts 


\section{LIST OF FIGURES:}

Figure 3.1: Location of the Case Study Area Within the Coal River Watershed

Figure 3.2: Coal River Mountain, in the Raleigh County portion of the Coal River

Figure 3.3: Coal River Mountain with MTR permits, Valley Fills, and Previous Mining.

Figure 3.4: Proximity of Communities to Blasting on Cherry Pond Mountain.

Figure 3.5: Seasonal Wheel of Activities in the Coal River Valley.

Figure 6.1: Perceived Flooding Impacts from Current and Pending Mountaintop Removal Operations in the Case Study Area

Figure 6.2: Pettry Bottom in relation to the Edwight Surface Mine

Figure 6.3: Perceived Danger to Communities from the Brushy Fork Slurry Impoundment through Dam Failure or Blow-Outs

Figure 6.4: Logging Area at the Head of Sturgeon’s Fork, Dry Creek

Figure 6.5: Community Tension at June 23, 2009 anti-MTR ralley

Figure 6.6: Blasting Radiuses Around Current and Pending Surface Mines on Coal River Mountain

Figure 6.7: “Hell’s Gate”on Kayford Mountain.

Figure 6.8: Concerns of Residents in Sycamore Hollow Regarding Impacts of MTR

Figure 6.9: Concerns of Residents in Horse Creek Regarding Impacts of MTR

Figure 6.10: Concerns of Residents in Rock Creek Regarding Impacts of MTR

Figure 7.1: Nonviolent Direct Actions to stop blasting on Coal River Mountain

Figure 7.2: Online Permit Map for the Bee Tree Surface Mine, WVDEP 


\section{Terms and Abbreviations}

\section{Authorities of Delimitation: See Formation of an Object}

Clean Water Act (CWA): Section 404 of the Clean Water Act of 1972 allows for the permitting the discharge of "fill" material to create valley fills. The CWA is administered by the Environmental Protection Agency (EPA) and the U.S. Army Corps (Corps).

Conditions of possibility: A philosophical concept made popular by Immanuel Kant. A condition of possibility is a necessary framework for the possible appearance of a given list of entities.

Discourse: Constituted by the rules that define who can speak, when, where, and in what way. For example, how is a resident's decision to speak out against MTR impacted by these rules, and to what degree does their gender, age, or current family employment impact their participation in the discourse of resistance?

Discursive Formations: systems of thought within a discourse. One effect of these discursive formations is to make it virtually impossible to think or work outside of them:

Environmental Protection Agency (EPA): The Clean Water Act is administered by the EPA

Formation of an Object: To create a 'mini-archeology' of MTR, I draw from Foucault's archeological method regarding the formation of an object: map the first surfaces of emergence, describe the authorities of delimitation, and analyze the grids of specification

Surfaces of emergence: specific discursive and institutional sites in which objects first emerge or are re-configured. Applied to Foucault's archeological work on medicine, surfaces of emergence show where individual differences were accorded the status of disease, dementia, etc, and then be designated and studied (Foucault, 1972, pg 41)

Authorities of delimitation: subject positions from which individuals have or acquire the right to define and delineate the objects of a discursive formation. Applied to the discourse of mountaintop removal, authorities of delimitation are the people who were originally able to define and construct mountaintop removal as an object.

Grids of Specification: the classificatory dimensions along which an object is located within a discursive formation. Applied to the legal formation of mountaintop removal, grids of specification would place attention on the specific classification and permitting of mountaintop removal in the case study area.

Historial a Priori — that ground knowledge and its discourses - to represent the conditions of possibility for those discourses. 
Incidental boundary revision (IBR): An IBR is part of the permit revision process stipulated by the WVDEP. The permit supervisor of the surface mine in question reviews the section of the permit being revised and determines if the change is "significant” or "insignificant."

Insurrection of Subjugated Knowledges: Foucauldian term for 1) historical contents that had been buried or disguised and/or 2) Forms of knowledge that were disqualified or located low on the hierarchy: a "particular, local, regional knowledge” (Foucault, 1980, pg 82).

Mountaintop Removal (MTR): The USEPA defines MTR as “a surface mining practice involving the removal of mountaintops to expose coal seams, and disposing of the associated mining overburden in adjacent valleys—-valley fills'” (USEPA, 2009h).

Office of Surface Mining (OSM): SMCRA is administered by the US Department of Interior's Office of Surface Mining at the federal level

Outside Agitating Treehuggers (OATS): An author-defined term referring to the depiction of activists against mountaintop removal by the dominant discourse

Participatory GIS (PGIS): The combination of geospatial technologies with participatory methods that makes significant strides towards addressing many of the ethical issues raised by the social theory critique of GIS.

Power: a network of relations between people which is 'negotiated' within each encounter. Each institutionally sanctioned power relation can be negotiated at a local level and can be challenged overtly or covertly.

Social Construction Approach: An approach to analysis of maps which "emphasizes the genealogy of power in mapping practices and enables multiple, contingent and exploratory perspectives of data” (Crampton, 2001, pg 235).

Surface Mining Control and Reclamation Act (SMCRA): SMCRA was enacted by Congress and signed by Jimmy Carter in 1977 to regulate surface coal mining and reclamation operations on both private and public land. SMCRA is used as the first surface of emergence of mountaintop removal coal mining in this dissertation.

Surfaces of Emergence: see Formation of an Object

U.S. Army Corps (Corps): Section 404 of the Clean Water act, which permits valley fills, is administered by the Corps.

Valley Fills: The use of excess overburden to fill in valleys adjacent to mountaintop removal sites. Permitted through Section 404 of the Clean Water Act. 
West Virginia Department of Environmental Protection (WVDEP): Administrators at the West Virginia Department of Environmental Protection have been delegated primary program management authority by OSM for the regulation and oversight of surface mining activities. 


\section{CHAPTER ONE}

\section{INTRODUCTION}

"What we're trying to do is find balance, you know that, I mean it's tough to find a balance in an extraction state. Looking for those balances..."

"We're the mountain state."

(Pause) “Pardon me?”

"We're the mountain state. We're not the extraction state, we're the mountain state."

"But we're the extraction...we have been...we're been producing energy for over a hundred years."

- Conversation between Governor Joe Manchin and Coal River Valley resident Lorelei Scarborough ${ }^{1}$

On April $5^{\text {th }}$, 2010, our national media focused its spotlight on a fatal mine explosion at the Upper Big Branch mine in the Coal River Valley of southern West Virginia. Through the following five days of waiting and hoping for the 29 men and their families, news anchors overwhelmingly represented the Coal River Valley with dire statistics about poverty, high school drop-out rates, and shared perceptions of fatalism and resignation to

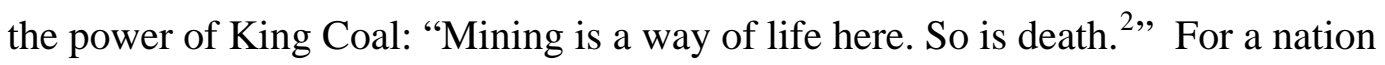
blissfully ignorant of the daily realities of life in an "extraction state”, the mine explosion served to educate many about the human cost of coal mining - as well as to shine light on the power dynamics and corruption of the local elite - yet did little to question the larger impacts of coal mining on the people and land of West Virginia.

The work of geographers Ulack and Raitz (1982) on perceptions of Appalachia resonated in this national media coverage of the Coal River Valley. Their work shows how “outsiders” picked images of 'poverty' and 'low education' to describe Appalachia, while

\footnotetext{
${ }^{1}$ Conversation between Gov Joe Manchin and Lorelei Scarborough during the delivery of a community letter to Governor Joe Manchin regarding Coal River, Oct 19, 2009

${ }^{2}$ Bluestein, G., and V. Smith. "Mine rescue effort turns to recovery,” MSNBC.msn.com, April 10, 2010
} 
“insiders” chose more positive images, such as 'family' and 'farming.' Academia may have moved away from notions of a fatalistic culture of poverty in the last thirty years, but national television still portrays the men who died underground and the lives they led as part of an homogenous other. As a local grandmother and life-long resident of the Coal River Valley stated, "we're considered as the coalfields in this area. I'd like to think that we are much more than that. We have hopes, families, dreams, just like anyone else outside of the coalfields" (CR \#2).

In the face of the Upper Big Branch tragedy, West Virginians and mining families across Appalachia stood together to mourn and raise awareness about the dangers of coal mining to the men and women who work underground. However, just a scratch on the surface of this homogenous voice reveals divisive and bitter differences between West Virginians about the costs and benefits of a particularly controversial form of surface mining: mountaintop removal coal mining. The Coal River Valley had already gained nationwide attention before the mine explosion due to organized resistance and, beginning in February of 2009, non-violent civil disobedience against mountaintop removal. And as the nation questioned whether or not coal mining was worth the risk, the more essential question remained: the risk to whom?

For the landscape of the Coal River Valley contains many geographies of risk: risk to the miner through work- related injuries, risk to families who lose water quality or have homes damaged by blasting, risk to communities living downstream from toxic slurry impoundments and massive denuded landscapes. A great deal of solidarity exists regarding the need to address the risk to miners from work-related injuries obtained while providing our nation with cheap electricity. View are much more polarized, however, when the focus broadens to question the cost of mountaintop removal coal mining on the landscape, health, and safety of mountain communities living in an "extraction" state.

In this dissertation, I investigate the concerns of local residents about the impacts of mountaintop removal on their mountains and on their communities. Contrary to the dominant portrayal of anti-MTR concerns as primarily held by “outsiders," this discourse 
of resistance comes from local residents of the Coal River Valley, many of whom are multi-generational residents with a strong connection to their coal mining heritage. To illustrate this discourse of resistance - constituted by the rules that define who can speak and in what way - I use participatory mapping and interviews to represent local concern geographically and at intersections of gender, age, and livelihood. In this dissertation, I examine two discourses: the local discourse of resistance within the Coal River Valley, and the legal discourse that continues to permit MTR and valley fills despite the consequences to local people and their land. The objectives of my study are to illuminate how dominant legal discourse continues to subjugate the subaltern discourse of MTR and to identify possible spaces of resistance within which the subaltern discourse can challenge issues of landscape change and use in the case study area.

The dynamics of the dominant discourse of mountaintop removal pit "local miners" against "outsiders," disempowering questions about risk and quality of life by associating those concerns with 'outsiders' uninformed with the daily sacrifice and dedication required to make a life in the southern coalfields. This subaltern discourse represented in this dissertation shows this paradox - the local miner fighting for his/her job against outsider environmentalists - to be largely a fallacy. Massey Energy, the owner of the Upper Big Branch Mine, is based in Virginia and often employs men and women from outside of the area to work in the Coal River Valley. Many of the most vocal opponents to mountaintop removal coal mining are in fact residents who are speaking out about decreasing quality of life and increasing risks to their family and their community. Many of these residents, including prominent organizers such as Goldman prize winners Judy Bonds and Maria Gunnoe, come from coal mining families themselves and do not stand against coal in general.

The power to define the discourse as a false dichotomy between jobs and the environment, to decide what the two ideals are that are being balanced, in itself disqualifies the most powerful voice of resistance to mountaintop removal: the people who live there. U.S. Sen. Robert C. Byrd (D-W.Va) challenged the assumption as well: "the old chestnut that 'coal is West Virginia's greatest natural resource' deserves 
revision. I believe that our people are West Virginia's most valuable resource. We must demand to be treated as such.” ${ }^{3}$ What would it mean to treat West Virginians as a resource more important than coal, as Senator Byrd asks? This dissertation asserts that the first step in valuing West Virginia's people as a resource more important than coal is to listen directly to the concerns of coalfield residents about the human and environmental costs of coal. Within this larger discourse regarding coal lies the focus of this dissertation: the perspectives of Coal River Valley residents regarding the human and environmental cost of coal mined through mountaintop removal methods, including the creation of valley fills in the "heads of the hollows."

The Upper Big Branch tragedy gave the nation a brief glimpse into the powerful reach of King Coal into the daily life and survival of families in the coalfields. What then are the concerns that residents feel so strongly about that they would speak out against this powerful dominant discourse? Are there dominant themes of concern within this discourse as well, and if so, what factors influence these concerns? This dissertation illustrates the hidden human and environmental costs behind our nation's cheap electricity by listening to the families who live in the "extraction” zone for mountaintop removal coal. This research investigates the perspectives of local residents, termed the subaltern discourse, within the Coal River Valley who are concerned about the impacts of mountaintop removal on themselves, their families and communities, and their environment.

A primary finding of this dissertation is that the way the subaltern discourse interprets the landscape contradicts both the environmental concerns of the "outsiders" and the economic concerns of "local miners", law makers, and mining companies. Participants in the Coal River Valley clearly see their homeland as much more than just an economic or environmental landscape. While residents do share many environmental and economic concerns, their interpretation of changes in their landscape includes associated social concerns such as loss of community structure, decreased quality of life for children, and loss of heritage / culture. Depending on the age group, these social concerns were held

\footnotetext{
${ }^{3}$ May 5, 2010 statement by Senator Robert C. Byrd
} 
by $100 \%$ of participants. As Lorelei stated to the Governor, West Virginia is a mountain state, not an extraction state, and this dissertation argues that the mountain landscape is filled with communities and families, not just forest and mineral resources.

This subaltern discourse of resistance directly challenges the polarized portrayal of "local miners" versus "outsiders." Firstly, all of the participants in this study are local residents in the Coal River Valley, most of them come from mining families, and many of them are current or retired underground miners. The discourse of resistance illustrated in this dissertation is a local discourse that discredits the presentation of anti-MTR concerns as belonging only to "outsider agitating treehuggers" (OATS). The dominant claim that MTR is about providing good jobs to local residents is also unpacked by the finding that "job loss" as a result of MTR is a primary concern of current and retired miners. Local miners represented in this discourse clearly argue that they are not concerned about coal mining in general, (in fact they encouraged more underground mining, if done safely) but rather are concerned specifically about the practice of MTR.

Additionally, the subaltern discourse contains a discursive formation of "Total Devastation" in which participants were unable to specifically describe the impacts of MTR. Instead, participants described MTR as destroying all environmental and associated social values of their home and community. While "Total Devastation" could be discredited by the dominant discourse by claiming these concerns were overly emotional, the first hand descriptions in this dissertation provide evidence of homes that were totally destroyed by flooding, the burial of a hollow under a valley fill, or the construction of a slurry impoundment.

However, under the legal conditions of possibility described in this dissertation, there is no way to legally address "total destruction." The question I pose, then, is if this dialogue of total destruction can't be legally addressed, why does the coal industry go to such lengths to disempower it by associating it with outsiders? I assert that the reason for framing the discourse of "total devastation" as one that originates outside of West Virginia is to maintain division within the community by asserting that environmentalists 
and treehuggers, not the coal industry, are the outside threat. If the dialogue of total destruction could be heard as "truth" by more local residents, could the origin of threat slowly begin to shift for pro-MTR miners from "outsider agitators" to the coal industry itself?

This dissertation argues that "spaces of resistance" can be found by treating local knowledge as expert knowledge, and focusing on the representation of "total devastation" from mountaintop removal as the expert concerns of multigenerational residents with coal mining heritages. Situated in this way, the dominant discourse can not discredit these claims by associating them with outsiders. This dissertation also argues that participatory mapping projects have the potential to aid in the representation of local knowledge as expert knowledge. These changes in perspective could be the 'miniscule displacement' that Foucault speaks of regarding the 'insurrection of subjugated knowledges.'

\section{1. a. Study Background and Statement of Objectives}

The process of mountaintop removal coal mining (MTR) entails removing mountaintop rock and soil above multiple horizontal seams of coal. After the coal is removed, the rock and soil are returned and reclaimed in an effort to restore the approximate original contour of the mountain. The excess rock is used to fill adjacent mountain hollows and create valley fills. Enormous landscape change occurs as a result of clear cutting the timber, using explosives to remove the overburden, filling in headwater streams with the overburden, and leaving the area denuded and flat. As of a 2008 USGS report, surface mining is now the dominant driver of land use change in central Appalachia (Saylor, 2008). Over 1 million acres have been mined and 470 mountains have been leveled across Central Appalachia as of 2007 (Appalachian Voices et al, 2007). The creation of valley fills has destroyed nearly 2,000 miles of streams in Central Appalachia, with 800 miles of direct stream impact in West Virginia alone. 
MTR is the cheapest way to mine coal due to the externalization of both current and longterm environmental and social costs. The use of massive draglines such as Big John allowed coal companies to reach multiple seams of coal after using dynamite to blast the tops off the mountains. Therefore, MTR can recover a higher percentage of coal, use less manpower, and meet the demands for low sulfur coal. However, recent research has documented "serious environmental impacts that mitigation practices cannot successfully address” from the burial of headwater streams beneath valley fills (Palmer et al, 2010, pg 149) as well as a "high potential for human health impacts" from exposure to polluted streams or airborne toxins (Hendryx et al, 2009) .

The process of MTR began in the 1970s, grew throughout the 1980s, and exploded through a combination of advanced mining technology, lenient regulatory interpretation of federal legislation, and the national demand for low-sulfur coal. Mountaintop removal does not occur in all coal mining states: in fact, in Appalachia it is widespread only throughout eastern Kentucky, West Virginia, and southwestern Virginia. Within West Virginia, the nine counties of Boone, Fayette, Kanawha, Logan, McDowell, Mingo, Nicholas, Raleigh, and Wyoming account for more than 67 percent of the total production of coal in West Virginia. (Burns, 2007). My case study area includes the communities affected by mountaintop removal mine sites on Coal River Mountain in Raleigh County, WV. There are currently three large surface mine permits either pending or approved for Coal River Mountain. Together, these permits would cover 5,782 acres of Coal River Mountain and create seventeen valley fills.

Community organization and resistance to the practices of MTR has grown along with the expansion of the mines. Many residents now organize against MTR due to immediate impacts on their land, home, and families. The Ohio Valley Environmental Coalition has worked since 1987 to preserve the mountain ecosystems and culture of the Central Appalachian region, with ending mountaintop removal / valley fill strip mining as a primary issue. Within the case study area, Coal River Mountain Watch has been organizing for the social, economic and environmental wellbeing of southern West 
Virginia against the destructive practices of MTR and the coal companies since 1998. More recently, groups have formed to organize around specific issues such as the Sludge Safety Project, to stop slurry impoundments and slurry injection, and Pennies of Promise, to raise money to provide a safe school for children attending Marsh Fork elementary. Mountain Justice started in the summer of 2005 to add to the growing anti-MTR citizens movement, demand an abolition of MTR and protect the cultural and natural heritage of the Appalachia coal fields (Shapiro, 2010).

In 2006, Appalachian Voices, a non-profit based in Boone, NC, paired with Google Earth to create a sub-layer entitled “Appalachian Mountaintop Removal.” Previous to this digital representation, the only way to convey the extent of MTR was to arrange for a flyover. Now, however, coalfield residents use this layer for outreach and education as well as local organization and activism. The Google Earth layer also prompted interest in a form of mapping that would allow concerned residents to have more control over the final results: participatory GIS. Participatory GIS (PGIS) offers a methodology with the potential to incorporate the diverse perspectives of local people into the mapping process. PGIS attempts to make GIS more relevant to community concerns, increase community access to decision-making, address ethical issues such as knowledge distortion, and incorporate qualitative methodologies (Harris and Weiner, 1996).

This research originated out of a desire of residents in the Coal River Valley to use participatory mapping to illustrate the impacts of mountaintop removal that was inclusive and helpful to local residents. In this dissertation, I investigate the discourse of mountaintop removal regarding landscape change and use with a focus on the legal discourse that permits MTR and the local discourse of resistance within the Coal River Valley. The objectives of my study are to illuminate how dominant legal discourse continues to subjugate the subaltern discourse of MTR and to identify possible spaces of resistance within which the subaltern discourse can challenge issues of landscape change and use in the case study area. To address my objectives, I have formulated two research questions: what are the legal discursive formations that define and allow the permitting 
of MTR in the case study area, and what are the subaltern discursive formations regarding the implementation of MTR in the case study area?

This participatory mapping project of the Coal River Valley is situated within a Foucauldian framework that locates my case study within the larger power dynamics controlling mountaintop removal within the valley. The strength of this combination of PGIS methodologies and Foucauldian theory allows for the conceptual placement of the subaltern discourse within a specific geographical and temporal emergence of the dominant discourse of MTR. Using a Foucualdian lens, investigating of the initial construction of MTR as an object separate from other forms of mining allows for the creation of the "conditions of possibility" that impact the existence and formation of the subaltern discourse. The use of a PGIS approach to construct the subaltern discourse allows for local residents in the case study area to provide "expert" data regarding their concerns and to play an active role in how their concerns and home place are represented. Finally, the Foucauldian framework allows me to use the data collected through the construction of first, a "mini-archeology" of MTR, and second, a PGIS of the Coal River Valley, to analyze the power relations that continue to subjugate the subaltern discourse.

\section{1. b. Organization of Dissertation}

This dissertation is divided into eight chapters. Chapter Two, the Conceptual Framework and Literature review, focuses on the connections between diverse literatures and outlines the themes used to accomplish the objectives of my research. In the first section of my review, I outline the Foucauldian method of archeology, additional conceptual tools, and relevant practical examples. The premise of Foucault's archaeological method is that systems of thought (epistemes) and knowledge (discursive formations) are governed by rules that operate beneath the consciousness of individual subjects. These systems of thought and knowledge define the "conditions of possibility" that in turn determine the boundaries of thought in a given place and time. Practical applications of a Foucauldian framework to investigate the discourse of development (Escobar, 1995) and the discourse 
of Foucault within geography (Hannah, 2007) are presented as case studies. The second section of my Conceptual Framework and Literature review highlights the importance of themes such as dis/empowerment of communities and individuals through the process, product, and long term outcome of PGIS research, legitimization by participation, the role of researcher/facilitator, and the integration of qualitative and quantitative methodologies through a mixed method strategy. Literature from both critical cartography and critical GIS is drawn upon to explain why I have chosen PGIS to illustrate the "particular, local, regional knowledge” referred to by Foucault as an “insurrection of subjugated knowledges” (Foucault, 1980, pg 81) within the Coal River Valley.

The third section of Chapter Two investigates relevant literature on the political economy and subaltern perspectives surrounding the case study area to help situate the subaltern discourse of resistance to MTR as well as provide a basis for a selection of culturally appropriate research methods. To understand the context for subaltern and elite discourse within West Virginia, I engage in the larger debates surrounding political economy and the evolving theories on culture and poverty in Appalachia. This section gives a broadbrush overview of the progression of these theories with particular attention to the role of elites and patterns of absentee landownership in central Appalachia. The use of the term “subaltern” as applied to the Coal River Valley discourse is explained as well as the context for investigating subaltern discursive formations along lines of gender, age, and livelihood in the case study area.

Chapter Three introduces the case study area for this dissertation: the Coal River Valley of southern West Virginia. This chapter outlines general geography and demographics, examines natural resource extraction and resistance, and sketches the importance of multiple livelihood strategies and connection to the land. This chapter proceeds to justify my choice of case study area and then outline the geography and demographics of the communities surrounding Coal River Mountain where I conducted my research. The internal periphery lens (Walls, 1978) is used to examine the case study area with an emphasis on resource extraction and the rise of mountain top removal coal mining. The 
review looks at the history of union organizing and the formation of community groups as forms of resistance in the Coal River Valley. Finally, the chapter concludes with a focus on the importance of connection to land, family and the use of multiple livelihood strategies in the case study area.

Chapter Four details my research questions, methodology, and methods. The methodology for this study uses a PGIS approach within a Foucauldian framework to address two research questions regarding the initial legal discourse of mountaintop removal as well as the subaltern discourse of resistance to this specific type of surface mining. This combination of PGIS methodologies and Foucauldian theory allows for the conceptual placement of the subaltern discourse within a specific geographical and temporal emergence of the dominant discourse of MTR. A mixed method strategy of inquiry was chosen to combine both traditional geospatial data with "expert" local knowledge regarding the impacts of mountaintop removal on landscape change and use in the case study area. Four research methods were used to collect data for this research: mini-archeology construction, semi-structured interviews, base-map construction, and participatory mental mapping. To address my first research question, I draw on Foucault's archeological method to construct a mini-archeology of MTR. The analysis proceeds in three steps to examine the legal structure that defined MTR at the federal statutory level, the regulatory level, and finally within the case study area. I apply Foucault's archeological method to understand how the legal discursive formations around MTR created the "conditions of possibility" for MTR to exist in the case study area. For my second research question, I use a PGIS approach to illustrate the subaltern discourse of MTR. I use interviews and participatory mental mapping to illustrate the concerns of local residents regarding the existing and potential impacts of mountaintop removal on the landscape of the Coal River Valley.

Chapter Five addresses my first research question by constructing a mini-archeology of the legal and regulatory discourses of mountaintop removal coal mining. In order to situate and unpack the subaltern discourse of resistance to MTR in the Coal River Valley, this first data analysis chapter investigates the legal discourse that first created MTR as an 
object to be permitted. I apply the archeological method to my research to show how mountaintop removal was legally formed and reformed as an object within its spaces of dispersion. I draw from Foucault's archeological method to unpack the formation of MTR as an object primarily using three dimensions: surfaces and temporalities of emergence, authorities of delimitation, and grids of specification. The construction of the mini-archeology therefore proceeds in three steps: the unpacking of the original legal construction of MTR through federal legislation, the reconstruction of MTR through "rule-making" agencies, and finally the specific implementation of MTR on Coal River Mountain. The Surface Mining Control and Reclamation Act of 1977 and the Clean Water Act of 1972 serve as the initial surfaces of emergence for the purposes of this study, and the investigation of regulatory rule-making then highlights the agencies and authorities empowered by these original statues.

Chapter Six addresses my second research question by illustrating local knowledge and resistance perspectives regarding the impacts of mountaintop removal in the Coal River Valley. The term 'subaltern' is used to illustrate the concerns of local residents as subjugated knowledges that have been disqualified or located low on the hierarchy: a "particular, local, regional knowledge, a differential knowledge incapable of unanimity and which owes its force only to the harshness with which it is opposed by everything surrounding it” (Foucault, 1980, p. 82) As previously defined, subaltern represents a heterogeneous community of resistance with multiple discursive formations. The analysis proceeds to break down the themes by specific geographic location on the mountain. Finally, discursive formations of concern are examined at the intersections of gender, age, and livelihood.

Chapter Seven, my final data analysis chapter, investigates the power-knowledge relationships between the original legal construction of MTR, the regulatory reinterpretation and implementation of MTR permitting processes, and the subaltern discursive formations of resistance to MTR. By focusing on the specific spaces in which the subaltern discourse moves outside of the dominant discourse, I illuminate the possible spaces of resistance within which issues of landscape change and use can be challenged. 
The final step in data analysis positions the subaltern discourse within the conditions of possibility outlined in chapter five to illuminate possible "spaces of resistance.” I investigate the power-knowledge relationships between the original legal construction of MTR as an object, the regulatory reinterpretation and implementation of MTR permitting processes, and the subaltern discursive formations regarding landscape change and use in the case study area. I analyze the PGIS maps in relation to the permit maps as practices of power-knowledge (Harley, 1988; Wood, 1992; Pickles, 1995; Crampton, 2001). Next, my analysis focuses on where the subaltern perspective, represented through my PGIS, extends beyond the conditions of possibility constructed by the dominant discourse. I unpack where local knowledge addresses landscape change and use outside of the regulatory reconstruction of MTR. Specific analysis focuses on the discursive formations that are not privileged as "expert knowledge” by the dominant discourse. By focusing on the specific spaces in which the subaltern discourse moves outside of the dominant discourse, I illuminate the possible spaces of resistance within which issues of landscape change and use can be challenged.

In my concluding chapter, I return to the Upper Big Branch explosion and summarize how the subaltern discourse discredits the polarized discourse of "local miners" versus "outside agitating tree huggers" regarding the impacts of mountaintop removal coal mining. I draw from PGIS literature to address the potential of participatory maps to legitimize local knowledge and directly address the illegal nature of MTR as produced on the landscape of Coal River Mountain. I summarize my major findings and contributions and suggest additional research to support community concern in the Coal River Valley.

\section{1. c. Significance of Study}

The illustration of local knowledge and resistance perspectives to MTR through the construction of the PGIS is the centerpiece of my dissertation as well as a noteworthy addition to Appalachian studies literature and social activism. However, it is through the Foucauldian analysis of the relationship between the subaltern discourse of MTR in the 
Valley and the dominant discourse that created and permits MTR that this dissertation has the potential to illuminate spaces for the "possibilities of resistance" (Crampton, 2001, 236).

This dissertation has the potential to be the first application of PGIS methodologies to southern West Virginia, be the first application of Foucault to the discourses of MTR, and contribute to social action by illuminating the spaces of "possibility of resistance" for the subaltern discourse. Outcomes include an analysis of the legal context within which MTR is occurring in the Coal River Valley and the creation of participatory tools and resources to support the empowerment of local resistance groups. For example, sections of non confidential interviews, photographs, and participatory maps were incorporated into an online multimedia website: JourneyUpCoalRiver.org. This website was created in partnership with participants in the Coal River Valley to share these useful resources for organizing, education, and outreach. ${ }^{4}$ Website themes include: history and social geography, land use, a community and strip-mining, public health and coal slurry, what is mountaintop removal, and renewable energy on Coal River Mountain. In 2010, this participatory website won the e-Appalachia website of the year from the Appalachia Studies Association.

\section{1. d. Conclusion}

In the aftermath of the Upper Big Branch tragedy, West Virginians and mining families across Appalachia stood together in solidarity to mourn and raise awareness about the dangers of coal mining to the men and women who work underground. The explosion served to educate many about the human cost of coal mining, yet did little to question the larger impacts of coal mining on the people and land of West Virginia. When the focus broadens to question the impacts of coal mining on the landscape, health, and safety of mountain communities, the discourse becomes polarized. The dynamics of the dominant

\footnotetext{
${ }^{4}$ JourneyUpCoalRiver.org was completed with financial help from the West Virginia Humanities Council, the Switzer Foundation, the Mark Vann Foundation, the Sierra Club, Coal River Mountain Watch, and the Ohio Valley Environmental Coalition.
} 
discourse of mountaintop removal pit "local miners" against "outsiders," disempowering questions about larger impacts by associating those concerns with 'outsiders' uninformed with the daily sacrifice required to live the southern coalfields. Within this polarized discourse regarding coal lies the focus of this dissertation: the perspectives of Coal River Valley residents regarding the human and environmental cost of coal mined through mountaintop removal methods, including the creation of valley fills in the "heads of the hollows."

In this dissertation, I examine the local discourse of resistance within the Coal River Valley as well as the legal discourse that continues to permit MTR and valley fills despite the consequences to local people and their land. The objectives of my study are to illuminate how the dominant legal discourse continues to subjugate the subaltern discourse of MTR and to identify possible spaces of resistance within which the subaltern discourse can challenge issues of landscape change and use in the case study area.

In this dissertation, I investigate the concerns of local residents about the impacts of mountaintop removal on their mountains and on their communities. Contrary to the dominant portrayal of anti-MTR concerns as primarily held by “outsiders," this discourse of resistance comes from local residents of the Coal River Valley, many of whom are multi-generational residents with a strong connection to their coal mining heritage. I use semi-structured interviews, base map construction, and participatory mapping to represent local concern geographically and at intersections of gender, age, and livelihood. A primary finding of this dissertation is that the way the subaltern discourse interprets the landscape contradicts both the environmental concerns of the "outsiders" and the economic concerns of "local miners", law makers, and mining companies. Participants in the Coal River Valley clearly see their homeland as much more than just an economic or environmental landscape. Additionally, the dominant claim that MTR is about providing good jobs to local residents is also unpacked by the finding that "job loss" as a result of MTR is a primary concern of current and retired miners. 
To illustrate the legal and regulatory discourse, I draw on Foucault to construct a miniarcheology of MTR to create the conditions of possibility within which the subaltern discourse of resistance is situated. I use Foucauldian themes of power, discourse and knowledge to situate the subaltern discourse within these "conditions of possibility" to investigate the "spaces of resistance" and fulfill the objectives of this study. This dissertation argues that "spaces of resistance" can be found by treating local knowledge as expert knowledge, and focusing on the representation of "total devastation" from mountaintop removal as the expert concerns of multigenerational residents with coal mining heritages. This dissertation also argues that participatory mapping projects have the potential to aid in the representation of local knowledge as expert knowledge.

The Upper Big Branch tragedy gave the nation a brief glimpse into the powerful reach of King Coal into the daily life and survival of families in the coalfields. This dissertation illustrates the hidden human and environmental costs behind our nation's cheap electricity by listening to the families who live in the "extraction" zone for mountaintop removal coal. This dissertation must draw from a wide range of literatures to provide the historical and cultural background of the case study area as well as outline the participatory methods and Foucauldian conceptual framework employed in this work. Therefore, the next chapter gives an overview of relevant literature regarding Foucault, PGIS, and Appalachian political economy. 


\section{CHAPTER TWO}

\section{CONCEPTUAL FRAMEWORK AND LITERATURE REVIEW}

This chapter draws from three literatures to situate the discourse of resistance to mountaintop removal coal mining and explain the use of the term “subaltern” in referring to this discourse. This review brings together the literature of Foucault within geography, critical cartography and participatory GIS, and evolving theories of political economy within Appalachia.

To outline my conceptual framework as well as address my first research question regarding the legal discourse of mountaintop removal in the case study area, I outline Foucault's archeological method as applied to writing a mini-archeology of the legal formation of MTR. Practical applications of a Foucauldian framework to investigate the discourse of “development” (Escobar, 1995) and the discourse of "Foucault” within geography (Hannah, 2007) are presented. Crampton and Elden’s Space, Knowledge and Power provides an overview of the connections between Foucault and geography (2007), with work from Harley (1999, 1998), Wood (1992), Pickles (1995), and Crampton (2001) outlining the application of Foucault to mapping and geospatial technologies more specifically.

To address my second research question focusing on the subaltern discursive formations of resistance to MTR, I draw from the literature on critical cartography / GIS and participatory GIS to situate my methodology and participatory methods. I include literature on the evolving theories of Appalachian political economy to construct local social context and situate the subaltern discourse along intersecting lines of gender, age, and livelihood. 


\section{2. a. Foucauldian Framework}

Foucault is a philosopher of the 'miniscule ... displacement'. He turns (often reverses) the kaleidoscope of our received views to produce new, frequently liberating perspectives.

Flynn, 2005, pg 97, quoting Foucault, The Order of Things

Foucault was a descriptive historian who challenged history and the way that it has been written. He was not a philosopher, nor even a post-structuralist, despite how others have categorized him. Thomas Flynn described Foucault's contributions as shifting the kaleidoscope of our perspectives just a fraction to present an entirely different view. For this reason, I chose to situate my research on the impacts of mountaintop removal on local residents within a Foucauldian framework. What new and possibly liberating views might result from a kaleidoscopic shift in perspective regarding the hegemonic presentation of mountaintop removal as necessary for the energy needs of our nation? What voices and types of knowledge are excluded from this dominant narrative?

Foucault's work on the relationships between knowledge, discourse and power are the basis of the conceptual framework of this study. This section of the literature review will give a brief overview of Foucault's archeological method and conceptual tools to be used in data analysis. Attention will be paid to key Foucauldian terms that will be used throughout the analysis section. Applications of a Foucauldian framework to investigate the discourse of "development" (Escobar, 1995) and the discourse of "Foucault" within geography (Hannah, 2007) are presented as case studies. 


\section{2. a. i. Foucault's Archeological Method and Conceptual Tools}

In Archeology of Knowledge (1972), Foucault presents an 'archeology' as a methodology of the descriptive methods he used in his first three books of history: Madness and Civilization, The Order of Things, and The Birth of the Clinic. He writes that the project of an 'archeology' is "the study of forms of knowledge at the level of their material manifestation as bodies of discourse composed of finite sets of effective oral or written utterances” (Foucault, 1980, pg 244). Applied to this dissertation, an archeology allows for the production of sanctioned forms of knowledge regarding mountaintop removal to be described according to their governing discursive rules and their historical conditions of possibility.

The application of aspects of Foucault's archeological methods can offer interpretive insights into familiar discourses not available through more traditional perspectives. For example, Escobar's Encountering Development uses a Foucauldian framework to direct development away from political economy and towards issues of discourse and culture, specifically within Latin American social movements (1995). He states that Foucault's work on the 'dynamics' of discourse and power was "instrumental in unveiling the mechanisms by which a certain order of discourse produces permissible modes of being and thinking while disqualifying and even making others impossible” (1995, pg 39). These discursive practices "set the rules of the game" regarding who could speak, with what authority, if that authority was recognized as legitimate, and from what point of view (Escobar, 1995, pg 41). Escobar questions how social movements can become objects of knowledge within the rules of the game, and whether the "hegemonic epistemological space of development, inscribed in multiple forms of knowledge, political technologies and social relations, be significantly modified? ... who can 'know,' according to what rules, and what are the pertinent objects?” (Escobar, 1995, pg 3).

The archeological methodology that Foucault illustrates involves its own set of specific terms that are essential in comprehending his descriptive methods. Foucault developed 
an original definition of discourse as being constituted by the rules that define who can speak, when, where, and in what way. For example, how is a resident's decision to speak out against MTR impacted by these rules, and to what degree does their gender, age, or current family employment impact their participation in the discourse of resistance? In Discipline and Punish, Foucault illuminated the role of discourses in the construction of current truths regarding prisons and the incarcerated, the maintenance of those truths, and the power relations involved (1977). Applying Foucault to social work, Lessa summarizes discourse as "systems of thought composed of ideas, attitudes, courses of action, beliefs and practices that systematically construct the subjects and the worlds of which they speak" (2006, pg 384).

Foucault defines discursive formations as systems of thought within a discourse. One effect of these discursive formations is to make it virtually impossible to think or work outside of them: "discourse itself is both strongly constituted by, and ensures the reproduction of, the social system through forms of selection, exclusion, and domination” (Hook, 2001, pg 2). Examining the discursive formations within the discourse of resistance to mountaintop removal can aid in understanding how certain types of knowledge are excluded and how different subject positions impact the authority with which knowledge is appropriated. For example, what types of subaltern knowledge are excluded by discursive rules? How are those types of knowledge selected, and others dominated?

An archeology brings forward the historial a priori-that ground knowledge and its discourses - to represent the conditions of possibility for those discourses. He abandons preconceptions about historical unities, and instead works to uncover discontinuity and to explain why certain discourses occur and why others do not:

We must question those ready-made syntheses, those groupings that we normally accept before any examination, those links whose validity is recognized from the outset; we must oust those forms and obscure forces by which we usually link the discourse of one man with that of another; they must be driven out from the darkness in which they reign (Foucault, 1972, pg 22). 
Using this descriptive method, unities are to be questioned as they are "always themselves reflexive categories, principles of classification, normative rules, institutionalized types” (Foucault, 1972, pg 22). Investigating the discourse of mountaintop removal, then, would involve not only looking at the actual "oral or written utterances" of the 'strip miner' and the 'activist', but also illustrating the discursive rules that categorize each person with that label. For example, what are the discursive rules that lead to the identification of an individual as a miner? From the subject position of a deep miner, strip miners are "heavy machine operators." From the subject position of a union deep or strip miner, non union miners are "scabs." Foucault goes on to state that "these pre-existing forms of continuity, all these syntheses that are accepted without question, must remain in suspense...we must show that they do not come about of themselves, but are always the result of a 'construction,' the rules of which must be known, and the justifications of which must be scrutinized (Foucault, 1972, pg 25). The use of a Foucauldian lens in this research calls attention to the construction of terms such as "subaltern" and highlights the need to remain diligent in questioning the unities created within my own research.

\section{2. a. ii The Formation of an Object}

Applying the archeological method to my research, my task will be to show how mountaintop removal was legally formed and reformed as an object within its spaces of dispersion. This dissertation chooses the legal creation of mountaintop removal as the starting place for the construction of this mini-archeology in order to describe the legal conditions of possibility within which the subaltern discourse of resistance exists. To create a 'mini-archeology' of MTR, I draw from Foucault's archeological method regarding the formation of an object: map the first surfaces of emergence, describe the authorities of delimitation, and analyze the grids of specification (Foucault, 1972, pgs 4049). The following section uses examples to illustrate the terms Foucault developed in regards to the formation of an object. Chapter 4 will specifically outline the application of Foucault's archeological method to the legal formation of mountaintop removal. 
Surfaces of emergence are specific discursive and institutional sites in which objects first emerge or are re-configured. Applied to Foucault's archeological work on medicine, surfaces of emergence show where individual differences were accorded the status of disease, dementia, etc, to be designated and studied as separate objects(Foucault, 1972, pg 41) In the case of $19^{\text {th }}$ century medicine, these surfaces were constituted by the family, immediate social groups, the religious community, etc. These surfaces are different depending on the society, time period, and the discourse. In these surfaces of emergence, the initial differentiation limits the discursive domain and makes an object “manifest, nameable, and describable” (Foucault, 1972, pg 41). For example, an initial surface of emergence for mountaintop removal would be within the Surface Mining Control and Reclamation Act, in which the concept of "mountaintop removal" as an object “manifest, nameable, and describable” first legally emerged.

In Hannah’s archeology of Foucault within geography, “surfaces” of emergence included university bookstores offering English translations of Foucault, interdisciplinary seminars, and conversations between academics (Hannah, 2007). Hannah adds “temporalities” as an additional analytical layer to include the timeframes and duration for each emergence. Within this analysis, attention can be paid to the re-emergence (a republication of an article) or re-configuration (a critique or rewrite of an article) of objects.

The next step in describing the formation of an object is to illustrate the authorities of delimitation. In the $19^{\text {th }}$ century, 'medicine' became the primary authority of delimitation, with the power to designate and establish madness as an object. Penal law and the religious community were also authorities of delimitation. In Hannah's archeological sketch, he defines authorities of delimitation as subject positions from which individuals have or acquire the right to define and delineate the objects of a discursive formation. Applied to the discourse of mountaintop removal, authorities of delimitation are the people who were originally able to define and construct mountaintop removal as an object. Questions that arise from describing the authorities of delimitation 
include: who can speak and from what institutional positions? Who has the authority to delineate objects? And perhaps most importantly, what discursive formations were ignored or eliminated?

Finally, "grids of specification" are the classificatory dimensions along which an object is located within a discursive formation. In medicine, these would be the systems according to which different 'kinds of madness' were "divided, contrasted, related, regrouped, classified, and derived from one another as objects” (Foucault, 1972, pg 42). In Hannah's illustration of the formations of 'Foucault,' investigating the grids of specification involved questioning where Foucault was placed within disciplines such as geography or philosophy and what labels were ascribed to him. Applied to the legal formation of mountaintop removal, grids of specification would place attention on the specific classification and permitting of mountaintop removal in the case study area.

\section{2. a. iii Power-Knowledge}

An additional conceptual tool that I draw from Foucault is his conceptualization of power. In Foucault's conceptualization of power, it is not "a binary structure with dominators on one side and dominated on the other, but rather a multiform production of relations of domination...” (Foucault,1980, pg 142). Power is not the yin/yang of good versus evil, nor is it just an oppressive force:

\footnotetext{
If power were never anything but repressive, if it never did anything but to say no, do you really think one would be brought to obey it? What makes power hold good, what makes it accepted, is simply the fact that it doesn't only weigh on us as a force that says no, but that it traverses and produces things, it induces pleasure, forms knowledge, produces discourse. It needs to be considered as a productive network which runs through the whole social body, much more than as a negative instance whose function is repression” (Foucault, 1980, pg 119)
}

Foucault sees power as a network of relations between people which is 'negotiated' within each encounter. Elaborating further, each institutionally sanctioned power relation 
can be negotiated at a local level and can be challenged overtly or covertly. For example, regarding coal mining, an agent with the Department of Environmental Protection has the institutional authority to determine if a waterway is being polluted by a mine site. A local resident and miner might have much greater experiential knowledge about the cause and exact impacts of the pollution on his watershed, but less institutional power to address the problem. This initial uneven power dynamic can be negotiated to some degree if the local can prove his concerns by pointing out the pollution source or showing the DEP agent maps and permits, yet the DEP agent is still the one who has been given the authority to delineate the problem. What positions, then, are negotiable? Who gets to speak the 'truth' in a given discourse?

Foucault believes that in discourse, power and knowledge are joined together. Foucault (1980) stated that knowledge was both the creator and the creation of power. He used these inter-related aspects to coin the term power-knowledge. Foucault further argued that power is always present and can both produce and constrain the truth: "power is not an institution, a structure, or a certain force with which certain people are endowed; it is the name given to a complex strategic relation in a given society” (Foucault, 1980, pg 236). Thus, power is inherent in every human relation and every form of specialized knowledge.

Foucault refers to an "insurrection of subjugated knowledges," for which he ascribes two definitions. Firstly, the historical contents that have been "buried and disguised in a functionalist coherence of formal systemisation” (Foucault, 1980, pg 81). He believes that the "immediate emergence of historical contents" allowed for a effective criticism of the asylum, for example. Secondly, the insurrection of subjugated knowledges refers to forms of knowledge that were disqualified or located low on the hierarchy: a "particular, local, regional knowledge, a differential knowledge incapable of unanimity and which owes its force only to the harshness with which it is opposed by everything surrounding it” (Foucault, pg 82). 
In his 1980 afterward to Power/Knowledge, Colin Gordon theorizes on the ethical applications of Foucault's work: "For the recent eruptions of 'popular knowledge' and 'insurrections of subjugated knowledges' which he celebrates, what Foucault may have to offer is a set of possible tools, tools for the identification of the conditions of possibility which operate through the obviousness and enigmas of our present, tools perhaps also for the eventual modification of those conditions" (Foucault, 1980, pg 258). This section has highlighted a set of Foucauldian tools that will be used both to identify the conditions of possibility for the subaltern discourse and illuminate possible spaces for the insurrection of these subjugated knowledges.

This section gave an overview of the Foucauldian framework and conceptual tools employed in this dissertation. Elements of Foucault's archeological method are used to investigate the legal formation of MTR as an object by constructing a mini-archeology in Chapter five. The subaltern discourse of resistance to MTR within the Coal River Valley is then situated as within a specific geographical and temporal emergence of the hegemonic MTR discourse. Finally, the Foucauldian framework allows me to use the data collected through the construction of first, a "mini-archeology" of MTR, and second, a PGIS of Coal River Valley, to analyze the power relations that continue to subjugate the subaltern discourse.

Foucault states that in order to do an "analysis of power...we must speak of powers and try to localize them in their historical and geographical specificity' (Crampton and Elden, 2007, pg 6). The Foucauldian analysis of the relationship between the subaltern discourse of MTR in the Valley and the dominant discourse that created and permits MTR that this dissertation has the potential to create spaces for the "possibilities of resistance" (Crampton, 2001, pg 236). The following section will introduce participatory mapping / GIS as my methodology to illustrate the subaltern discourse of resistance to mountaintop removal. 


\section{2. b. Critical Cartography/GIS and Participatory GIS}

What would be helpful would be to offer professional assistance, on bended knee
if necessary, to all the people trying to ameliorate their situation by mapping it:
the First Peoples who have come to realize it's map or be mapped; the
impoverished locals trying to grapple with the impact of transnational mining,
logging, and industrial development...

Cartography is Dead (Thank God!), Wood, 2003

This section situates participatory GIS (PGIS) within critical cartography/GIS as a methodology to map the subaltern discourse of mountaintop removal in the Coal River Valley. Literature from both critical cartography and critical GIS is drawn upon to explain the "particular, local, regional knowledge” referred to by Foucault as an “insurrection of subjugated knowledges” (Foucault, 1980, pg 81) within the Coal River Valley. The work of Harley, Wood, Pickles and Crampton is discussed, with a focus on the integration of post-structuralist theory to see maps as sites of power-knowledge. This chapter proceeds with a brief overview of PGIS and its origins in the GIS and Society debate. I develop some of the dominant themes within PGIS such as its marginalization and empowerment of communities, legitimization by participation, the role of researcher/facilitator, and the integration of qualitative and quantitative methods through multimedia applications. Finally, I highlight three relevant case studies with a focus on community empowerment through the PGIS process, product, and long term outcomes.

\section{2. b. i The ‘Collision’ of Critical Human Geography and GIS}

Critical cartography surfaced as a challenge to academic cartography through its linkage of geographic knowledge with power (Harley, 1988; Wood, 1992). Within both cartography and GIS, "critical” is a term used to examine the assumptions that shape our knowledge, and how these assumptions are related to the power and production of truth (Crampton and Krygier, 2006). Critical cartography / GIS is the result of a collision between elements of "critical” human geography with GIS methods and techniques. Despite initial difficulties in communication between the disciplines, well represented in 
Pickles' Ground Truth, by the late 1990s productive conversations were occurring between human geographers and GIS researchers. Two examples include the US National Center for Geographic Information and Analysis Research Initiative 19: "GIS and Society: the social implications of how people, space and environment are represented in GIS," as well as a specialist group meeting (Harris and Weiner, 1996) to develop specific research themes for critical GIS and investigate the "social implications of how people, space, and environment are represented in GIS.”

Major issues raised within the social theory critique generally included: GIS as a return to positivism, the social and spatial marginalization of communities (Harris and Weiner, 1998; Pickles, 1995), corporate and military use of GIS (Smith, 1992), and privacy (Armstrong and Ruggles, 2005). Critical GIS encompasses many different disciplines but "remains concerned with power embedded in the production and use of technology" and desires a GIS that is "compatible with the emancipatory scholarship advanced by feminist researchers, post-structuralist scholars, Marxian scientists, and post-colonial thinkers” (Harvey et al, 2005, pg 1). This focus on power-knowledge relations within critical cartography / GIS, therefore, is an appropriate fit within the Foucauldian framework outlined in the previous section.

\section{2. b. ii Maps as Sites of Power-Knowledge}

Within critical cartography / GIS, authors such as Harley, Wood, Pickles and Crampton integrate post-structuralist theory to see maps as constructed representations and sites of Foucault's power-knowledge. Harley $(1988,1989)$ argued that the authority of the map comes from the absence of clear information about who made it. Harley examined two arenas of power-knowledge regarding the "authorship" of a map: the "inner voice" of the map maker, including his skill and perspective, and the "outer voice" of the map patron, including capital and larger interests. In “Maps, Knowledge, and Power,” Harley (1988) illustrated how maps are culturally produced and could be used to promote and make legitimate the world views which were powerful at the time. Authors such as Crampton and Krygier stated that maps make reality: "maps are active; they actively construct 
knowledge, they exercise power and they can be a powerful means of promoting social change"(2006, pg 15). Maps, like knowledge, are both a creator and a creation of power. Wood (1992) contributed the idea that "maps construct, not reproduce, the world," and that "the interest a map serves is often masked." Wood's claim that these "hidden interests" could be revealed and then made to work for marginalized groups was described as a "manifesto" for counter mapping projects (Crampton and Krygier, 2006).

Crampton outlines the application of Foucault to mapping and geospatial technologies more specifically. In "Maps as Social Constructions," Crampton (2001) draws upon Harley's work to suggest how his theories might translate into practice, and how Foucauldian power-knowledge can create spaces for the "possibilities of resistance." Crampton states that Harley failed to note Foucault's denial of a "unitary" author (Foucault, 1972) and questioned that power can be divided into external or internal sources (Crampton, 2001). As reviewed in the previous section, Foucault's definition of power-knowledge did not see power as inherently negative, but more as strategic relations. Incorporating these insights, Crampton outlines the "maps as social construction" as an approach which "emphasizes the genealogy of power in mapping practices and enables multiple, contingent and exploratory perspectives of data" (Crampton, 2001, pg 235).

Crampton's work is crucial in connecting maps as sites of power-knowledge with Wood's proclamation that counter-mapping can be used to illustrate the "insurrection of subjugated knowledges” (Foucault, 1980, pg 81). Recall that Foucault gave two definitions of an "insurrection of subjugated knowledges," historical contents that had been buried or disguised, as well as forms of knowledge that were disqualified or located low on the hierarchy: a "particular, local, regional knowledge" (Foucault, 1980, pg 82). Wood's claim that these "hidden interests" could be revealed (by deconstructing them as Harley suggested) and then made to work for marginalized groups was described as a "manifesto" for counter mapping projects (Crampton and Krygier, 2006) to integrate participatory methods in creating multiple representations of knowledge that include traditionally marginalized perspectives. For example, using counter-mapping to 
strengthen local resource rights, empower greater community decision making, influence policy, reclaim lost lands, and promote intra-community cooperation (Alcorn, 2000). Wood discusses the response of "professional cartography" to the creative and evolving work of "unprofessional” cartographers. He suggests that cartographers should offer their services on "bended knee if necessary" to "the First Peoples who have come to realize it's map or be mapped; the impoverished locals trying to grapple with the impact of transnational mining, logging, and industrial development.” Wood states that cartographers played a significant role in making the world "safe for colonizers, mining conglomerates, and the military. We need to pay a little back” (Wood, 2003, p. 7).

\section{2. b. iii Participatory GIS}

Participatory GIS (PGIS) is a methodology within critical cartography / GIS that responds to Wood's call to "pay a little back.” The combination of geospatial technologies with participatory methods makes significant strides towards addressing many of the ethical issues raised by the social theory critique of GIS. PGIS brings together many different disciplines through its potential to combine local knowledge with more formal "expert" information to produce geospatial information that can be used to support community concerns. Rambaldi et al (2006) states that unlike traditional GIS, PGIS places "control on access and use of culturally sensitive spatial data in the hands of those communities who generated it” (pg 2). Participatory tools and methods used in PGIS practice include: ephemeral mapping (drawing on the ground), sketch mapping, scale mapping, 3D modeling, photomaps, the use of global positioning systems, maplinked multimedia information systems, and integration of GIS (Rambaldi et al, 2006). There are a number of different terms that relate to participatory GIS: PGIS (participatory GIS), and PPGIS (public participation GIS), and CiGIS (Community integrated GIS). Local context often determines which form of PGIS is used, the degree of participation, and the form that the final product takes.

The potential revolutionary power that originally drew my attention to participatory GIS regards the shifting of mapping power-knowledge from elites to subaltern perspectives in 
support of local social movements and advocacy. I witnessed this potential first-hand in Ecuador ${ }^{1}$ when the Huaorani villagers of Quehueriono decided to work with USAID, EcoCiencia, TROPIC, and the Instituto Geografico Militar in Ecuador to produce a participatory map of their territory and the areas they wished closed to oil extraction (Osha and Weiner, 2006). After that experience, I became interested in the transfer of power-knowledge in the relations between the dominant and subaltern discourses regarding MTR in the Coal River Valley. The work of Renee Sieber (2000) caught my attention due to her statement that her work had "an activist bias to facilitate the diffusion of GIS technology to the grassroots and guide conservationists in an implementation that supports not only diverse and distributed technology platforms and data structures, but also diverse ideologies and goals” (pg 788).

PGIS has been cited as an avenue for addressing some of the GIS and Society critique of GIS as inherently positivist and masculine. Gendered GIS can explore relationships of power between researchers and informants and how those relationships affect the interpretation and representation of knowledge (Mullings, 1999). PGIS takes this exploration one step further by removing the barrier between the dichotomy of researcher/informant through the incorporation of communities into the power structures that can empower or marginalize. Applications such as PPGIS, CiGIS, and multimedia GIS allow for productive inclusions of qualitative information such as pictures, video, oral history, and multiple forms of knowledge and spatial perceptions. Kwan (2002) states that an "urgent need exists to go beyond the conventional understanding of GIS as a largely quantitative practice and to recognize the potential of such realization for disrupting the rigid distinction between quantitative and qualitative methods in geographic research" (pg 656). In "Theorizing with GIS: A tool for critical geographies,” Pavlovskaya (2006) makes an important contribution to critical GIS by "disentangling" the assumption that GIS is only and always associated with quantitative science. After challenging the assumption that qualitative and quantitative methods must always oppose, she illustrates the many "openings" in GIS that enable qualitative research. She claims that GIS can "uniquely contribute to critical geographical theory by

\footnotetext{
${ }^{1}$ I served as a WorldTeach volunteer in Riobamba, Ecuador, 1997-1998
} 
becoming a visual tool for representing spatiality,” although so far, GIS has only “marginally fulfilled” its' potential for quantitative research (pg 26). Pavlovskaya’s (2006) examples of overcoming the "current bias of GIS towards numerical information" are very relevant to my research, such as examples where hand drawn maps, video, and photographs have been combined (pg 28).

\section{2. b. iv Simultaneous Empowerment and Marginalization of Communities}

The literature and the online community, as evident in the active dialogue in the Open Forum on Participatory Geographic Information Systems and Technologies (www.ppgis.net) and Integrated Approaches to Participatory Development (www.iapad.org), illustrate the potential of participatory mapping / GIS through numerous connections and conversations between practitioners from varying backgrounds. Robert Chambers, at the Institute of Development Studies, states that PGIS has "spread like a pandemic with many variants and applications. . .in natural resource management” (Chambers, 2006, pg 1). On the part of NGOs and open-minded governmental agencies, PGIS offers an opportunity to create more sustainable and grassroots oriented natural resource and planning projects (Kingston, 2007; Chapin, 2006; Aberly, 1993). On the part of local communities, PGIS can empower residents to be able to participate more fully in resource decisions. Communities can be empowered through PGIS using conflict resolution (Chapin, 2006; DeVera, 2005; Kyem, 2004), consensus building (DeVera, 2005), community interaction and networking (Harris and Weiner, 1998), formation of new leaders, use of "hidden interests" for marginalized groups (Wood, 1992), and increased access and participation in community and local resource planning (Aberly, 1993). 


\begin{tabular}{|c|}
\hline Public Participation in Final Decision \\
\hline $\begin{array}{c}\text { Public Participation in Assessing Risks and } \\
\text { Recommending Solutions }\end{array}$ \\
\hline $\begin{array}{c}\text { Public participation in Defining Interests, Actors, and } \\
\text { Determining Agenda }\end{array}$ \\
\hline Public Right to Object \\
\hline Informing the Public \\
\hline Public Right to Know \\
\hline
\end{tabular}

Table 2.1: Citizen Participation Ladder (Weidemann and Femer, 1993)

To increase the potential for community empowerment, participatory GIS facilitators are encouraged to consider their target audience as well as fundamental ways that the PGIS can be linked into local institutional mechanisms for creating change. Weiner et al (2002) discuss how PGIS projects can specifically aid communities by increasing participation in public planning. Weiner et al reference Weidemann and Femer's participation ladder (Table 2.1) to discuss how the different access that communities have on this "ladder" can range from "evasion to full empowerment" (Cited in Weiner et al, 2002). On the lowest rung, Public Right to Know, citizens are sometimes provided with requested information. For example, the Surface Mine Control and Reclamation Act (SMCRA) requires that information about a new strip mine permit must be published in local newspapers, giving the community access to the first and second rung of the ladder. Residents are even given the right to object, the third rung, but there is no legal requirement that citizen objections be incorporated into the final decision. At the top rung, citizens have a full voice in the final decision and often have organized themselves into a community organization. SMCRA does not allow citizens access to this top rung of the citizen participation ladder. Close attention to the parameters surrounding the "public," or the target audience, as well as a clear understanding of the functioning of local, state, and federal institutions involved in the decision making process will be critical in the development of the participatory maps in this dissertation.

Even with the best intentions, however, PGIS can and often does marginalize the exact communities that practitioners intend to support. Rambaldi et al (2006) state that practice of PGIS is "scattered with critical stepping stones all calling attention to troubling dilemmas and overarching issues about empowerment, ownership and potential 
exploitation." PGIS can also result in the loss of local control (McLafferty, 2005; Alcorn, 2000), generalization and abstraction of local issues when scale is "jumped” (Harris, 2006), cooption of data (Abbot et al, 1998), criminal prosecution (De Vera, 2005; Bujang, 2005), decrease of GRO performance due to time spent on PGIS (Sieber, 2000), privilege of expert data over local knowledge (Harris and Weiner, 1998), and legitimization of decisions that were not truly participatory (Harris and Weiner, 1998). Elwood (2006) adds that "a central tenet of PPGIS practice is its commitment to incorporating local knowledge and representing multiple perspectives, but the ambiguities of the everyday practices that negotiate knowledge production in PPGIS illustrate the challenges of doing so” (pg 206). This research assumes that PGIS has the potential for simultaneous empowerment and marginalization of communities (Harris and Weiner, 1998).

One ethical area of concern regarding the marginalization potential of PGIS centers around the potential for "participation" to be used simply as a form of legitimization. In response to “overarching questions about empowerment and ownership,” Chambers asks the following questions: "Who is empowered and who disempowered? And, who gains and who loses?”(Chambers, 2006, pg 1). When investigating who is participating within a community, the essential question concerns the definition of community itself. Social context is essential to the selection of participatory methods. For example, methods which seek out a few local people (for example, friends of the researchers) to represent a community can result in participation simply as a form of legitimization (Craig et al, 2002). Different individuals (race, ethnicity, gender, age, status) will be affected in varying ways by the PGIS. The way in which the community is defined through methodological scale by the researcher has a large impact on who is included, who is going to receive the benefits from the project (education, expertise, additional rights, a voice in decision making) and who is going to be left out. This study assumes that due to the heterogeneous qualities of the residents within the Coal River Valley this PGIS has the potential to empower and marginalize individuals simultaneously in different ways within the study area (McLafferty, 2005). 


\section{2. b. v Community Dis/Empowerment through Process, Product, and Long- term Outcome}

In addition to the spatial component of individual empowerment within a community, the temporal components of PGIS, including process, product, and long-term outcome, also affect individuals and communities in a variety of ways. Three studies conducted by Kyem (2002), DeVera (2005), and Bujang (2005) offer different perspectives on the temporal aspects of process, product, and long term outcomes within specific case studies.

Kyem (2002) used PGIS to assist in conflict resolution involving forest use in southern Ghana. In response to increasing conflict between local forest land owners versus state foresters, the Ghanaian government sought a new forest use policy to integrate local community groups into forest management. Kyem was concerned that the use of GIS in the collaborative forest project would make it "likely that issues of unequal access to data, technology, and expertise would reinforce the status quo and work against free and open discussions" (2002, pg 219). He implemented a PPGIS project to "demonstrate an alternative, less elitist application” of GIS technology (Kyem, 2002). In their own words, community members found the process of PGIS to be empowering because they were able to negotiate with state foresters with "hard data." An important element of cultural support for this empowerment was their tribal system of negotiating conflict resolution through group meetings, dialogue, and consideration of minority opinions. Their PGIS products included 'Conflict' and 'Final Allocation' maps that helped locals, state foresters, and industrial loggers agree on management practices. Results were used to satisfy the state's requirement for local input into land use, providing evidence of PGIS helping move local communities from the bottom to the top rung of the citizen participation ladder (Table 1). However, long term outcomes of the project were disappointing. Without Kyem's presence, the local community structure fragmented, and no final resolution was reached between the locals and the department of forestry (Kyem, 2002). 
De Vera (2005), the executive director of the Philippine Association for Intercultural Development (PAFID), is the author of the second study. In response to the 1997 Indigenous People's Rights Act which accommodated the right of self determination of indigenous peoples, numerous NGOs began to map boundaries and local geographical knowledge in the Philippines. The problem addressed by PGIS in this case was the loss of forest cover, government-promoted mining, and migration of lowland families into indigenous ancestral land. One cultural aspect that supports this empowerment was the sketch maps that communities already used to discuss resource management. The product of this PGIS project, 1 million hectares surveyed and hundreds of Certificates of Ancestral Domains issued, was overwhelmingly positive. Long-term outcomes included community based map-making and management without help from outsiders as well as the ability to monitor and maintain their own boundaries. PGIS projects in Philippines “seriously challenged the status quo" (De Vera, 2005). As a result, the Geodetic Engineering Act of 1998 made PGIS activities not conducted by official state engineers illegal. Informal mapping was even criminalized. Despite this severe setback, participatory mapping projects have still emerged as a powerful negotiating tool for the indigenous people of the Philippines... powerful enough to draw the government's attention.

In the third case study, Bujang and PGIS practitioners addressed land conflict in Borneo between the native customary rights (NCR) of the Dayak people and government concessions to logging, oil-palm industries, and tree plantations. The Dayaks had historically relied on traditional NCR. As of 2005, however, the Malaysian government has licensed out logging concessions for $70 \%$ of the land area of Sarawak. In response, the Dayak people issued blockades and were arrested and assaulted. As in the other case studies, Dayak tribes were empowered by the process of mapmaking. Participating communities became more mobilized and organized. As in the study in the Philippines, communities were able to use maps to reach the highest rung on the participation ladder. A Dayak tribe, the Ruman Hor, used their PGIS in 2001 to keep a pulp company off of their land. However, the Sarawak State government acted as the Phillipine government: in 2001, the Land Surveyors Ordinance declared community mapping illegal. Long term 
outcomes of this case study included the criminalization of indigenous groups who had learned map making skills.

One of the most important themes drawn from this literature is the importance of the role of the researcher in supporting successful outcomes from PGIS projects. Chambers (2005) states that the difference between empowering and marginalizing communities often depends on the behavior and attitude of facilitators, as well as who controls the process. The importance of "transparency, time, and trust" in the attitude of the facilitator (Chambers, 2005; Drew, 2003; Kindon, 2001) and the need to be self reflective and open about how decisions are reached and who is included in the decision making process (Drew, 2003; Corbett et al, 2006) are essential themes guiding the methods of this dissertation.

This section of the literature review has focused on themes such as marginalization and empowerment of communities, legitimization by participation, the role of researcher/facilitator, and the integration of qualitative and quantitative methods through multimedia applications. The inclusion of three PGIS case studies highlighted the potential for community dis/empowerment through the temporal impacts of process, product, and long term outcome. Themes within this literature make it evident that the participatory GIS holds potential for the empowerment of communities, although not without risk. However, as De Vera (2005) states, "an empowered community will always be challenged" (pg 6) and I take this official reaction as another sign that PGIS is a methodology that can support positive change for marginalized groups.

In summary, local context often determines which form of PGIS is used, the specific methods, the degree of participation, and the form that the final product takes. In order to inform my methods, as well as elucidate Foucault's "historical and geographical specificity" (Crampton and Elden, 2007, pg 6), the next section will focus on relevant literature within Appalachian Studies to aid in situating the discourse of resistance to mountaintop removal in central Appalachia. 


\section{2. c. Appalachian Political Economy, Identity, and the Subaltern}

Having failed to learn the environmental lessons of resource overdevelopment at the turn of the twentieth century, we continued to see the mountains (just as we saw mountain culture) as a barrier to progress, something to be overcome and its resources tapped in the name of growth

Uneven Ground: Appalachia since 1945, Eller, 2008, pg 7

An essential lesson drawn from the previous section on participatory GIS is the need to recognize the potential for my research to cause simultaneous community empowerment and marginalization. Drawing from Chambers' (2006) work on power relations in participatory mapping, it is important to ask who might be empowered or disempowered individually within the community by this research? To understand the context for subaltern and elite discourse within West Virginia, I first had to engage in the debates surrounding political economy and the evolving theories on culture and poverty in Appalachia. This section gives an overview of the progression of these theories with particular attention to the role of elites and patterns of absentee landownership in central Appalachia. The use of the term "subaltern" as applied to the Coal River discourse is also explained. The review then focuses on the context for investigating discursive formations along lines of gender, age, and livelihood. Finally, the review examines literature regarding how the initial stereotypes created by the culture of poverty still impact Appalachia and the discourse of resistance.

\section{2. c. i Culture of Poverty}

In the early $19^{\text {th }}$ century, Appalachia was treated as an isolated folk culture that drew the attention primarily of ethnographers. Appalachia was initially considered to be a homogenous region in terms of ethnicity, religion, social structure, and mountain environment. Environmental determinism, as evident in the works of the early geographer Ellen Churchill Semple, contributed to the idea of Appalachia as a homogenous mountain area with a "tendency towards defection" (Semple, 1903). The use of modernization theory in place of regional history in these early narratives 
contributed to the development of a culture of poverty model that blamed the "backwardness" of mountain people on cultural defects (Caudill, 1963; Weller, 1965).

Under the culture of poverty model, attention was put on the poor themselves instead of investigating the economic and political structures that both produced and then reproduced poverty. For example, in "Yesterday's People," Weller presented a patronizing perspective of all mountaineers as a homogenous group without any specific place-based identity. Weller's narrative was ahistorical, anecdotal, and laden with assumptions which he generalized to include all mountain people. Weller's basic assumptions concerning the existence of a distinctive Appalachian folk culture included individualism, traditionalism, fatalism, action-seeking, isolation, and family. Summarizing many of the criticisms of cultural deficiency models, Eller stated that "efforts to explain and deal with the social problems of the region have focused not on economic and political realities in the area as they evolved over time, but on the supposed inadequacies of a pathological culture which is seen to have poorly equipped mountain people for life in the modern industrial world" (in Lewis et al, 1978, pg 37).

\section{2. c. ii Internal Colony and Internal Periphery}

Many Appalachian scholars countered with differing models of the political economy of Appalachia in response to these numerous problems and stereotypes within the cultural deficiency model. The internal colony model (Lewis et al, 1978; Eller, 1982; Rasmussen, 1994) introduced the political and economic aspects of absentee landowning patterns and the exploitation of local people by outside industry.

The internal colony model helped to focus attention on the exploitation of land, labor and resources by outside corporate interests. As Lewis stated in her introduction to Colonialism in Modern America: The Appalachia Case, "we need a model which explains and examines the relation between economic power, political power, and cultural systems, how they change and how people's perceptions of their situation are formed and changed”(pg 5). Walls found the application of the model of internal 
colonialism, however, to be "strained," stating "the deception and fraud used in Appalachia by the vanguard of land, timber, and mineral agents do not appear to differ in kind from those techniques used generally by capitalists and their agents throughout the country in the period of industrial expansion” (pg 6). In "Internal Colony or Internal Periphery?”, Walls (1978) drew on the three-tiered system developed by Immanuel Wallerstein to show how the possibility of attaining semi-peripheral status could prevent a strong alliance of one region within Appalachia with another region that is worse off. He gives evidence of this possibility in the move of Northern and Southern areas of Appalachia towards semi-peripheral status while Central Appalachia remains behind. Walls concludes by offering a variation of the internal colony model in which he proposed that Central Appalachia is best characterized as a peripheral region within an advanced capitalist society (1978).

Despite these steps forward in considering the political economy of Appalachia, these authors still largely portrayed Appalachia as a homogenous region. In both the internal colony and internal periphery models, all of Appalachia was considered to be part of the subaltern discourse disenfranchised by outside elites. Internal colony writers presented antebellum Appalachia as an isolated, subsistence farm culture lacking social stratification and ethnic differences. From this starting point, outside corporate interests came in and exploited Appalachian homogeneous "victims.” Specific regional studies (Weise, 2001; Dunaway, 1996; Pudup et al, 1995; Mitchell, 1991; Dunn, 1988) focus on preindustrial Appalachia to provide a more realistic basis for academic discussion regarding the region's economic diversity as well as the role of local and outside elite in exploiting the Appalachia’s natural resources.

These regional studies are important to the ongoing dialogue about sources of Appalachian poverty because they portray many regions in the $19^{\text {th }}$ century as having strong market ties and agricultural surpluses, in contrast to the traditional view of preindustrial Appalachia as isolated and based on subsistence farming. This shift in perspective on preindustrial Appalachia portrays Appalachians as becoming impoverished because they believed in the capitalist system, as opposed to earlier 
arguments that poverty was caused by Appalachian's disinclination and isolation from market systems. A specific example of this shift in perspective is found in Lewis' Transforming the Appalachian Countryside (1998). His work is situated within revisionist history which suggests that modernization itself, not its absence (isolationism), gave rise to the severe poverty and exploitation of Appalachia by the mid 1900s. Lewis states that the "financial benefits derived from the development of the forest industry accrued to a select few over the short term, whereas the cost of widespread destruction was borne by the taxpayers” (pg 264). Large absentee firms acquired a disproportionate influence over West Virginia both economically and politically (Lewis, 1998). More recent scholarship (Billings and Blee, 2000; Billings and Tickamyer, 1993; Waller, 1988) has focused on the role of local elite, political corruption, as well as variations within regional ability to provide capital investment throughout the industrial period as additional factors in the impoverishment of Appalachian people.

\section{2. c. iii Absentee Landowners and the Role of Local Elites}

In both the internal colony and internal periphery models, the role of absentee land owners was emphasized as a reason for local exploitation of people and of natural resources. Scarce capital existed in the sparsely populated mountains, so the majority of capital was invested by absentee owners. In Absentee Landowning and Exploitation in West Virginia, Rasmussen studies the patterns of land ownership and political control in Randolph, Tucker, Pocahontas, Monroe and Clay counties from 1760 to 1920.

Rasmussen's thesis is that the patterns within these five counties show that Appalachia is “economically distressed because residents and resources were consciously exploited by identifiable others." She argues that the evidence that she found disproves theories that Appalachia was “victimized” by its own "regional and cultural characteristics” (pg 1). She argues that Appalachians fought hard for their land and community.

The desire to keep land taxes low was one reason, she argues, that absentee landowners holding land in the West (West Virginia) joined forces with the powerful land owners in 
Virginia. Large land owners did not stand to profit from settlers, who would require taxsupported institutions as well as challenge absentee ownership of land. As a result, Virginia taxed livestock and personal property, successfully putting the tax burden upon mountain settlers, even though the settlers outnumbered eastern residents by 1850 (pg 45). Rasmussen states that "the West was so thoroughly controlled by absentees and speculators that taxes were shifted permanently away from the land” (pg 51). This discussion helps to explain one of the reasons for West Virginia's current lack of internal development and infrastructure.

Rasmussen's argues that local residents fought hard to advance their society and protect their land. For example, Rasmussen states that "farmers were not ignorant of their rights, nor were they willing to yield easily to outside pressure, but they were outmatched in the courtrooms” (pg 61). Settlers were also continually outmaneuvered politically by politicians in Richmond who contended that majority should reflect those who held the most property, as opposed to numerical superiority. Therefore, when Western residents sought to bring internal development through political means, they were easily outvoted. Absentees could use superior land deeds to negate settler claims made through disorganized courthouses. Unfair taxes levied on personal property, as opposed to land, put the weight of infrastructure on the shoulders of Western residents and primed them to welcome outside investment to build needed roads.

In Eller’s (1982) landmark study Miners, Millhands, and Mountaineers, Eller showed how the "new mountain" economic order after industrialization was "highly dependent, labor intensive, and tied to the export of single extractive commodities.” In contrast to earlier treatments of the internal colony model to Appalachia, Eller devotes an entire chapter to role of internal elites in the disenfranchisement of local residents. His 1982 work found that the region's poverty was rooted deeply in the industrial process that created modern America. In his recent work, Uneven Ground: Appalachia since 1945, Eller (2008) states that “Appalachia endures as a paradox in American society in part because it plays a critical role in the discourse of national identity but also because the region's struggle with modernity reflects a deeper American failure to define progress in 
the first place" (pg 3). He goes on to state that we have too often "mistaken growth for development, change for progress," and cites the environmental damage and short term employment caused by mining and other extractive industries as an example.

\section{2. c. iv The Subaltern: Gender, Age, and Livelihood}

My dissertation draws from Walls' internal periphery model to locate "subaltern" within the study area, but relies on recent scholarship to focus on the heterogeneous community of resistance and existence of multiple discursive formations within the discourse of MTR. The Foucauldian framework employed by this dissertation necessitates that unities, such as the idea of a singular discourse of resistance to mountaintop removal, be questioned. Therefore, the intersections and overlaps of discursive formations within the subaltern will be investigated regarding gender, age, and livelihood of participants.

Subaltern originates from the work of Italian Marxist Antonio Gramsci and refers to any person or group of inferior rank due to factors such as race, class, gender, ethnicity, sexual orientation, or religion. The Subaltern Studies Group (SSG) arose in the 1980s to construct a "history from below" of India and South Asia. SSG focuses on the subalterns, or the non-elites, as agents of social and political change. According to Guha, the people is synonymous with subaltern classes and refers to all people not included in national, regional, or local elite identity (Guha and Spivak, 1988).

Walls' (1978) work drew on Gramsci's work on cultural hegemony, or the obtaining of consent rather than the use of force in the perpetuation of class structures, in his evaluation of the applicability of the internal colony model to Appalachia. Cherniavsky's work (1996) took the term subaltern from its origin in South Asia and applies it to the US framework. Authors Kingsolver (1991) and Taylor (1992) applied subaltern to development discourses in rural Kentucky and to industrial workers in southern West Virginia. In the context of my work, the term subaltern is used to encompass the variety of discourses of resistance to mountaintop removal in the Coal River Valley. 
The use of subaltern to qualify the discourse of resistance in Coal River Valley allows for the existence of multiple discursive formations within the "history from below." This dissertation focuses on intersections and overlaps between gender, age, and livelihood as elements of the social identities of participants within the larger discourse of resistance. In my own words, "reconstructing” social identity in Appalachia refers to an individual's comprehension of him/herself as a separate entity that is simultaneously similar and different from culturally constructed others. Regarding this "reconstruction" of identity in Appalachia, specific pictures emerge around gender (Latimer and Oberhauser, 2004; Oberhauser, 1995; Tickamyer and Tickamyer, 1991), ethnicity (Hayden, 2004; FonesWolf and Lewis, 2002; Trotter, 1990; Lewis, 1987) and social identity (Scott, 1995). I draw from this literature specifically regarding gender to inform my representation of multiple identities within the subaltern discourse of resistance to MTR.

In this dissertation, a gendered lens is essential to help situate the concerns of women regarding the impacts of mountaintop removal as well as the ability for their concerns to be voiced and heard within the subaltern discourse. Recent literature examines the gendered dimensions of poverty (Latimer and Oberhauser, 2004; Tickamyer and Tickamyer, 1991), women in union organizing (Maggard, 1987), and gender inequalities in the region as well as income disparities (Latimer and Oberhauser, 2004; Tickamyer and Tickamyer, 1991). Latimer and Oberhauser (2004) investigated how gender relations impacted the distribution, causes and consequences of social and economic inequality and uneven development.

Many of the most vocal leaders speaking out on both sides of the debate around mountaintop removal are women. It Comes From the People (1995), Hinsdale et al. look at gendered aspects of community building, leadership, and local economic development. The authors state that "as plants close and economic growth bypasses rural areas, communities are not just being marginalized by the economic restructuring; they are responding to these changes in creative ways. In rural areas, it is the women who have taken the lead in the efforts to rebuild and revitalize communities”(pg 2). Maggard’s 
(1987) work highlighted the participation of women in the coal strikes of the 1970s in Harlan County. She was "surprised" to find that many of the key figures in these movements were women. Her research involved questions such as the reasons why women mobilized, stayed active, and stepped outside the bounds of their everyday lives. A particularly relevant element of her argument was that traditional studies of collective protest focus on the worker (usually a man) as the connection between work and family. Therefore, she pays particular attention to the structure and operation of households in analyzing women's participation in class conflict and perceptions of class structure. I will draw upon Maggard's work to illuminate the additional ways that women participate in the movement and voice their concerns outside of the traditional focus on the male worker.

Differing discursive formations around the age of participants within the subaltern discourse will also be examined. Within the discourse of resistance to MTR, age often corresponds directly to the participations of miners in the UMWA (Aurora Lights, 2009). Many older miners were strong union supporters and continue to support the union even after retirement. Please see Chapter Three for a further discussion of union activities within the case study area. In Bringing Down the Mountains, Burns states that "the fierce anti-union sentiment witnessed throughout southern West Virginia is particularly offensive to a union that fought long, hard, and often bloody battles to gain recognition in the coalfields” (Burns, 2007, pg 27.) The combined impact of a weakened UMWA, an increase in mechanization and expendability of the workforce, and an overall drop in coal employment has resulted in vastly different job choices for the current generation of workers. Massey Energy, the fourth largest coal producer in the nation, reported in 2003 that only 193 of its 4,428 employees were UMWA members (Burns, 2007, pg 27.) Tension can exist between younger miners, forced to choose between working out of state or working for a non-union mine, and their strongly union parents.

Discursive formations within the subaltern discourse can be heavily influenced by the choice of livelihood within each family. Robert Chambers and Gordon Conway define livelihood as "the capabilities, assets (including both material and social resources) and 
activities required for a means of living' (Chambers and Conway, 1992). Ellis (2000) defines livelihood as 'the activities, the assets, and the access that jointly determine the living gained by an individual or household'. In early fieldwork, the type of livelihood was the greatest indicator of willingness to speak with me (Osha, 2009), with current strip miners and their families either unwilling to speak with me or requiring full confidentiality. Within the dominant discourse of MTR, it is the type of livelihood that is the basis for the labels of "miners," meant to represent everyone whose livelihood comes from the mines, versus "treehuggers," who either are perceived to have no livelihoods or work for non profit organizations. Although this dissertation research does not examine the assets of participants regarding this livelihood, it will investigate differing discursive formations regarding the activities involved in making a living. For example, an underground miner conducts different activities than a surface miner. Along with the generational differences mentioned previously regarding union participation, family tensions over underground mining versus surface mining also exist. Despite the label of "miner," the differing livelihood activities of underground miners versus surface miners can influence specific concerns regarding mountaintop removal.

Additionally, investigating discursive formations around livelihood reflects the importance of informal livelihoods such as stay-at-home mothers and land-based families who use their surrounding mountain ecosystem to create a multiple livelihood strategy based on hunting, gathering, and gardening. In her online work "Tending the Commons," Hufford (1999) uses interviews and photographs to document the ability of some families to offset economic hardship through a close seasonal relationship with the mountains. A family that survives job loss due to their knowledge and proximity to forested land may have very different concerns from a miner currently employed by a strip mining company. Additionally, the ability of a family to participate in this study or speak out against mountaintop removal can be heavily influenced by family members currently working in the mines. 


\section{2. c. v Pervasive Stereotypes}

At the local level, the divisive and bitter differences of opinion between families about the costs and benefits of mountaintop removal certainly discredit the idea of a homogenous discourse. Regarding the Upper Big Branch tragedy, however, national media still portrayed the men who died underground as part of a homogenous "other." As a local grandmother and life-long resident of Coal River stated, "we're considered as the coalfields in this area. I'd like to think that we are much more than that. We have hopes, families, dreams, just like anyone else outside of the coalfields” (CR \#2).

Despite progress in academia away from the cultural deficiency model, the stereotypes created in part by the cultural model are still applicable to the case study area. An important result of the diversification of the Appalachian experience has been the inclusion of an academic discussion of the impact of cultural poverty models and resulting stereotypes on Appalachians themselves (Batteau, 1990; Becker, 1998; Billings et al, 1999; Fisher, 2002) and the use of this cultural deficiency model to reproduce stereotypes about the origins of poverty (Billings, 1974). Billings (1974) also warns that the dominance of cultural deficiency models on the work of "social actors who have power over the poor" become in themselves one more factor in the "identity maintenance" of the poor. The subaltern discourse of resistance, therefore, must compete not only with the dominant discourse of MTR, but also stereotypes about hillbillies and West Virginians in general. 


\section{2. d. Conclusion}

In this review, I draw from three literatures to situate the discourse of resistance to mountaintop removal coal mining and explain the use of the term "subaltern" in referring to this discourse. I bring together the literatures of Foucault within geography, critical cartography and participatory GIS, and evolving theories of Appalachian political economy.

An overview of the Foucauldian framework is applied to my research to define some of the tools that I will be using in this research, and to explain why I chose a Foucauldian lens for my dissertation. Elements of Foucault's “archeological” method are introduced to investigate the legal formation of MTR as an object by constructing a mini-archeology in Chapter five. Using this framework, the subaltern discourse of resistance to MTR within the Coal River Valley can then be situated as within a specific geographical and temporal emergence of the hegemonic MTR legal discourse. Finally, I explain how the Foucauldian framework allows me to use the data collected through the construction of first, a "mini-archeology" of MTR, and second, the subaltern discourse of resistance in Coal River Valley, to analyze the power relations that continue to subjugate the subaltern discourse. The Foucauldian analysis of the relationship between the subaltern discourse of MTR in the Valley and the dominant discourse that created and permits MTR that this dissertation has the potential to create spaces for the "possibilities of resistance" (Crampton, 2001, pg 236).

A brief literature review of participatory mapping / GIS is introduced to situate participatory GIS (PGIS) within critical cartography/GIS as a methodology to map the subaltern discourse of mountaintop removal in the Coal River Valley. Literature from both critical cartography and critical GIS is drawn upon to explain the "particular, local, regional knowledge" referred to by Foucault as an "insurrection of subjugated knowledges” (Foucault, 1980, pg 81) within the Coal River Valley. Authors such as Harley, Wood, Pickles and Crampton integrate post-structuralist theory to see maps as constructed representations and sites of Foucault's power-knowledge. The potential of PGIS to combine local knowledge with more formal "expert" information to support 
community concerns is highlighted. On the part of local communities, PGIS can empower residents to be able to participate more fully in resource decisions. Even with the best intentions, however, PGIS can and often does marginalize the exact communities that practitioners intend to support. This research therefore assumes that PGIS has the potential for simultaneous empowerment and marginalization of communities (Harris and Weiner, 1998). Three case studies are used to examine dis/empowerment of communities and individuals through the process, product, and long term outcomes associated with participatory projects.

Due to the heterogeneous qualities of the residents within the Coal River Valley, this literature review also points to the potential for PGIS to empower and marginalize individuals simultaneously in different ways within the study area (McLafferty, 2005). Foucault states that in order to do an "analysis of power...we must speak of powers and try to localize them in their historical and geographical specificity' (Crampton and Elden, 2007, pg 6). Therefore, literature from Appalachian political economy is used to help situate the discourse of resistance within larger theories of poverty and culture as well as outline the local social context for the selection of appropriate participatory methods. Working through Foucault's conceptual lens, unities such as a "discourse of resistance" must be questioned. Therefore, the subaltern discourse of resistance is examined with attention to discursive formations around gender, age, and livelihood. The next chapter will introduce the case study area for this dissertation: the Coal River Valley of West Virginia. 


\section{CHAPTER THREE}

\section{RESOURCE EXTRACTION AND RESISTANCE IN THE CASE STUDY AREA: COAL RIVER VALLEY OF SOUTHERN WEST VIRGINIA}

The previous chapter brought together literatures from Foucault, participatory GIS and critical cartography, and Appalachian studies to outline the conceptual framework and methodology of this study. This chapter introduces Coal River Valley, specifically the communities surrounding Coal River Mountain, as the case study area for this dissertation. In the mini-archeology used to collect data for my first research question ${ }^{1}$ regarding legal discursive formations, the case study area serves as the geographical surface of emergence of the legal and regulatory discourse. For my second research question $^{2}$ illustrating discursive formations of resistance, the case study area is where I conducted interviews, constructed the base map, and facilitated participatory mental mapping.

This chapter proceeds to justify my choice of case study area and then outline the physical and social geography of the communities surrounding Coal River Mountain. The review briefly looks at gender, age, and livelihood demographics in the case study area. The case study area is then examined through the internal periphery lens with an emphasis on resource extraction and the rise of mountain top removal coal mining. The history of union organizing and the formation of community groups are examined as forms of resistance in Coal River Valley. Finally, the chapter concludes with a focus on the importance of multiple livelihood strategies and community land use in understanding the concerns of residents regarding the impacts of mountaintop removal coal mining in the case study area.

\footnotetext{
${ }^{1}$ What are the legal discursive formations that define and allow the permitting of MTR in the case study area?

${ }^{2}$ What are the subaltern discursive formations regarding the implementation of MTR in the case study area?
} 


\section{3. a. Justification of Case Study Area}

I chose the Coal River Mountain as the geographical surface of emergence for mountaintop removal and the communities surrounding the mountain as the source of qualitative information to represent the subaltern discourse for four reasons. Firstly, concerned residents in the communities surrounding Coal River Mountain have first-hand knowledge of the impacts of MTR due to their close proximity to two large MTR sites to the north and the west of the mountain. Secondly, Coal River Mountain was the last “mostly intact” mountain in the watershed, providing security and stability to residents impacted by blasting, flooding, and dust from neighboring MTR sites. Therefore, the potential loss of the protection of Coal River Mountain concerns residents across many different discursive lines. Thirdly, the combination of the previous factors has contributed to a rise in local resistance and organizing, allowing greater opportunities to access the subaltern discourse. Finally, considering the requirements of "time and trust" in building local relationships to support participatory research, I had established relationships with both community groups and local residents over a time period of six years prior to beginning this research.

\section{3. b. Overview of Physical and Social Geography}

The case study for this dissertation is located in the Coal River Watershed of southern West Virginia. Although parts of eight counties are included within this watershed, Raleigh and Boone counties make up the majority of the watershed (Figure 3.1). The watershed derives its name from the Big Coal River, which rises in Raleigh County as two streams, Clear Fork and Marsh Fork, which join near Whitesville and flow northwest through Boone County. 




Figure 3.1 : The Case Study Area within the Coal River Watershed, WV 
Coal River Valley is located within the eastern section of the unglaciated Appalachian Plateaus Province. It is characterized partially by its "rugged and steep” hills, a factor that has had a major influence on the economic development of the southern coalfields (Hicks, 1998). Coal River Valley is within the central hardwood region, a forest type comprised predominately of a diversity of hardwoods as well as conifers such as pine, hemlock, and spruce. More specifically, the areas still forested are covered with the most biologically rich temperate forest in the world: a mixed mesophytic hardwood forest (Braun, 1947). An important geologic feature that has had an enormous impact on the central hardwood region has been the occurrence of coal. Coal seams outcrop along the hills in the Appalachian Plateaus’ Province where streams have eroded away the intervening valleys.

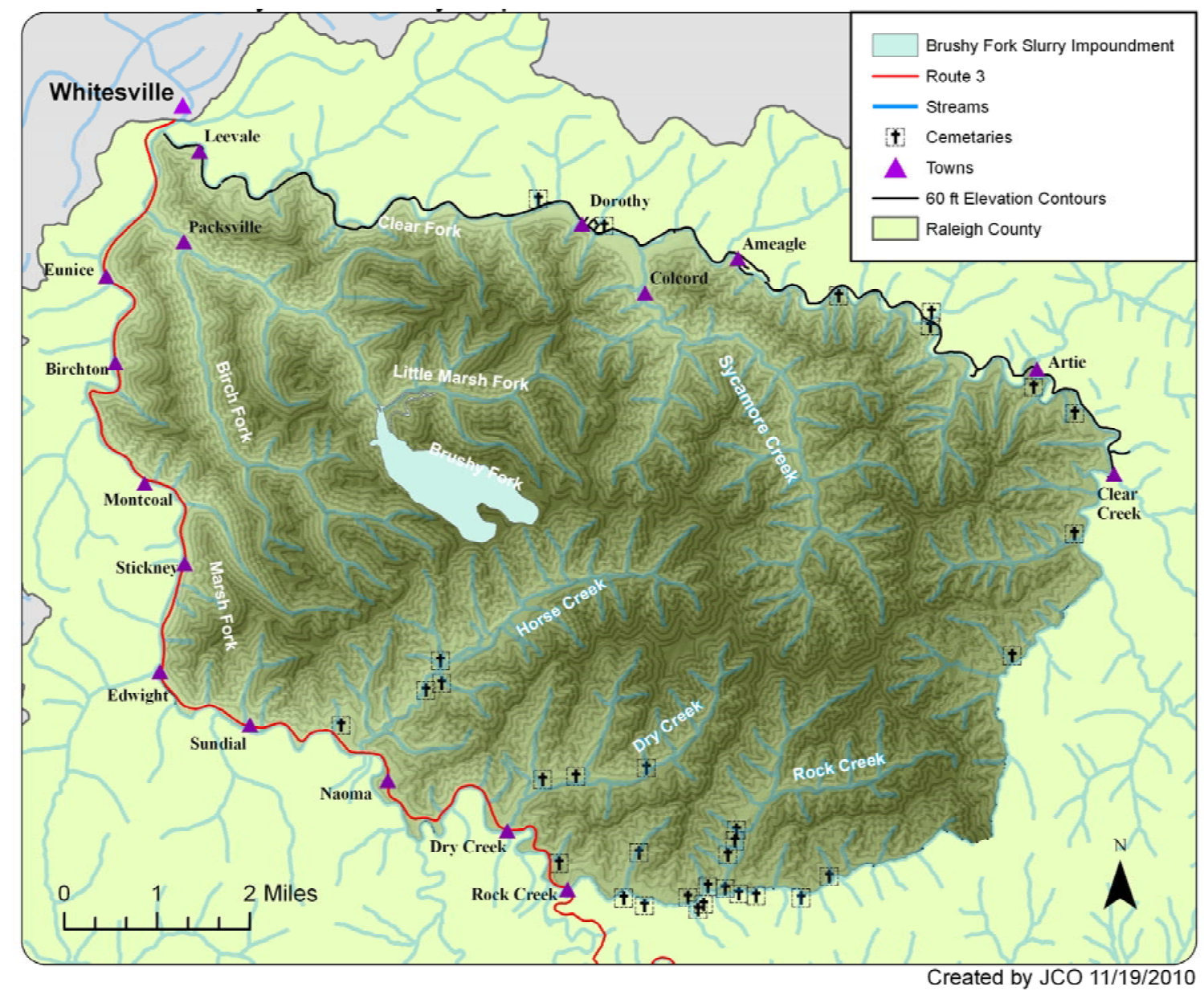

Figure 3.2: Coal River Mountain in the Raleigh County portion of the Coal River Watershed with key towns and hollows. JCO (5/17/10) 
My case study focuses on a specific geographical portion of the Coal River Valley: the communities on or surrounding Coal River Mountain that would be impacted by mountaintop removal operations on the mountain (See Figure 3.2). Coal River Mountain stands between the Clear and Marsh Forks of the Little Coal River, and spans an area of approximately 62 square miles. Although Coal River Mountain has been mined underground, strip mined in places, and contains the Brushy Fork slurry impoundment, the majority of the mountain is still forested and accessible to the community. The impacted communities are located to the north of the mountain along Clear Fork Road (Route 1), along Coal River Road (Route 3), to the west and southwest of the mountain (See Figure 3.2), and in the hollows of Rock Creek, Dry Creek, Horse Creek, and Sycamore.

As one of the last “intact” mountains in the valley, Coal River Mountain provides a buffer to communities along Clear Fork and Route 3 that have already impacted by blasting, flooding, and dust from neighboring MTR sites. Residents living along Clear Fork live directly south of one of the largest contiguous MTR sites in West Virginia. Residents living along Route 3 live directly to the east of two MTR sites. For these communities, mountaintop removal coal mining on Coal River Mountain would sandwich residents between mining on two sides. Residents living up the hollows of Horse Creek, Dry Creek, Sycamore, and Rock Creek at the roots of Coal River Mountain have been relatively untouched by MTR thus far (See Figure 3.2).

\begin{tabular}{||lrr|}
\hline \multicolumn{1}{|c}{ Age } & Case Study Area & WV \\
$0-14$ & $18.10 \%$ & $18.1 \%$ \\
$15-24$ & $12.60 \%$ & $13.5 \%$ \\
$25-34$ & $12.30 \%$ & $12.7 \%$ \\
$35-44$ & $13.30 \%$ & $15.1 \%$ \\
$45-54$ & $17.60 \%$ & $15.0 \%$ \\
$55-64$ & $11.10 \%$ & $10.3 \%$ \\
Over & $14.90 \%$ & $15.3 \%$ \\
65 & $100.00 \%$ & $100.0 \%$ \\
& Table 3.1: Age Distribution \\
\multicolumn{3}{|c}{ Source: US Bureau of Census, 2000 } \\
\hline
\end{tabular}

The approximate population of the communities in the case study area is 5,059 people, ${ }^{3}$ with nearly an equal representation of men (49.6\%) and women (50.4\%). Table 3.1 shows the breakdown of population by age within the case study area and the state of West Virginia, with a median age of 43 years old (compared to 38 at the state level). Census data from 2000 supports local concern regarding outmigration of working adults, shown clearly in the age groups 34-44 and 45-54, to search for higher paying jobs. Median income

\footnotetext{
3 This data was gathered by combining 2000 census data for the zip codes encompassing the case study area. I use the word "approximate" because the census data covers a larger area than the case study area.
} 
by gender shows a significant difference: $\$ 33,000$ for full-time male workers, and a significantly lower \$20,672 for full-time female workers from Raleigh county census data. Of the 2,038 households in the case study area, $71.8 \%$ are family households, and 38\% have children under 18 living at home. Regarding this 71.8\% majority of family households, I use Oberhauser's (1995) work on the intersections of gender, households, and economic restructuring to situate the concerns of stay-at-home mothers or women who work part time in combination with other home work. The $\$ 13,000$ income gap between women and men also highlights the need to focus on the ability of women to supplement family income through informal livelihoods (Oberhauser and Turnage, 1999; Oberhauser, 1995). The gender lens employed in this research helps to situate the concerns of women as well as highlight gendered dimensions of poverty (Latimer and Oberhauser, 2004; Tickamyer and Tickamyer, 1991). For example,

Raleigh county data shows a median household income of $\$ 28,181$, compared to $\$ 29,696$ at the state level, and \$35,315 for families, compared to \$36,484 at the state level. An overwhelming $99 \%$ of the population is white, with less than $1 \%$ represented by African Americans, American Indian, Hispanic or two or more races. Due to these overwhelmingly white demographics, I did not choose to investigate discursive formations around ethnicity in Coal River. These general demographics do support my decision to investigate discursive formations at intersections of gender, age, and livelihood.

\section{3. c. Coal River as Periphery: Natural Resource Extraction}

This dissertation builds upon the work of Walls (1978) in viewing Appalachia- and more specifically the case study area - as a periphery zone within an advanced capitalist society. Through this lens, Coal River acts as an extraction zone to supply cheap natural resources to the dominant, core society. This view of the political economy of Appalachia includes the role of political elite. In her work Bringing Down The Mountains, Burns (2007) defines the political elite in the southern West Virginia coalfields as composed of the "coal corporations, organizations with coal centered 
agendas (such as the West Virginia Coal Association and Friends of Coal), other large industries with vested economic interests in coal (such as machine manufacturers and distributors), and politicians who support ideas and legislation that benefit the coal industry” (p. 3). This section proceeds to give an overview of resource extraction and the role of absentee land owners in the case study area.

The Thompson (1995) family story is also woven in to this overview to provide specific examples of how resource extraction impacted the lives of one family over generations within the case study area. The work of Vera Thompson Treadway (1995) on her Thompson ancestors provides an excellent window into the interweaving of family, land, and livelihoods that evolved to support their family throughout different phases of resource extraction. Her genealogical work provides a narrative of the Thompson family from 1837 to 1986 in the Coal River Valley (Thompson, 1995). "Land was passed from parent to children, from generation to generation,” writes Vera Thompson of her family. "Although one hundred and sixty-five years, more or less, have passed since Chapman Thompson came to the valley, much of his original land is still in the possession of his descendants" (Thompson 1995).

The Coal River Valley's wealth in coal and timber attracted a steady procession of people wishing to farm, hunt, mine, or harvest timber. Much of the history of the Coal River Valley is a story of the conflicts between the people who have controlled its rich natural resources, and the constant tensions around decisions to preserve or exploit the land and its people. The rugged topography of the Coal River Valley resulted in a temporary bypass from the expansion from the Eastern Colonies until 1742, when the colonial government of Virginia commissioned an exploration of the unsettled regions between the Mississippi river and the Appalachians. Upon reaching the Coal River, John Salley described the region as "...Mountainous, but farther down...in these mountains we found plenty of coal, for which we named it Coal River” (Wood, 1994, p. 9) In 1750, Dr. Thomas Walker was chosen to lead an expedition down the Marsh Fork, reaching the Coal River at present day Edwight (Wood, 1994, p. 9). Although the Virginia colony had an official claim on what is now southern West Virginia, the difficult terrain and remote 
location again kept the Coal River region unsettled for many more decades (Wood, 1994, p. 33).

The internal periphery model focuses on the exploitation of land, labor and resources by outside corporate interests. Throughout the $19^{\text {th }}$ century, large areas of land were bought up by timber and mineral companies (Lewis, 1998; Rasmussen, 1994; Eller, 1982) seeking to provide much needed sources of fuel to the nation's industrial economy. Davis states that the "consolidation of land into large private and federal timber holdings had a profound impact on the subsistence economy of the mountain region" (Davis, 2002). In Absentee Landowning \& Exploitation in West Virginia, 1760-1920, Rasmussen details the enormous amount of land held by absentee landowners as well as the superiority of the land deeds over disorganized and often conflicting courthouse records of local land claims. In contrast, she states that "farmers defined their claims by the crops they grew, the fences they built, and the taxes they paid” (p. 44). The result was that descendents of land speculators and mountain settlers often had claims to the same lands. Rasmussen gives examples of mountain settlers who were unable to travel to distant courthouses, or whose land deeds were "lost" in the creation of new counties and courthouses. These patterns of outside land ownership continue in Coal River to this day.

For example, most Thompsons of Coal River can trace their lineage back to Chapman Thompson, who came to the Clear Fork in 1837 as a young man, staying his entire life in the valley (Thompson, 1995). Chapman Thompson's first son, Squire, worked as a logger in Marsh Fork during this time, supplementing his income with wood and leather working as well as drilling the "first oil well" in Sycamore. Squire leased property on both "sides of the mountain" from Rowland Land Company on Clear Fork and Marsh Fork. As his lease stipulated that Rowland Land owned all lumbering rights, he received no rent from 35 logging families living on his property (Thompson, 1995).

Until the mid-nineteenth century, absentee landowners were largely content to acquire land, keep their taxes low, and build political power. In Coal River, the Rowland Land Company was formed in 1886, purchasing 60,000 acres of land on Marsh Fork and Clear 
Fork. In 1891, the Bowman Lumber Company logged heavily on Hazy Creek and became one of the most powerful timber companies in the region, owning rights to much of the area surrounding Coal River Mountain (Hufford, 2002, p. 14). However, Hufford writes that the construction of the first railroad in Coal River in 1904 dramatically changed the land-use priorities of absentee landowners (p. 15). First, the struggle was over land. The struggle shifted to natural resources, largely controlled by absentee owners, and then moved on to encompass human labor as well.

Coal extraction started at a small scale in the 1850s, about the same time as Raleigh County started work on a program of road construction throughout the county. Many WV farmers became part-time farmers or seasonal miners, and then eventually moved to full time work as laborers in factories, mines, or logging camps (Hicks, 1998; Lewis, 1998; Eller, 1982). Many of the new towns that subsequently formed derived their names from founders and employees of the coal or timber industries. Dorothy and Colcord, both located on the Clear Fork, were named after a manager of Rowland Land Company and his daughter (Hufford, 2002, p. 14-15). The coal industry built “company towns” at Sundial, Edwight, Birchton, Stickney, Montcoal, Eunice, and Pettus (See Figure 3.2)

During this time, the Thompsons continued to live in the "old home place" up Sycamore hollow through the generations until the Bowman Logging Company moved out in 1916. Thompson writes that most of the hollows in Sycamore were named for the people that logged them. The Thompson family employed a multi-livelihood strategy to provide for their needs. When they were young, their children worked in the fields, took care of cattle grazing across their land, wild crafted, and hunted, and then combined field work with work in the coal mines when they were older (Thompson, 1995). Modest, the eldest son of the third generation of Thompsons, logged the virgin timber in Horse Creek as well as working in the mines. Modest Thomson worked for 37 years in the mines, suffering three accidents (Thompson, 1995).

In 1949 the first two strip mines opened in the Coal River Valley on Marsh Fork. At roughly the same time, the introduction of mechanical loaders greatly impacted deep 
mining (Dix, 1988). The combination of the mechanization of the mines, strip mining, and the decline in demand for coal led to a massive outmigration of residents from Coal River to search for jobs. Fifteen mines on Coal River shut down during this period (Hufford, 1998, p. 25-27).

In the 1970s, many Coal River residents returned to the Coal River Valley to find their homes impacted by the strip mines. Despite the migratory work needs of many residents, the strong connection of families to their land was not diminished. Their ability to make use of land-based multi-livelihood strategies, however, was greatly diminished due to the impacts of strip mining on the natural resources around their homes. Residents returned home to find that strip mining had occurred at the heads of most hollows on Cherry Pond Mountain, Coal River Mountain, and Kayford Mountain. Hufford writes that "Shank stripped the head of Shumate’s Branch; Truax Trayer stripped on Dry Creek; Ranger Fuel stripped on Peach Tree; Consolidated Coal stripped on Workman’s Creek” (Hufford, 1998, p. 27).

In the 1980s, mountaintop removal coal mining (MTR) first began in the Coal River Valley. Although conventional strip mines had been operating in the Valley for close to 40 years, mountaintop removal produced larger scale impacts due to the methods of coal extraction and waste dispersal. There are currently three mountaintop removal mining permits either pending or approved for Coal River Mountain: Bee Tree, Eagle II, and Leather Leaf. Taken together, these permits would cover 5,782 acres of Coal River Mountain, or approximately nine square miles (referred to as 'New MTR permits' in Figure 3.3). The permits show that every headwater stream from Coal River Mountain will be filled with mining waste with the construction of 18 valley fills. Participating residents requested that individual houses be included in the map to demonstrate the close proximity of homes to the mining. The majority of the mountain is still forested, and the loss of the absorptive capacity of the forest coupled with the loss of streams will places the communities below in danger of severe and rapid flooding every time there is a heavy rain. Clear cutting is proceeding rapidly across the mountain as the vanguard of eminent stripping. 




Figure 3.3: Coal River Mountain with MTR permits, valley fills, and previous mining. JCO (5/18/10)

Work has begun on the Bee Tree surface mine alongside the massive Brushy Fork impoundment. If it continues, the blasting will move over the communities of Colcord, Horse Creek and Dry Creek toward the Leather Leaf permit area on the east end, ending above the communities of Rock Creek and Armeagle. The blasting will come within a half-mile of many of these communities, and will happen up to two or three times per day. Based on information provided in the permit applications, the mining is expected to last for 17 years.

Additionally, blasting has already destroyed some of the mountain's wind potential. Since 2007, Coal River Mountain has been the focus of debate regarding the economic and environmental trade offs between wind and MTR. Coal River Mountain has one of 
the highest potentials for wind energy development in West Virginia (McIlmoil, 2007). The potential to use Coal River Mountain as a site for wind energy as opposed to MTR is another reason that the mountain has been the focus of organizing and resistance.

\section{3. $d$. Resistance in the Coal River Valley}

Organized resistance in the Coal River Valley has taken two forms: organizing work done by the United Mine Workers Association (UMWA) and the formation of community groups. At the turn of the $19^{\text {th }}$ century, the Kanawha Valley coalfields of southern West Virginia were unionized, but Coal River remained non-union (Wood, 1994, p. 367). Five years later, the UMWA began a new drive to unionize the Coal River fields and tensions rose quickly between hired detectives, coal operators, and union miners. In 1912, these strikes turned violent in Paint and Cabin Creek, just to the northeast of Coal River Valley, when hired detectives opened fire on union campsites. Although the rest of the "mine wars," including the Battle of Matewan, the assassination of Sid Hatfield, and the Battle of Blair Mountain, did not occur in the Coal River Valley itself, the events are often referenced by both miners and activists in the Valley in reference to the growing tensions around mountaintop removal.

The UMWA was stifled for a decade after the Battle of Blair Mountain in 1921. Mine operators brought in African Americans as well as Eastern and Southern European immigrants to break strikes (Corbin, 1981). As a result, Coal River became more diversified until the waves of outmigration in the mid $20^{\text {th }}$ century. In 1933, Coal River was finally unionized when President Roosevelt threatened to send the army into the coalfields if coal operators would not accept union contracts (Savage, 1990, p. 164). The high demand for coal to supply the industrial needs of World War II brought an era of prosperity to Coal River. By 1940, Marsh Fork had a population of 7,428 and Clear Fork had a population of 5,129 (Wood, 1994, p. 367). By the end of the war, 3,000 miners were employed by eleven coal companies in Coal River, and union miners produced 90\% of that coal (Wood, 1994, p. 441). In the 1970s, Strikes were common, culminating in a 
118 day strike in which the UMWA won an industry wide benefit plan (Hufford, 1998, p.26). However, the union was losing its grip in the valley. Throughout the next decade, the Valley lost many of the benefits that local union miners had worked and striked for.

“A.T. Massey” first made its appearance in the Valley in 1981, opening a non-union mine in Sylvester through its subsidiary Elk Run. The UMWA met Massey's first non-union entrance with protests and strikes in which dozens of miners were arrested, including Cecil Roberts. During this time, a study released by the Appalachia Landownership Task Force showed that nearly 90 percent of the land in southern West Virginia was owned by absentee land owners (1981).

In 1984, Don Blankenship hired strikebreakers from Kentucky in order to break a UMWA strike. The UMWA responded with snipers in the trees and the destruction of three of Blankenship's bullet-proof cars. Peabody Coal continued Massey's unionbusting with the transfer of a large underground mine at Montcoal when Armco's lease ran out in 1986. Many local Valley union miners had worked for Armco, and Montcoal mine was a source of Union strength in the Valley. Peabody shut down the mine and opened it as non union, marking the beginning of the decline of the union in Coal River Valley. After decades of union rule in the valley, the coal bosses were running the show again. Residents remember the evacuation of the entire community on Shumate's Branch in 1987. Today Shumate's branch is buried under a valley fill created from fill material from the Edwight strip mine (Aurora Lights, 2009).

In addition to the general decline of mining jobs, the union has continued to lose ground. Attempts to forge solidarity between the anti-MTR movement and the UMWA have continually failed, despite the fact that the number of union miners working on MTR sites is small and only getting smaller. In 1992 Blankenship became chairman of Massey, continuing the union-busting campaign in combination with a new method of strip mining that would increase Massey's profits and decrease dependence on local labor: mountaintop removal. 
The expansion of mountaintop removal throughout the 1980s and 1990s met with challenges across the coalfields. Organizations such as Kentuckians for the Commonwealth and Save Our Cumberland Mountains had already formed in response to the social and economic impacts of strip mining (Fisher, 1993). The Citizens Coal Council, a coalition of community-based coalfield organizations from across the country, was started in 1987 in Lexington, KY. In 1998, a flood in White Oak on the Clear Fork killed two people. In the same year, members of Coal River communities created Coal River Mountain Watch to fight for the social, economic and environmental wellbeing of southern West Virginia against the destructive practices of MTR and the coal companies (Coal River Mountain Watch, 2009). Prominent national figures such as NASA climate scientist James Hansen and Robert F. Kennedy, Jr., who called mountaintop removal the “worst environmental tragedy in American History” (Kennedy, 2009) have stepped forward to stop mountaintop removal and, in particular, to save Coal River Mountain.

A primary source of community organizing and concern in the case study area is the MTR mine on Cherry Pond Mountain, called the Edwight Surface mine, and the elementary school that sits directly in the mouth of the slurry impoundment. The Edwight Surface Mine covers 2,016 acres of Cherry Pond Mountain. The 2.9 billion gallon Shumate sludge impoundment is also part of the complex. The communities of Naoma, Pettry Bottom, Peach Tree, Clays Branch and Hazy all lie within a mile of the mine site. Blasting on the mine site occurs daily within 1,000 feet of homes (See Figure 3.4). 


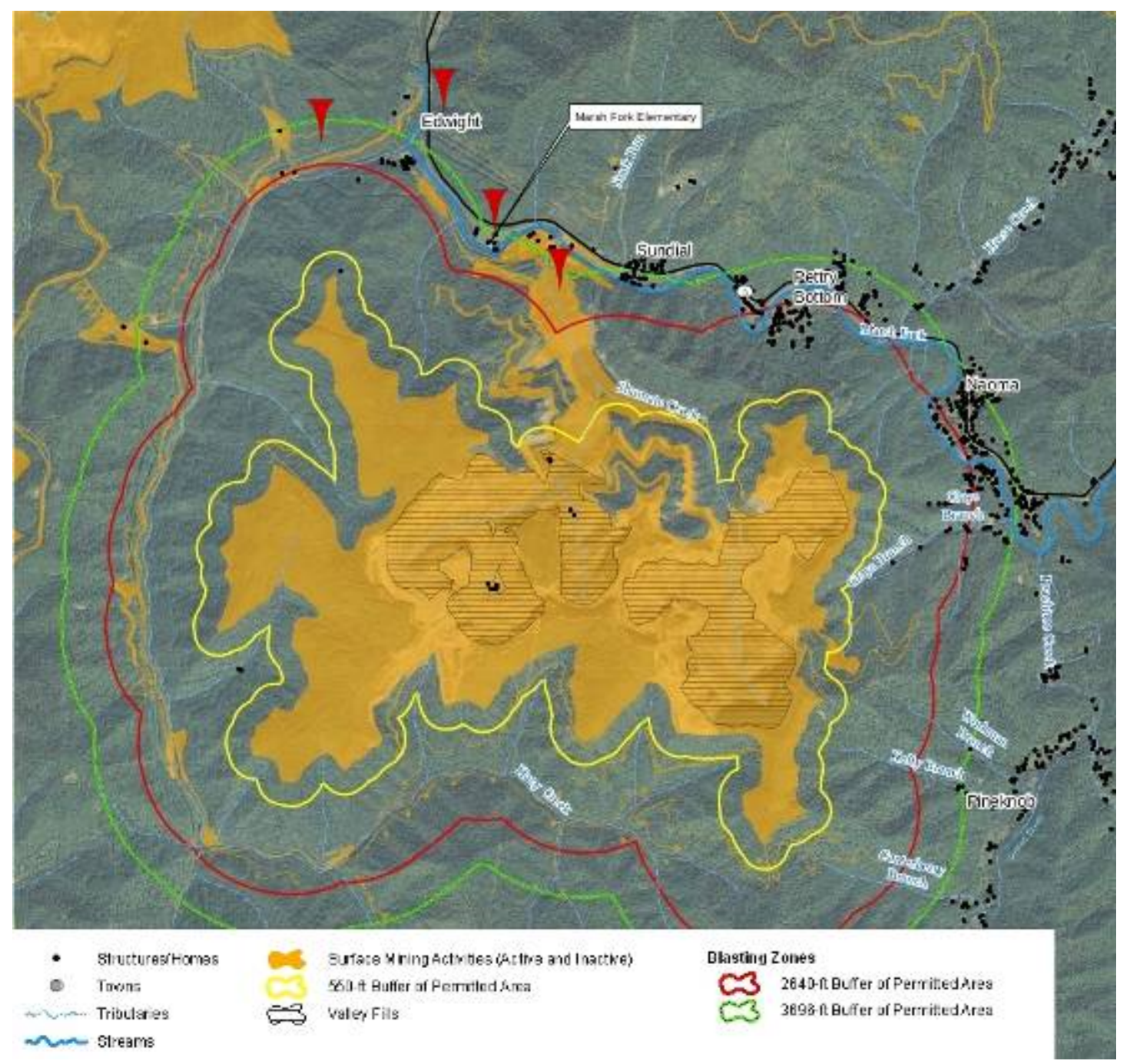

Figure 3.4: Proximity of communities to blasting on Cherry Pond Mountain. (Down Stream Strategies, 2009).

A renewed organizing energy is evident through the grassroots groups of Coal River Wind, Pennies of a Promise, Kayford Mountain Heirs, Sludge Safety, and the non-violent direct action campaign of Climate Ground Zero. Since the beginning of 2009, there has been a steady upwelling of direct, non-violent civil disobedience to stop mountaintop removal and raise awareness about the dangers of slurry impoundments. The first action occurred on February 3rd when 14 people were arrested and six people chained to a bulldozer up on Coal River Mountain. Since February of 2009, more than 150 residents and activists have been arrested in more than 15 actions. Now, one year later, Coal River is making headlines such as "From Birmingham to Coal River” (Roselle, 2009), equating the growing non-violent direct action movement in the southern coalfields with the civil 
rights movement of the 1960s. A current google search for "the Battle for Coal River Mountain” within quotes turns up more than 300,000 links, a result that would have been unimaginable even a year ago.

\section{3. e. Multiple Livelihood Strategies and Community Land Use}

In his recent work Uneven Ground, Eller states: "rural mountain residents had always been close to the land, although that closeness was reflected more in strong ties to family and place than to any ethic to preserve the land” (p. 11). In addition to the Thompson family, many other families in this area can trace their ancestry back to the original settlers, often living on the same land. The first permanent settlers included Daniel Shumate in Shumate Hollow, James Ellison on Hazy Creek, Drewry Farley on Drew's Creek, John Scarbrough on Rock Creek, Jacob Stover on Clear Fork (Hufford, 2002, p. 9), and Chapman Thompson on Clear Fork (Thompson, 1995). These surnames account for many of the most common surnames in the Valley today.

The culture of Coal River Valley is deeply connected to the use of the land and mountains for supplementing food and income as well as tying communities together (Aurora Lights, 2009). Community land use in Coal River draws from the heritage of early settlers who used their surrounding mountain ecosystem to create a multiple livelihood strategy based on hunting, gathering, and gardening. These multiple livelihood strategies continued to provide important means of gaining alternative income as family members moved to work within the extractive industries, and continue to be an important part of family traditions and land use in the Coal River valley today (Aurora Lights, 2009; Hufford, 2001). This dissertation investigates discursive formations around livelihood to reflect the importance of informal livelihoods such as stay-at-home mothers as well as land-based families who use their surrounding mountain ecosystem to create a multiple livelihood strategy based on hunting, gathering, and gardening. 
In “Reinventing the Appalachian Commons,” Boyer defines the multiple livelihood strategy: the Appalachian people "obtained these shared resources by employing a strategy of multiple livelihoods, including gardening and cash cropping, buying and selling in periodic markets, and working in factories and in the service sector”(Boyer, 2008). Boyer adds that this strategy "reflects patterns derived from the myriad tasks of small-scale farming with limited mechanization across much of Appalachia”(Boyer, 2008). Randy Halstead, a Ginseng trader in Coal River Valley, explains the importance of multiple livelihood strategies to family economic sustainability (Hufford, 2001):

My dad was a coal miner and there was the union that they were discussing organizing and he was involved in that. So a lot of times we were out of work and when you have to send ten or twelve children to school and you're only working every now and then you had to find money any way you could. So we would dig Ginseng to get money to buy school clothes so we could go back to school in the fall.

The traditions of community land use and multiple livelihood strategies in the Coal River Valley mean that local concerns about environmental impacts from the process of mountaintop removal include numerous social concerns as well. These social impacts from mountaintop removal were noted as well in a 2009 memorandum of understanding implementing the Interagency Action Plan on Appalachian Surface Coal Mining:

“...this mining practice often stresses the natural environment and impacts the health and welfare of surrounding human communities. Streams once used for swimming, fishing, and drinking water have been adversely impacted, and groundwater resources used for drinking water have been contaminated. Some forest lands that sustain water quality and habitat and contribute to the Appalachian way of life have been fragmented or lost. These negative impacts are likely to further increase as mines transition to less accessible coal resources within already affected watersheds and communities.” (USEPA, 2009)

As outlined in the previous section, the communities in the case study area are already located within watersheds affected by mountaintop removal. However, even though Coal River Mountain had been mined both underground and stripped in areas, until 2009 residents in the surrounding communities still had access to the mountain and to its resources. As the last "mostly intact" mountain in the watershed, Coal River Mountain provided security and stability to residents impacted by blasting, flooding, and dust from neighboring MTR sites. The loss of Coal River Mountain also represents the end of 
community access to one of the last mountains that could support recreational activities and multiple livelihood strategies for local residents. The use of the mountains by community members was important not only to strengthening communities and maintaining heritage, but also as a way to fight exploitation in both the cultural and material realms. Activities such as gardening, gathering and community events, are dependent on the cyclical changes of seasons and natural surroundings of Coal River throughout the year (See Figure 3.5).

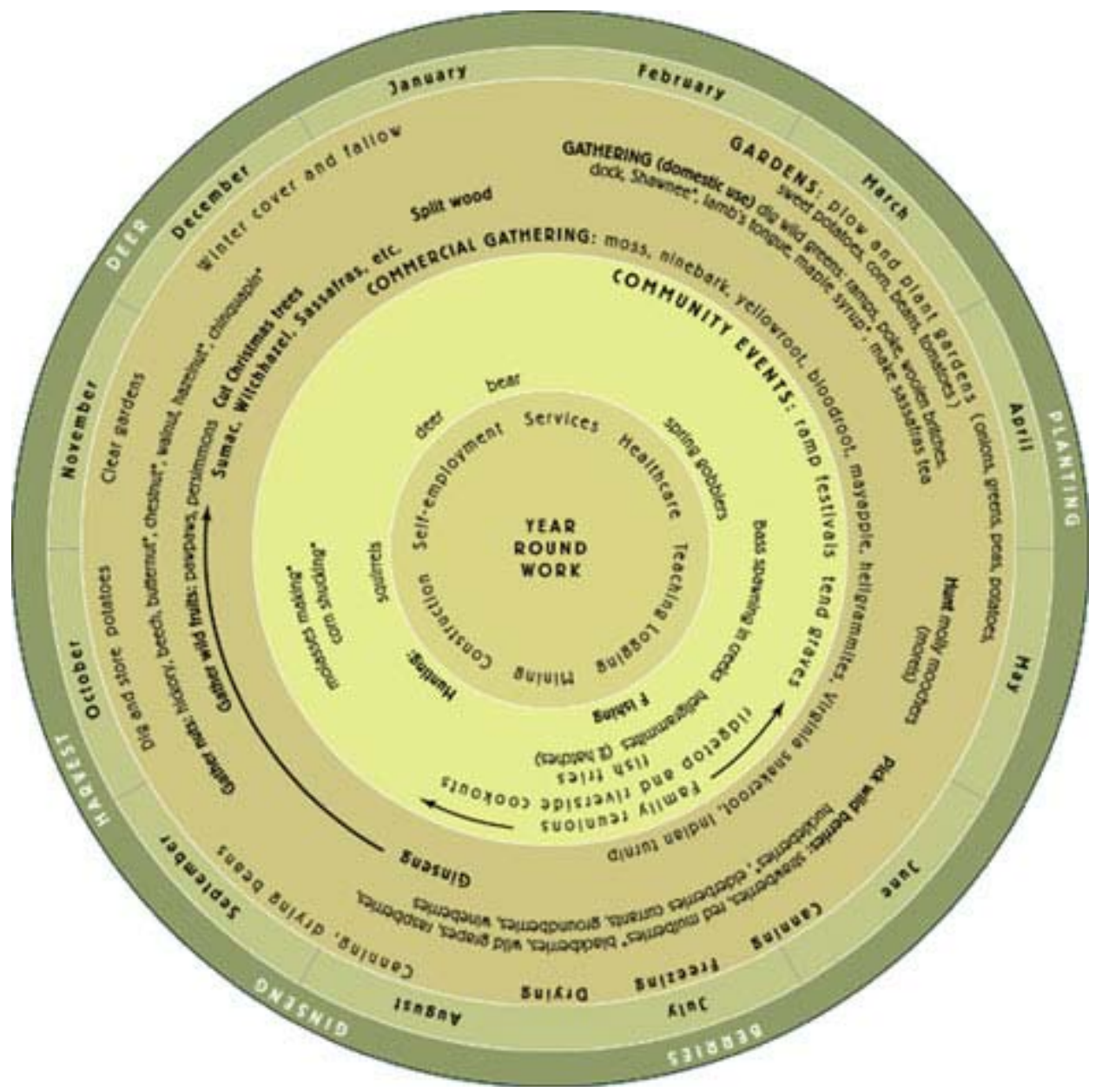

Figure 3.5: Seasonal wheel of activities in the Coal River Valley. Mary Hufford, 2001.

Figure 3.5 depicts one year of activities within the Coal River Valley on a monthly and seasonal basis. The outermost circle shows the general seasonal activities of planting, berry gathering, ginseng gathering, harvest, and deer hunting. In the third circle in, these activities are further broken down into more steps and specifics. For example, the canning, freezing, and drying required as part of the harvest, and specific berries and wild 
plants that are harvested during a particular time of the year. The seasonal nature of garden work, commercial gathering, foraging, and hunting is compared to the year round work, not seasonally based, such as mining, teaching, logging, construction, and other forms of self-employment, that are represented in the middle circle. Hufford also includes seasonal social events within the community, showing again the integration of social and environmental uses of the mountains.

\section{3. f. Conclusion}

This chapter justified my choice of case study area and outlined the geography and demographics of the Coal River Valley. The specific geography of the mountain and location of communities regarding current mountaintop removal sites was detailed, as well as the importance of Coal River Mountain as the last "mostly intact" mountain in the watershed. Using the internal periphery lens, the chapter briefly reviewed the history of resource extraction within the case study area that led to mountaintop removal. The review looked at resistance in the form of union organizing and the formation of community groups, and concluded with a focus on the importance of multiple livelihood strategies and community land use in understanding local concerns about MTR. Chapter four proceeds to outline the research questions, methodology and research methods used to complete my research.

Descendants of the Thompsons still live in the same hollow to this day: Sycamore hollow, the site of fourteen proposed valley fills. The constant portrayal by Big Coal and local media of mountaintop removal protestors as outsiders and tree huggers continues to undercut the on the ground reality of the impacts of mountaintop removal on local residents, such as the Thompsons, who have lived there for generations. Williams states that "the enduring issue is not ownership as such but the extent to which the use of West Virginia resources will be governed by considerations of local benefits and needs" (202). This dissertation attempts to illustrate and give voice to the needs and concerns of local residents, miners, and their families about the impact of mountaintop removal on the landscape of their homes. 


\section{CHAPTER FOUR}

\section{RESEARCH QUESTIONS, METHODOLOGY AND METHODS}

This study uses a PGIS approach within a Foucaudian framework to address two research questions regarding the initial legal discourse of mountaintop removal (MTR) as well as the subaltern discourse of resistance to this specific type of surface mining. Foucault's work on the relationships between knowledge, discourse and power are the basis of the conceptual framework of this study. For my first research question, I draw on Foucault's archeological method to construct a mini-archeology of MTR. For my second research question, I situate the PGIS in the Coal River Valley as a methodology to illustrate the subaltern discourse of MTR. Finally, I use Foucauldian themes of power, discourse and knowledge to situate the subaltern discourse within the "conditions of possibility" illuminated through the mini-archeology to investigate the "spaces of resistance" and fulfill the objectives of this study.

An important lesson drawn from the literature review of participatory GIS is the potential to both empower and marginalize participating communities not only through the PGIS

itself, but also through the process as well. Literature investigating the political economy and situating the subaltern discourse of resistance within the case study area also helped to provide the foundation for selecting culturally appropriate participatory methods. This chapter proceeds to outline the research questions, methodology, and methods selected for this socially driven, inclusive research. 


\section{4. a. Research Questions}

1. What are the legal discursive formations that define and allow the permitting of mountaintop removal (MTR) in the case study area? The first question proceeds in three steps to examine the legal structure that defined MTR at the federal statutory level, at the regulatory level, and finally on Coal River Mountain, to determine the "conditions of possibility” for the subaltern discourse.

a) How was MTR originally constructed as an object within the legal discourse? For example, how was MTR defined within the Surface Mining Control and Reclamation Act and the Clean Water Act? How did these federal statutes delimit the boundaries around MTR as a practice separate and unique from other forms of strip mining? What authorities have Congress empowered through these statutes to write the procedures and define the permitting process?

b) How have national and state regulatory agencies reconstructed MTR ? In the rulemaking process, regulatory agencies are responsible for writing "rules and procedures" to fulfill the mandated goals of federal statutes. What specific definitions regarding the process of mountaintop mining and disposal of overburden are reconstructed in this rulemaking process?

c) What are the "temporalities and surfaces of emergence" of MTR specifically within the case study area? What are the specific mines and fill discharge areas on the mountain, and how do they fit within the original legal definitions of mountaintop removal and valley fills?

\section{What are the subaltern discursive formations regarding the implementation of} MTR in the case study area? The second question proceeds in two steps to represent the concerns of local residents regarding the impact of MTR on the landscape of the Coal River Valley. 
a) What are the subaltern discursive formations regarding the existing or potential adverse affects of landscape change and use? For example, what concerns do residents have regarding changes in forest cover, access to land for hunting and forest products, placement of slurry impoundments, loss of water quality, etc?

b) Where are possible "spaces of resistance" within the subaltern discourse? Where do the subaltern discursive formations have the potential to impact the dominant discourse of MTR?

\section{4. b. Methodology}

My overview of critical cartography and participatory GIS informs my decision to use participatory GIS as my methodology to investigate the relationship between the dominant discourse of MTR and specialized place-based geographic knowledge regarding land change and use. I draw from this literature to situate the use of participatory maps as “insurrections of subjugated knowledges” (Foucault, 1980, p.81) within the “maps as social construction approach” (Harley, 1988; Wood, 1992; Pickles, 1995; Crampton, 2001). The strength of this combination of PGIS methodologies and Foucauldian theory allows for the conceptual placement of the subaltern discourse within a specific geographical and temporal emergence of the dominant discourse of MTR. Using a Foucualdian lens, investigating of the initial construction of MTR as an object separate from other forms of mining allows for the creation of the "conditions of possibility" that impact the existence and formation of the subaltern discourse. The use of a PGIS approach to construct the subaltern discourse allows for local residents in the case study area to provide "expert” data regarding their concerns and to play an active role in how their concerns and home place are represented.

A PGIS methodology offers an avenue through which to integrate qualitative and quantitative methods and data (McClafferty, 2002; Kwan, 2002; Shuurman and Kwan, 2004; Abbot et al, 2008) with the goal of producing socially driven, inclusive research. I 
facilitated a PGIS due to the importance of including qualitative data such as interviews and mental maps to represent the subaltern discourse of MTR in relation to larger powerknowledge regimes. PGIS methodologies grew from mainstream participatory research and planning frameworks (Weiner et al, 2002) with the intent to include the public in development decisions that affect their interests. Participatory tools and methods used in PGIS practice include: ephemeral mapping (drawing on the ground), sketch mapping, scale mapping, 3D modeling, photomaps, the use of global positioning systems, maplinked multimedia information systems, and integration of GIS (Rambaldi et al, 2006).

Residents in the Coal River Valley are not given meaningful opportunities, nor access to the "decision-making arena” (Barndt, 2002), regarding natural resource decisions around their homes. Therefore, it is essential to use a methodology that emphasizes the importance of local knowledge as well as context-specific data collection methods to draw out the subaltern discourse. Additionally, to gain a deeper understanding of the motivations and concerns of the grassroots resistance in southern West Virginia requires a flexible methodology that uses a number of techniques, specifically public participation methods combined with geospatial methods. The emphasis on participatory mapping as opposed to just participatory methods derives from the geographical nature of mountaintop removal both in terms of its direct physical impact on the landscape and the location of communities impacted by the process.

Although PGIS methodologies hold great potential to aid local empowerment, this study assumes that Coal River is a socially differentiated community in which differential access to resources may simultaneously empower and marginalize community members (Weiner et al, 2002). Like all decision-making processes, those around participatory GIS contain many different power relations between class, gender, structural forces of capitalism, unequal access to spatial data, and unanticipated and antidemocratic outcomes (Crampton, 2006; Elwood, 2006; McLafferty, 2005; Sieber, 2000; Aitken and Michel, 1995). 
An investigation into the theory of how research should proceed exposes a fundamental difference in participatory methods from many other social science methods. A primary goal of PGIS methodology is that research must do more than just describe or analyze social reality: it must work towards changing it. PGIS methodology emphasizes both the process (community organizing) as much as the actual product (the map) itself, as noted by the review of three PGIS case studies in Chapter Two. Due to concern regarding the two to three year time-frame of my dissertation, as well as the lack of immediate relevance of my research to participating families in the case study area, I sought input regarding helpful products to return to the community. I gathered suggestions informally from my gate-keepers as well as before or after the formal interviews. The resulting final product, the creation of a multimedia, participatory website of the Coal River Valley, will be discussed more fully in Chapter Seven.

While the origin of this PGIS project is from Coal River residents who are resisting mountaintop removal, one of the lessons drawn from my literature review on PGIS was the importance of continued "transparency, time, and trust” (Chambers, 2005; Drew, 2003; Kindon, 2001) throughout the methods process. I lived or worked within the case study area on and off since the summer of 2000 and established trust and good relationships with many Coal River residents. My fieldwork was conducted over a time period of 16 months, during which a great deal of effort was put into developing and maintaining relationships within the community. In most cases, a great deal of time was needed to develop trust, especially with families currently employed by the coal industry, and some level of trust was required before I could even begin interviews. As discussed, the culture of Coal River Valley is deeply connected to the use of the land and mountains for supplementing food and income as well as tying communities together (Aurora Lights, 2009). I found that the best way to develop trust and facilitate "transparency" in research decisions was to participate directly in these multi-livelihood strategies: gardening, cooking, preserving food, gathering firewood, hunting, or identifying and gathering herbs and roots. Through this process, I was rewarded with a hands-on education in mountain living and skills that I now pass on to my children. 
My history and evolving role within the movement against mountaintop removal necessitates that I be self-reflective about my positionality as a researcher and facilitator. My positionality allows me a "different kind of objectivity” (Mansvelt and Berg, 2005, p.252) that is supported by my methodology. In their work in South Africa, Harris and Weiner address their positionality by stating that they were "known in the community and viewed as friends and advocates of popular local causes” (2002, p. 248). This type of post-structuralist positionality situates knowledge "by making the knower accountable to their position" and as a product of "specific embodied knowers, located in particular places and spaces” (Mansvelt and Berg, 2005, p.252). I draw from the work of Sieber (2000) in stating that my work also has an "activist bias" due to the close and participatory linkage of my work with community concerns.

One area of concern in this methodology is that my affiliation with activists within the watershed would result in a biased representation if I attempted to embody the views of the entire community within my research. More specifically, I would not be able to interview many of the pro-MTR families to include their points of view. Therefore, in order to address concerns of legitimization through selective participation, I decided both to concentrate the PGIS on a more specific area of the watershed (Coal River Mountain) as well as clearly indicate that the PGIS is a method to map subaltern discourse. This focus on "subaltern" discourse allowed space for the multiple discursive formations regarding mountaintop removal that I was able to access and represent. Therefore, an additional strength of this PGIS methodology was its potential to incorporate various forms of knowledge production through mapping and interviews to be inclusive of multiple perspectives within the subaltern discourse. As there is no consensus within the literature regarding what specific methods to use, I chose inclusive methods that emphasize trust, transparency, and critical reflexivity regarding positionality and the role of the researcher. 


\section{4. c. Research Methods}

This study uses a mixed method strategy of inquiry to gather data for my research questions. Qualitative methods are defined by Hay (2001) as investigative approaches and techniques that seek to elucidate human environments and human experiences. A concurrent nested strategy was used to guide my data collection and analysis (Creswell, 2003). 'Concurrent' means that both quantitative and qualitative data were collected in one data collection phase. Results from both methods were then integrated during my data analysis. Equal priority, however, was not given to both qualitative and quantitative methods. Within this model, I "nested” my quantitative methods within my qualitative methods. I chose this model because its purpose is less to verify findings than to expand the study to gain a broader and more detailed perspective. Data analysis occurred in three phases: analysis of data from my first research question to construct dominant legal discourse, analysis of data from my second research question to construct subaltern discourse, and finally an analysis of power-knowledge relationships between the dominant and subaltern discourses.

Five data collection methods were initially used in this research: mini-archeology construction, base map construction, semi-structured interviews, focus group discussions, and participatory mental mapping. After several unsuccessful trials, my methods were adjusted to reflect a lack of community interest in focus groups as well as an increased interest in interviews and one-on-one participatory mental mapping. In the following sections, each method is summarized and related back to the two research questions.

\section{4. c. i Construction of Mini-Archeology}

The construction of this mini-archeology was the primary method of data collection to address my first research question: What are the legal discursive formations that define and allow the permitting of MTR in the case study area? I used the term "mini" archeology to specify that I had to limit the scope of this method to focus on landscape change and specific legal and regulatory discursive formations of key terms defining 
MTR within the case study area. The construction of an archaeology is about examining the discursive formations left by the past in order to write a 'history of the present'. Applied to my dissertation, I applied Foucault's archeological method to understand how the legal discursive formations around MTR created the “conditions of possibility” for MTR to exist in the case study area. The mini-archeology was constructed after completion of my fieldwork.

The construction of my mini-archeology consisted of three steps to address the specific sub questions. After the data was collected for each step, analysis immediately followed before the construction of the next step. The first step of analysis unpacked the original legal construction of MTR through federal legislation. The second step investigated the reconstruction of MTR through “rule-making” agencies. Finally, the last step illuminated the specific implementation of MTR on Coal River Mountain within the conditions of possibility created by the original legal construction.

To address the original legal construction of MTR, I investigated documents that demonstrated where the process of mountaintop removal was defined as separate and different from other types of mining. I located, read, and pulled out legal definitions from the Surface Mining Control and Reclamation Act and the Clean Water Act in regards to the original construction of MTR as an object. ${ }^{1}$ I also interviewed one environmental lawyer, Kevin Thompson, regarding the initial legal construction of MTR and transcribed his interview. A list of regulatory agencies at both the state and federal level empowered by Congress to permit and enforce these two acts was also created. After my data collection, I entered the legal definitions applicable to MTR and valley fills as well as my transcribed interview with Kevin Thompson into Nvivo ${ }^{2}$. I then developed initial coding and themes to draw out the legal discursive formations that determined the boundaries around MTR as an object. For example, how was MTR defined specifically

\footnotetext{
${ }^{1}$ The National Environmental Policy Act, the Endangered Species Act, the Administrative Procedures Act, and various other Clean Water Act sections also applied to some portion of the mountaintop removal process. However, I determined that these additional acts were outside the original scope of my study regarding original definitions of MTR and Valley Fills, and will be the subject of future study.

${ }^{2}$ NVivo is a qualitative data analysis computer software package produced by QSR International for use by researchers with rich text based and / or multimedia information.
} 
as different from conventional strip mining? Who was given the authority to make these distinctions, and what types of knowledge were privileged as evidence?

Within this original legal creation of MTR, regulatory agencies were given the authority for "rule-making" regarding the actual requirements and process of obtaining a surface mine permit (under SMCRA) or a valley fill permit (under the CWA). Therefore, to address the second sub question, I located the rule-making documents created by these regulatory agencies regarding the procedures and permitting of mountaintop removal and valley fills. My list of regulatory agencies included the Office of Surface Mining (OSM), located in Charleston, under the Department of the Interior; the Region III Environmental Protection Agency (EPA), located in Philadelphia; the Department of Mining and Reclamation (DMR), under the state Department of Environmental Protection, located in Beckley; and the District office of the Army Corps of Engineers, located in Huntington. I used online information regarding rule-making on the Certified State Registry and the Certified Federal Registry to compile a list of reconstructed definitions and procedures regarding MTR and valley fills. In this step, I pulled specific procedures and requirements for both coal operators and residents participating in the permit process. I entered these definitions and procedures into NVivo and developed initial coding and themes to draw out how MTR was reconstructed through the regulatory agencies. For example, how have regulatory agencies interpreted their federal mandate to create legal procedures through which MTR is permitted? What types of specialized knowledge were created and privileged through these legal procedures? This step illustrates more specific authorities of delimitation as well as additional surfaces of emergence of MTR and Valley fills as objects.

Data collection for my third sub question regarding the emergence of MTR in the case study area involved the collection of all mountaintop mining and valley fill permits on Coal River Mountain. I gathered this information from Coal River Mountain Watch and from the DEP at Oak Hill, Raleigh County. At the time of data collection for this miniarcheology, the Bee Tree Surface Mine was permitted, Eagle II was in the process of being permitted, and Leather Leaf had not yet been officially applied for (See Figure 3.3). 
Due to court litigation through the Clean Water Act regarding Nationwide 21 permits, as authorized through SMCRA, no valley fill permits had been given for Coal River Mountain. However, an Incidental Boundary revision had been issued for the Brushy Fork Impoundment, through which Marfork Coal has started disposing of overburden directly around the slurry impoundment. Therefore, permit data was gathered for Bee Tree, Eagle II, Leather Leaf, and the Brushy Fork Impoundment. I entered, coded, and drew out additional themes from the permit language. My final step of analysis drew from the legal, regulatory, and specific case study data to address the following themes: How are the decisions to issue MTR and valley fill permits on Coal River Mountain made to fit within the regulatory discourse? Who has the authority to decide? What is the relationship between the physical production of MTR and the legal discourse that originally defined it? What then are the "legal” discursive formations that have evolved to allow these permits?

\section{4. c. ii Semi-Structured Interviews}

Semi-structured interviews were the primary qualitative input to answer my second research question. Two interviews, however, were conducted regarding the legal discourse of MTR and integrated into the mini-archeology to elicit data for my first research question. I interviewed Kevin Thompson, an environmental lawyer familiar with the both the federal statutes and regulatory rule-making governing the permitting process. I also interviewed Jack Spadaro, former Director and engineer for the Mining Safety and Health Academy, regarding the implementation of these regulations in the Coal River Valley.

To gather data for my second question and represent the subaltern discourse, I initially proposed to conduct 35-40 interviews. However, the failure of the focus group method necessitated that I conduct more interviews. In total, 59 local interviews were conducted with Coal River residents to illustrate the subaltern discourse of MTR.

The first round of "initial interviews" was semi-structured (Dunn, 2005) with room for open-ended questions at the end. I asked the same three questions at each interview, but 
allowed space at the end of the interview both to check that I was asking the right questions as well as allow interviewees to express additional opinions. Questions focused on concerns regarding landscape change and alternative land use in the Coal River Valley (please see Appendix 4). All interviews were tape-recorded and transcribed. Participants were given the option to be anonymous. Informed consent was provided verbally. I obtained quantitative data about their age, gender, job, and years of residency at the beginning of each interview. At the end of the interview, participants were asked if they would like to participate further or if they would recommend anyone else to speak with.

After addressing their areas of concern regarding the impacts of MTR on landscape change and alternative land-use, I had proposed to then give participants the base maps and give them the option to suggest features they would like included. I found, however, that many participants wanted to use the base map to explain their answers to my questions. After the first few difficult transcriptions in which participants talked while gesturing at the map, I began handing the map and different colored pens to participants at the beginning of the interview. With this new method, participants could mark directly on the map while answering my questions. Additionally, some participants did not want to respond on the maps or participate in mapping at all. I found that presenting the map at the beginning of the interview session allowed me to determine if the participant was comfortable talking geographically about his or her immediate surroundings. If not, I could ask additional questions in the interview to determine spatial information regarding concerns. In response to problems with my focus groups, I incorporated the participatory mental mapping into my interview process.

To begin my interviews to evoke the subaltern discourse, I used personal contacts as well as contacts through organizations workings against MTR to establish gatekeepers. In this research, gatekeepers are people within the study area who are well connected with residents active within the discourse of resistance against MTR. My personal contacts had been developed within the community over many years through sharing work such as gardening and chopping firewood, or community events such as concerts and church 
events. These personal contacts did include two gatekeepers that were not affiliated with the movement against MTR, which helped me to gain access to other families that did not like MTR but were not part of the movement, either. Over time I worked with Coal River Mountain Watch, Ohio Valley Environmental Coalition, Mountain Justice, Friends of the Mountains, Keepers of the Mountains, Pennies of Promise, Prenter Water Fund, and Appalachian Voices to identify additional gatekeepers.

I used contacts with these initial gatekeepers to gain access to other informants through the snowball sampling method. Snowball, or chain sampling, identifies other potential participants from the connections of the original gatekeepers (Dunn, 2005). One of the strengths of this method is that it can be used to reach inaccessible groups of people. Inherent in this method, however, is a number of biases. However, as data collected to answer my second research question was not meant to be representative of the entire Coal River community, but rather of local residents resisting mountaintop removal, I chose it for this study. Additionally, exploratory fieldwork conducted previous to this proposal allowed me substantial time to develop strong relationships with my gatekeepers.

After my first trip down I realized that the communities south and east of Rock Creek were not directly impacted by the mining on Coal River Mountain, so I have refocused my study area to exclude Masseyville, Arnett, and Stover. Additionally, I found that communities such as Dorothy, due to their location directly under Kayford mountain, are more likely to talk about impacts from Kayford mining than mining on Coal River. The families that are most impacted by the mining live in the hollers of Sycamore, Rock Creek, Horse Creek, and Dry Creek.

After a month of interviews, I located a supporting family in each of the four hollers where I primarily conducted my research: Dry Creek, Rock Creek, Horse Creek, and Sycamore. In addition to these gate-keeping families, I was taken in by retired union underground miners, who took me house to house to meet other miners. I had some memorable experiences such as using a union code name to be allowed into a new house. My positionality as the niece of a UMWA organizer and my coal mining heritage played a large part in earning the trust of some of the local union men. This was a new 
connection for me that helped me greatly to get outside of the "outsider activist" community and into a group of men and their families who were involved with union strikes and organizing. Being brought into this circle also allowed me access to the men and their families who do not want to be a part of the environmental movement, but were very concerned about the impacts of MTR on their ability to hunt, ride 4 wheelers, and use non timber forest products such as ginseng and morels. In summary, the way that I was initially visualizing conducting these interviews on a town to town basis is not as relevant as searching out the areas where families are directly under the mining.

I collected quantitative information at each interview and assembled an excel spreadsheet with this data. I also took notes during each interview and assembled these notes. I saved my transcripts, interview files, and notes in two separate places after the end of each week in the field. In these documents, participant names were changed to numbers, and quantitative information such as age and years or residency were put into categories to protect the anonymous requirement of some participants. I transcribed all interviews and entered them in NVivo. I also developed a codebook which, in addition to my personal notes, I used in combination with the coding abilities of NVivo. The coding process consisted of: referencing and amending the codebook, preparing the transcript for analysis, ascribing the codes to text, retrieving similarly coded text, and reviewing the data by themes (Hay, 2001). I entered quantitative information regarding each participant into NVivo as well, which allowed for analysis of participant concerns to be broken down by gender, age, or livelihood.

\section{4. c. iii Focus Group Discussions}

I had initially proposed to use two rounds of focus groups to gather qualitative data for the subaltern discourse in Coal River Valley. Bedford and Burgess define a focus group as "a meeting of between four and eight individuals who are brought together to discuss a particular topic chosen by the researcher who moderates or structures the discussion" (2001, pg 121). Benefits of focus groups include the ability for conversation to develop 
in a more comfortable environment than an interview, the ability of individuals to challenge and contest each other, and the ability of the research to gain access to the a more critical "discourse" without an informant feeling threatened by the researcher (Bedford and Burgess, 2001).

I planned to use focus groups with the particular hope of creating a less threatening environment that would allow participants to share ideas or challenge each other. I attempted three different focus groups during the first four months of my fieldwork. None of the five participants showed up for the first group. For the second focus group, people did show up, but all throughout the day, so I ended up with 4 interviews instead of a focus group. The third focus group was cancelled by participants over the phone due to fear that neighbors would see my truck in their driveway and associate them with the resistance.

In my proposal, I did foresee a problem with this method: the difficulty of getting attendance at focus groups to a combination of lack of transportation, distance, fear over confrontation, and an inability to miss work or family responsibilities. I also proposed a number of ways to deal with this problem: asking for suggestions from participants regarding the time and place of the meeting, having more meetings with smaller numbers of people, having gender or age specific groups, and having anonymous meetings.

Until February, I continued to try these different approaches to draw people to focus groups. However, I decided to stop organizing focus groups when a participant lost trust in me after I asked about the focus group. No matter what I said, one perception was that I was organizing the meetings for one of the local activist groups. Many of my contacts were wary of being associated directly with local resistance groups. I lost one interview of my initial 60 because the participant believed that I was employed by the wind industry to put coal out of business. I believe that the increase in local concern about being seen at a focus group was directly related with the beginning of a non-violent civil disobedience campaign in February, and the heightened community tension. 


\section{4. c. iv Base Map Construction}

The construction of base maps was the first method used to address my second research question regarding subaltern discourse in the case study area. Due to the participatory methodology of this study, the construction of base-maps involved several stages to allow for greater transparency and participation.

The first draft of the base map consisted of producing 2 sub maps: a small-scale map of the Coal River watershed and a larger-scale map of the Coal River Mountain and surrounding communities. On the small-scale map, data on roads, major rivers, county lines, and the location of the communities in the study area was included to situate the location of the study groups. The larger-scale map showed all of the individual communities within the specific study area, smaller tributaries, MTR permits (shaded according to level of activity), slurry impoundments, and roads. The first draft of the base maps was brought to all of the interviews and used to support the question-asking for participant's views' on data to include in the second draft base map. Due to the failure of the focus groups, I ended up bringing these first draft base maps with me to all of my interviews. I learned quickly that the small-scale map was only helpful to develop an initial geographic understanding of the location of MTR sites, slurry impoundments, and impacted communities. The small scale, however, did not allow for participants to express specific concerns from the MTR sites. The large-scale map of Coal River Mountain, therefore, served as the base map for mental mapping, conducted one on one instead of in focus groups. Information regarding names of hollows, additional features of concern, color and scale were added to the second draft base map at the request of participants (See Figure 3.2 and 3.3). These second draft base maps were also incorporated in our final participatory product, JourneyUpCoalRiver.org, with the addition of specific geographic points of interest and concern.

Although only two drafts of base maps were envisioned at my proposal stage, a total of four maps, three drafts and a final, were done. The third draft of the base-maps included geographical input regarding the concerns of residents about MTR, added through mental 
mapping. These third draft maps were reviewed in February by participants before being incorporated in their final version onto the online PGIS. The final maps, as well as the original base maps and participatory drafts, were analyzed using Crampton’s ‘social construction approach,' an approach which “emphasizes the genealogy of power in mapping practices and enables multiple, contingent and exploratory perspectives of data” (Crampton, 2001, pg 235). Analysis focused on the production of the map, including the changes suggested by participants throughout the drafts, as well as the final product. Attention was also paid to the objects that participants chose to include that the permit maps did not include.

\section{4. c. v Participatory Mental Mapping}

The literature review of PGIS in Chapter Two highlighted the potential for PGIS to combine local knowledge with more formal “expert” information to produce geospatial information that could be used to support community concerns. Participatory tools and methods used in PGIS practice include: ephemeral mapping (drawing on the ground), sketch mapping, scale mapping, 3D modeling, photomaps, the use of global positioning systems, map-linked multimedia information systems, and integration of GIS (Rambaldi et al, 2006). For this dissertation, participatory mental mapping was used due to the ability to acquire socially differentiated local knowledge to incorporate into the PGIS (Harris and Weiner, 1998; Abbot et al, 1998). Chambers (1994a) listed and highly recommended participatory mental mapping as a data source for researchers working with marginalized groups. As a base map was used for all mental mapping, this type of mapping would also be referred to as scale mapping.

Participatory mental mapping is defined as "the use of tracing paper overlaid on topographic map sheets and/or GIS map products” (Harris and Weiner, 2002). Participatory mental mapping was used to evoke the spatial discourse of landscape change in the valley. My first interviews were conducted with the participant using the map as they answered my three questions. At the end of the interview, then, we worked together to put their concerns and points of interest on the maps. My initial method 
involved using transparent paper over the base map, as suggested in Harris and Weiner's definition of participatory mental mapping. However, the transparent paper obscured the map and initial participants quickly tired of trying to draw on the transparent paper. I printed out my second draft base map for each interview with the result of having a separate map for each participant or family group that indicated an interest. I learned through this process that many residents of Coal River do view these questions spatially, and that combining the interviews and the participatory mental mapping worked out very well.

\section{4. $d$ Conclusion}

This chapter has outlined the relations between elements of Foucault's work on knowledge, discourse and power with the PGIS methodology and selected methods of my research. A mixed method strategy of inquiry was chosen to combine both traditional geospatial data with "expert” local knowledge regarding the impacts of mountaintop removal on landscape change and use in the Coal River Valley. I drew from Foucault to construct a mini-archeology of the original legal definitions, regulatory rule making, and specific geographical specificity of mountaintop removal in the case study area. To illustrate the subaltern discourse of resistance to mountaintop removal on Coal River mountain, semi-structured interviews, base-map construction, and participatory mental mapping were used.

My choice of appropriate methods was influenced by the importance of themes within the PGIS overview such as dis/empowerment of communities and individuals through the process, product, and long term outcome of PGIS research, legitimization by participation, the role of researcher/facilitator, and the importance of transparency and trust. The next chapter proceeds to discuss the formation of mountaintop removal as an object through the construction of a mini-archeology of the legal discourse of this specific type of surface mining. 


\section{CHAPTER FIVE \\ MINI-ARCHEOLOGY OF THE LEGAL DISCOURSE OF MOUNTAINTOP REMOVAL AND VALLEY FILLS}

There's a huge disconnect between the language used by the industry and regulators versus the plain language meaning of the words. This disconnect of language serves to virtually enslave the residents of the coalfields.

Kevin Thompson, Environmental Attorney

Thompson and Barney

As reviewed in Chapter Two, Foucault's work on the relationships between knowledge, discourse and power are the basis of the conceptual framework of this study. The premise of Foucault's archeological method is that systems of thought and knowledge are governed by rules that operate beneath the consciousness of individual subjects. These systems of thought and knowledge define the "conditions of possibility" that in turn determine the boundaries of thought in a given place and time. Therefore, in order to situate and unpack the subaltern discourse of resistance to MTR in the Coal River Valley, I investigate the legal discourse that first defined and created MTR as an object to be permitted. What are the conditions of possibility within which the subaltern discourse resists the permitting of mountaintop removal sites on the Coal River Mountain?

In composing my Foucauldian “toolbox” to construct a mini-archeology, I relied initially on the practical guides offered in Escobar (1995) and Hannah's (2007) application of Foucault's archeological method to the fields of development and geography as a starting point for my descriptive analysis. I made two adjustments to Foucault's archeological method as I applied it to my own work. Firstly, the addition of "temporalities" to the first dimension of the formation of MTR as an object. Secondly, individual human agency is given a more prominent place in this analysis, particularly as it relates to the discursive positioning of individuals. The prefix "mini” signifies that the scope of this study requires that I limit the focus of the archeology. If I were writing a more comprehensive archeology, I would then proceed to use the other major categories Foucault presents to finish the description of MTR as a discursive phenomenon. Additionally, in a full 
archeology the search for emergences of MTR as an object would have investigated the discourse that resulted in the passage of the Surface Mining Control and Reclamation Act of 1977. For the purposes of this study, I constructed a mini-archeology of the formation of MTR as an object through legal and regulatory statutes, procedures, and permits.

The primary method of data collection for my first research question ${ }^{1}$ was the construction of a mini-archeology. Applying the archeological method to my research, my task is to show how mountaintop removal was legally formed and reformed as an object within its spaces of dispersion. I draw from Foucault's archeological method to unpack the formation of MTR as an object primarily using three dimensions: surfaces and temporalities of emergence, authorities of delimitation, and grids of specification. The construction of the mini-archeology therefore proceeds in three steps: the unpacking of the original legal construction of MTR through federal legislation, the reconstruction of MTR through "rule-making” agencies, and finally the specific implementation of MTR on Coal River Mountain. The Surface Mining Control and Reclamation Act of 1977 and the Clean Water Act of 1972 serve as the initial surfaces of emergence for the purposes of this study, and the investigation of regulatory rule-making then highlights the agencies and authorities empowered by these original statutes. The chapter concludes with a brief location of the three mountaintop removal sites on Coal River Mountain as instances of specific spaces of dispersion. Due to the length of legal passages referenced in this miniarcheology, endnotes are used in this chapter to refer to specific sections of legal statutes and state regulations. 


\section{5. a. The Original Legal Definition of 'Mountain Top Removal' and 'Valley Fills'}

The process of mountaintop removal coal mining, including the creation of valley fills, is governed primarily by two federal statutes: the Surface Mining Control and Reclamation Act of 1977 (SMCRA) and the Clean Water Act of 1972 (CWA). Due to the broad impact of mountaintop removal on both land and water resources, the National Environmental Policy Act of 1970 and the Endangered Species Act are also applicable to some portion of the process. ${ }^{1}$ Foucault states that as it is not possible to describe all the relations as they emerge, a "provisional division must be adopted as an initial approximation: an initial region that analysis will subsequently demolish and, if necessary, reorganize” (Foucault, 1972, p. 29). Therefore, for the purposes of this study, I focus on the original legal definitions that apply to the mining and reclamation processes (SMCRA) and the disposal of resulting overburden in adjacent hollows (CWA).

Additionally, the definition of 'mountaintop removal' is highly contested. The USEPA defines MTR as "a surface mining practice involving the removal of mountaintops to expose coal seams, and disposing of the associated mining overburden in adjacent valleys_-'valley fills’” (USEPA, 2009h). In Mountaintop Mining/Valley Fills in Appalachia Draft Programmatic Environmental Impact Statement, the US EPA (USEPA, 2003) states that “for the purposes of this EIS, 'mountaintop mining' considers all types of surface coal mining (mountaintop removal, contour, area, etc.) in the steep terrain of the central Appalachian coalfields.” This first step of the mini-archeology will trace the emergence of "mountain top removal” and the associated process of valley fills through the initial legal formations.

\footnotetext{
${ }^{1}$ Regarding the Endangered Species Act, as of 1996 policy states that MTR can never damage endangered species or their habitat as long as mining operators comply with federal surface mining law. Since 1996, this policy has exempted many strip mines from being subject to permit-specific reviews of impact on individual endangered species.
} 


\section{5. a. i The Surface Mining Control and Reclamation Act of 1977: Permitting a "Higher and Better Use" of the Mountains}

This bill will never work unless it is very rigorously enforced, and enforced in such a way as to overcome the pressures of the coal industry.

Ken Hechler to President Carter, 1977

U.S. House of Representatives,

West Virginia, 1959-77

The first surface of emergence of mountaintop removal coal mining used for this research is found in the Surface Mining Control and Reclamation Act (SMCRA) of 1977. SMCRA was the result of a sustained effort throughout the 1970's to enact a comprehensive federal statute to regulate coal mining and reclamation, in part due to the failure of state regulation to address the problems. During this time, the United States was in economic turmoil from the oil embargo of October 1973 and under pressure to increase domestic energy security through the use of national coal resources. At the same time, many in the United States were fearful of another environmental catastrophe like the 1972 Buffalo Creek disaster which killed 125 people. Harold Quinn, Senior Vice President of the National Mining Association, remembered the legislative debate as a struggle to “...strike a balance between our nation’s need for coal as an essential energy source and protection of the environment” (Quinn, 2007).

The legislature hotly debated how to regulate that "balance” for seven years. In 1971, West Virginia Congressional Representative Ken Hechler introduced a bill that would have abolished surface mining. Two more attempts were passed by congress, but vetoed by President Ford in 1974 and 1975 (Burns, 2007). Looking back at the passage of SMCRA, sponsor U.S. Rep. Udall remarked that it is "more than a piece of legislation: it is a vehicle of hope for those who live in America's coalfields and their children” (Squillace, 1990). In contrast, former U.S. Rep Ken Hechler, quoted above in his words to President Carter the day SMCRA was signed, withheld his vote for the passage of SMCRA due to his belief that abolition, not regulation, was needed to protect residents from the impacts of surface mining (Hechler, 2007). 
SMCRA was enacted by Congress and signed by Jimmy Carter in 1977 to regulate surface coal mining and reclamation operations on both private and public land. As the legislation proceeded through successive congressional sessions, the product transformed from a 17-page version passed by the House of Representatives in 1972 to a 90-page bill reported by the conference committee and signed by President Carter on the morning of August 3, 1977 (Quinn, 2007). The version that I cite contains the amendments of 1990 and 1992.

Under SMCRA, mining companies must obtain permits that detail their responsibilities for extracting the coal, minimizing environmental impacts, and posting bonds that are supposed to cover reclamation costs and avoid the creation of more abandoned mine lands. Regarding reclamation, the statute provides detailed requirements for the standards of reclamation and requirements for giving a permit. The land must be restored to a "condition capable of supporting uses...prior to mining" or to "higher or better uses of which there is reasonable likelihood." These "reasonable" uses must not present any "actual or probable hazard to public health or safety," nor any "probable threat of water diminution or pollution.” The proposed land use must fulfill a double negative: be "not deemed to be impractical or unreasonable" nor "inconsistent" with local land use policies. Finally, the post mining land use must not involve "unreasonable delay" or break any Federal, State, or local laws. ${ }^{2}$

In regards to the impact of strip mining on the actual contour of the land, SMCRA begins to delineate how a mountain must be put back under the law. The defining language regarding "approximate original contour”(AOC) is controversial enough to have appeared in a great deal of publicity regarding the process of mountaintop removal mining. ${ }^{3}$ In respect to the backfill of all coal mining operations, companies are required to compact and grade the site in order to "restore the approximate original contour." The statute goes on to specify requirements for restoring the AOC, and states again that at a minimum operators use all overburden and spoil to attain the "lowest practicable grade but not more than the angle of repose." The definition of "angle of repose" would have to be tackled by regulators during the rule making process. ${ }^{4}$ 
Thus far, the written intent of SMCRA clearly allows surface mining only if environmental concerns, such as water contamination and restoration of original contour, are put first. However, the first six words of Sec 515 a (3) of SMCRA open a discursive loophole: "Except as provided in subsection (c )." Section C of the statute states that each state and federal program can allow for procedures to be made during "rule making" that would allow for exceptions for applicants who meet all of the previous requirements except for the AOC. "Section C" may be granted for the surface mining of coal where the "mining area will remove an entire coal seam or seams running through the upper fraction of a mountain, ridge, or hill by removing all of the overburden and creating a level plateau or a gently rolling contour with no high walls." ${ }^{5}$ Section $C$ allows the regulatory authority to grant a permit for this "mountain, ridge, or hill” mining if the post-mining land use is "deemed to constitute an equal or better economic or public use of the affected land, as compared with premining use." Here, then is the first specific reference to mountain top removal: "mountain, ridge, or hill mining." The statute goes on to delineate specific requirements to determine the economic or public value of the post mining land use ${ }^{6}$ and requires that the "governing body" where the land is located, as well as any state and federal agencies that might have an "interest in the proposed use," be notified and given sixty days to review and comment on the proposed use. ${ }^{7}$

Finally, section C proceeds to list detailed requirements ${ }^{8}$ for the regulatory agency that determine the procedures, or "rule making," that govern the granting of permits through, allowing as well that the regulatory agency can impose additional requirements. ${ }^{9}$ Of particular interest is the requirement that "no damage will be done to natural watercourses” by the permitted action. Permits granted under this section must be reviewed not more than three years from the date the permit was issued, unless the applicant proves that the proposed development is "proceeding in accordance with the terms of the approved schedule and reclamation plan." 10

Hannah (2007) defines "authorities of delimitation" as subject positions from which individuals have or acquire the right to define and delineate the objects of a discursive formation. Therefore, the members of the House, Senate, and the President would be the 
direct authorities of delimitation in regards to the creation of SMCRA. However, as the bill was hotly contested for seven years, there are many authorities that could be uncovered. In this case, in order to unearth the authorities of delimitation regarding SMCRA, I would need to search previous strip mining bills, committee hearings and reports, floor discussions in the Senate and House of Representatives, as well as dig into the nonofficial conversations and concerns regarding the bill. Comments from anti-strip mining activists and residents would also need to be investigated. However, for the purposes of this mini-archeology, the legal statutes themselves serve as the authorities of delimitation.

Even though SMCRA never actually states the words “mountaintop removal," this statute is the first surface of emergence of the discursive loophole that legalized the practice. As written, the requirements regarding public health or safety as well as impacts on water diminution or pollution would prohibit any form of mountaintop removal. However, Congress, as the primary authority of delimitation, leaves room for interpretation regarding a few key phrases. The requirement that the land must be restored to a premining use, or a "to a higher or better use" is problematic. How does one restore a mountain to its approximate original contour? At what point does a hazard become “actual or probable” to public safety? Who, then, is the person or agency that has the authority to determine what is probable, what is a threat to public safety, what is a higher and better use for a mountain? Many of these regulatory authorities of delimitation will be defined through the rule-making process and discussed in section 5.b. 


\section{5. a. ii The Clean Water Act of 1972: Permitting the Discharge of "Fill"}

Streams flow through these valleys prior to the placement of overburden. The valley fills permanently bury the streams, destroying the aquatic ecosystems within the streams. The coal companies may only fill the streams pursuant to a permit issued by the Corps, as the overburden is classified as "fill material" according to the CWA regulations.

-Robert Chambers, US District Judge

OVEC v. Army Corps, 2007

The Clean Water Act (CWA) is the primary federal statute that governs water pollution in the United States and serves as the first surface of emergence for the permitting of the excess overburden created by MTR. The CWA was passed in 1972 in response to the nearly unregulated dumping of pollution into our nation's waters. At the time, two-thirds of the country's waters were unsafe for swimming or fishing.

The stated goal was to reduce pollution in all U.S. waters to "restore and maintain the chemical, physical, and biological integrity of our nation's waters." ${ }^{11}$ CWA governs discharges to "navigable waters," this includes all waters with a "significant nexus" into navigable waters. The law called for "zero discharge of pollutants into navigable waters by 1985 , and fishable and swimmable waters by $1983 . "{ }^{12}$ The principal body of law is based on the Federal Water Pollution Control Act amendments of 1972. Additional amendments were enacted in the Clean Water Act of 1977 and the Water Quality Act of 1987. The primary section of the Clean Water Act that applies to mountaintop removal is section 404 of the CWA, which regulates the discharge of "fill" material into waters of the United States. This section governs the permitting of valley fills created from excess “fill” from MTR sites.

In defining authorities of delimitation through the rule making process, Congress granted States the right and responsibility to "prevent, reduce, and eliminate pollution" and to "plan the development and use (including restoration, preservation, and enhancement) of land and water resources" with the requirement that States consult with the Administrator of the EPA in the "exercise of this authority" through SMCRA. ${ }^{13}$ States were granted the 
authority to implement the permit programs under sections 402 and 404 . The State is required to be involved from the outset. Section 401 requires that applicants for the section 404 permit program must provide the Corps with a certification from the State in which the fill discharge will occur. ${ }^{14}$ The State must "establish procedures for public notice” regarding applications for section 404 certification as well as procedure for public hearings "to the extent it deems appropriate." In fact, the Act goes on to state that "nothing in this section shall be construed to limit the authority of any department or agency pursuant to any other provision of law to require compliance with any applicable water quality requirements.” 15

The CWA specifically forbids all dumping (except for a list of specific uses) that is not approved by the Army Corps of Engineers. Valley fills, however, are permitted through section 404, which authorizes the Secretary of the Corps to permit the discharge of “dredged or fill material” into the "navigable waters" of the nation. ${ }^{16}$ The CWA also requires that the public be notified no later than 15 days after the permit application is submitted and given the opportunity for a public hearing. It does not specify the level of participation allowed or required at the public hearing, nor the procedures for setting up the public hearing and notifying residents.

The section 404 permit system, or the "fill rule," was written for developers seeking to build projects in wetlands, like a subdivision, or parking lot. Ironically, it is the Division of Wetlands within the Corps that oversees the permits which are used to allow valley fills. The Act states that the "guidelines" required for each permit shall be based upon criteria applicable to the "territorial seas, the contiguous zone, and the ocean.” 17 Therefore, the original legal definitions that guide the process of granting permits to fill valleys were written within the discursive field of "wetland” ecosystems and smaller development projects.

The CWA provides authorization for the Corps to prohibit or withdraw a defined area as a "disposal site” if he determines that the "discharge of such materials into such area will have an unacceptable adverse effect on municipal water supplies, shellfish beds and 
fishery areas (including spawning and breeding areas), wildlife, or recreation areas.” 18 The Act goes on to state that the Secretary of the Corps can issues Section 404 general permits on a state, regional or nationwide basis for "any category of activities involving discharges of dredged or fill material” with the following requirements: the categories must be similar in nature, cause only minimal adverse environmental effects separately,

and have only minimal cumulative adverse effect on the environment. ${ }^{19}$ General permits can not be granted for a period of more than five years, and the Corps is given the authority to revoke or modify the permit if the Secretary determines that the activities have an "adverse impact on the environment” or should be more authorized by individual permits. Additionally, the Administrator of the EPA is still given oversight and the power to veto a 404 permit. This distinction between general permits and individual permits will be a significant cause of contention in the following regulatory rule making section, as will be the ability of the EPA to veto a 404 permit.

\section{5. b. Regulatory Rule-Making}

Mountaintop removal mining involves multiple statutes and agencies at both the federal and state levels. In fact, the jumble of laws and actors, along with the accompanying overlapping jurisdictions and fragmented decision-making, explains a great deal about regulation in this area. Frequently, governmental officials in one agency did not know what officials in another were doing. These regulatory "blind spots" opened the door to a dramatic expansion of mountaintop mining.

-Charles Davis, 2008

The previous section unpacked the original legal construction of MTR and valley fills within two federal statutes: the Surface Mining Control and Reclamation Act of 1977 (SMCRA) and the Clean Water Act of 1972 (CWA). These statutes served as the initial surfaces of emergence for the purposes of this study. The statute is supposed to be a broader guideline that the regulatory agency “defines” so that the regulated entity, for example the coal company, has more specific guidance: “it comes down to a difference in language. The legislators are writing laws that will be interpreted by lawyers. The 
regulatory agencies are writing rules that will be carried out by engineers” (Thompson, 2010).

This section investigates the regulatory rule-making conducted by the agencies and authorities empowered by SMCRA and the CWA to be authorities of delimitation. For the purposes of this study, authorities of delimitation are defined as subject positions from which individuals have or acquire the right to define and delineate the objects of a discursive formation (Hannah, 2007). SMCRA is administered by the US Department of Interior's Office of Surface Mining (OSM), and the Clean Water Act of 1972 (CWA) is administered by the Environmental Protection Agency (EPA) and the U.S. Army Corps of Engineers (Corps). This section proceeds to illustrate the regulatory reconstruction of MTR as an object by these authorities of delimitation.

\section{5. b. i Authorities of Delimitation from SMCRA: The Office of Surface Mining}

SMCRA appointed the Office of Surface Mining to further define the procedures and “authorities” for the surface mining permits and reclamation standards. Basically, Congress created the authorities of delimitation, in terms of designated agencies, who would take the language from SMCRA and turn it into step by step actions. Through this regulatory reformation of MTR as an object, the discursive field was successively refined and confused. The first attempt to implement the entire range of permanent program requirements produced 150 pages of regulatory text to “flesh-out” an already 90-page statute. An additional 400 pages were required to explain what the regulations meant (Quinn, 2007).

As previously discussed, SMCRA allowed for limited exceptions to the requirement to return land disturbed by mining to its AOC. Although Section 515 C of SMCRA first opened the discursive loophole for mountaintop removal by permitting "mountain, ridge, or hill” mining, the term 'mountaintop removal' first came into affect through OSM's 
regulatory reformation of the statutory language regarding exceptions to AOC. A "mountaintop removal" operation is one that, by definition, will not restore the area to AOC, but will instead reclaim the land to a level plateau or a gently rolling contour, with no high walls remaining. In order to receive this exception, operators were required to restore the mined land to one of several enumerated post mine land uses. ${ }^{20}$ In general, an AOC variance could only be permitted when the benefits of the post mine land use would outweigh the adverse impacts of not returning the land to AOC.

The state of West Virginia has delimited and approved three different types of AOC variances-remining, mountaintop removal, and steep slope. Remining AOC variances are used for certain lands that have been previously mined, but not reclaimed, and for which the regulatory agency deems there is insufficient spoil to return the remined land to the shape of the original mountain. By contrast, the other two types of AOC variancesmountaintop removal and steep slope-may be approved for specific types of operations on land in mountainous areas, even though the land could physically be reclaimed to AOC. In these cases, federal and state regulations allow the operator to reclaim the land without regard to the AOC requirement if the land will be suitable for certain post mining land uses (PMLUs). OSM policy advises that mountaintop removal and steep slope AOC variances should be granted "only in situations where beneficial land uses could compensate for the adverse effects of not returning the land to AOC.” 21

Through the rule-making process, the OSM alternative post mining land use regulations require a "higher and better use" standard. Additionally, a post mining land use cannot be approved "where the use could be achieved without the waiving of the AOC requirement, except in those rare instances where it is demonstrated that a significant public or economic benefit will be realized there from; and the post mining land use must always offer a net benefit to the public or the economy." ${ }^{22}$ So, in other words, if the post mining land use is "better" than the pre mining use, then an AOC waiver can be granted to the mine operator. Who is responsible for determining what use is "higher and better" than another? The OSM has a specific list of uses constituting better usage: industrial, commercial, agricultural, residential, and public facility. ${ }^{23}$ 
Industrial uses: "Heavy and light manufacturing facilities, production of materials for fabrication and storage of products." These industrial uses are considered a higher and better use due to the potential to create local job opportunities and stimulate the economy.

Commercial uses: "Retail or trade of goods or services, including hotels, motels, stores, restaurants, and other commercial establishments." These uses are considered higher and better due to potential services to residents and increases in tourism.

Agricultural and Forestry uses: OSM regulations state that low-intensity, lowmaintenance agricultural activities, such as grazing and pastureland are discouraged.

Residential use: "Land used for single- and multiple-family housing, mobile home parks, or other residential lodgings. " This is considered a higher use due to the potential to provide housing for residents, especially in areas with high flood potential.

Public facility: "May include schools, hospitals, airports, reservoirs, museums, and developed recreational sites such as picnic areas, campgrounds, ball fields, tennis courts, fishing ponds, equestrian and off-road vehicle trails, and amusement areas together with any necessary supporting infrastructure such as parking lots, and rest facilities."

If included as part of the plan for a public facility, fish and wildlife habitat can be approved by the OSM as a better use. However, by itself, Fish and Wildlife habitat does not qualify.

This list constitutes OSM's definition of land uses that are considered to be "better uses. However, as stated, OSM policy advises that mountaintop removal and steep slope AOC variances should be granted only when beneficial land uses can "compensate" for the adverse effects caused by not returning the land to AOC. The question of who can define the adverse effects, and what they consist of, is not ever addressed by OSM. 


\section{5. b. ii Authorities of Delimitation from the CWA: USEPA and the Army Corps}

The Clean Water Act is administered by the U.S. Environmental Protection Agency (EPA), which sets water quality standards, handles enforcement, and helps state and local governments develop their own pollution control plans. However, Congress empowered the Army Corps of Engineers as the authorities regarding rule making for section 404 permits. The text I will reference is from the Regulatory Program of the Army Corps of Engineers, located on the Certified Federal Registry.

Although the Army Corps of Engineers has no direct regulatory authority in regards to MTR, it does play an indirect role through its control over the 404 permits for valley fills. The Section 404 program is jointly administered by the Corps and the EPA, and the Fish and Wildlife Service (FWS) and the national Marine Fisheries Service (NMFS) have advisory roles. However, the relatively small role that the Corps does play has been highlighted by the resistance as a weak point: without a 404 permit for valley fills, mountaintop removal coal mining can not proceed. Therefore, the 404 permit is the only part of MTR permitting where the state does not have primacy of enforcement: the EPA can veto a Corps issued 404 permit. CWA 404(c) delegates the EPA as the discretionary authority, although the EPA is judicious in its use of 404 (c) and has only vetoed 12 projects since the CWA was passed in 1972.

Part 328 of the Regulatory Program of the Corps defines the Corps interpretation of the term "waters of the United States" and "prescribes the policy, practice, and procedures" to determine the "extent of jurisdiction" of the Corps. ${ }^{24}$ In this regulatory definition, rivers, streams, and intermittent streams are included as waters of the United States. ${ }^{25}$ Additionally, all impoundments of said waters are included in its jurisdiction as well as the tributaries of those waters.

Part 323 of the Regulatory Program contains the procedures for permitting dredged or fill material under section 404 of the CWA. The first definition applicable to valley fills is 
their definition of the term 'fill material': "any material used for the primary purpose of replacing an aquatic area with dry land or of changing the bottom elevation of an waterbody.” A key qualification states that this term does not include any “pollutant discharged into the water primarily to dispose of waste," 26 as that activity is regulated under a different section of the CWA and is not the responsibility of the Corps. The next definition, “discharge of fill material," includes placement of fill necessary for the “construction of any structure” in US waters such as an impoundment, and "site fills for recreational, industrial, commercial residential, and other uses.” 27 However, the preceding definition of "fill”" that excludes waste disposal causes this definition to be a contentious point.

The distinctions between individual permits versus nationwide permits for valley fills, as generally outlined in section 404 of the CWA, evolve as well in the rule making process. Individual permits are issued on a case-by-case basis, with the requirement that the proposed discharge is in the "public interest." 28 General permits refer to a Corps authorization issued on a nationwide or regional basis when the activities are "substantially similar in nature and cause only minimal individual and cumulative environmental impacts." 29 Both individual as well as nationwide permits have been used by the Corps to authorize valley fills. As individual permits require more stringent evidence that the fill is in the "public interest” and also require a public hearing, coal operators have broken up large valley fills into smaller pieces to qualify for the nationwide permits. In 2007, nationwide permits for valley fills were declared in violation of the Clean Water Act. This ruling remained in effect until the Fourth Circuit Court in Richmond overturned it in early 2009. As of June 2010, The Army Corps has suspended nationwide permits as an "interim measure to protect the aquatic environment while we evaluate modification of NWP 21 or until NWP 21 expires in 2012" (Corps, 2010.)

In the first step of this mini-archeology, the text of SMCRA and the CWA were the original surfaces of emergence in the formation of mountaintop removal as an object. 
Within these original legal creations of the various aspects of MTR, regulatory agencies were given the authority for "rule-making" regarding the actual requirements and process of obtaining a surface mine permit (SMCRA) or a valley fill permit (CWA). In both statutes, Congress created the authorities of delimitation for the creation of rules and procedures regarding the permitting, enforcement, and oversight of the federal regulations. These rules and procedures further defined the discursive formations within which the process of mountaintop removal materialized in the Coal River Valley.

\section{5. c. Intersection with Case Study Area}

Economics dictate that the plain meaning of statutory language be twisted into tortured readings which allow coal companies to maximize profit.

Kevin Thompson, Environmental Attorney

Thompson and Barney

In this final step of the mini-archeology, I look at the grids of specification regarding mountaintop removal in the case study area. The legal and regulatory discursive formations of MTR intersect my case study area through the specific issuance or denial of surface mine and valley fill permits on Coal River Mountain. Referring to Chapter Two, "grids of specification” are the classificatory dimensions along which an object is located within a discursive formation. Applied to the legal formation of mountaintop removal, grids of specification place attention on the specific classification and permitting of mountaintop removal in the case study area.

There are currently three large surface mine permits either pending or approved for Coal River Mountain: Bee Tree, Eagle II, and Leather Leaf (See Figure 3.3). Taken together, these permits would cover 4,400.25 acres of Coal River Mountain, about seven square miles (See Table 5.1 below). In this final step of the mini-archeology, a timeline is constructed of “emergences” and "re-emergences” of legal and regulatory definitions of mountaintop removal and valley fills within these permits. For the purposes of this overview, I focus on the Bee Tree permit, which is now active on Coal River Mountain. 


\begin{tabular}{|l|l|l|l|l|}
\hline Permit Name & Permit ID & Acres Impacted & \# of Valley Fills & Issuance Date \\
\hline Bee Tree & S301004 & 1090.00 & 6 & $07 / 11 / 06$ \\
\hline Eagle II & S302805 & 2039.89 & 6 & $06 / 06 / 08$ \\
\hline Leather Leaf & S300210 & 1270.36 & 5 & Pending \\
\hline
\end{tabular}

Table 5.1: Surface Mines on Coal River Mountain. Source: WVDEP

\section{5. c. i Bee Tree Surface Mine}

The Bee Tree mountaintop removal site is the first physical emergence of post-SMCRA surface mining on Coal River Mountain. Marfork coal company, a subsidiary of Massey Energy Corporation, applied to the WVDEP for the permit in 1994 and was issued a surface mining permit (S301004) in July, 2006. Blasting to remove overburden and access coal started in October, 2009 on the Bee Tree permit, despite the face that no CWA 404 permits for the six valley fills were issued.

Bee Tree has three activities allowed: contour mining, high wall mining, and steep slope mining (See Appendix 5.1 for Bee Tree permit). This list of activities is misleading, as the list does not represent all of the types of mining occurring on Bee Tree, but rather the highest percentages of mining occurring. As contour mining represented more than 50\% of the permit, the DEP applies regulations from contour mining. Mountaintop mining is not listed as one of the activities allowed and there is no AOC variance granted, despite the fact that the Bee Tree permit is considered mountaintop removal by the EPA: "a surface mining practice involving the removal of mountaintops to expose coal seams, and disposing of the associated mining overburden in adjacent valleys—'valley fills’” (USEPA, 2009h). Therefore, despite the inclusion of Bee Tree by the EPA as a mountaintop removal site, this mine is not classified by the DEP as such.

Pre-mining land uses for the Bee Tree permit include: Fish and Wildlife Habitat /Recreation, Previously Mined and Not Reclaimed, Forestland, and Combined. Postmining land use is also Fish and Wildlife Habitat/Recreation, and Combined. 
Therefore, this permit is being reclaimed to a "condition capable of supporting uses...prior to mining" and not to "higher or better uses,"30 which would be required of a mountaintop removal site to obtain a section C AOC variance. Therefore, in the case of Bee Tree, Marfork coal is required to restore AOC but not reclaim to a higher use standard (See Appendix 1).

The Bee Tree Surface Mine Application shows the creation of six valley fills (See Figure 3.3), yet Marfork coal has not received any of the required CWA 404 permits to dispose of overburden. However, work on the surface mine has begun even without these required valley fill permits. How is this possible? Two "incidental boundary revisions" (IBRs) were issued in November 2008 and November 2009 for the Bee Tree permit. An IBR is part of the permit revision process stipulated by the DEP. The permit supervisor of the surface mine in question reviews the section of the permit being revised and determines if the change is "significant" or "insignificant." If the permit is found to be "significant," then "specific" government agencies must be notified and public comment allowed. $^{31}$

In this case, the November 2008 "incidental boundary revision”(IBR) submitted by Marfork to the WVDEP allowed for "fill” material from the Bee Tree site to be disposed of on a nearby permitted area: the Brushy Fork slurry impoundment. The Brushy Fork impoundment is one of the largest coal waste dams in the world (See Figure 3.2). Coal River Mountain Watch and the Sierra Club appealed to the Surface Mine Board in March of 2009, claiming that the IBR violated state AOC regulations as well as allowed Marfork to begin mining without required CWA 404 permits, ${ }^{32}$ but the Board voted to allow the permit revision. EPA officials stated their concern regarding the commencement of operations without a CWA 404 permit in a letter to Marfork Coal in November, 2009: "EPA is concerned that Marfork Coal Company may be committing significant resources and conducting operations in reliance on a Section 404 permit that has not been issued....we have some concern that ongoing activities at the site could impact such waters if sufficient precautions are not exercised.” However, mining continued on Bee Tree due to the fact that the impacted waters were not deemed to be "navigable waters of 
the United States,” and therefore not under the jurisdiction of the Corps. ${ }^{33}$ Therefore, overburden from blasting on the Bee Tree site is being put on the Brushy Fork Impoundment, which already has a 404 permit, but none of the additional six valley fills can be created without a CWA 404 permit. If issued, this CWA 404 individual permit would impact 17,392 linear feet, or 3.3 miles, of the Clear Fork watershed.

The Bee Tree permit lists that a "contemporaneous reclamation variance” was granted for the mine. The contemporaneous reclamation variance signifies that the coal operator must post 5,000 per acre bond to avoid reclaiming the land "contemporaneously” with mining. Kevin Thompson stated that "contemporaneous reclamation" variance is one of the major legal loopholes, and that the cost for the bond is "negligible compared to the actual cost of proper reclamation. And during the interim, residents living down slope are inundated with flood waters that would be greatly reduced had proper reclamation been truly contemporaneous” (Thompson, 2010).

\section{5. c. ii Eagle No. 2 and Leather Leaf Surface Mines}

The Eagle No. 2 surface mine is the second physical emergence of post SMCRA surface mining on Coal River Mountain (See Appendix 2 and 3). Marfork coal company, a subsidiary of Massey Energy Corporation, applied to the WVDEP for the permit in 1995 and was issued a surface mining permit (S301004) in June 2008. Although the surface mine permit was granted, work has not begun on this site, nor have any CWA 404 permits been issued for the six valley fills proposed for the site. The Leather Leaf surface mine is the third physical emergence of post SMCRA surface mining on the mountain. Also owned by Marfork, this application was applied for in 2010 and is currently pending. Activities allowed on both sites include area mining, contour mining, high wall mining, and steep slope mining. Neither of these permits are classified by the WVDEP as mountaintop mining, and neither have AOC variances. Both surface mines, however, have a "contemporaneous reclamation variance.” 


\section{5. d. Analysis and Conclusion}

This chapter addresses the primary method of data collection for my first research question through the construction of a mini-archeology with the purpose of showing how mountaintop removal has been legally formed and reformed as an object within its spaces of dispersion. I drew from Foucault's archeological method to unpack the formation of MTR as an object using three dimensions: surfaces and temporalities of emergence, authorities of delimitation, and grids of specification.

The first step focused on the original legal construction of MTR through two federal statutes: the Surface Mining Control and Reclamation Act of 1977 and the Clean Water Act of 1972. Under SMCRA, the land must supposedly be restored to a condition that can support premining land use, must not present any "actual or probable hazard to public health or safety,” nor any threat of water pollution. Companies are required to restore the mountain to "approximate original contour," although debate continues regarding how to do so, or apply for a Section C “AOC variance” which would allow coal companies to skip the AOC requirement all together. Section $\mathrm{C}$ allows the regulatory authority to grant a permit for this "mountain, ridge, or hill” mining if the post-mining land use constitutes an equal or better economic or public use of the affected land. Although SMCRA never uses the term "mountaintop removal," section C opened the discursive loophole that allowed for this "mountain, ridge, or hill” mining without the requirement to restore the land to AOC.

Regarding the creation of valley fills, the CWA provides authorization for the Corps to issue 404 permits to discharge fill material in the "navigable waters of the United States" with the qualification that the discharge will not have an "unacceptable adverse effect on municipal water supplies,” fisheries, wildlife, or recreation areas. The CWA specifically forbids all dumping that is not approved by the Army Corps of Engineers. Valley fills, however, are permitted through section 404, which authorizes the Secretary of the Corps to permit the discharge of "dredged or fill material” into the "navigable waters" of the nation. The section 404 permit system was written for developers seeking to build 
projects in wetlands and is administered by the Division of Wetlands within the Corps. Therefore, the original legal definitions that guide the process of granting permits to fill valleys were written within the discursive field of "wetland" ecosystems and smaller development projects, like subdivisions or parking lots.

The second step of this mini-archeology focused on the reconstruction of MTR through "rule-making" agencies that were given the authority by federal statutes to write the regulatory mechanisms that would govern the permitting of surface mining and valley fills. SMCRA is administered by the Office of Surface Mining (OSM), and the Clean Water Act is administered by the Environmental Protection Agency (EPA) and the U.S. Army Corps (Corps). Although Section $515 \mathrm{C}$ of SMCRA first opened the discursive loophole for mountaintop removal by permitting "mountain, ridge, or hill” mining, the term 'mountaintop removal' first came into affect through OSM's regulatory reformation of the statutory language regarding exceptions to AOC. A "mountaintop removal” operation is one that, by definition, will not restore the area to AOC, but will instead reclaim the land to a level plateau or a gently rolling contour, with no high walls remaining. OSM took steps towards defining what post mining land uses constituted better usage - industrial, commercial, agricultural, residential, and public facility - but offered no further procedures about how to prioritize the adverse effects of an AOC variance in comparison to the potential benefits of the designated post mining land use. Additionally, the question of who can define the adverse effects, and what they consist of, was not addressed by OSM.

The first definition applicable to valley fills is their definition of the term 'fill material': "any material used for the primary purpose of replacing an aquatic area with dry land or of changing the bottom elevation of an waterbody.” A key qualification states that this term does not include any "pollutant discharged into the water primarily to dispose of waste," ${ }^{34}$ as that activity is regulated under a different section of the CWA and is not the responsibility of the Corps. The next definition, "discharge of fill material," includes placement of fill necessary for the "construction of any structure" in US waters such as an impoundment, and "site fills for recreational, industrial, commercial residential, and 
other uses." 35 However, the preceding definition of "fill” that excludes waste disposal causes this definition to be a contentious point. Additionally, the distinctions developed by OSM between nationwide permits and individual permits continued to evolve and which was required for a valley fall have continued to evolve. As of June 2010, nationwide permits have been suspended, and coal operators must use individual permits to apply for valley fills.

In the final step, three surface mine permits on Coal River mountain were reviewed within the grids of dispersion outlined by the legal and regulatory formation of mountaintop removal. As defined by the WVDEP, the permitting agency for the surface mine permits, none of these three permits are classified as mountaintop removal, despite the fact multiple seams are being accessed using explosives with the intent to place fill in neighboring hollows. None of the three surface mine permits have AOC variances, but the active site, Bee Tree, has been challenged already before the Surface Board regarding the AOC requirements that are in place for the reclamation plan. All three permits have forestland as a pre-mining land use, yet plan to replace the forest with wildlife habitat, a lower land use. Finally, all three permits have a variance for contemporaneous reclamation, allowing Marfork coal to post a \$5,000 per acre bond in case reclamation is not finished. The Bee Tree surface mine is the only mine that is currently operating. Despite the requirement that Marfork coal apply for CWA 404 individual permits for the 6 valley fills on this permit, work has already begun. Marfork was able to dispose of overburden by using an "incidental boundary revision" on the neighboring permit, the Brushy Fork Slurry Impoundment, to dispose of overburden without going through the Clean Water Act. In fact, despite the regulatory definition of the Corps authority of the "waters of the United States," the surface mine board found that the Brushy Fork Impoundment, the largest impoundment in the United States, was not within the jurisdiction of the Corps.

Both the CWA and SMCRA clearly state the intention to protect the environmental protection of the nation's waterways and mined areas. However, the "balance” between our need for coal and the protection of the environment referred to by Harold Quinn has 
shifted towards economic extraction through the use of discursive loopholes such as the "AOC variance" and the definition of "fill." Despite SMCRA's mission to prevent post mining land uses that could be an "actual or probable hazard to public health or safety," the subaltern discourse contains many concerns about impacts to their health and safety from the material manifestation of MTR near their homes. Chapter six focuses on the subaltern discourse of mountaintop removal through the use of semi-structured interviews, base-map construction, and participatory mental mapping to illustrate the concerns of Coal River residents regarding the impacts of mountaintop removal in the case study area.

\footnotetext{
${ }^{1}$ What are the legal discursive formations that define and allow the permitting of MTR in the case study area?
}

${ }^{2}$ SEC. 515. a.(2) restore the land affected to a condition capable of supporting the uses which it was capable of supporting prior to any mining, or higher or better uses of which there is reasonable likelihood, so long as such use or uses do not present any actual or probable hazard to public health or safety or pose any actual or probable threat of water diminution or pollution, and the permit applicants' declared proposed land use following reclamation is not deemed to be impractical or unreasonable, inconsistent with applicable land use policies and plans, involves unreasonable delay in implementation, or is violative of Federal, State, or local law; [30 U.S.C. 1265]

${ }^{3}$ For a partial list, see Ken Ward’s Mining the Mountains series.

${ }^{4}$ SEC. 515. a.(3) except as provided in subsection (c) with respect to all surface coal mining operations backfill, compact (where advisable to insure stability or to prevent leaching of toxic materials), and grade in order to restore the approximate original contour of the land with all highwalls, spoil piles, and depressions eliminated (unless small depressions are needed in order to retain moisture to assist revegetation or as otherwise authorized pursuant to this Act): Provided, however, that in surface coal mining which is carried out at the same location over a substantial period of time where the operation transects the coal deposit, and the thickness of the coal deposits relative to the volume of the overburden is large and where the operator demonstrates that the overburden and other spoil and waste materials at a particular point in the permit area or otherwise available from the entire permit area is insufficient, giving due consideration to volumetric expansion, to restore the approximate original contour, the operator, at a minimum, shall backfill, grade, and compact (where advisable) using all available overburden and other spoil and waste materials to attain the lowest practicable grade but not more than the angle of repose, to provide adequate drainage and to cover all acid-forming and other toxic materials, in order to achieve an ecologically sound land use compatible with the surrounding region: And provided further, That in surface coal mining where the volume of overburden is large relative to the thickness of the coal deposit and where the operator demonstrates that due to volumetric expansion the amount of overburden and other spoil and waste materials removed in the course of the mining operation is more than sufficient to restore the approximate original contour, the operator shall after restoring the approximate contour, backfill, grade, and compact (where advisable) the excess overburden and other spoil and waste materials to attain the lowest grade but not more than the angle of repose, and to cover all acid-forming, and other toxic materials, 
in order to achieve an ecologically sound land use compatible with the surrounding region and that such overburden or spoil shall be shaped and graded in such a way as to prevent slides, erosion, and water pollution and is revegetated in accordance with the requirements of this Act; [30 U.S.C. 1265]

${ }^{5}$ SEC. 515. c. Where an applicant meets the requirements of paragraphs (3) and (4) of this subsection a permit without regard to the requirement to restore to approximate original contour set forth in subsection 515(b)(3) or 515(d)(2) and (3) of this section may be granted for the surface mining of coal where the mining operation will remove an entire coal seam or seams running through the upper fraction of a mountain, ridge, or hill (except as provided in subsection (c)(4)(A) hereof) by removing all of the overburden and creating a level plateau or a gently rolling contour with no highwalls remaining, and capable of supporting postmining uses in accord with the requirements of this subsection. [30 U.S.C. 1265]

${ }^{6}$ SEC. 515. c. (B) the applicant presents specific plans for the proposed postmining land use and appropriate assurances that such use will be -

(i) compatible with adjacent land uses;

(ii) obtainable according to data regarding expected need and market;

(iii) assured of investment in necessary public facilities;

(iv) supported by commitments from public agencies where appropriate;

(v) practicable with respect to private financial capability for completion of the proposed use;

(vi) planned pursuant to a schedule attached to the reclamation plan so as to integrate the mining operation and reclamation with the postmining land use; and

(vii) designed by a registered engineer in conformance with professional standards established to assure the stability, drainage, and configuration necessary for the intended use of the site; [30 U.S.C. 1265]

${ }^{7}$ SEC. 515. c. (D) the regulatory authority provides the governing body of the unit of general-purpose government in which the land is located and any State or Federal agency which the regulatory agency, in its discretion, determines to have an interest in the proposed use, an opportunity of not more than sixty days to review and comment on the proposed use; [30 U.S.C. 1265]

${ }^{8}$ SEC. 515. c. (4) In granting any permit pursuant to this subsection the regulatory authority shall require that -

(A) the toe of the lowest coal seam and the overburden associated with it are retained in place as a barrier to slides and erosion;

(B) the reclaimed area is stable;

(C) the resulting plateau or rolling contour drains inward from the outslopes except at specified points;

(D) no damage will be done to natural watercourses;

(E) spoil will be placed on the mountaintop bench as is necessary to achieve the planned postmining land use: Provided, That all excess spoil material not retained on the mountaintop shall be placed in accordance with the provisions of subsection (b)(22) of this section;

(F) insure stability of the spoil retained on the mountaintop and meet the other requirements of this Act; [30 U.S.C. 1265]

${ }^{9}$ SEC. 515. c. (5) The regulatory authority shall promulgate specific regulations to govern the granting of permits in accord with the provisions of this subsection, and may impose such additional requirements as he deems to be necessary. [30 U.S.C. 1265]

${ }^{10}$ SEC. 515. c. (6) All permits granted under the provisions of this subsection shall be reviewed not more than three years from the date of issuance of the permit, unless the applicant affirmatively demonstrates that the proposed development is proceeding in accordance with the terms of the approved schedule and reclamation plan. [30 U.S.C. 1265]

${ }^{11}$ SEC. 101. (a) The objective of this Act is to restore and main-tain the chemical, physical, and biological integrity of the Nation's waters. In order to achieve this objective it is hereby declared that, consistent with the provisions of this Act [ 33 U.S.C. 1251] 
${ }^{12}$ SEC. 101. (a) It is the national goal that wherever attainable, an in-terim goal of water quality which provides for the protection and propagation of fish, shellfish, and wildlife and provides for recreation in and on the water be achieved by July 1, 1983 [ 33 U.S.C. 1251]

${ }^{13}$ SEC. 101. (a) It is the policy of the Congress to recognize, preserve, and protect the primary responsibilities and rights of States to prevent, reduce, and eliminate pollution, to plan the development and use (including restoration, preservation, and enhancement) of land and water resources, and to consult with the Administrator in the exer-cise of his authority under this Act. It is the policy of Congress that the States manage the construction grant program under this Act and implement the permit programs under sections 402 and 404 of this Act. [ 33 U.S.C. 1251]

${ }^{14}$ Section 401 (a)(1)Any applicant for a Federal license or permit to conduct any activity including, but not limited to, the construction or operation of facilities, which may result in any discharge into the navigable waters, shall provide the licensing or permitting agency a certification from the State in which the discharge originates or will originate, or, if appropriate, from the interstate water pollution control agency having jurisdiction over the navigable waters at the point where the discharge originates or will originate, that any such discharge will comply with the applicable provisions of sections 301, 302, 303, 306, and 307 of this Act. [33 U.S.C. 1341]

${ }^{15}$ Section 401 (a)(6) [33 U.S.C. 1341]

${ }^{16}$ Section 404 (a) The Secretary may issue permits, after notice and opportunity for public hearings for the discharge of dredged or fill material into the navigable waters at specified disposal sites. Not later than the fifteenth day after the date an applicant submits all the information required to complete an application for a permit under this subsection, the Secretary shall publish the notice required by this subsection. [33 U.S.C. 1344]

${ }^{17}$ Section 404 (b) Subject to subsection (c) of this section, each such disposal site shall be specified for each such permit by the Secretary (1) through the application of guidelines developed by the Administrator, in conjunction with the Secretary which guidelines shall be based upon criteria comparable to the criteria applicable to the territorial seas, the contiguous zone, and the ocean under section 403(c), and (2) in any case where such guidelines under clause (1) alone would prohibit the specification of a site, through the application additionally of the economic impact of the site on navigation and anchorage. [33 U.S.C. 1344]

${ }^{18}$ Section 404 (b) [33 U.S.C. 1344]

${ }^{19}$ Section 404 (e)(1) In carrying out his functions relating to the discharge of dredged or fill material under this section, the Secretary may, after notice and opportunity for public hearing, issue general permits on a State, regional, or nationwide basis for any category of activities involving discharges of dredged or fill material if the Secretary determines that the activities in such category are similar in nature, will cause only minimal adverse environmental effects when per-formed separately, and will have only minimal cumulative adverse effect on the environment. [33 U.S.C. 1344]

20 OSM, Postmining Land Use: Exceptions to Approximate Original Contour Requirements for Mountaintop Removal Operations and Steep Slope Operations, June 2000, available at

http://www.osmre.gov/guidance/docs/mtpmlureport.pdf.

${ }^{21}$ U.S. Department of the Interior, Office of Surface Mining, Final Report: An Evaluation of Approximate Original Contour and Post-Mining Land Use in West Virginia, May 1999; and An Evaluation of Approximate Original Contour and Post-Mining Land Use in Kentucky, May 2000.

${ }^{22}$ OSM. 1999. Enforcement: Exceptions to Approximate Original Contour Requirements for Mountaintop Removal Operations and Steep Slope Mining Operations. 
${ }^{23}$ OSM, 1999

${ }^{24} 33$ CFR Part 328.1 This section defines the term "waters of the United States" as it applies to the jurisdictional limits of the authority of the Corps of Engineers under the Clean Water Act. It prescribes the policy, practice, and procedures to be used in determining the extent of jurisdiction of the Corps of Engineers concerning "waters of the United States." The terminology used by Section 404 of the Clean Water Act includes "navigable waters" which is defined at Section 502(7) of the Act as "waters of the United States including the territorial seas." To provide clarity and to avoid confusion with other Corps of Engineer regulatory programs, the term "waters of the United States" is used throughout 33 CFR Parts 320330 .

2533 CFR part 328.3 (3) All other waters such as intrastate lakes, rivers, streams (including intermittent streams), mudflats, sandflats, wetlands, sloughs, prairie potholes, wet meadows, playa takes, or natural ponds, the use, degradation or destruction of which could affect interstate or foreign commerce including any such waters:

${ }^{26} 33$ CFR part 323.a(e) The term "fill material" means any material used for the primary purpose of replacing an aquatic area with dry land or of changing the bottom elevation of an waterbody. The term does not include any pollutant discharged into the water primarily to dispose of waste, as that activity is regulated under section 402 of the Clean Water Act. See Section 323.3(c) concerning the regulation of the placement of pilings in waters of the United States

${ }^{27} 33$ CFR part 323.2 (f) The term "discharge of fill material" means the addition of fill material into waters of the United States. The term generally includes, without limitation, the following activities: Placement of fill that is necessary for the construction of any structure in a water of the United States; the building of any structure or impoundment requiring rock, sand, dirt, or other material for its construction; site-development fills for recreational, industrial, commercial, residential, and other uses; causeways or road fills; dams and dikes; artificial islands; property protection and/or reclamation devices such as riprap, groins, seawalls. breakwaters, and revetments; beach nourishment; levees; fill for structures such as sewage treatment facilities, intake and outfall pipes associated with power plants and subaqueous utility lines; and artificial reefs.

${ }^{28} 33$ CFR part 323.2 (g) The term "individual permit" means a Department of the Army authorization that is issued following a case-by-case evaluation of a specific project involving the proposed discharges) in accordance with the procedures of this part and 33 CFR Part 325 and a determination that the Proposed discharge is in the public interest pursuant to 33 CFR Part 320.

${ }^{29} 33$ CFR part 323.2 (h) The term "general permit" means a Department of the Army authorization that is issued on a nationwide or regional basis for a category or categories of activities when:

(1) Those activities are substantially similar in nature and cause only minimal individual and cumulative environmental impacts; or

(2) The general permit would result in avoiding unnecessary duplication of regulatory control exercised by another Federal, state, or local agency provided it has been determined that the environmental consequences of the action are individually and cumulatively minimal.

${ }^{30}$ SEC. 515. a.(2) restore the land affected to a condition capable of supporting the uses which it was capable of supporting prior to any mining, or higher or better uses of which there is reasonable likelihood, so long as such use or uses do not present any actual or probable hazard to public health or safety or pose any actual or probable threat of water diminution or pollution, and the permit applicants' declared proposed land use following reclamation is not deemed to be impractical or unreasonable, inconsistent with applicable land use policies and plans, involves unreasonable delay in implementation, or is violative of Federal, State, or local law; [30 U.S.C. 1265]

${ }^{31}$ WVDEP Permit Handbook, 13-3- Permit Revisions, http://www.dep.wv.gov/dmr/handbooks/Documents/Permitting\%20Handbook/sect13.pdf

32 "Massey wins round in Coal River Mountain fight" 
March 16, 2009 by Ken Ward Jr.http://blogs.wvgazette.com/coaltattoo/2009/03/16/massey-wins-round-incoal-river-mountain-fight/

${ }^{33}$ Conversation with Joe Lovett, Executive Director, Appalachian Center for the Economy and the Environment, 5/25/10

${ }^{34} 33$ CFR part 323.a(e) The term "fill material" means any material used for the primary purpose of replacing an aquatic area with dry land or of changing the bottom elevation of an waterbody. The term does not include any pollutant discharged into the water primarily to dispose of waste, as that activity is regulated under section 402 of the Clean Water Act. See Section 323.3(c) concerning the regulation of the placement of pilings in waters of the United States

3533 CFR part 323.2 (f) The term "discharge of fill material" means the addition of fill material into waters of the United States. The term generally includes, without limitation, the following activities: Placement of fill that is necessary for the construction of any structure in a water of the United States; the building of any structure or impoundment requiring rock, sand, dirt, or other material for its construction; site-development fills for recreational, industrial, commercial, residential, and other uses; causeways or road fills; dams and dikes; artificial islands; property protection and/or reclamation devices such as riprap, groins, seawalls. breakwaters, and revetments; beach nourishment; levees; fill for structures such as sewage treatment facilities, intake and outfall pipes associated with power plants and subaqueous utility lines; and artificial reefs. 


\section{CHAPTER SiX}

\section{“SO Go THE MOUNTAINS, SO GOES THE MOUNTAINEER”: \\ Subaltern Discourses of Mountaintop Removal in the CoAl River VALLEY}

The previous chapter unpacked the evolution of MTR as an object through federal legislation, regulatory reconstruction, and then material manifestation of MTR in the case study area. The purpose of this mini archeology was to bring forward the "historial a priori" that ground knowledge and its discourses regarding MTR. Chapter Six focuses on a different discourse: the perspectives of concerned Coal River residents regarding the impacts of MTR in the case study area.

This chapter focuses on the data collected to address my second research question: What are the subaltern discursive formations regarding the implementation of MTR in the case study area? Local knowledge and resistance perspectives are illustrated regarding the impacts of mountaintop removal in the Coal River Valley. This chapter uses the term subaltern to illustrate the concerns of local residents as subjugated knowledges that have been disqualified or located low on the hierarchy: a “particular, local, regional knowledge, a differential knowledge incapable of unanimity and which owes its force only to the harshness with which it is opposed by everything surrounding it” (Foucault, 1980, p. 82) As previously defined, the term subaltern is used to represent a heterogeneous community of resistance with multiple discursive formations at the intersections of gender, age, and livelihood. In illuminating the subaltern discourse of resistance to MTR, discourse is defined as written texts, visual representations such as maps and pictures, and practices such as oral narratives. To construct this representation of the subaltern in the Coal River Valley, semistructured interviews, base map construction, and participatory mental mapping were used.

Chapter six begins with an introduction to the interview subjects who participated in this research and then moves to present their greatest concerns regarding the environmental and social impacts of mountaintop removal. The focus of analysis is on the discourse of resident concern, which involves illustrating the perspectives of locals regarding the impacts of MTR as opposed to a quantitative study of the manifestation of those concerns. While this is an unusual approach, the focus of this dissertation is to illustrate the specific concerns that local residents have regarding the impact of 
mountaintop removal on their homes. The perspectives of local residents, many of whom come from families that have many generations of knowledge about their landscapes, are treated as expert knowledge in this dissertation. Participatory maps created from participant concern regarding flooding impacts, dangers from blow outs, and blasting impacts are introduced. The review then proceeds to focus geographically on the concerns of residents in three hollows of Coal River Mountain: Horse Creek, Rock Creek, and Sycamore. I was only able to interview two participants in Dry Creek, so information about Dry Creek was included in overall participant concerns but not in a special geographical focus. After a discussion of these concerns and related participatory maps, the review investigates the subaltern discursive formations at intersections of gender, age, and livelihood. I draw from the literature on Appalachian political economy and the subaltern to inform my representation of multiple identities within the subaltern discourse of resistance to MTR.

\section{6. a. Introduction to Participants}

Fifty-nine semi-structured interviews were conducted over a sixteen month time period in the communities surrounding Coal River Mountain. Quantitative data such as age, gender, type of employment, history of employment, and years of residency was collected from participants to supplement qualitative data from interviews and focus groups (Appendix 5). To protect confidentiality, each resident is referred to by a number. Additionally, their age and years of residency were put into 10 year divisions to reduce the ability to determine their identity.

I used personal contacts as well as contacts through organizations working against MTR to establish “gatekeepers": people within the study area who were connected with residents active within the discourse of resistance. I then proceeded from these gatekeepers to use the snowball sampling method to gain access to more participants. As reviewed in Chapter Four, snowball, or chain sampling, identifies other potential participants from the connections of the original gatekeepers (Dunn, 2005). One of the strengths of this method is that it can be used to reach inaccessible groups of people. These participants, therefore, do not represent a cross section of the entire case study area. They do, however, represent a cross section of residents who do not support mountaintop removal for a variety of reasons. This chapter proceeds to illustrate the different discursive formations regarding the reasons why participants are against MTR. 


\begin{tabular}{|cc|}
\hline \multicolumn{3}{|c|}{ Residency } \\
\hline $0-9$ & $8 \%$ \\
10 to 19 & $8 \%$ \\
$20-29$ & $12 \%$ \\
$30-39$ & $14 \%$ \\
$40-49$ & $8 \%$ \\
$50-59$ & $17 \%$ \\
$60-69$ & $19 \%$ \\
$70-79$ & $10 \%$ \\
$80+$ & $3 \%$ \\
\hline Table 6.1: Years of residency & for participants \\
\hline
\end{tabular}

To represent the perspectives of residents with strong ties to Coal River, I made an effort to interview residents who had strong and often multigenerational connections with the land. All participants interviewed currently live within the study area. The average length of residency for participants is 44 years (See Table 6.1). I determined residency by the number of years that they physically lived in the valley. Therefore, the average residency is slightly low because many participants left home to find work, yet still remained in communication with family and returned home for vacations. The longest period of residency was 91 years. Four participants lived in the valley for less than four years. However, in all

four cases, the participants had spent substantial time in the valley during childhood or had married into families with long standing residency. Additionally, due to the history and importance of coal mining in the area, it was important to speak with residents who were familiar with the coal industry. $81 \%$ of all interviewees have a family history of coal mining or have current family members working as either underground miners or strip miners.

\begin{tabular}{|c|c|c|c|}
\hline Employment & Female & Male & Total \\
\hline $\begin{array}{r}\text { Retired } \\
\text { Current } \\
\text { Quit }\end{array}$ & $0 \%$ & $\begin{array}{r}54 \% \\
62 \% \\
29 \% \\
10 \%\end{array}$ & $36 \%$ \\
\hline Other Full Time & $20 \%$ & $18 \%$ & $14 \%$ \\
\hline Other Part Time & $20 \%$ & $10 \%$ & $17 \%$ \\
\hline Other Retired & $10 \%$ & $13 \%$ & $12 \%$ \\
\hline Stay at Home Mother & $50 \%$ & $0 \%$ & $19 \%$ \\
\hline Disability & $0 \%$ & $5 \%$ & $3 \%$ \\
\hline Total & $100 \%$ & $100 \%$ & $100 \%$ \\
\hline
\end{tabular}

Table 6.2: Total and gender specific employment type for participants

Regarding gender, 34\% of participants interviewed were female, and 66\% were men (See Table 6.2). At the midpoint of my fieldwork, only $20 \%$ of my interviews conducted were with women. I made a conscious effort to reach out to more female residents and was able to raise the percentage of interviews with women. However, in three cases, women sat in with their husbands during the interview and indicated that they did not want to speak with me, but that their husbands could speak 
for them. Although they indicated that I could represent their views as well from their husband's interview, I choose only to include their husband's name. In two cases I was able to return at a later date and interview the wife when her husband was at work. Of the women interviewed, 50\% are stay at home mothers, $20 \%$ have part time work, $20 \%$ have full time employment, and $10 \%$ are retired (see Table 6.2). None of the women interviewed have ever worked in the coal industry, or currently received a disability check. As reviewed in Chapter 3, 71.8\% of the households in Raleigh county are family households, and 38\% have children under 18 living at home. Although 50\% of women self identified as stay at home mothers, I rely on Oberhauser's (1995) to show their households as ".... dynamic space where production and reproduction occur simultaneously, the distinction between public and private is clouded, and, in the case of homework, the domestic sphere and work place become one” (pg 3). Multiple livelihood strategies employed by women can incorporate home activities such as gardening, canning, or other informal economic activities to support their households (Aurora Lights, 2009). Women working part-time also can combine multiple activities such as income generation, child rearing, and other household activities (Oberhauser, 1995).

Within the group of male participants, the coal industry was by far the highest employer at 54\%. An overwhelming $90 \%$ of the male participants who have worked within the coal industry are union coal miners. $62 \%$ are retired coal miners, $29 \%$ currently work on surface mines or underground, and $10 \%$ quit. The next highest employment type, at $18 \%$, is full-time outside of the coal industry. Some of these jobs include electrician, teacher, and logger. 13\% are retired from outside the coal industry, such as rubber, timber, or government jobs, $10 \%$ have other part-time work, and 5\% receive a disability check (See Appendix 5). An in-depth review of gender-specific concerns is given in section 6.d. of this chapter.

Regarding age, $76 \%$ of the participants are over the age of 50 , with $47 \%$ over the age of 60 . The youngest participant was 26 years old, the oldest was 91 years old. The median age of participants is 57 years old, as compared to a median age of 43 years old in the case study area and 38 years at the state level (See Table 3.1). Of course, case study and statewide data incorporate children and teenagers, whom I did not interview, in the data used for the median. Even considering this difference in data, I have very low participation in the age group from 20-50 years old. I have 


\begin{tabular}{|l|r|}
\hline & Age \\
\hline $0-9$ & $0 \%$ \\
10 to 19 & $0 \%$ \\
$20-29$ & $3 \%$ \\
$30-39$ & $8 \%$ \\
$40-49$ & $12 \%$ \\
$50-59$ & $29 \%$ \\
$60-69$ & $29 \%$ \\
$70-79$ & $15 \%$ \\
$80+$ & $3 \%$ \\
Table 6.3: Age breakdown \\
\multicolumn{2}{|c|}{ of participants } \\
\hline
\end{tabular}

several hypotheses for why I was largely unable to access residents between the age of 20 and 40. As reviewed, the combined impact of a weakened UMWA, an increase in mechanization and expendability of the workforce, and an overall drop in coal employment has resulted in vastly different job choices for the current generation of workers. Many men in this age group work non-union surface mines or related industries and therefore are more difficult to reach due to my positionality within the case study area. Tension can exist between younger miners, forced to choose between working out of

state or working for a non-union mine, and their strongly union parents. Older union, retired miners were often more willing to speak with me, as represented in part by the $47 \%$ of participants over the age of 60. Section 6. e. takes a more detailed look at the discursive formations at intersections of gender, age, and livelihood.

\section{6. b. The Impacts of Mountaintop Removal: "They'll be nothing here left for anyone”}

This section focuses on the overarching concerns held by the participants in reference to my second research question ${ }^{1}$, which focused on existing and potential impacts on the landscape from mountaintop removal coal mining. Although the focus of this dissertation focused on the physical changes on the landscape as a result of MTR, participants interpreted the landscape in different ways. A resident of Edwight expressed the connection between landscape change and social changes in just one sentence: "the landscape has definitely changed [as a result of MTR] because here in Edwight it used to be a big community, houses on both sides of the road with a whole bunch of people, all the time” (CR \#54). Even though my question was about physical changes in the landscape, he answered immediately with a definition of landscape that focused on community. As expressed in the title of this chapter, "So go the mountains, so goes the mountaineer" (CR\#20), the

\footnotetext{
${ }^{1}$ a) What are the subaltern discursive formations regarding the existing or potential adverse affects of landscape change and use?
} 
traditions of community land use and multiple livelihood strategies mean that concerns about environmental impacts in the subaltern discourse come bundled with numerous social concerns as well. One resident who lived in Marfork hollow (\#20) had to move from her family home of generations due to water contamination and danger of collapse from the construction of the Brushy Fork Slurry Impoundment. For residents who grew up in Shumate Hollow, for example, landscape changes from mountaintop removal resulted in the complete relocation of all residents, even their cemetery, and the literal burial of the community beneath a valley fill (CR \#44, \#45). Certainly the physical burial of their hollow resulted in numerous social impacts as well.

Therefore, the first characteristic of the subaltern discourse is the inclusion of both environmental and social concerns as a result of changes in the landscape from MTR. I grouped participant concerns into two categories: impacts on the physical landscape, and the resulting social impacts on individuals, families, and communities. Table 6.4 shows the major themes drawn from participant concerns regarding the current impacts of mountaintop removal.

\begin{tabular}{|c|c|}
\hline \multicolumn{2}{|c|}{ Perceived Impacts on Landscape } \\
\hline Increased Flooding & $90 \%$ \\
Loss of Water Quality & $69 \%$ \\
Slurry Impoundment Failure & $68 \%$ \\
Deforestation & $54 \%$ \\
\hline Perceived Social Impacts \\
\hline Loss of Community Structure & $92 \%$ \\
Blasting Damage & $71 \%$ \\
Loss of Access to Mountain & $71 \%$ \\
Destruction of Home-place & $69 \%$ \\
Decreased Quality of Life for Children & $59 \%$ \\
Increased Coal Dust & $54 \%$ \\
Dangerous Traffic and Roads & $53 \%$ \\
Loss of Heritage / Culture & $51 \%$ \\
\hline
\end{tabular}

Table 6.4: Participant Concerns Regarding Impacts from Mountaintop Removal Coal Mining 
In Table 6.4, participant concerns were analyzed based on the number of participants who mentioned the themes. Initial themes were developed by summarizing concerns directly from the transcripts and then dividing them into physical and social concerns. Due to the high number of initial themes that I found, some were combined together for ease of analysis. For example, loss of water quality included concerns about increased sedimentation as well as black water and other contamination. Concerns shared by more than $50 \%$ of participants were included in this table. Additional concerns regarding perceived impacts on the landscape included loss of beauty of the mountain (46\%), increased landslides and erosion (37\%), loss of wildlife (37\%), poor reclamation (22\%), and increased wind (22\%). Participatory mapping regarding these concerns was generally specific to the hollow of residency, and is incorporated into smaller scale maps discussed later in this chapter.

Concerns regarding perceived social impacts were expressed verbally in the interviews, not geographically through the participatory mental mapping process. Additional social concerns included emotional impacts of fear, anger, and depression (42\%), danger to public health (32\%), and increased noise from heavy machinery and blasting (17\%). Outside of the formal interview, I noticed that informal conversations often included many more concerns than participants had indicated while being recorded. Additionally, concerns such as decreased quality of life for children and loss of heritage / culture overlap, yet I only included the concern if the participant specifically mentioned it. These experiences make it clear that the list of themes and percentages is best used as a guide for understanding the stand-out issues that each participant specifically articulated as opposed to an all-inclusive and quantifiable list. If I had included the concerns voiced by participants outside of the formal interview as well as concerns that were indirectly voiced, then the percentages would have been higher.

Table 6.4 represents the specific landscape and social concerns that residents articulated regarding the impacts of mountaintop removal. Not all residents, however, were able to represent their concern initially, or at all, with specific problems. The title of this section, "there'll be nothing here left for anyone,” (CR\#20) represents this difficulty in specifically explaining the dismantling of their cultural and natural heritage. Some residents (see Table 6.5 below) speak of the Coal River as a whole much greater than the sum of all its parts. Trying to describe how MTR changed the landscape of their homeland was like trying to explain the death of a loved one by describing the loss 
of each limb. In this instance, descriptions of loss from areas that have been already been mined extend beyond discursive formations of physical or social impacts. For some participants, concern about impacts from pending MTR on Coal River Mountain also extends beyond the discursive formations in Table 6.4: "the entire area will be wiped out. Coal River will be wiped out"(CR \#49). This difficulty in dissecting their connection to the land into measurable injuries can be seen in the following list of descriptions of the impact of MTR on landscape change and use:

\begin{tabular}{|c|c|}
\hline Participant & Description of Impacts from Mountaintop Removal \\
\hline CR \#13, 18, 24, 25 & "total devastation" or "total destruction" \\
\hline CR \#20 & "there'll be nothing left here for anyone" \\
\hline CR \#14 & "like a warzone, except they're not shooting us with guns" \\
\hline CR \#42 & $\begin{array}{c}\text { "Our lives are in danger if we don't stop this... we'll be snuffed out or we'll be } \\
\text { forced to move" }\end{array}$ \\
\hline CR \#15 & "I don't' see how we're gonna survive, them taking all that mountain" \\
\hline CR \#18 & "a wasteland as far as humanity is concerned;" "the land will be destroyed forever" \\
\hline CR \#40 & "it hurts everything around here when it comes down to it" \\
\hline CR \#49 & "the entire area will be wiped out. Coal River will be wiped out" \\
\hline CR \#54 & "unrepairable damage" \\
\hline CR\#22 & "it's abuse to the land" \\
\hline CR \#47 & $\begin{array}{l}\text { "it'll completely destroy the communities that are around up in these hollers...I } \\
\text { think it'll just totally ruin us" }\end{array}$ \\
\hline CR \#29 & "everything is gone" \\
\hline CR \#30 & "the place is dying" \\
\hline
\end{tabular}

Table 6.5: Descriptions of mountaintop removal as completely destructive of associated environmental and social impacts

As discussed in Chapter Three, the culture of Coal River Valley is deeply connected to the use of the land and mountains for supplementing food and income as well as tying communities together (Aurora Lights, 2009). These multiple livelihood strategies continue to be an important part of family traditions and land use in the Coal River valley today (Aurora Lights, 2009; Hufford, 2001). For example, loss of access to the mountain for a land-based family can result in loss of deer and turkey meat, which many families rely upon as part of a multi-livelihood strategy. Loss of access also results in the inability to seasonally gather ramps, mushrooms, "spring greens,” medicinal 
plants, and ginseng (Aurora Lights, 2009). Coal dust and/or water contamination can impact home gardens for families that depend on canning to offset grocery costs, impact the health of individuals drinking the polluted water and air, and generally result in a decrease of the quality of life for children. The interwoven nature of many of these concerns, whether in the physical or social realm, result in responses such as "it hurts everything around here when it comes down to it" (CR \#40). Within this framework, the responses of the participants in Table 6.5 above indicate a strong connection between landscape change from mountaintop removal and the perceived loss of "Coal River:” of "everything” (CR\#29). The next section moves on to examine each of the concerns held by more than $50 \%$ of the participants in more depth.

\section{6. b. i Perceived Impacts on Landscape}

This section focuses on the most prominent concerns shared by participants regarding impacts on the physical landscape as a result of current or pending mountaintop removal sites. At the time of the interviews, current MTR sites included those on Kayford Mountain to the North, and on Cherry Pond to the West. Coal River Mountain serves as the last relatively intact and forested mountain in the watershed to buffer communities from flooding and to provide clear water. As overviewed in Table 6.4, the concerns shared by more than $50 \%$ of all participants include: increased flooding (90\%), loss of water quality (69\%), slurry impoundment failure (68\%), and deforestation (54\%). Additional concerns regarding perceived impacts on the landscape included loss of beauty of the mountain (46\%), increased landslides and erosion (37\%), loss of wildlife (37\%), poor reclamation (22\%), and increased wind (22\%). 


\section{Increased Flooding}

This hollow will wash out and everybody in this hollow will be dead (CR\#35)

The community can't be no community. Pretty soon, it's gonna be all filled with water, and the homes and everything else will be gone. (CR \#21)

Increased flooding was the concern that was mentioned the most often (90\%) in both the interviews as well as through participatory mapping. In this section, flooding refers to an increase in run off from the loss of vegetation resulting from strip mining as well as the construction of valley fills in headwater areas. Concerns regarding safety from slurry impoundments were grouped together in the theme safety of slurry impoundments which follows later in this section.

The removal of vegetation, loss of topsoil, compaction of soil, and changes in mountain topography have been documented to lead to increased magnitude and frequency of flooding in downstream communities (McCormick et al, 2009; Ferrari et al, 2009; Negley and Eshleman, 2006). With or without this documentation, however, a correlation between surface mining activities with increased danger from flooding is deemed "common sense” (CR\# 10) to residents intimately familiar with the natural seasonal variations of rainfall and water level at their Home-places. All communities in the case study area were affected severely during the 2001 and 2002 floods, ${ }^{2}$ but the communities along Clear Creek, including Whitesville, were particularly hard hit. Participants remember damage to belongings (CR\# 8,9,10, 21, 23), destruction of homes (CR\#21, 55, 56), severe emotional or physical health impacts (CR\#55, 56, 57, 58), and the death of two community members. As previously mentioned in the case study chapter, Coal River Mountain serves as the last relatively intact and forested mountain in the watershed to buffer communities from flooding.

\footnotetext{
${ }^{2}$ For first-hand stories and pictures of the impacts of the 2001 and 2002 floods, see The Coalfield Communities of Southern West Virginia: http://www.wvcoalfield.com
} 


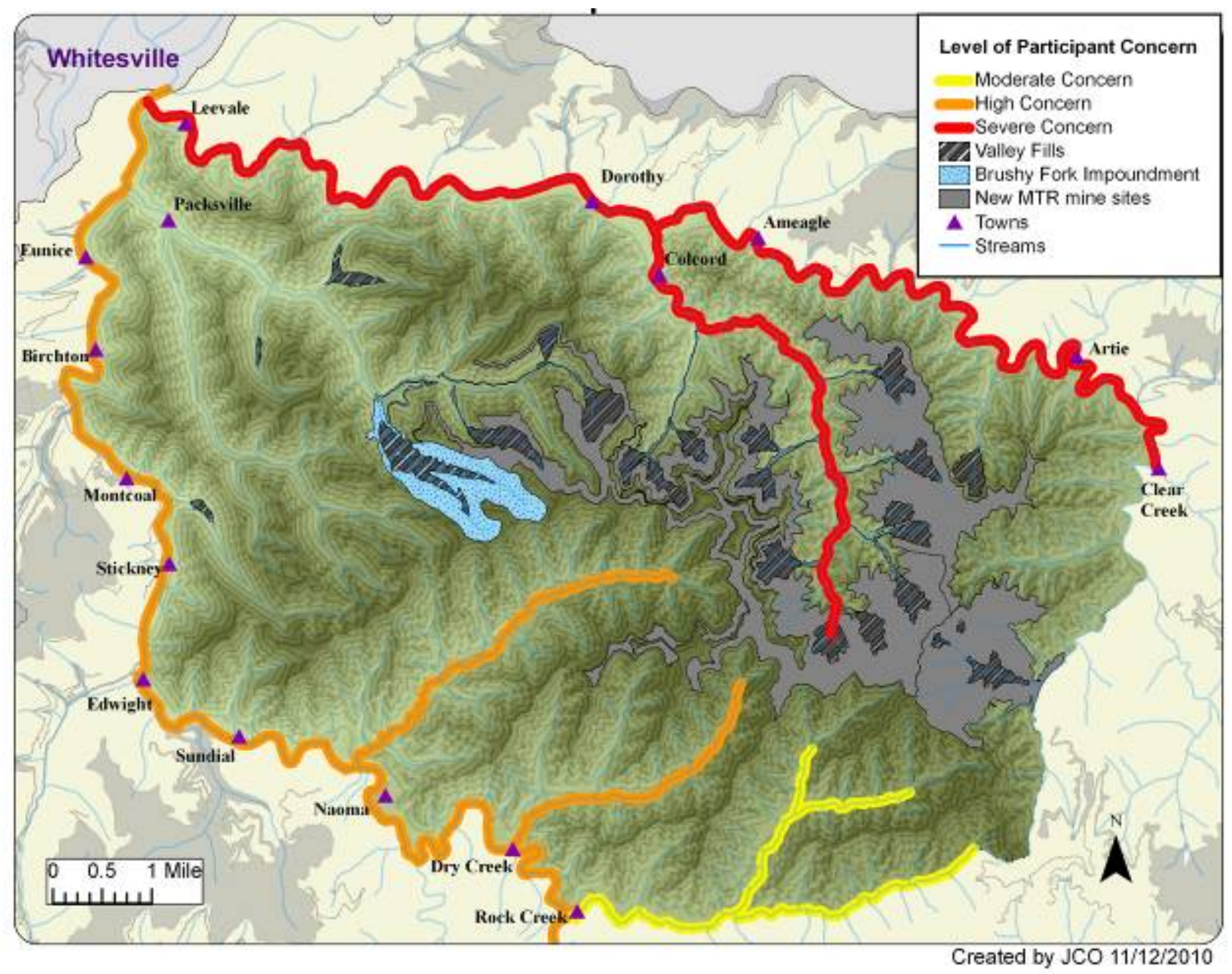

Figure 6.1: Perceived Flooding Impacts from current and pending mountaintop removal operations in the case study area

Figure 6.1 is a participatory map constructed from base maps, mental mapping, and thematic input from interviews to represent the level of concern regarding flooding in the communities surrounding Coal River Mountain. The categories of Moderate, High, and Severe were chosen to represent the elevated level of concern expressed by the participants regarding flooding from existing and pending mountaintop removal sites. The term Moderate was chosen to portray the lowest level of expressed concern in Rock Creek, where $67 \%$ of residents believe there will be increased flooding. The term High was chosen to represent Horse Creek, with 83\% participant concern, Route 3, with 93\% concern, and Dry Creek ${ }^{3}$, with $100 \%$ concern. In these three areas, participants are highly concerned about the potential for flooding to destroy their property even without additional mountaintop

\footnotetext{
${ }^{3}$ Only two people agreed to interviews in Dry Creek, so the $100 \%$ number is misleading
} 
removal. In particular, the communities of Naoma, Edwight, and Pettry Bottom are concerned about flooding due to the close proximity of the Edwight mine directly above them, on Cherry Pond mountain, to the south/southwest of Coal River mountain.

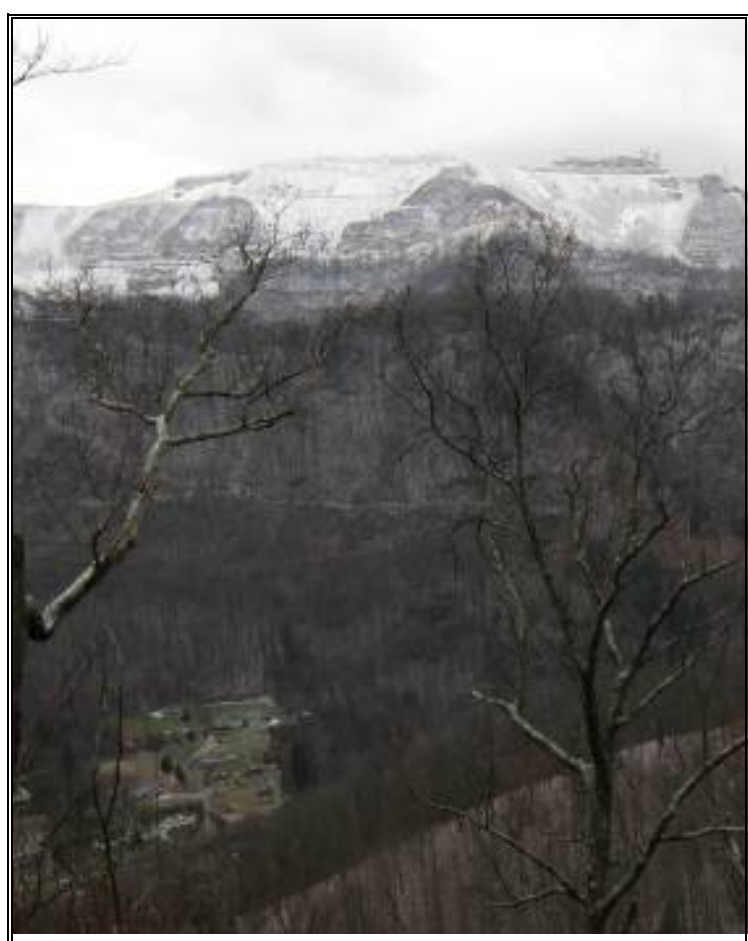

Figure 6.2: Pettry Bottom, bottom left, and the Edwight mine site in snow
Figure 6.2 shows the community of Pettry Bottom in the lower left hand corner. The picture was taken at the request of confidential participants to show the close proximity of current mining to their homes. The picture was taken from Coal River mountain facing west across Route 3 to Cherry Pond mountain. Pettry Bottom is a geographical area of specific concern regarding impacts from blasting, deforestation, and decreased quality of life for children. Current flooding problems originate from the Edwight mine site, behind the homes. Additional run off from surface mines on Coal River Mountain would run into Marsh Fork. As one life-long resident remarked: "we're right in the middle of it all, aren’t we?” (CR\#32). Just up Route 3, another life long resident stated that there was nothing above his home but rocks, rubble, and downed trees: “it’s going to come down on top of us as soon as the rains come” (CR\#42).

Yet the residents of Sycamore hollow and downstream communities are represented as in even more danger then these proceeding geographical areas. The 2001 and 2002 floods hit the communities of Sycamore hollow and Clear Fork road severely. One participant describes the flooding:

“It looked like a war-zone. The road was all washed out, peoples' houses were washed...maybe 100 ft down the road. Some of them you could see the ground all eat out from underneath the foundations, their house just a hangin' there... all the land, if a house was there it took the house, the highway, it took it all” (CR \#15). Susan Shea, mother of three children, and her fifteen year old neighbor, James Stover, were drowned when they stepped out of their car to walk across the street to their homes (Loeb, 2003). Two participants lost their home and all their belongings in the flood as 
well: "the flooding has really devastated us. It's cost us thousands and thousands and thousands of dollars to recover from the flood" (CR\# 56). Therefore, the label Severe was chosen to represent the $100 \%$ level of concern regarding the danger of increased flooding from the twelve valley fills and surface mine activities pending for Sycamore hollow. Additionally, every one of the 14 participants in this area mentioned flooding more than once. More than $50 \%$ of these flooding concerns were described in fatal terms, such as: "this hollow will wash out and everybody in this hollow will be dead and Massey will come in here and say, well, now we don't have to pay them” (CR \#35). Even residents from other areas of the mountain remarked about the danger from flooding to families living in Sycamore hollow: “valley fills are gonna bust, and they're gonna wash everybody out” (CR \#21).

Increased flooding was also linked as a cause for the social concerns destruction of home-place, decreased quality of life for children, and emotional impact: fear. A portion of interview between a husband and wife who lived through the 2001 and 2002 floods illustrates the interwoven nature of these three social impacts:

Male: The kids have seen what happened during the flood. And little kids especially that don't know no better, when it comes a rainin', first thing they look at, they say, 'we gonna get flooded again?'

Female: We gonna get another new house?

Male: It's impacted them.

Female: Am I gonna lose my bicycle again?

Male: It's impacted them because of the fear... and it's all, every bit of its caused because of taking the tops of the mountains off. I don't care what they say, if you take the trees away, where's the water gonna go?

Female: And if you live in a close knit community like we do...three little boys almost got drowned... around here everyone looks out for each other. Something happens to one, they are all concerned. I drove by, one little girl just standing there, crying, and just see her standing there looking at all her stuff [washed away.] She was just standing there with a little pink helmet (CR\# 57, 58).

As vividly described in this interchange, the destruction of homes by flooding in 2001 greatly impacted the quality of life for children in the impacted area by damaging them both physically (through the loss of their material items) and emotionally (through fear that it would happen again.) Another story that brings together these three social concerns as an impact of increased flooding is a mother's story of her children going to sleep in their clothes to be ready to run in the middle of the night if there is a flood (CR \#2). 


\section{Loss of Water Quality}

Clean Water. You used to be able to go up any holler, kneel down and get you a drink out of the creek. Not anymore, not anymore. That clean water is gone for the most part in most of our little hollers. (CR\#2)

Loss of water quality was the second highest overall concern (67\%) regarding landscape impact. Participant concern regarding black water spills, water contamination, and stream structure are included in this grouping. As with the theme of increased flooding, evidence exists documenting the impacts of mountaintop removal and valley fills on water quality (Palmer et al, 2010; Allan, 2004) More specifically, water emerging from the base of valley fills has been found to contain "a variety of solutes toxic of damaging to biota" and "significant linear increases in the concentrations of metals, as well as decreases in multiple measures of biological health” (Palmer et al, 2010).

For some families, the loss of water quality has resulted in the loss of their drinking water: "we have to buy drinking water now. Before we had a well and we had a spring. So we buy a lot of our drinking water and I filter my cookin' water (CR\#7). For others, the loss of water quality signifies the end of a healthy stream that supported fishing - "there's nothing in that water now" (CR\#2) - or allowed children to play in the creek (CR \#2-5, 8-10, 16, 19, 20, 27).

First hand experience with black water spills and associated fish kills and health impacts were cited as perspective-altering events for some residents regarding the impacts of MTR on their homes (CR\# $6,11,16,20,23,30)$. One local mother decided to move her family away from their traditional Home-place out of concern for her grandson, whom she found playing in their creek surrounded by black water and dead fish:

Black water just rolled out of that holler and just- it shocked me because I'd never seen black water before. And then we noticed there was at least two fish kills up there and there was white gooey stuff at the bottom of the creek there...And that was a creek that myself and six generations of my family had enjoyed all their lives, And if you've ever, ever seen black water rolling down a creek, it's the nastiest thing you've ever seen in your life. And I saw one come out of there that looked like-the water looked like thick pea soup it was really nasty, really thick...it was awful, it was awful, I couldn't believe it. (CR\#20) 
In the case of this family, the black water spill was coming from the Brushy Fork Slurry Impoundment. A former mine inspector and participant in this research described black water releases from slurry ponds: “you build a sludge pond and you divert the water... and then you're pumping the water back down to the prep plant and reusing it. Now when they reclaim it, they pump the water out... where does the water go? They pump it into the river. They pump it into a little hole, a little catch pond, take a little filter there to keep the black out of it, and put it back into the creek” (CR\# 6). He also compared the slurry ponds, even dried up and reclaimed, to "putting all those chemicals in a big jar and punching a hole in it...they just feed out so much at a time” (CR\#6). The high participant concern (67\%) regarding water contamination prioritizes this theme within the subaltern discourse of resistance. The Sludge Safety project was established by Coal River Mountain Watch, the Ohio Valley Environmental Coalition, and concerns citizens in Mingo County to address community concern regarding contamination from slurry impoundments and underground injections. Loss of water quality was also linked as a cause for the social concerns destruction of home-place, decreased quality of life for children, and dangers to public health.

\section{Safety of Slurry Impoundments}

They will eventually ride us down the river on a sludge dam. First time we have a good sized rain. (CR \#13)

Breaks in coal slurry impoundments can threaten the lives and health of area residents, destroy homes and businesses and contaminate water supplies. This dangerous potential looms over coal mining regions in West Virginia and throughout Appalachia.

- Senator Robert C. Byrd

$68 \%$ of participants are concerned that there is danger to themselves or to their families from slurry dam failure. The Coal River Valley is the unfortunate home of the largest impoundment in the United States, and it is built on top of previously mined coal seams. The Brushy Fork Slurry Impoundment is operated by Marfork coal, a subsidiary of Massey energy. Currently, this Class C High Hazard dam is permitted to hold over nine billion gallons of slurry and stand 900 feet from toe to crest of the dam. For comparison, this dam is higher than the New River Gorge Bridge. As briefly reviewed in Chapter Five, the Brushy Fork Impoundment was originally permitted in 
November of 1995. Numerous community concerns regarding the safety of this class C high hazard dam have been raised through legal channels since the original permit. At a public hearing addressing the expansion of the dam, the following concerns were raised: the quality of the compaction of the dam as of 1999, the adequacy and life expectancy of the drainage system, the adequacy of the monitoring plan and overall concerns about the safety of the impoundment throughout its life expectancy (Eades, 2000). At of the writing of this dissertation, violations have already been given to Massey regarding the compaction of the dam as well as several "black water" releases into the Coal River.

At a second public hearing held to address additional mining and the expansion of Brushy Fork, Rick Eades, a respected hydrologist, added concerns about the impact of additional blasting on the stability of the dam. He questioned "blasting where underground mines existed in the Eagle coal seam, the possibilities for adversely affecting near surface bedrock in a way that could possibly enhance pathways for slurry to be released via the subsurface and bypass the dam" (Eades, 2000). Dr. Eades was expressing concern over was the possibility of a slurry breakthrough not through the dam itself, like in Buffalo Creek, but through the bottom of the dam, into an underground mine shaft, and out the side of the mountain. This type of slurry breakthrough is called a blowout, as was the cause of the massive slurry spill in Martin County, KY, in 2000.

After the hearing, the WV Department of Environmental Protection approved a 100-foot increase in dam height (the request had been for a $400 \mathrm{ft}$ increase) and Coal River Mountain Watch appealed directly to the Surface Mine Appeal Board. The permitted expansion, called an "Incidental boundary revision (IBR)," allowed for the expansion of the impoundment from 270 acres to 645 acres. In May 2000, when the Surface Mine Appeal Board heard Coal River’s appeal, Dr. Eades challenged the DEP about their monitoring plan for potential breakthrough of the slurry into the underlying Eagle coal seam. Previous underground mining in the Eagle coal seam was found to be directly beneath the impoundment, and in some places less than 200 feet of "interburden," or rock between the impoundment and the mine shafts, existed as a barrier. This area, where mining exists directly under the dam and the pond, is called the "shadow zone." 
The theme safety of slurry impoundments represents concerns that blasting could cause a rupture in the dam itself, or cause a breakthrough from the bottom of the dam into an underground mine shaft that would blow out the side of the mountain. Figure 6.3 below is a participatory map showing levels of concern regarding two different safety hazards posed by the impoundment. The first possibility is a failure through collapse of the impoundment into underground mine shafts and a resulting "blow out," as occurred in the Martin County Spill in 2000. In Figure 6.3, the GPS locations of "punch outs," where a mine shaft comes to the surface, were gathered with participants in Horse Creek and Sycamore Hollow. A failure of the dam itself would result in flooding from the impoundment northwest to Packsville, and then to Whitesville. The emergency evacuation plan written for Brushy Fork states that if the dam fails, in twelve minutes a wave of sludge 72 feet tall would hit the community of Pettus. Whitesville would be hit in 18 minutes by a 50 foot wave, and the slurry would continue all the way to the northern end of the valley, Racine, where it would hit in three hours, 25 feet tall (Marfork Coal Company, 2007).

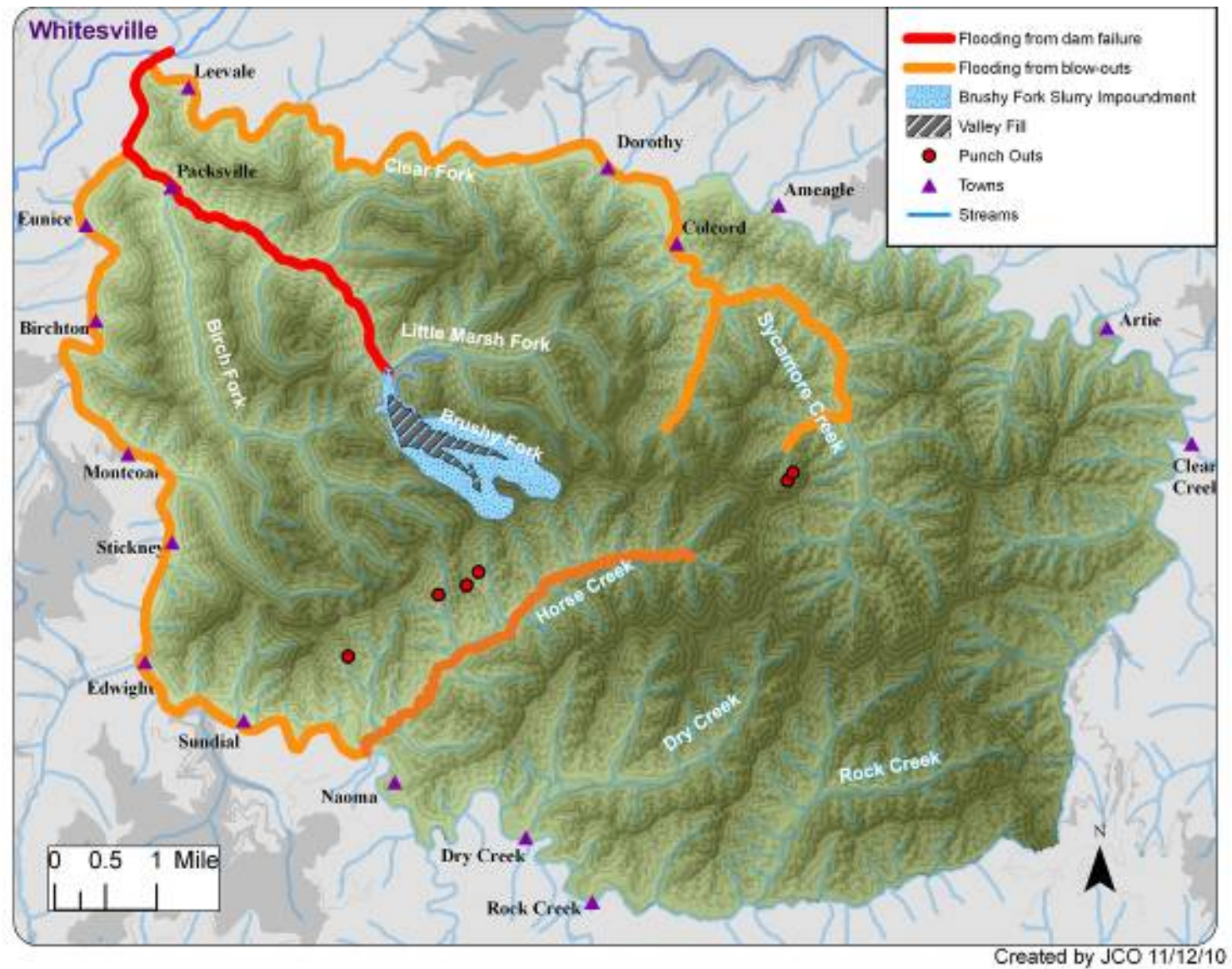

Figure 6.3: Perceived Danger to communities from a failure from the Brushy Fork Slurry Impoundment through dam failure or blow-outs 
The start of mountaintop removal on Coal River Mountain adds additional concerns to the safety of this impoundment. As reviewed in Chapter Five, permit revision for the Bee Tree Surface Mine will allow for blasting to occur within 200 feet of the impoundment, above the "shadow zone." The concerns listed above by Dr Eades, Coal River Mountain Watch, and the Ohio Valley Environmental Coalition as of 2000 have not been addressed as of the writing of this dissertation, and blasting could damage the remaining pillars, deemed weak ten years ago, that support the weight of the impoundment. One union minor and life long resident of Coal River Valley describes it this way: “...do you know what's going to happen if you get a roof cave in on that slurry? It's gonna be like a shotgun and it'll come out” (CR\#8).

Residents in Sycamore describe the danger of Brushy Fork:

Man1: Well, over there, they build that big old impoundment pond over an old mine site. They know right now...we know...that there are forty pillars under that site, in them old mines. When that thing collapses, though, the same way it did [in Kentucky...built it over an old mine site...and when it falls through, when the bottom falls out of that thing and shoots out through all them old sites, its going to blow out all through that mountain. I pray that your kids or your grandkids is not in the ballpark playing ball that day. Because they're all be dead.

Woman2: And that's where we play ball.

Man1: They built that [slurry impoundment] over there!

Woman2: Those kids play ball there!

Man1:...play ball there and on any given day there in the summer there are probably a hundred people there in that ballpark with kids, playing ball...And that's right there were [the slurry] is going to come, right down through the hollow...blow it all out of there (CR\#35,36).

An additional slurry impoundment that is a source of concern is the Shumate Dam, located above the communities of Edwight and Sundial, as well as Marsh Fork elementary school. Although the dam is not within the case study area, the communities on route 3 to the north of Sundial are part of the case study area. The theme safety of slurry impoundments was also linked as a cause for the social concerns destruction of home-place, decreased quality of life for children, loss of community structure, dangers to public health, and the emotional impacts fear, anger, and depression. 


\section{Increased Deforestation}

Oh, they're guttin it! I mean, they're cutting, there ain't no sense in how they're cutting. They'd fired us, we'd been home a long time ago if we'd logged the way they're logging now! They're just cutting it all (CR\#40).

54\% of participants are concerned about increased deforestation as a result of MTR. As reviewed in Chapter Three, Coal River Mountain lies within the central hardwood region (CHR), a forest type comprised predominately of hardwoods as well as conifers such as pine, hemlock, and spruce. The CHR is the "largest and most extensive area of deciduous hardwoods in the world and represents a rich mixture of valuable tree species that is approaching the threshold of economic maturity" (Hicks, 1998, p. 73). This region is one of the most biologically diverse temperate forest regions on earth, with as many as 30 tree species at a single site. Mountaintop removal operations impact forest cover through the destruction of forests in the mining process, filling in the forests in the hollows through the creation of valley fills, and through the disposal of top soil into the valleys instead of for reclamation and reforestation. Bill Maxey, the Director of the WV Division of Forestry from 1993 to 1998, retired due to his concerns about the impacts of MTR. "In other words, our valuable hardwoods forest is lost for the next 150 to 200 years," stated Maxey. “[It’s like] trying to plant a tree in concrete. It doesn't work" (Ward, 1998). To add insult to injury, residents are not allowed to use the cut timber for firewood: “They won't let you touch it. I talked to [a MTR worker] about getting some of it. He said, ‘No ain’t allowed to,' they push it down and burn it” (CR \#30). 

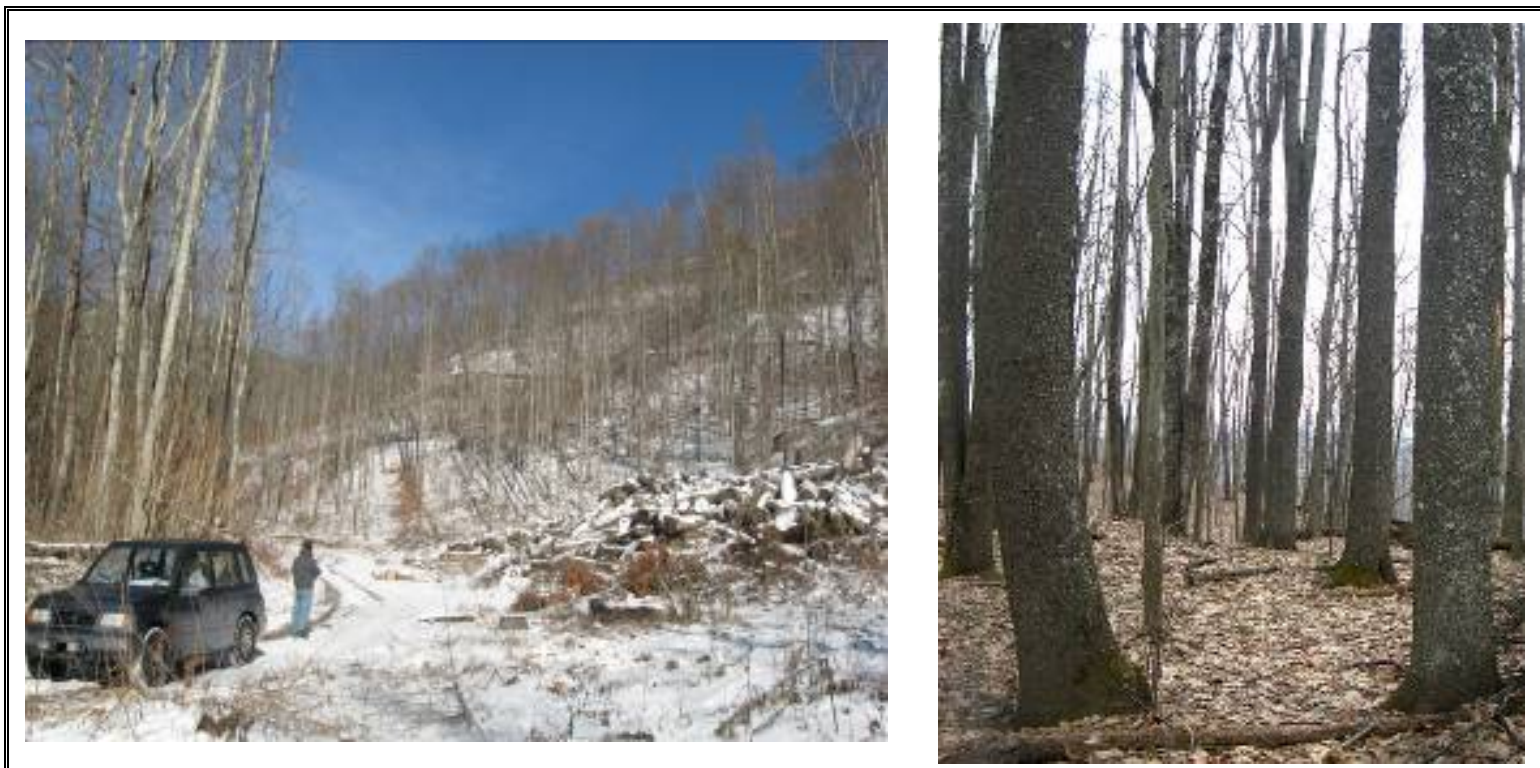

Figure 6.4: To the left, logging area of participant concern at the head of Sturgeon's Fork, Dry Creek. To the right, a mature stand of cherry trees on Pond Knob. J/C/O 2009

Participants also indicate concern about the use of clear cutting as opposed to selection cuts, where trees are harvested with concern for regeneration of a healthy forest. One local resident notes, "back years ago, when they would come in and timber a place, they would cut the big timber and not leave the messes that they're leavin now. In six or eight years, it was back. The smaller timber had a better chance to grow after the big timber was cut. But now they're cutting everything. . . and they just leave it. They don't clean it up. When you see that they're doing the clear cutting, you know what's coming behind that. They just don't care" (CR\#40). "They just don't care” is a reference to loggers and landowners who know that surface mining is about to commence, negating any purpose in leaving a healthy forest behind through selective harvesting methods. Figure 6.4 shows an area of participant concern in Dry Fork, where clear cutting is proceeding rapidly in front of pending mountaintop removal, even on areas that are not to be directly impacted by MTR. To the right is a stand of mature cherry trees on Pond Knob, Coal River Mountain, which has escaped timbering and served as a community camping spot for families for generations (Aurora Lights, 2009). Increased deforestation was also linked as a cause for the social concerns decreased quality of life for children, dangers to public health, loss of access to mountain, dangerous traffic and roads, loss of heritage / culture, and the emotional impacts fear, anger, and depression. 


\section{6.c.ii Perceived Social Impacts}

They are taking a piece of the people away from them when they take away their mountains (CR\#53).

Although the focus of this dissertation focused on the physical changes on the landscape as a result of MTR, participants interpreted the landscape beyond just its physical components. As expressed in the title of this chapter, "So go the mountains, so goes the mountaineer" (CR\#20), the subaltern discourse incorporates numerous social impacts into concerns about how MTR is impacting the landscape. Traditions of community land use and multiple livelihood strategies closely link access and use of the land with family economic survival, cultural heritage, and freedom (Aurora Lights, 2009). The inability of land-based families to access the mountains, whether due to lack of access of the destruction of mountain, can disempower families but cutting off their ability to be independent and sustainable and forcing them to buy food instead of hunting and gardening. As listed in Table 6.4, the concerns held by more than $50 \%$ of participants regarding social impacts from MTR include: loss of community structure, blasting damage, loss of access to mountain, destruction of home-place, decreased quality of life for children, increased coal dust, dangerous traffic and roads, and loss of heritage / culture. Loss of community structure, blasting damage, loss of access to mountain, destruction of home-place, decreased quality of life for children, and loss of heritage / culture will be reviewed in detail here. Additional concerns are located within specific geographical locations on the mountain in the next section.

\section{Loss of Community Structure}

Another impact that I feel that it has - MTR - is the division of families, as well as division of communities. Of course, people have to work. You take what is available. So you have a lot of tension within the community, because you have on one hand someone that is destroying everything that you have ever known in your life, everything that has always kept you safe, or where your roots are at. But on the other hand, how are they going to feed their kids.

(CR\#2) 
This theme represents concern regarding the impacts of MTR on the relationships within the community, even within families, and on the daily bonds that tie Coal River residents together. 92\% of participants indicated concern about the impacts of MTR on these community relationships. A life long resident explains the impacts of MTR by remembering his community before MTR: "So before mountain top removal I would say we had a very friendly community and we all, everyone around here, enjoyed the mountains. We went and got ramps in the springtime and molly moochers and everybody talked with each other and you'd stop and talk to your neighbors” (CR\#42) Many of my interviews, especially with the older generation, consisted of stories about life before the explosion of surface mining (CR\#20, 27, 34-36). CR \#42 continues: "Since mountaintop removal... mountaintop removal has alienated neighbors...because they pit neighbor against neighbor. You know 'My son works at a strip mine... and my cousin and my dad and my uncle' and you know, all that. So if you're opposed to mountaintop removal, which is what you're seeing happen in this community, there's this divide that's created. So people don't talk to each other like they used to.”

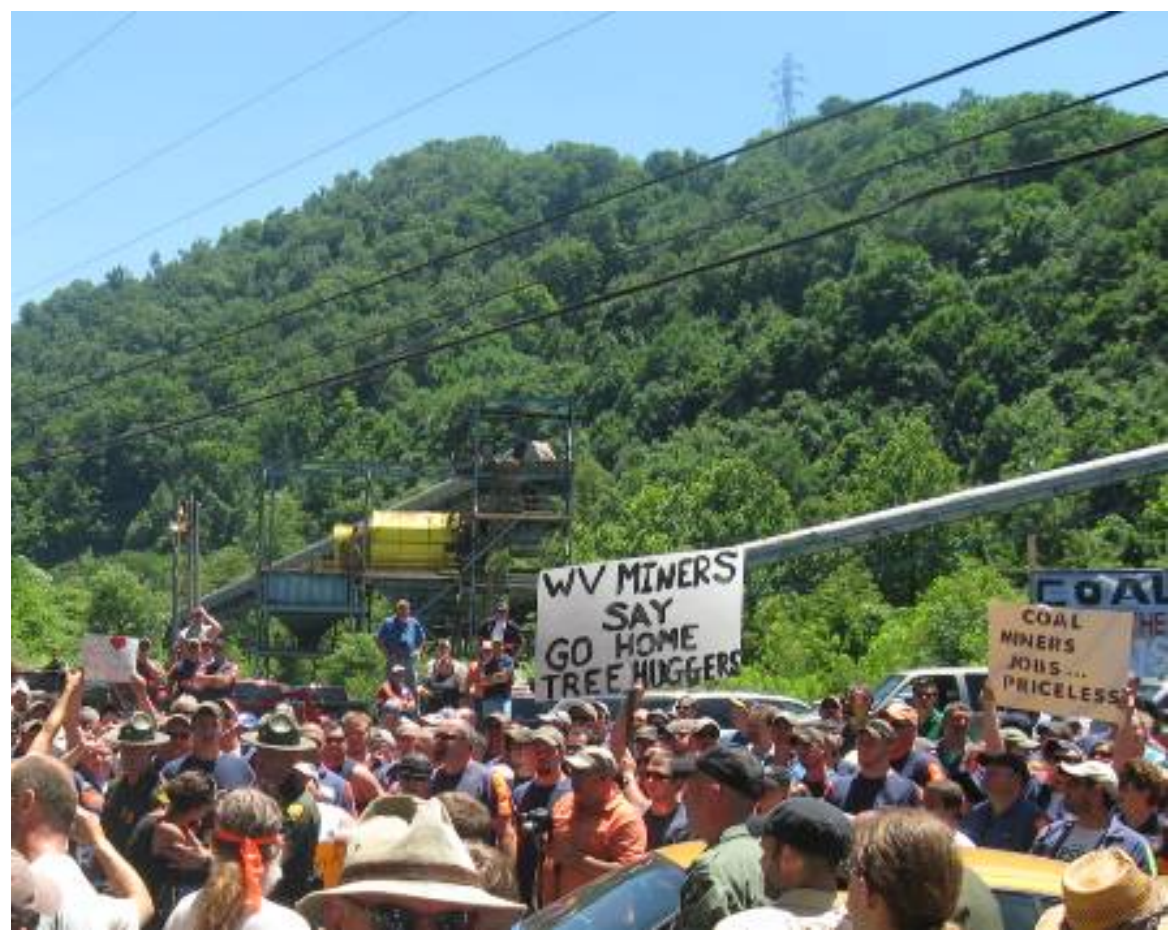

Figure 6.5: Evidence of community tension between pro-MTR miners and residents versus anti-MTR residents, miners and "outside activists.” Note the sign portraying the tension as between local miners and treehuggers who should go "home.” JCO 6/23/2009 
Figure 6.5 above is a photograph taken on June $23^{\text {rd }}, 2009$, at a rally that was held at Marsh Fork elementary to protest mountaintop removal and the dangerous location of the elementary school. The heightened emotions and threats at this rally are presented as an example of CR \#42's articulation of how division over MTR practices have damaged community structure and relationships: "the fight against mountain top removal has severely divided the community" (CR\#46).

Additionally, the divisions apparent at this protest, expressed specifically in the sign saying "WV miners say go home treehuggers," demonstrate how the polarized labels of “miner” versus "treehugger" manifest directly within the community. To the right, men and women representing themselves as "West Virginia miners” and wearing the orange Massey stripes, hold the bridge against protesters termed “outsiders” and "tree huggers.” Despite the label of "WV miners," many of them were not actually local miners (CR \# 10). During the protest, men dressed in orange Massey stripes told speakers protesting mountaintop removal to "go back where they came from" (personal observation, 2009). One speaker responded by saying that he was not an outsider: he could walk home from where he standing. In the lower left, police are arresting local residents and well known “outsider” activists such as James Hansen and Daryl Hannah. At this protest, one local mother and organizer was punched in the face by a wife of a coal miner.

This incident is a dramatic manifestation of these tensions that occur just under the surface in many daily relationships with friends, family, and neighbors. This concern about the impact of mountaintop removal on relationships within the community, combined with the possibility of job loss, was one of the primary reasons given by participants who wanted to remain completely confidential when they spoke with me. Another issue expressed by participants regarding community structure is the "divide and conquer" approach used by the coal industry to approach residents whose property stands in the way of mining. Residents who do not want to sell their property state that they will be "run off" the property (CR\# 13, 14, 28, 29, 42), others are given a fair price to move (CR\#20, CR\#15-16), while others are offered a marginal price, or none at all. These dividing tactics work to undermine the tight knit community structure of families, neighbors, and residents. 


\section{Impacts from Blasting}

All the blastin, it's knocking out people's windows. It knocked mine out. One of my bedroom windows, my girl, she was just getting out of bed and the window went out right beside of her. That was in November...It just shattered the whole damn thing, on the ground, and on her bed. (CR \# 21)

Blasting from the Edwight site could be heard daily at the house where I stayed for my fieldwork at about 4:15 in the afternoon. At one interview with a young family living directly beneath the surface mine, the television was turned up and the children encouraged to dance and clap their hands at 4:10, so that the children wouldn't notice when the house shook (CR\#43). She and her family are concerned that the blasting occurring above their house will dislodge a boulder or cause fly rock to his their house:

CR\#44: ...Living where we live at now, we got a hollow up behind the house, where they had them timber, so with them blasting, going to take the top off now, now you got to worry about, if, the blast.

CR\#45: If it's going to slide.

CR\#44: If it's going to slide....and worry about our dogs in the yard. And if we got the kids out in the yard there, playing, or if we're out in the yard. You know, you just don't know what's going to happen, at any time.

CR\#45: Um, what I'm worried about, is if they going to take the top off, if they're going to get anything a rolling. I'd hate to see it happen.

CR\#44: Cause, you know, they might get a good worker on their dozers or excavators, whatever they use, but they're not a hundred percent guarantee that they're not going to get anything rolling this way.

CR\#45: All's they got do is bump it.

CR\#44: Everybody is human. You know. Everybody does make mistakes and you just don't you know what's going to happen. At any time.

$71 \%$ of participants are concerned about damage to their homes from blasting. Blasting is said to break windows (CR\#21), make glasses and pictures fall and break (CR\#27), cause cracks in house foundations (CR\#25-26), break window seals (CR\#59), and cause additional structural damage (CR 28, 29). Impacts from blasting are linked with participant concern regarding the destruction of their 


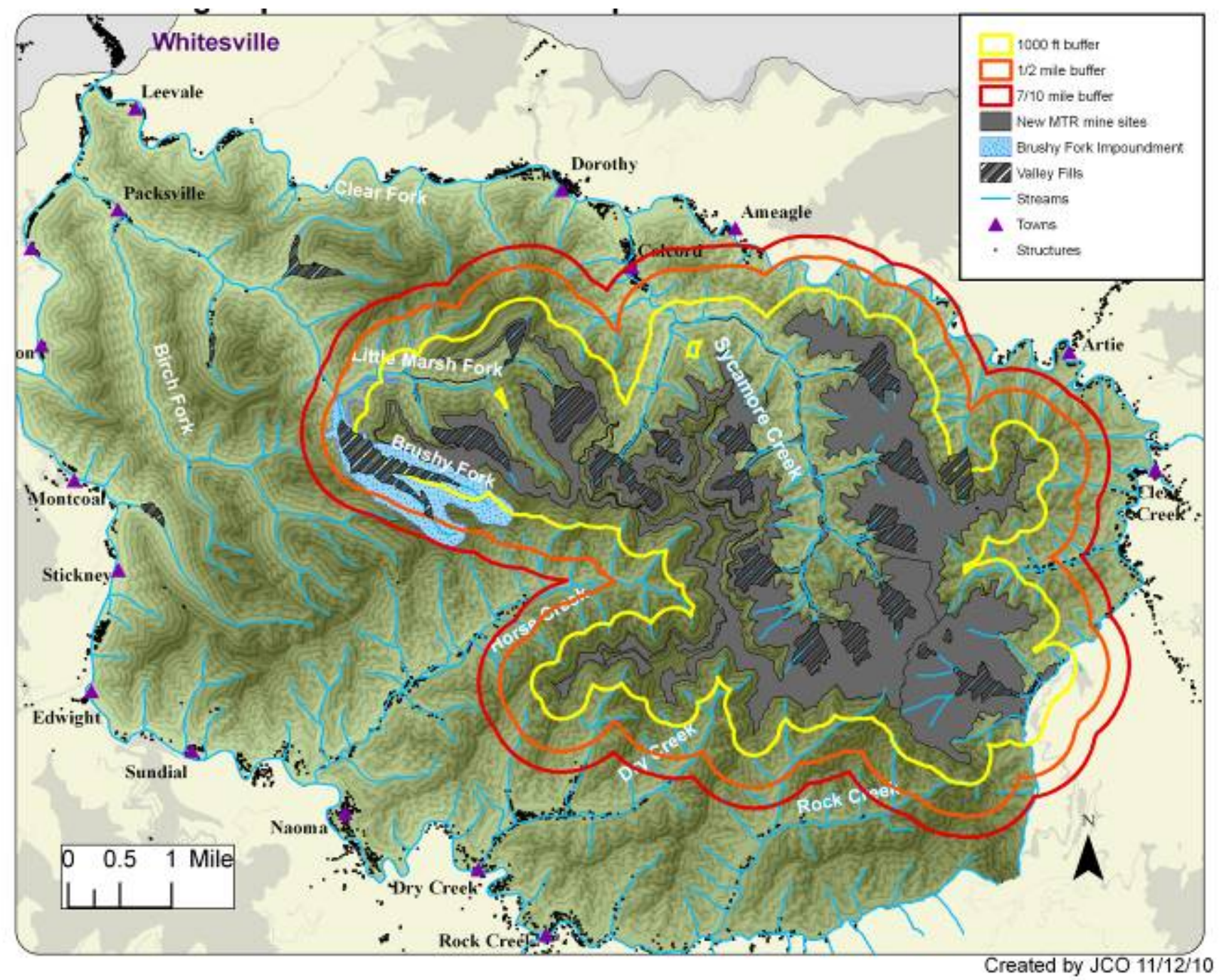

Figure 6.6: Blasting radiuses around current and pending surface mines on Coal River Mountain

home place from mountaintop removal activities. For residents living up the major hollows on Coal River Mountain, the commencement of blasting on the Bee Tree permit represents the first time that their homes have been in close proximity to blasting. The participatory map below represents the three buffer lines required for the blasting plan. According to the WVDEP Office of Explosives and Blasting, blasting may not be conducted within 300 feet of a dwelling unless permission is granted by the owner of the structure. Blasting may not be conducted within 300 feet of a school, church, or hospital and not within 100 feet of a cemetery (WVDEP<2002). Seismographic monitoring, pre blast surveys, and ground water monitoring are required at the $1 / 2$ and $7 / 10$ buffers, depending on the size of the site. Participants wanted figure 6.6 to show the location of homes in relation to the blasting lines as well as the acreage directly impacted by the surface mining practices. As indicated 
below, many of the residents of Sycamore hollow and the town of Colcord fall within the $1 / 2$ mile and 7/10 buffer. Residents at the heads of Horse Creek, Dry Creek, and Rock Creek hollow also will be close to these buffer lines.

\section{Loss of Access to Mountain}

You used to be able to go up any holler and pick black berries or molly moochers or ginseng. Not anymore. It's gated off, it's protected by security guards. So MTR has changed a lot in this area. I don't want to say its put us in jail, but its kept us in one small area where we used to think it was all the community's, and its not anymore. (CR\#2)

Loss of access to mountain represents the concern of $71 \%$ of participants regarding loss of access to the commons on Coal River Mountain: "my grandparents lived in this hollow for over two hundred years... and it's a shame that we can’t even drive up the road here now” (CR\#35). This theme includes concern over the loss of non-timber forest products (NTFPs) such as morels, ginseng, ramps, and medicinals such as blue and black cohosh, which will be discussed further in the theme Loss of heritage / culture below. Loss of access was a concern that was shared by both residents who used the land for multiple livelihood strategies (CR\# 8, 9, 10, 13, 14, 20, 34-37), as well as hunters, campers, and ATV riders who see the mountain as a source of family fun (CR\#20, 34-37) and freedom (CR \#4, 14, 54). The practice of putting up gates brings out confrontation between miners and local hunters and mountain men, who otherwise might not speak out against MTR (CR 10) with the result that gates are often ripped out and put up again, multiple times.

\section{Destruction of Home-place}

...he just bought that land up there and the house, put a lot of money in it and he's concerned about losing his home" (CR\#30).

Destruction of home-place refers to a participants concern that their Home-place, which refers to their house as well as their property, will be destroyed by MTR. A family cemetery can also be included in the idea of home-place. Participant concerns were grouped under this way if their concern was primarily the destruction of their home and land but without a primary cause of destruction. For example, concern could include destruction from flooding, blasting, being forced to 
move out, or the inability to stay due to severe water or air contamination. Like total destruction, this theme refers to a fear that MTR will do more than just impact their home and family: it will destroy their home-place. However, unlike total destruction, this theme refers to a participants concern that their own property will be destroyed, not the entire valley. Again, the memory of the fate of the residents of Shumate hollow plays a prominent role in these concerns:

Male2: And they all had to leave their home place... and cause of the coal mines.

Male2: Bought out all Shumate's Branch and, ah, in the process, they moved the whole cemetery. Reburied them.

Jen: So the community you grew up in isn't even there anymore?

Male1: Right, it’s gone.

Jen: Yeah?

Male1: Yeah, it's history.

Male2: Whenever dad was growing up, Ed White used to be a big booming town. Now, there's nothing down there.

Male1: Yeah, it's gone.

Male2: Theater and pool hall and country store (CR \#44, 45).

In the dialogue above, the grandfather had to move from Shumate, and his entire home place and community were destroyed. Now his son and family are the closest home to an active mine site, and are experiencing heavy water and blasting damage.

\section{Decreased Quality of Life for Children}

Who wants to have a school with young kids in it, young kids right close to a big [slurry] pond and a coal mine right behind them, with a big silo right standing...it looks like its right on top of the school. (CR \#46)

That's the biggest concern of mine, that my children and grandchildren will eventually have to leave... what would have been home, due to progress supposedly. (CR \#18)

The loss of access to Coal River Mountain is strongly tied to the belief that mountaintop removal results in a decreased quality of life for children: "they're not allowed to go up in these mountains because of the mountains no longer there or because there's a gate up...so these kids are losing their culture of who they are, they've disconnected from their elders. These kids will never know the value of these mountains (CR\#20). 59\% of participants indicated concern that MTR has resulted in decreased quality of life for children. A profound sense of loss was shared with me when parents 
and grandparents spoke of the mountain life that they won't be able to share with their children: "So, I'll never be able to take my kids and say, hey, this is where I found my first arrowhead, or shot my first Turkey... and that's what generations of people here have been able to do" (CR\#53).

Parents expressed concern about the safety of their children, or children in the community, at Marsh Fork elementary due to the close proximity of a preparation plant, a slurry impoundment, and an active surface mining site (CR\# 1, 2, 4, 12, 15, 23, 31, 32, 42, 46). Additional perceived dangers to children include from dangerous traffic and road conditions (CR \#8-10, 34-37), and from the loss of water quality, damage from blasting, and black water spills (all reviewed previously).

\section{"Loss of Heritage / Culture”}

These kids can't go up in the mountains anymore the way we did when we were kids. They can't go up in the hollers, they can't go up in the springs, they can't fish the way we did. Its like the last child out of the woods these kids are losing who they are. They have no idea of who they are. (CR\#20)

The way I look at it is they've come in here, in our back door and expect us to adapt to what they're doing. How would they feel if we went in their back door and wanted to move their cemeteries and tear their heritage up? (CR \#23)

Loss of heritage / culture is in many ways an umbrella concern shared by $51 \%$ of participants containing issues such as declining quality of life for children, loss of access to the mountain, and impact on community structure. The connection to the land in Coal River Valley and multiple livelihood strategies are based on the collected heritage of the early settlers who farmed and gathered the surrounding landscape, and these traditions remain important parts of the Coal River communities. These traditions can not only provide supplements for family income and food, but they also maintain the cultural connection to the streams, hollows and mountains. The impacts of mountaintop removal coal mining, however, destroy the source of this mountain culture and heritage: the mountains themselves:

You know, when I was a young boy we could do about anything in these mountains that we wanted to do. We ate out of the mountains. I'm from a big family. And we ate wild game that we dug out of a hole or were lucky enough to kill with a shotgun. We could go anywhere in these mountains and get what w had to have to survive on. When I was about six years old my dad taught me to Ginseng... and there were so many in my family that we had to dig ginseng. My dad worked in the 
mine loading coal. If he came out of the mine... and had time...he'd go in the mountains to kill game or try to dig enough 'seng. And then we had liberty to go on any of these mountains we wanted to and hunt, do what we wanted to do on the rivers. Now you'd ...go with a fun to shoot something and these, these guards want to arrest you for being in the mountains, trying to make a living. Where, that's all we've done all our life. CR\#33)

Additionally, some residents of Coal River Valley worry that the destruction of their cultural mountain commons could destroy vital lessons necessary for the entire nation: "people in the city need to learn how to survive like people in the mountains and other parts of the country. They need to learn from older people, to teach them how to can, how to garden, how to sew” (CR\#4).

One geographical area in the case study area serves as an example for the connections between land and culture that residents feel are being threatened. Pond Knob is a mountain summit in Raleigh County that reaches 3,317 feet above sea level. It is named after a natural pond that sits near the top of the mountain. Pond Knob, near Rock Creek and Dry Creek, was a popular destination for camping, four-wheeling and community meeting places because of its natural beauty (CR\# 6, 8, 10). "Used to be a big thing, everyone would go up to Pond Knob and get together the first week of April. Main reason was to hunt for Indian artifacts and ramps," says a life long resident of Horse Creek (CR\#10). By 'everyone,' he meant his family and at least three other families that came up the mountain with their fathers, and now brought their own children.

Pond Knob also has a deep historical and cultural significance for Coal River Valley. A Native American hunting trail passed through Indian Gap on Pond Knob, and the remains of these hunting parties can be found in arrowheads and burial mounds on the mountain. The potential destruction of Pond Knob by surface mining on Coal River mountain is linked to destruction of local history: “they're taking our history away. People buried back there... there's a lot of Indians buried back there cause I've seen the mounds...That's not right." [6] Pond Knob was also the site of a plane crash on September 7, 1958, in which four people died. Local writer Rick Bradford stated that "One of A.T. Massey's gigantic mountaintop strip mines is headed that way right now and another piece of our history will be lost” (Bradford, 2008).

As expressed in the title of this chapter, "So go the mountains, so goes the mountaineer" (CR\#20), the subaltern discourse overwhelming views the landscape as a mountain landscape filled with 
communities and families, not just forest and mineral resources. Participants in Coal River clearly see their homeland as much more than just an economic or environmental landscape. While residents do share many environmental and economic concerns, their interpretation of changes in their landscape include the many associated social concerns reviewed in the previous section. I argue that the first discursive formation that sets the subaltern discourse apart from the dominant discourse is the inclusion of families and communities that are damaged by MTR. Viewed from this perspective, local resistance to MTR is not about saving the mayflies, but clearly about the safety and well being of their communities that are closely tied to their land.

To give voice to the discursive formation of the landscape as a physical and human geography, I grouped participant concerns into two categories: impacts on the physical landscape, and the resulting social impacts on individuals, families, and communities. Another key discursive formation was that outside of the concerns that were grouped into environment or social, a discursive formation of MTR as total destruction of all associated social and environmental values was revealed. Some residents spoke of the Coal River as a whole much greater than the sum of all its parts. This difficulty in dissecting their connection to the land into measurable injuries can be seen in the list of descriptions of the impact of MTR on landscape change and use in Table 6.5.

As overviewed in Table 6.4, the environmental concerns shared by more than $50 \%$ of all participants include: increased flooding (90\%), loss of water quality (69\%), slurry impoundment failure (68\%), and deforestation (54\%). Concern over increased flooding was illustrated in a participatory map rating level of concern as moderate, high, and severe, due to the fact that there was no area with a low concern. Coal River Mountain serves as the last relatively intact and forested mountain in the watershed to buffer communities from flooding. The case study area was hit hard by the 2001 and 2001 floods, and many participants are very concerned that MTR on Coal River Mountain will cause additional flooding. Loss of water quality included concern regarding black water spills, water contamination, and stream structure, with some residents losing their ability to drink their own water, fish in the stream, or allow their children to play in the streams. Safety of slurry impoundments referred to participants concerned about the safety of the two impoundments in the case study area: the Brushy Fork Slurry Impoundment, and the Shumate Impoundment behind Marsh Fork elementary school. Commencement of blasting on the Bee Tree permit, adjacent to the 
Brushy Fork impoundment, has greatly heighted tension regarding public safety. Finally, increased deforestation includes impacts from the destruction of forests in the mining process, filling in the forests in the hollows through the creation of valley fills, and through the disposal of top soil into the valleys instead of for reclamation and reforestation.

Associated social concerns shared by more than $50 \%$ of participants included loss of community structure (92\%), blasting damage (71\%), loss of access to the mountain (71\%), destruction of homeplace (69\%), decreased quality of life for children (59\%), increased coat dust (54\%), dangerous traffic and roads (53\%), and loss of heritage / culture (51\%). This section illustrated the overall participant concerns regarding the impacts on landscape and perceived social impacts from mountaintop removal in the case study area. My experience listening to the interviews as well as informal conversations leads me to believe that the list of themes and percentages is best used as a guide for understanding the stand-out issues that each participant specifically articulated as opposed to an all-inclusive and quantifiable list. If I had included the concerns voiced by participants outside of the formal interview as well as concerns that were indirectly voiced, then the percentages would have been higher. The next section proceeds to look at concern by geographical location. 


\section{6. d. Participant Concern by Geographical Location}

\section{6. d. i Residents in Sycamore Hollow and along Clear Fork Road}

Life's going to be tough for folks in Dorothy, Sycamore and Colcord, up that way. It's going to be really tough, because they've got the flooding coming already from Kayford Mountain. They got blasting dust coming from Kayford Mountain and they're going to get it from Coal River Mountain. As a matter of fact most of the valley fills on the permit for Coal River Mountain proposal are on the Clear Fork side...so they're in danger of more flooding. (CR\#42)

Residents in this geographical grouping live to the north of Coal River Mountain (See Figure 6.8 below) and up Sycamore hollow, including the town of Colcord. Residents in this area are already impacted from surface mining and valley fills on Kayford mountain, just to the north of Coal River Mountain. Figure 6.7 was taken on Kayford mountain, looking south to Coal River mountain, which can be seen intact in the background to the left. Coal and silica dust from the blasting and heavy machinery is evident as well in this picture. The dynamite charges, which look like white circles on the left on the picture, are set directly above some of the communities in this geographical grouping.

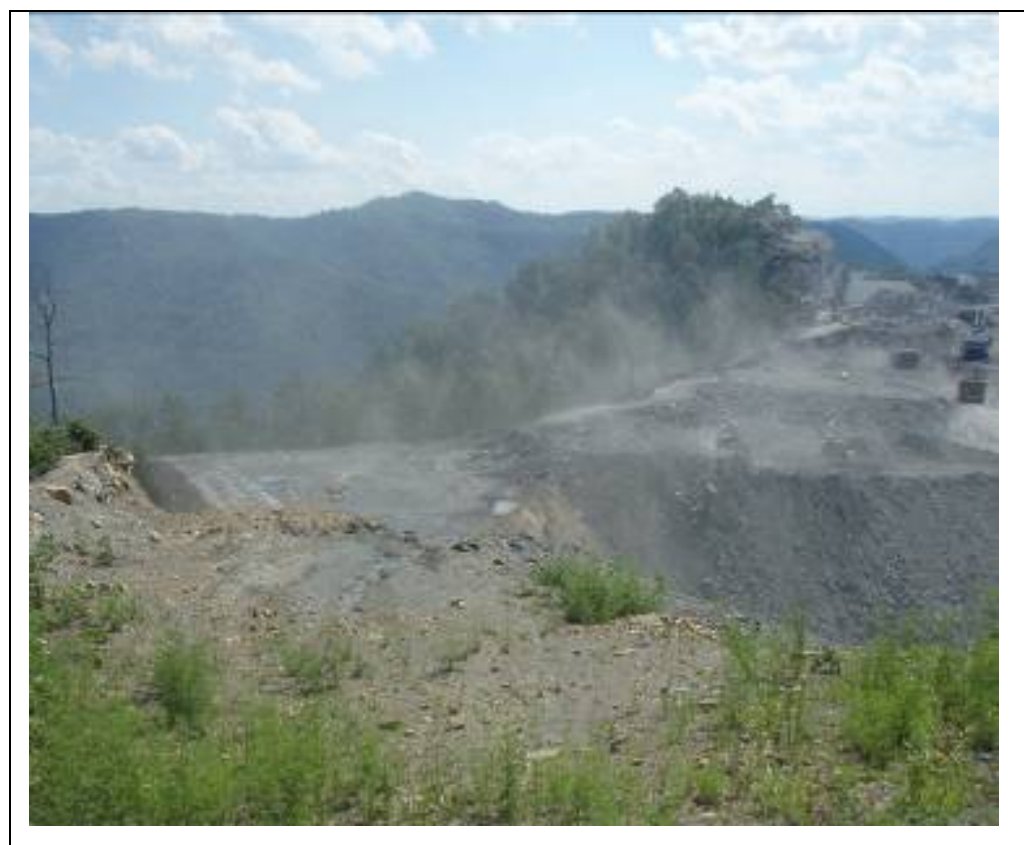

Figure 6.7: Photos at “Hell’s Gate”on Kayford Mountain.

As shown in Figure 6.1, , downstream communities in this area stand to be highly impacted from the 13 valley fills that were indicated on the permit maps in addition to the mining already happening on Kayford Mountain. One resident in Sycamore hollow puts it this way: we got hollows on the both sides here of us plus the main hollow doming in on us... [we're] going to get washed out. It's going to come” (CR \# 33). Currently, Sycamore creek is one of the cleanest creeks in the area (CR\#5) and the hollow is a source of 


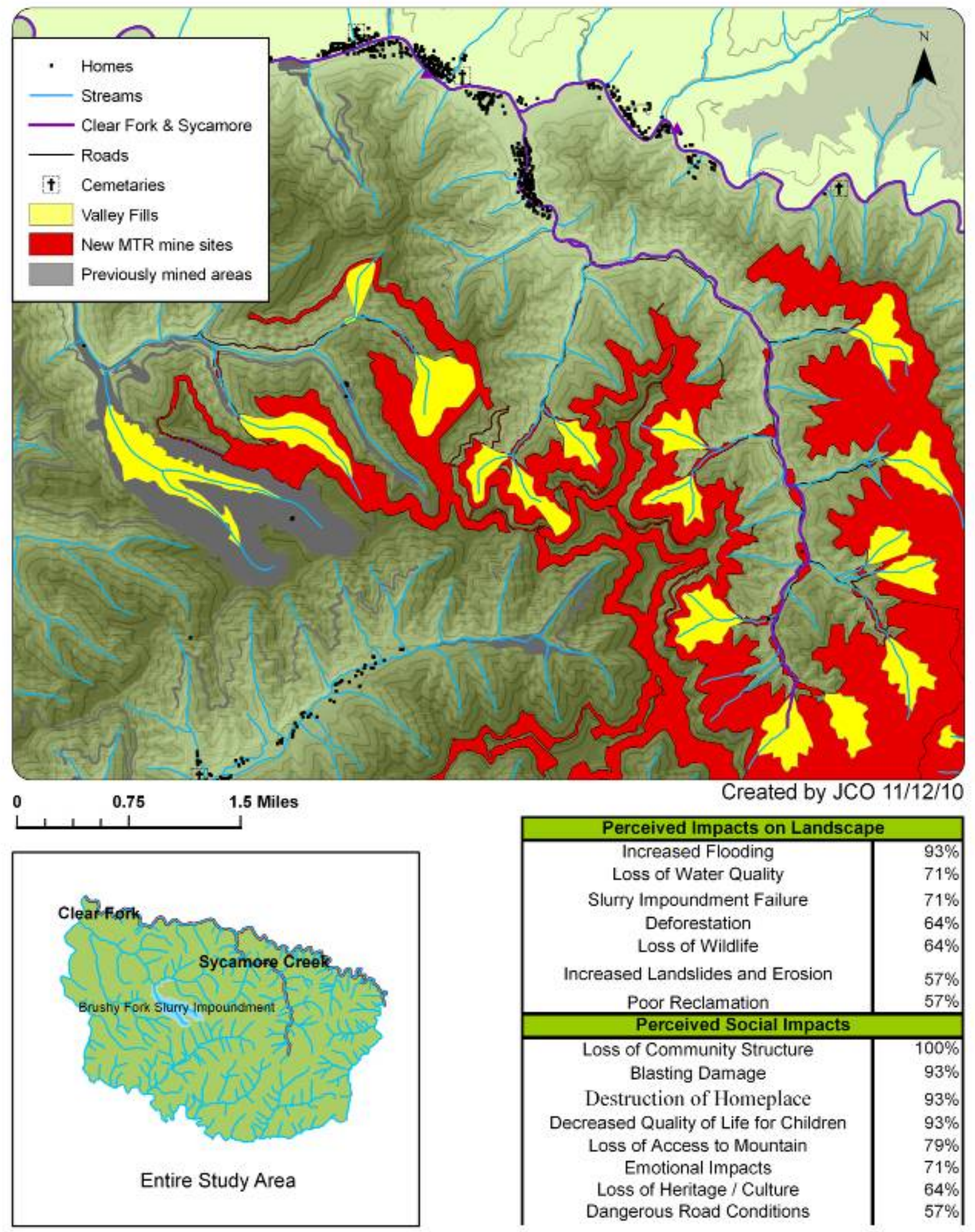

Figure 6.8: Concerns of Residents in Sycamore Hollow Regarding Impacts of MTR 
(CR \#33l, 34-37). Loss of water quality, deforestation, and increased landslides and erosion in Sycamore hollow are the highest concerns after flooding. The danger from a blow out from the Brushy Fork Slurry Impoundment (See Figure 6.2) is considerable enough that some locals travel to punch out sites on their four wheelers to monitor water levels (CR\# 33).

The story of the Thompson family, recorded by Vera Thompson, was referenced in the case study chapter as an example of a multigenerational family that still lives in the case study area. Although the original Thompson homestead is now the site of power lines, descendants still live in Sycamore hollow and spend time on the mountain ginsenging, hunting, camping, and swimming (CR\# 34-37). If work begins on the Eagle II permit, and the Leather Leaf permit is granted, participants are overwhelmingly concerned that their neighbors and friends will move, and that their homes might be destroyed by blasting or flooding (See Figure 6.8). In this hollow, concern about the loss of heritage / culture is manifested by the actual destruction of the old homestead as well as a community area used by many locals. Timbering up the hollow has already resulted in dangerous road conditions (CR:36,37) to the point that one young mother and her niece sat in the road to get the trucks to slow down. If surface mining commences, the small road of Sycamore will have to support heavy machinery, trucks, as well as the traffic of miners at shift change.

\section{6. d. ii Residents in Horse Creek}

My concern....not having my home that I grew up in, that I plan on livin in. Not being able to drive up this holler in ten to fifteen years and show my kids, this is where I grew up. It won't be here. It'll be gone. You probably won't even be able to drive up the holler. This is where I live, this is my home, and there's no place like it. (CR\#19)

Horse Creek is a hollow located on the western side of Coal River Mountain. 93\% of participants in this hollow have noticed substantial changes in either the stream structure or the contamination of Horse Creek, once very clean and full of holes for swimming and fishing. Residents have experienced flooding that they believe to be from timbering operations at the head of the hollow that left the tops of the trees and brush in the creek (CR \#8), and 83\% are concerned about how strip mining the head of the hollow will increase water levels. Although there are no valley fills slated to drain into Horse Creek, flooding from run off as well as from a possible blow out from the Brushy Fork impoundment (58\%) are sources of concern. 50\% of participants in Horse Creek are concerned 
about the loss of the mountains not just for the loss of resources, but for the loss of the beauty and peacefulness that the mountains provide for their family.

Horse Creek is a tight-knit community in which $100 \%$ of participants feel that MTR has damaged their community structure. Horse Creek contains several four wheel and hiking trails leading up Coal River Mountain that were open to community access, and 83\% of participants are concerned that MTR will impede their use of the mountain for recreational purposes as well as multi-livelihood needs like hunting, ginseng, and forest resources. More than $50 \%$ of participants in Horse Creek are also concerned about destruction of home-place, decreased quality of life for children, and loss of heritage / culture.

Horse Creek is the only hollow in which concern over dangerous road conditions was more than $50 \%$. Participants have already noticed changes in their community from miners driving up the hollow to and from work, as indicated by the $83 \%$ participant concern about dangerous roads. Twice a day, at shift change, it is dangerous to drive up Horse Creek. Many of the interviews collected in Horse Creek (CR \#8,9) were a result of parents' concern regarding the safety of their children on the bus, or sadness that their children can no longer ride their bikes or play in the street (CR \#18): people don't let their kids out on these roads no more...it's not that you can't, but its either put them out on the road and let them get run over, or put them in the yard to play" (CR\#19). It is a common to hear a resident suggest that guests stay and visit until after shift change. Indeed, I learned quickly to schedule my visits to Horse Creek around shift change after being forced off the road, even in my large truck, by a caravan of more than 10 miners. 

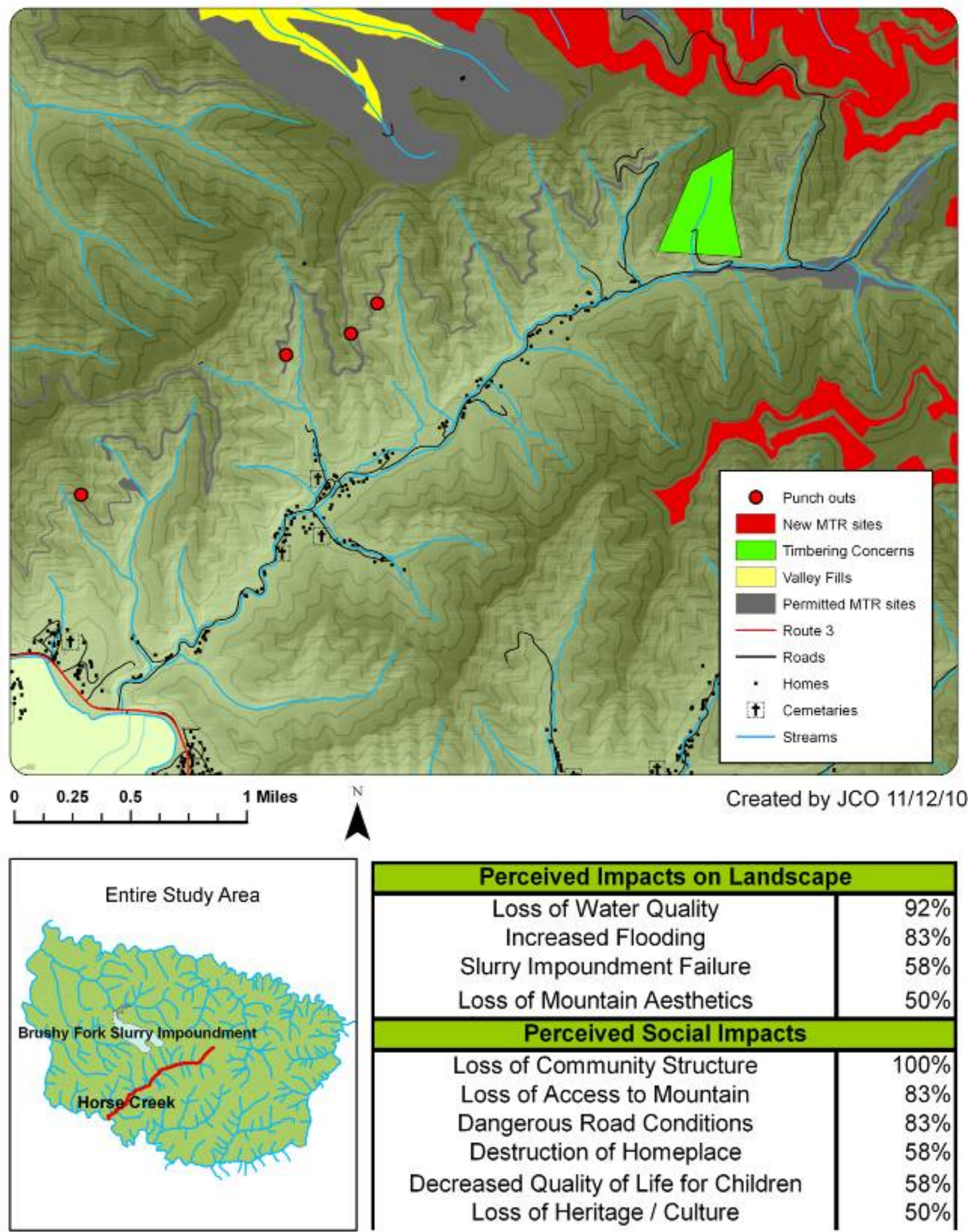

\begin{tabular}{|c|r|}
\hline \multicolumn{2}{|c|}{ Perceived Impacts on Landscape } \\
\hline \multicolumn{2}{|c|}{ Loss of Water Quality } \\
Increased Flooding & $92 \%$ \\
Slurry Impoundment Failure & $53 \%$ \\
Loss of Mountain Aesthetics & $50 \%$ \\
\hline \multicolumn{2}{|c|}{ Perceived Social Impacts } \\
\hline Loss of Community Structure & $100 \%$ \\
Loss of Access to Mountain & $83 \%$ \\
Dangerous Road Conditions & $83 \%$ \\
Destruction of Homeplace & $58 \%$ \\
Decreased Quality of Life for Children & $58 \%$ \\
Loss of Heritage / Culture & $50 \%$
\end{tabular}

Figure 6.9: Concerns of Residents in Horse Creek Regarding Impacts of MTR 


\section{6. d. iv Residents in Rock Creek}

Well, the place that I live is a very comfortable, serene, peaceful place... There's the family cemetery there. There's a fresh water stream that runs by my house. There's abundant wild life. I can shoot a deer standing in my bathroom if I choose... There are fruit trees in the back yard that my husband and I planted together; apple and plum and pear. It is a place that could sustain life a lot longer than places where people are dependent on the infrastructure. My home, the cemetery, the fresh water that runs by my house, all of the wildlife, all of the forest, the air quality, the water quality everything has potential to be destroyed, based on what I know and what I have seen, if they do mountain top removal in close proximity to my house (CR\#46).

Rock Creek is located on the south side of Coal River mountain (See Figure 6.10). Unlike other hollows, the highest concern regarding impacts on landscape is the loss on wildlife: "there'll be nothing left on top of the mountains. There'll be no wildlife here. Why would wildlife stay where there's no trees?” (CR\#20). The other top landscape concerns are similar to the other hollows, including heightened concerns about flooding, loss of water quality, danger from slurry impoundments, and increased deforestation. One life long resident of Rock Creek reported that his bridge had been washed out six times in the last nine years (CR \#47). One of those occasions was on April 1, 1993, when water from an abandoned coal mine blew out a hole in the mountain 30 feet across and six feet wide. No one was seriously injured, but 75 families were evacuated and two families lost their homes (Aurora Lights, 2009). Regarding perceived social impacts, 56\% of participants are concerned about how the blasting will impact their community: "It's really, really scary when I hear the blasting even though I know that the blasting is far away from me [on the Edwight site]. If they're doing it within a mile of my house, behind my house, I can't imagine the terror that I would be living through, what other people of course are living through right now"(CR\#46). Another resident states that he wishes that the blasting would stop because "there are people here...they build a new home, they get new windows in their home and...they don't last because of the blasting that happens here all the time” (CR\# 59). Additional social concerns include loss of community structure, loss of access to mountain, increased coal dust, and decreased quality of life for children. 

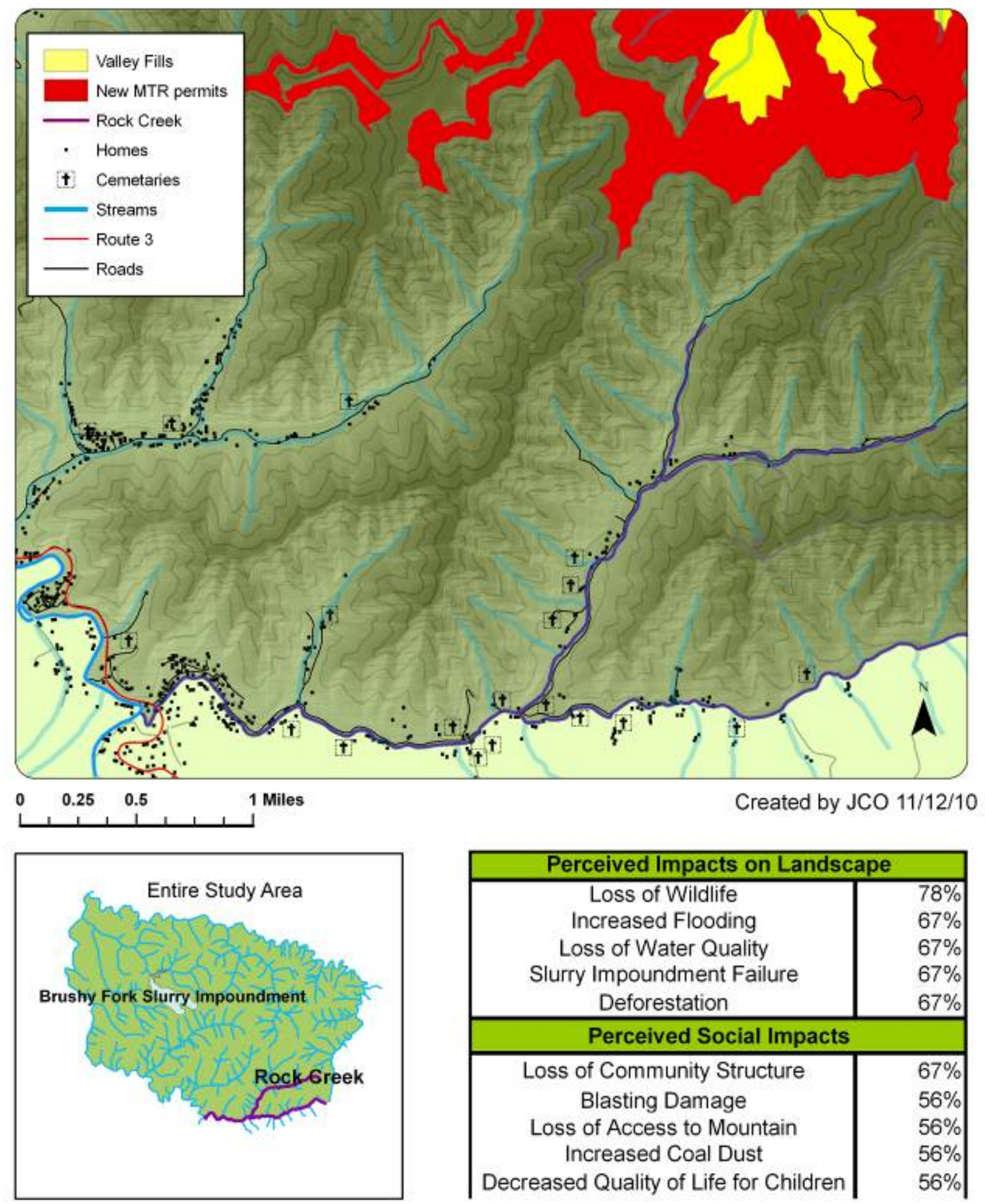

\begin{tabular}{|c|c|}
\hline \multicolumn{2}{|c|}{ Perceived Impacts on Landscape } \\
\hline $\begin{array}{c}\text { Loss of Wildlife } \\
\text { Increased Flooding } \\
\text { Loss of Water Quality } \\
\text { Slurry Impoundment Failure } \\
\text { Deforestation }\end{array}$ & $\begin{array}{l}78 \% \\
67 \% \\
67 \% \\
67 \% \\
67 \% \\
\end{array}$ \\
\hline \multicolumn{2}{|l|}{ Perceived Social Impacts } \\
\hline $\begin{array}{c}\text { Loss of Community Structure } \\
\text { Blasting Damage } \\
\text { Loss of Access to Mountain } \\
\text { Increased Coal Dust } \\
\text { Decreased Quality of Life for Children }\end{array}$ & $\begin{array}{l}67 \% \\
56 \% \\
56 \% \\
56 \% \\
56 \%\end{array}$ \\
\hline
\end{tabular}

Figure 6.10: Concerns of Residents in Rock Creek Regarding Impacts of MTR 


\section{6. e. Intersections of Gender, Age, and Livelihood}

So far, this review has looked at the 'unities' of concern held by the participants in this study, and then investigated more specific impacts within the hollows on Coal River Mountain. This section focuses on interpreting the discursive formations found within data from interviews and participatory mapping to bring forward different formations within the subaltern discourse. In my own words, “reconstructing” social identity refers to an individual's comprehension of him/herself as a separate entity that is simultaneously similar and different from culturally constructed others within the case study area. Regarding this “reconstruction” of identity in Appalachia, specific pictures emerge around gender (Latimer and Oberhauser, 2004; Oberhauser, 1995; Tickamyer and Tickamyer, 1991), ethnicity (Lewis, 1987; Trotter, 1990; Fones-Wolf and Lewis, 2002; Hayden, 2004), and social identity (Scott, 1995). Informed by Foucault’s questioning of the "unity of authorship and discourse,” my analysis focuses on differing subaltern discourses at intersections between gender, age, and livelihood.

When broken down by gender, participant concerns regarding impacts on the landscape are very similar (see Table 6.6 below). Men showed a higher concern for the loss of mountain aesthetics, and women showed more concern about the loss of wildlife. However, these two concerns overlap and do not present any tangible gendered differences in perspectives regarding impacts on the landscape from MTR. While men and women do seem to agree about the highest landscape concerns, their perspectives differ when we move on to the associated social impacts. For example, in Table 6.6, note the difference between men (51\%) and women (75\%) regarding the decreased quality of life for children. As $50 \%$ of the female participants are stay at home mothers (See Table 6.2), this greater concern makes sense. Additionally, loss of heritage / culture was held by $60 \%$ of women, but less than $50 \%$ of the men. As one grandmother put it, what's wrong with the kids in Coal River is that "they have a huge disconnect...they need that connection back with their parents and with the creator and with creation (CR \#20). She continues to draw the connection between loss of heritage and a decrease in quality of life for children: "they're missing those days that they spent time in the garden with their mom and their dad, or in the river swimming with sister or brother or cousin, or up in the mountains digging for ginseng or just walking around hiking or hunting...our kids have no 
idea who they are or what they are supposed to do other than drive a car... or go to the mall and buy things” (CR \#20).

Another gendered difference can be seen regarding loss of access to the mountain. Multi-livelihood strategies that rely on hunting to supplement family incomes are endangered when families are denied access to forested areas. As discussed previously, loss of access is a concern held by many hunters and recreational users of the mountain, both of which are traditionally - but not always male activities.

\begin{tabular}{|c|c|c|c|}
\hline \multicolumn{2}{|l|}{ Male } & \multicolumn{2}{|l|}{ Female } \\
\hline \multicolumn{4}{|c|}{ Perceived Impacts on Landscape } \\
\hline Increased Flooding & $92 \%$ & Increased Flooding & $90 \%$ \\
\hline Loss of Water Quality & $74 \%$ & Slurry Impoundment Failure & $65 \%$ \\
\hline Slurry Impoundment Failure & $69 \%$ & Loss of Water Quality & $60 \%$ \\
\hline Deforestation & $56 \%$ & Loss of Wildlife & $55 \%$ \\
\hline Loss of Mountain Aesthetics & $51 \%$ & Deforestation & $50 \%$ \\
\hline \multicolumn{4}{|c|}{ Perceived Social Impacts } \\
\hline Loss of Community & $92 \%$ & Loss of Community & $90 \%$ \\
\hline Loss of Access to Mountain & $77 \%$ & Decreased Quality of Life for Children & $75 \%$ \\
\hline Blasting Damage & $74 \%$ & Blasting Damage & $70 \%$ \\
\hline Destruction of Homeplace & $69 \%$ & Destruction of Homeplace & $70 \%$ \\
\hline Increased Coal Dust & $56 \%$ & Loss of Access to Mountain & $60 \%$ \\
\hline Dangerous Traffic and Roads & $54 \%$ & Loss of Heritage / Culture & $60 \%$ \\
\hline Decreased Quality of Life for Children & $51 \%$ & Increased Coal Dust & $50 \%$ \\
\hline & & Dangerous Traffic and Roads & $50 \%$ \\
\hline
\end{tabular}

Table 6.6: Gendered Perspectives on Impacts on Landscape and Perceived Social Impacts

The impact of age within the subaltern discourse will be examined next. As discussed in the overview of participants in this chapter, only $12 \%$ of my participants are under the age of forty. Within this age group, every participant requested a confidential interview. The rest of the confidential interviews are evenly spread throughout the other age groups. Another commonality is that every participant under the age of 40 also has a family history of mining. The type of employment is varied, as is the length of residency. $100 \%$ of participants under the age of 40, however, shared unanimous concern about increased flooding, loss of community structure, increased deforestation, and decreased quality of life for children. Participants under 40 are the only age group that shared a 100\% concern about decreased quality of life for children. 
In the group of participants within the ages of 40-59, concerns about blasting impacts on homes, destruction of the home place, and loss of heritage / culture were more elevated than within the under 40 age group. These concerns make sense with the increased likelihood that participants in this age group own their homes and are concerned about maintaining their investment (CR\#2, 23, 36, 46, 58). Interestingly, within the 40-59 age group, a belief that mountaintop removal was hurting the quality of life for children was held by $50 \%$ of participants, as opposed to $100 \%$ in the younger age group. There is a close split of employment types within this age group: 14 have never worked for the coal industry while 10 have worked for the coal industry. Four of the ten are currently either surface or underground miners. An overwhelming $90 \%$ of the miners in this age group are union miners.

The 60+ age group is the only discursive formation thus far showing loss of community structure as the highest concern. This concern is understandable, as the older residents can remember the valley before MTR started and, as discussed in the review of this theme, often miss the tight-knit relationships between family and community that existed before. Increased flooding, loss of access to the mountain, slurry impoundment failure, and destruction of home place were the other top concerns. Concern about dangerous traffic and roads were significantly higher for participants over the age of 60 than in the other groups. As reviewed in Chapter Two, many older miners continue to be strong union supporters. The combined impact of a weakened UMWA, an increase in mechanization and expendability of the workforce, and an overall drop in coal employment has resulted in vastly different job choices for the current generation of workers. Massey Energy, the fourth largest coal producer in the nation, reported in 2003 that only 193 of its 4,428 employees were UMWA members (Burns, 2007, p. 27.) Tension can exist between younger miners, forced to choose between working out of state or working for a non union mine, and their strongly union parents. Within this context, the desire of the younger participants to keep their interviews confidential is understandable.

Discursive formations within the discourse of resistance can be heavily influenced by the livelihood of the family. My choice to investigate formations around livelihood reflects the importance of informal employment such as stay at home mothers or land based families who rely on multi- 
livelihood strategies to supplement family incomes with seasonal wild crafting and hunting. In her online work "Tending the Commons," Hufford (1999) uses interviews and photographs to document the ability of some families to offset economic hardship through a close seasonal relationship with the mountains. A family that survives job loss due to their knowledge and proximity to forested land could have very different concerns from a miner currently employed by a strip mining company.

Interestingly, 52\% of the participants who have worked or currently worked for the coal industry cite the loss of jobs as a social impact of mountaintop removal: the percentage is even higher from the point of currently employed miners (67\%). One currently employed miner described it this way: "I've got nothing against coal mining if they do it right. You know I got my living that way. But every one of these MTR jobs replaces hundreds and hundreds of good coal miners” (CR \#8). Another currently employed underground miner, angry at the destruction of his home, stated: “....and in their mind I think they think they're doing a good thing, because they’ve employed 40 or 50 people, so they’ve done everybody a favor by doing this!” (CR \#12). Of the currently employed miners, all but one are union, four worked underground, and two had worked both underground and on surface mines. All participants expressed a support for coal mining in general, but expressed anger at the specific practice of MTR:

Male2: Well, a man's got to work. And for a coal miner, coal mining is in their blood and passion... But find another way to do mining other than taking the mountain tops off

Female: There's other ways to do it that's better. Coal provides a lot for the United States, period. But it don't have to destroy other people's home to get to it. (CR\#43, 44)

Finally, another direct contradiction to the dominant discourse expressed in this discursive formation around livelihood is the fallacy that MTR is created local jobs: “The local thing, it's a non factor...most of the people [working on the strip mines] they're coming from Cabin Creek, Beckley, Wyoming county...it's not that they're providing local people jobs. They are providing some jobs in this area, but that's pretty much it” (CR \#12). Retired miners in Horse Creek also referenced the out of state license plates as a possible reason for the disregard for children playing in the roads as well as the dangerous caravans of miners (CR \#8,9,10,18,19) 


\section{6. f. Conclusion}

"This is our habitat, we live here. If we were a horned owl, they would run these people off, but we're not a horned owl. We're not a protected species” (CR \#28).

This chapter began with an introduction to the fifty nine participants who participated in this research. It was important to illustrate the concerns of local, and if possible, muti-generational residents in this research, therefore all participants interviewed currently live within the study area. The average length of residency for participants is 44 years. Of the women interviewed, the highest employment was as a stay at home mother (50\%), and none had ever worked in the coal industry. Within the group of male participants, the coal industry was by far the highest employer at 54\%. An overwhelming $90 \%$ of the male participants who have worked within the coal industry are union coal miners. Regarding age, I had an older population group with $76 \%$ of the participants over the age of 50 , and $47 \%$ over the age of 60 .

Initially, key findings included the incorporation of both social and environmental concerns into participants' perception of their landscape. Far beyond viewing their home as an economic landscape for mineral resources, or an environmental landscape for recreational or forest resources, the subaltern discourse focuses on its human resources. Additionally, outside of the concerns that were grouped into environment or social, a discursive formation of MTR as "total destruction" of all associated social and environmental values was revealed.

The review then focused geographically on the concerns of residents of Sycamore and Clear Fork, Horse Creek, and Rock Creek. Overall, most of the concerns were similar between the three different hollows, but there were a few more specific, small scale differences. In Sycamore and Clear Fork, downstream communities stand to be highly impacted from the 13 valley fills that were indicated on the permit maps in addition to the mining already happening on Kayford Mountain. Residents in this area were severely impacted by the 2001 and 2002 floods, including the deaths of two residents, and the destruction of many homes. The participatory map of flooding showed consensus that residents in Sycamore and on Clear Fork were in severe danger of being flooded out, and possibly killed. The danger from a blow out from the Brushy Fork Slurry Impoundment is 
considerable enough that some locals travel to punch out sites on their four wheelers to monitor water levels.

Residents in Horse Creek unanimously agreed that MTR has damaged their community structure. While residents of Sycamore and Clear Fork are impacted geographically by their proximity to Kayford, Horse Creek residents are impacted by the constant mine traffic up their hollow.

Participants have already noticed changes in their community from miners driving up the hollow to and from work, as indicated by the $83 \%$ participant concern about dangerous roads, especially during shift change. Horse Creek contains several four wheel and hiking trails leading up Coal River Mountain that were open to community access, and 83\% of participants are concerned that MTR will impede their use of the mountain for recreational purposes as well as multi-livelihood needs like hunting, ginseng, and forest resources. Finally, Rock Creek was the only hollow in which the highest concern regarding impacts on landscape was the loss on wildlife. Unlike Horse Creek, which is a tight-knit community, residents of Rock Creek are divided into two major forks and spread out over a greater distance. There was less consensus on just one social impact, and a wider variety of social impacts. Residents in Rock Creek are also concerned about flooding from blow outs, in part due to a blow out in 1993 which caused the evacuation of 75 families.

When broken down by gender, participant concerns regarding impacts on the landscape are very similar. However, their perspectives differed regarding associated social impacts. Specifically, women were more concerned about the decreased quality of life for children, and men were more concerned about the loss of access to the mountains. As 50\% of the female participants are stay at home mothers this greater concern makes sense, along with women's higher concern about their ability to pass their culture and heritage on to their children. Regarding men, loss of access a concern held by many hunters and recreational users of the mountain, both of which are traditionally - but not always - male activities.

Discursive formations around age brought forward some interesting generational differences. Although only $12 \%$ of my participants were under the age of forty, within this age group, every participant requested a confidential interview. All participants had a family history of mining, as well as sharing shared unanimous concern about increased flooding, loss of community structure, 
increased deforestation, and decreased quality of life for children. Participants under 40 are the only age group that shared a 100\% concern about decreased quality of life for children. In the group of participants within the ages of 40-59, concerns about blasting impacts on homes, destruction of the home place, and loss of heritage / culture were more elevated than within the under 40 age group. These concerns make sense with the increased likelihood that participants in this age group own their homes and are concerned about maintaining their investment. The 60+ age group is the only discursive formation thus far showing "loss of community structure" as the highest overall concern. Concern about dangerous traffic and roads were significantly higher for participants over the age of 60 than in the other groups.

Investigating discursive formations around livelihood illustrated an important finding of this dissertation. In direct contrast to the portrayal of "local miners” as being pro MTR because of the creation of jobs, $52 \%$ of the participants who have worked or currently worked for the coal industry cite the "loss of jobs" as an social impact of mountaintop removal: the percentage is even higher from the point of currently employed miners (67\%). Also, local miners corrected the idea that many local residents are employed on the surface mines. In contrast, local miners state the high number of out of state employees or contract workers who are employed on the mine site.

The following chapter situates these subaltern discursive formations within the conditions of possibility created through the legal and regulatory discourse of MTR. I apply the Foucauldian framework to the data collected through the construction of first, a "mini-archeology" of the legal discourse of MTR, and second, a PGIS of participant concerns, to analyze the power relations that continue to subjugate the discourse of resistance in the Coal River Valley. 


\section{CHAPTER 7}

\section{The Power-Knowledge to Move Mountains}

As far as everybody in this whole entire globe is concerned, the company that I work for has set the standard and mark for production... what they don't know is that we cheated to get that. We run illegal everyday. And this is not like, you know, under adverse conditions...we do it illegal...every...fucking...day. The only time we do run legal is when mine inspectors come to where we're at (CR \# 12).

They don't call it "King Coal" for nothing. It's all right there. If someone could take that power away from those guys, and say you're not gonna have all the power; you're not gonna call all the shots. That's what it would take: somebody to stand up to them... I don't know what it's gonna take. But they're hearin' us now on a level they never have before (CR\#16).

The previous chapter unpacked the dominant themes within the subaltern discourse regarding physical changes and associated social impacts from mountaintop removal coal mining the case study area. This chapter proceeds to my final level of analysis to investigate the power-knowledge relationships between the subaltern discourse and the legal discourse of MTR as represented thus far in this dissertation.

The analysis proceeds in two steps to address the objectives of this study. First, in order to address the question of how dominant discursive formations continue to subjugate the subaltern discourse of MTR, I situate the subaltern discourse within the conditions of possibility created by the legal construction of MTR. Foucault developed an original definition of discourse as being constituted by the rules that define who can speak, when, where, and in what way. For example, how is a resident's decision to speak out against MTR impacted by these rules, and to what degree does their gender, age, or livelihood impact their participation in the discourse of resistance? I interpret specific themes to address specifically the specialized forms of knowledge empowered within the dominant discourse work to discredit local knowledge. Crampton (2001) states that a "richer account” of the purpose of maps can be reached by positioning those maps within their 
larger societal power relations. This chapter positions the PGIS maps in relation to the permit maps as practices of power-knowledge (Harley, 1988; Wood, 1992; Pickles, 1995; Crampton, 2001).

Second, the chapter focuses on where the subaltern perspective, as represented in the previous chapter, extends beyond the conditions of possibility constructed by the dominant discourse. This section unpacks where local knowledge addresses the impacts of MTR outside of the dominant legal discourse. Specific analysis focuses on the discursive formations that are not privileged as "expert knowledge" by the dominant discourse. What elements of this subaltern discourse relate back directly to the original legal definition of MTR, to the original purpose of the federal statutes? By focusing on the specific spaces in which the subaltern discourse moves outside of the dominant discourse, possible spaces of resistance are illuminated within which issues of landscape change and resulting social impacts can be challenged.

\section{7. a. Legal Conditions of Possibility}

Foucault states that in order to do an "analysis of power...we must speak of powers and try to localize them in their historical and geographical specificity' (Crampton and Elden, 2007, pg 6). The mini-archeology in Chapter Five brought forward the historial a priori-that ground knowledge and discourse regarding MTR - to represent the conditions of possibility for the subaltern discourse. What are the legal and regulatory conditions within which the three permits on Coal River Mountain were approved or applied for?

At the federal level under SMCRA, the land must be restored to a condition that can support premining land use, must not present any "actual or probable hazard to public health or safety," nor any threat of water pollution. Regarding the premining use, all three permits had forestland as a pre-mining land use, yet plan to replace the forest with 
wildlife habitat, a lower land use. Additionally, all three permits had a variance for contemporaneous reclamation, allowing Marfork coal to post a 5,000 bond per acre in case reclamation is not finished and the mountain is not even restored to wildlife habitat.

Also under SMCRA, companies are required to restore the mountain to "approximate original contour," although debate continues regarding how to do so, or apply for a Section C "AOC variance" which would allow the mountain to remain flattened if there is a "higher and better use." Interestingly, I discovered that none of these three permits were classified as mountaintop removal, despite the fact multiple seams were being accessed using explosives with the intent to place fill in neighboring hollows. None of the three surface mine permits had AOC variances, but the active site, Bee Tree, had been challenged already before the Surface Board regarding the AOC requirements that were in place for the reclamation plan. The process of defining and requiring that a surface mine site without an AOC variance was actually restored to AOC remains in debate today.

Regarding the creation of valley fills, the CWA provided authorization for the Corps to issue 404 permits to discharge fill material in the "navigable waters of the United States" with the qualification that the discharge will not have an "unacceptable adverse effect on municipal water supplies,” fisheries, wildlife, or recreation areas. At the regulatory level, the Corps then proceeded to define "fill material" as excluding any "pollutant discharged into the water primarily to dispose of waste, therefore centering much of the debate regarding valley fill permitting around the definition of the word "fill." On Coal River Mountain, despite the requirement that Marfork coal apply for CWA 404 individual permits for the 6 valley fills on the first permit, work has already begun on the Bee Tree permit. Marfork was able to dispose of overburden by using an "incidental boundary revision” (IBR) on the neighboring permit, the Brushy Fork Slurry Impoundment, to dispose of overburden and side step the Clean Water Act entirely. Through the use of this "incidental" revision, Marfork is now also able to use explosives in places within 200 feet of the Brushy Fork Slurry Impoundment. 


\section{7. b. "If West Virginia were a horse, we'd be the hind end:" The 'Situation' of the Subaltern}

It seems clear that there is a disconnect between the permitting of the surface mines and valley fills on Coal River and the original language of the federal statues. Where, then, does the subaltern fit within these legal conditions of possibility? Foucault defines discursive formations as systems of thought within a discourse. One effect of these discursive formations is to make it virtually impossible to think or work outside of them: "discourse itself is both strongly constituted by, and ensures the reproduction of, the social system through forms of selection, exclusion, and domination” (Hook, 2001, pg 2). These discursive practices "set the rules of the game” regarding who can speak, with what authority, if that authority was recognized as legitimate, and from what point of view (Escobar, 1995, pg 41). This next section proceeds to 'situate' the subaltern discourse within the conditions of possibility represented in the previous section. I examine what types of knowledge are excluded and how different subject positions impact the authority with which knowledge is appropriated.

\section{7. b. i When “expert knowledge” meets “local knowledge”}

We want the coal companies to know we are real people with lives, dreams, and hopes not only for ourselves, but for our children, grandchildren, and other people's children. We lost our home and all our personal belongings we had worked for and saved for 37 years in July 2001, and our concern with more and bigger sludge ponds being made now puts us at much more risk than ever before, even after we have built a new home and raised it more than 7 feet higher than our old home was, that we will be washed away. It seems the only thing the coal company wants is to be rid of us all and turn all our homes and land into one big landfill. $\quad$-- Community letter to Gov.Manchin, Mike and Lessie Maynor, Dorothy, WV

They got this higher education like they can talk down to a coal miner like he's nothing, but... a man who's worked in the coal mines hands on is a whole lot smarter than this man sitting behind a desk pushing a pencil. (CR\#58). 
As noted in the previous section, the land must be restored to a condition that can support “pre-mining land use” and must not present any "actual or probable hazard to public health or safety” or threat of water pollution. Yet the highest concerns held by all residents regarding the impacts of MTR on the landscape included increased flooding (90\%), loss of water quality (69\%), slurry impoundment failure (68\%) and deforestation (54\%). Flooding and slurry impoundment failure are certainly hazard to public health and safety, loss of water quality from black water spills are certainly water pollution, and deforestation occurs when the land use moves from 'forestland' to 'wildlife habitat,' assuming the land is reclaimed.

Under the CWA, the Corps can issue 404 permits to discharge fill material in the “navigable waters of the United States” with the qualification that the discharge will not have an "unacceptable adverse effect on municipal water supplies," fisheries, wildlife, or recreation areas. In this case, both the individual and nationwide permits for these valley fills have been held up in court, and there are currently no 404 permits on the mountain. As discussed previously, work has begun on the Bee Tree permit without a 404 permit, and overburden is being dumped on the Brushy Fork slurry impoundment, as well as removed with the use of explosives, through an "incidental” boundary revision that sidestepped the permitting requirements of the Clean Water Act. What types of knowledge were excluded from this permitting process, and how did different subject positions impact the authority with which that knowledge was appropriated and shared?

Chapter Six briefly reviewed the legal avenues that were taken to stop the original permitting and growing size of the impoundment. Dr Eades' review of the safety of the impoundment in 2000 had already indicated concerns about the impoundment and its location on top of underground mine shafts (Eades, 2000). Now, nine years later, the decision by the DEP to allow blasting on the Bee Tree permit on a containing ridge of the Brushy Fork impoundment heightened concern about public safety as well as frustration about the exclusion of local concerns from the permitting process. After all legal avenues were taken to address to address concerns about the impoundment, some residents and organizers decided to support different strategies of resistance. 
On February 3, 2009, nonviolent protests against blasting on Coal River Mountain took place in two locations. The first was on the Bee Tree mine site, where 6 protesters were arrested for chaining themselves to a bull dozer with a banner stating "Windmills, not toxic spills” to indicate support for a windmills instead of possibly causing a massive spill by blasting next to the impoundment (See Figure 7.1). The second protest occurred on the same day below the Brushy Fork impoundment, in front of the Marfork facility, where 8 people were arrested for trespassing. On October 19, 2009, residents hand delivered a letter to Governor Manchin stating: "we live in fear that the blasting could cause the dam to fail and create one of the greatest industrial disasters in our nation's history... given this risk, blasting should not be allowed until your Department of Environmental Protection has conducted a thorough geo-technical examination of the impoundment's stability in regards to the underground mines"1 (See Figure 7.1). It was during this meeting that Rock Creek resident Lorelei Scarboro and Governor Manchin had the interchange about West Virginia as an "extraction” state versus “mountain” state. Included in this letter were thirteen statements by local residents representing "local knowledge” about the dangers of the impoundment. In a statement published by local resident and organizer Chuck Nelson, the danger from the impoundment was clearly linked to additional social concerns: "my first and main concern is for the safety of the communities that live downstream of the Brushy Fork sludge impoundment, including many of my friends and family and my birthplace and hometown, Sylvester.” This representation of local knowledge clearly links the concern of $68 \%$ of participants regarding slurry impoundment failure with social impacts such as destruction of home place (69\%) and loss of heritage / culture (53\%).

\footnotetext{
1 “Community Letter to Joe Manchin”, JourneyUpCoalRiver.org http://auroralights.org/map_project/theme.php?theme $=$ crm\&article $=7$
} 


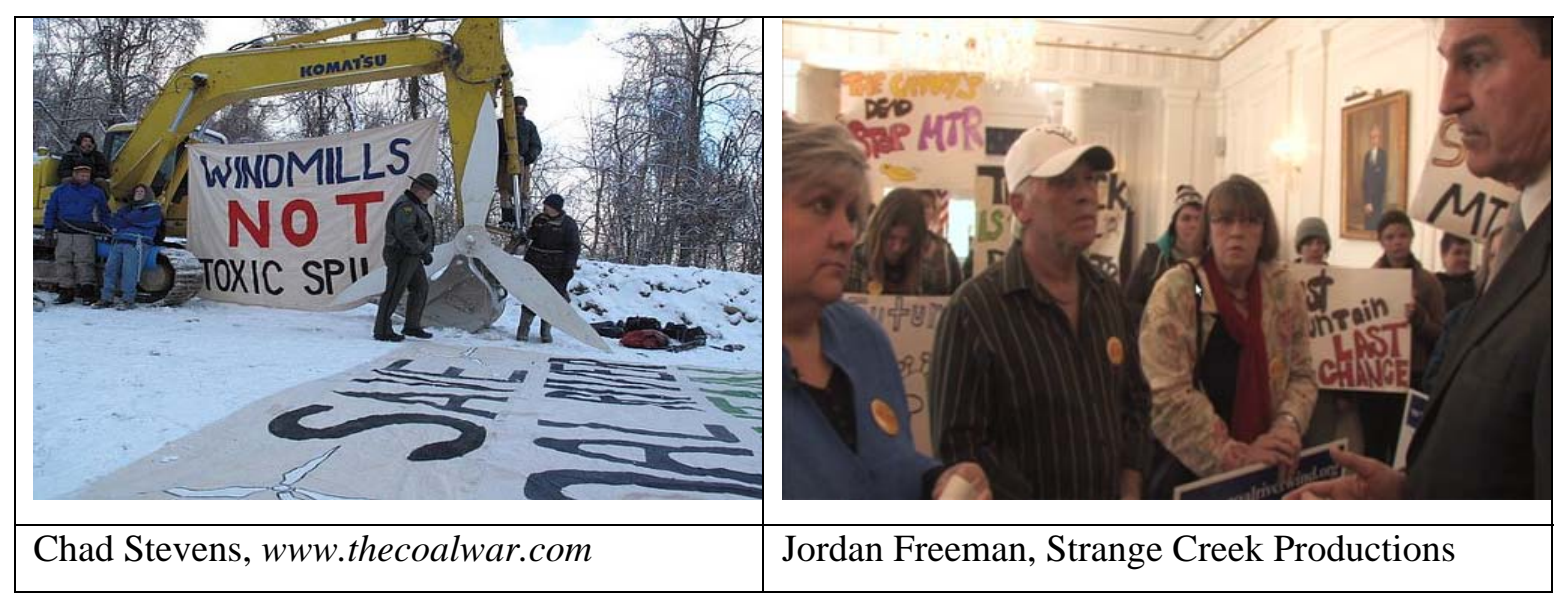

Figure 7.1: Nonviolent Direct Actions to stop blasting on Coal River Mountain

Yet despite representation of local knowledge from both resident and outsider subject positions, blasting is still occurring without even the additional geotechnical review of the stability of the pillars under the impoundment. In this example, local knowledge was not incorporated into the permitting process, nor given access to meaningfully intervene through the public participation process. The letter referenced above was delivered to Manchin personally in his office by residents surrounded by media after he refused to meet "the residents whose very existence is at stake if this destruction is allowed to go forward.” Referring to the Weidemann and Femer's (1993) Citizen Participation Ladder, local knowledge reached the third rung, "Public Right to Object," however there was no meaningful consequence from the objection. The blasting continued.

In the case of the Brushy Fork Impoundment, even the "expert knowledge” of a former mining engineer and director of the National Mine Health and Safety Academy did not make a difference. Jack Spadaro was the head of a team of engineers who went to investigate the causes of the blow out in Martin County that released 300 million gallons of coal slurry: "we were pursuing serious violations of the federal law, we had a list of at least 10 violations that we thought the company had violated, and some of them deliberately” (Aurora Lights, 2009). Spadaro was told to end his investigation despite having at least 30 more people to interview. He went public about what he perceived as a “cover up” by the Bush Administration about the causes of the disaster. Specifically, he noted that the documents submitted to obtain a permit for this impoundment showed a 
one hundred foot solid rock barrier between the bottom of the reservoir and the mine workings. However, drilling showed that the $100 \mathrm{ft}$ barrier was actually only 12 feet. The blow out occurred when this $12 \mathrm{ft}$ barrier broke, releasing slurry into two different watersheds.

An additional survey done through this investigation showed that 225 of 650 slurry impoundments sat on top of abandoned underground mine workings, and that they all "presented a hazard to the public” (Personal interview, 2009). Regarding the Brushy Fork Impoundment, Spadaro stated that "should a failure occur into the mine workings it would be catastrophic. And I am concerned about the Brushy Fork impoundment and its long term stability.” He recommended that Marfork coal should undertake a drilling program to determine the exact location of the mine workings in relation to the bottom of the reservoir, and a thorough geo-technical evaluation of the whole impoundment and its stability in relation to the underground mine workings needed to be done. He stated that the cost should be born by Marfork Coal, but that MSHA, OSM, and the WVDEP should require it: “All three agencies are responsible for the safety of people in the vicinity of these coal waste impoundments and they have really failed in their responsibility to protect the public” (Personal interview, 2009). Despite the intervention of local, first hand knowledge as well as expert knowledge from Spadaro, blasting continues within 200 feet of the impoundment without any geotechnical review.

\section{7. b. ii Maps as Surfaces of Power-Knowledge}

This section looks at the power-knowledge relationships evident between the permit maps for surface mining and the participatory maps created in this research. Crampton (2001) states that a "richer account" of the purpose of maps can be reached by positioning those maps within their larger societal power relations. This chapter positions the PGIS maps in relation to the permit maps as practices of power-knowledge (Harley, 1988; Wood, 1992; Pickles, 1995; Crampton, 2001). Crampton explains the key components that have marked an "epistemic break" with the idea that maps were simply unbiased ways of communicating knowledge. The two developments that he 
concentrates on are: investigations of maps as evidence of "power-knowledge", and how geographic visualization uses the “map's power to explore, analyze and visualize spatial datasets to understand patterns.” Crampton (2001) argues that these two developments are important in the 'maps as social constructions' approach as well as an opportunity for cartography to renew its relationship with a critical human geography.

The work of Harley (1988) also illustrated how maps can be used to promote and make legitimate the world views which are powerful at the time. Crampton and Krygier (2006) explained the "dominance of seemingly neutral scientific mapping as in fact a highly partisan intervention, often for state interests” (p. 16). His revolutionary work placed maps as social documents that, opposed to the dominant view that maps were "neutral," required historical context to be understood.

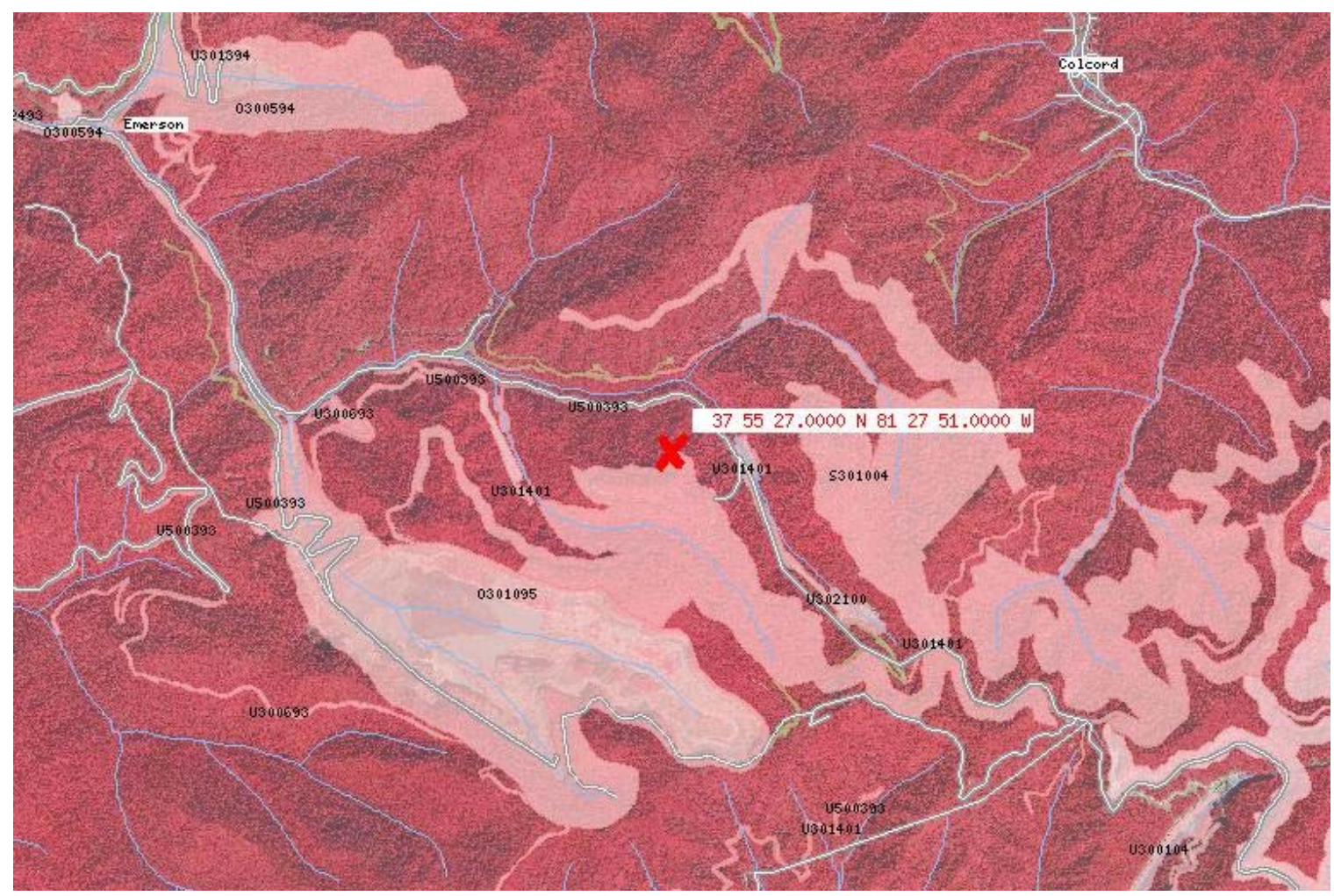

Figure 7.2: Map showing the location of the Bee Tree surface mine on Coal River Mountain. Source: WVDEP $^{2}$

\footnotetext{
${ }^{2}$ WVDEP Online permit search
} 
Residents currently have three ways that they can see maps of surface mine permits in their area. Firstly, residents can see it when it is published in the local paper. Secondly, residents can get onto the WVDEP website and use the permit or pending permit search and access the map (See Figure 7.1 above). When the map originally comes up, the mine permit is shown just as the red X. In order to actually see the boundaries of the permit, however, you have to turn on the layer and hit the redraw button on the map. Although this is not difficult, it also is not immediately obvious, and does cause some issues of technology access for some users. Additional options include: county boundaries, 2007 Aerial photography, USGS topographic map, hill shade, FEMA Q3 Floodplain, and the permit boundaries of the mine. Additionally, map users can zoom in or out, view the location of the permit within state boundaries, and move the location of the map.

Currently, online access to surface mine permits is the most accessible way for residents to learn more about surface mines permitted in their area. This online map, however, contains no representation of dwellings beyond the names of the towns, no location of local cemeteries, and no additional indication of any impacts on the community from these permits. Information about roads, rivers, creeks, and towns are included. This map satisfied the legal and regulatory requirements of the surface mine permit, however, and was paid for by Marfork coal and clearly serves the interests of the industry. As this is a surface mine permit, and not a CWA 404 permit, this map also does not show the location of the six valley fills. Again, for the regulatory purposes of the DEP, this map is complete and does represent improved access and information sharing with the public regarding the permitting process. However, in terms of conveying relevant information to the community about the impacts that might occur from this permit, much information is not supplied.

Thirdly, residents can call the WVDEP and order a permit CD which contains all of the permit information for that particular mine. On the $\mathrm{CD}$, residents can have access to all of the maps provided to the DEP. However, there are two issues of access involved. Concerned residents need to be aware that there is much more information available in the first place. How would residents know without knowledge of the permitting process 
that there is substantial geographical information missing from the permit? Next, the permit disk includes hundreds of folders labeled with numbers, not titles, containing the information through all the steps of the permitting process. It is very difficult and timeconsuming to find needed information as well as to have the right program on your computer to access this information.

In his article, “Cartography is Dead (Thank God!),” Wood stated that cartographers played a significant role in making the world "safe for colonizers, mining conglomerates, and the military. We need to pay a little back”(2003). Harris and Hazen (2007) define counter mapping as "any effort that fundamentally questions the assumptions or biases of cartographic conventions, that challenges predominant power effects of mapping, or that engages in mapping in ways that upset power relations.” The authors applied questions raised by Harley and Wood to the specific question of mapping for conservation. The participatory maps reviewed in Chapter Six fit within their third primary aspect of counter mapping, which includes "efforts that explicitly seek to counter predominant ecosocial inequalities” (Harris and Hazen, 2007).

\section{7. c. Spaces of Resistance}

Well do you know that when the mountains are gone, they're gone forever.

(CR\#13)

An analysis of the relationship between the subaltern discourse of resistance to MTR in the Valley and the dominant discourse that created and permits MTR has the potential to create spaces for the "possibilities of resistance” (Crampton, 2001, p. 236). Where, then, does the subaltern perspective extend beyond conditions of possibility? The subaltern discursive formations of concern and resistance are not privileged as "expert knowledge" by the dominant legal discourse, which designated regulatory authorities of delimitation to representatives of state and federal agencies. Subject positions of authority empowered through legal mandate and regulatory reconstruction do not include local 
residents, nor, as evidenced by Spadaro, regulators who take their mandate to protect the public as more important than their job security.

At the beginning of this dissertation, Flynn (2005) was quoted as saying that "Foucault is a philosopher of the 'miniscule ... displacement'. He turns (often reverses) the kaleidoscope of our received views to produce new, frequently liberating perspectives” (Flynn, 2005, p. 97). If local knowledge is privileged as expert, as stated in this dissertation, how could the subaltern discourse then relate back to the original statues in meaningful ways? Can the empowerment of local knowledge as expert be the "miniscule displacement” referenced above? And if so, perhaps the most important question is how can power-knowledge relationships between local residents and current authorities of delimitation be negotiated to empower and give meaningful access to concerned coalfield residents?

This next section looks at three possible spaces of resistance, through which the subaltern discourse extends beyond the legal and regulatory definitions and could have the possibility of influencing this miniscule displacement.

\section{7. c. i “Total Devastation”}

It looks to me like there will be nothing but a shell of what was West Virginia, left. We had the most beautiful mountains in this whole country, right in here, and people loved it, they loved the life they lived, they want to live here, and they've destroyed everything on this end of Coal River. (CR\#13)

As referenced in Chapter Six, the impacts of mountaintop removal were equated by some residents with an emotional response that is outside the discourse of legal impacts that can be regulated. Not all residents were able to represent their concern initially, or at all, with specific problems. A key finding was the concerns that were grouped into environment or social, a discursive formation of MTR as "total destruction” of all associated social and environmental values was revealed. Participants used phrases such as "unrepairable damage," "everything is gone," or "a wasteland as far as humanity is 
concerned" to describe the impacts of mountaintop removal. In the first level of analysis, I pulled these specific impacts from the interviews and grouped them by level of concern. The second time I analyzed the interviews, I heard a deeper level of communication when they talked about how landscape changes from mountaintop removal had impacted their lives. Loss of community, of access to their mountains, of culture and heritage, of property value, and impacts on public health and the quality of life for children; these social impacts are more varied across different discursive formations. However, the attempts to express the outcome of "total devastation" as the sum of all the parts that were destroyed, and the inability of some participants to explain these details of loss -is a part of this discourse that lies outside of the conditions of possibility of the legal discourse.

This description of MTR as total destruction does not represent a specific concern that can be regulated under SMCRA or the CWA, and therefore can be ignored legally. However, King Coal is quick to respond to these emotional outbursts and issue belittling statements equating care for the land with putting "mayflies over men." The dominant discourse also immediately labels these concerns as exaggerations that are voiced by outsiders, by agitators, by environmentalists. The question I pose, then, is if this dialogue of total destruction can't be legally addressed, why does the coal industry go to such lengths to disempower it by associating it with outsiders?

As evidenced in the brief review of resistance and union organizing in the case study area, as well as the response of community solidarity to the Upper Big Branch Disaster, the men and women of the southern coalfields are able to stand up for themselves in the face of a clearly defined threat to the well being of their lives and families, especially when it comes from out-of-state. I assert that the reason for framing the discourse of "total devastation" as one that originates outside of West Virginia is to maintain division within the community by asserting that environmentalists and treehuggers, not the coal industry, is the outside threat. 
However, the extent to which local voices can be heard, and their knowledge respected and represented as expert, will determine if this dialogue of total destruction could be a possible space of resistance. Despite consistent differences of opinions between the UMWA and local community groups, for example, The UMWA and local resistance to MTR both agree about the dangers to the community represented by the Brushy Fork Slurry Impoundment (Aurora Lights, 2009) as well as by coal companies, such as the owner of Upper Big Branch, who operate in continual violation of safety regulations. If the dialogue of total destruction could be heard as "truth" by more local residents, could the origin of threat slowly begin to shift for pro-MTR miners from "outsider agitators" to the coal industry itself?

\section{7. c. ii Local Knowledge as Expert: Representation of Concern by Local Residents.}

My daddy was a mountaineer before he was a coal miner. You know the coal industry's trying to rewrite heritage. They're trying to say 'well, what about your coal heritage?" Oh yeah, my coal heritage. I got plenty of that. That's my history of resistance against the abuses of the coal industry. That's my coal heritage” (CR\#20)

To aid in surfacing this discursive formation of total destruction, the discourse of resistance is stronger if the residents are members of multigenerational families to counter the "outsider" argument, and stronger yet if these people are members of the coal industry. This dissertation asserts that a possible space of resistance exists from which multi-generational residents with a past or current history of coal mining can directly address the impacts of mountaintop removal. The quote referenced above situates resistance to the impacts of mountaintop removal as part of her coal heritage, not opposed to it. As one of the primary purposes of this research was to represent the perspectives of local residents, as opposed to “outsiders," regarding mountaintop removal, I interviewed residents who had strong and often multi-generational connections with the land. As overviewed in Chapter Six, all participants interviewed currently lived within the study area during the time of the interview. The average length of residency for participants 
was 44 years. Additionally, due to the history and importance of coal mining in the area, it was important to speak with residents who were familiar with the coal industry. 81\% of all participants had a family history of coal mining or had current family members working as either underground miners or strip miners.

Foucault refers to an "insurrection of subjugated knowledges," for which he ascribes two definitions. Firstly, the historical contents that have been "buried and disguised in a functionalist coherence of formal systemisation” (Foucault, 1980, pg 81). He believes that the "immediate emergence of historical contents" allowed for a effective criticism of the asylum. Secondly, the insurrection of subjugated knowledges refers to forms of knowledge that were disqualified or located low on the hierarchy: a "particular, local, regional knowledge, a differential knowledge incapable of unanimity and which owes its force only to the harshness with which it is opposed by everything surrounding it” (Foucault, pg 82).

Applying elements of Foucault, unities are to be questioned as they are "always themselves reflexive categories, principles of classification, normative rules, institutionalized types” (Foucault, 1972, pg 22). The representation of concerns by local, multigenerational miners and their families directly questions the unity presented by the coal industry and in the media of "West Virginia miners" standing in solidarity against mountaintop removal against outsiders. For example, what are the discursive rules that lead to the identification of an individual as a miner? From the subject position of a deep miner, strip miners are "heavy machine operators." From the subject position of another surface miners, strip miners are "miners.” From the subject position of a union miner, MTR miners are “scabs.” From an outside point of view, miners are all the same in West Virginia.

Questioning this unity of “miners” through the representation of local concern about MTR from the point of view of local miners and their families is the first step towards questioning these normative categories. Additionally, the representation of this local, multigenerational concern also questions the unity of the label "tree-hugger," or the 
combined unity that I named earlier: outside agitating treehuggers (OATS). By situating the discourse of resistance to mountaintop removal as originating from local families who have worked in the coal industry, their discourse of resistance becomes "expert” to other local residents and other mining families. A discourse of resistance to mountaintop removal grounded in locally deemed "expert” knowledge about the first hand impacts on the families and land of Coal River can be seen Appalachians standing together to protect the mountain way of life. Perhaps then, finally, mountain top removal coal extraction by an out-of- state operation would be seen as the outside agitating force.

\section{7. c. iii Participatory Research and Counter Mapping}

[Participatory mapping] is a terrific idea. What we have said in the last five minutes- the people who live here, the homes that would be destroyed, the streams, the forests - these coal companies would never put on a map. They just draw what the land is, not what the land holds. (Larry Gibson, personal interview, 2007)

It is an interesting idea to think about ways to represent the concerns of local families in a way that would be considered expert knowledge by other Coal River families as well as by regulatory and federal authorities of delimitation. Herein lays the third possible space of resistance: participatory research / GIS and counter mapping to provide qualitative and quantitative representation of the local, multigenerational, mining situated discourse of resistance to MTR.

My review of PGIS literature addressed the potential of participatory maps to legitimize local knowledge and directly address the illegal nature of MTR as produced on the landscape of Coal River Mountain. The participatory output of this dissertation, the Journey Up Coal River website, included the first draft base maps with additional geotagged information as well as specific subthemes that were developed at the suggestion of participants. Participants who were interested in being involved in the online participatory mapping project were given an option to waive confidentiality and submit interviews, geospatial information, pictures, and suggestions to the Journey Up 
Coal River website. Additionally, interested participants allowed me to use their interviews as testimony in a civil case regarding the safety and location of Marsh fork elementary, helping to secure one million dollars to build a new, local school. Participants have also used the website and volunteers to create maps of the Brushy Fork Slurry Impoundment to highlight their concerns about the danger of the dam and its close proximity to more than one thousand residents.

This project was just the beginning. In the coalfields of southern West Virginia, opportunities exist for partnerships between local residents and non-profit organizations or student to create "hard evidence" through participatory mapping and research projects. Regarding the potential for these projects themselves to be spaces of resistance, I place emphasis on the need for a tangible and useful product to share with participants, with the type and scope of the product being determined in partnership with participants in the community. The importance of "transparency, time, and trust (Chambers, 2005; Drew, 2003; Kindon, 2001) in the attitude of the researcher is essential to maintain open channels of communication with participants regarding the type of final product. I also highlight the importance of creating the final product within a timeframe that is practical and useful to the involved community as well as fulfilling requirements within academia.

\section{7. d Conclusion}

“When are you going to start protecting us, the people that live here?” CR\#13

The objectives of this chapter were twofold: to illuminate how dominant legal discourse continues to subjugate the subaltern discourse of MTR , and to identify possible spaces of resistance within which the subaltern discourse can challenge issues of landscape change and use in the case study area. Regarding the first objective, I drew upon Foucault definition of power as a network of relations between people which is 'negotiated' within each encounter to briefly examine the relationship between expert knowledge and local knowledge. Each institutionally sanctioned power relation can be negotiated at a local 
level and can be challenged overtly or covertly. What positions, then, are negotiable? Who gets to speak the 'truth' in a given discourse? Regarding the Brushy Fork slurry impoundment, even the former director of MSHA was not able to speak against its permitting without losing his job. Through a comparison of permit maps and participatory maps, the geospatial information available and easily accessible to residents was yet another manifestation of the current power-knowledge relationships between the dominant and subaltern discourses.

Regarding my second objective, three possible spaces of resistance were identified: the portrayal of the impacts of mountaintop removal as "total devastation," the representation of local, multigenerational, mining-situated perspectives as expert knowledge, and the use of participatory research and counter mapping to provide tangible evidence and support this local, expert knowledge. In his 1980 afterward to Power/Knowledge, Colin Gordon theorizes on the ethical applications of Foucault's work: "For the recent eruptions of 'popular knowledge' and 'insurrections of subjugated knowledges' which he celebrates, what Foucault may have to offer is a set of possible tools, tools for the identification of the conditions of possibility which operate through the obviousness and enigmas of our present, tools perhaps also for the eventual modification of those conditions” (Foucault, 1980, pg 258). 


\section{CHAPTER EIGHT}

\section{SUMMARY AND CONCLUSIONS}

We've got to save [Coal River mountain.] It's a symbol. And not only a symbol, it's the only thing left where 20 years from now, someone here might be able to survive on their own with fresh water and wildlife. It's the only mountain left the wildlife can live on. It's the last mountain left intact that we can literally use to sustain our life here and to literally have something for our kids to be able to stay here. I think a lot of the residents here see that mountain as sort of like an Alamo. It's the last stand. (CR\#20)

Memorial Day in the Coal River Valley brings the tragedy of the Upper Big Branch mine explosion to the forefront of the community's thoughts and prayers once again. Signs for the lost miners and their families stand beside memorials to veterans all along Route 3. The national media has moved on, except for indignant disgust at the blatant corruption of Don Blankenship and King Coal. The solidarity shown by West Virginians and mining families across Appalachia to support our nation's miners has not yet yielded any immediate support or safety for local miners. Sections of the Upper Big Branch mine are still closed, and the coal company responsible remain the target of hard scrutiny at the federal level, but underground and surface coal miners still go to work each day in the same work situations as before the explosion. Cartoons are still turned up at 4:15 to comfort children who are frightened by the blasting, and the recent hard rain once again brought worry over flooding or black water spills or a slurry impoundment break.

At the beginning of this work, I referenced the urging of U.S. Sen. Robert Byrd (DW.Va) to view our people as “West Virginia's greatest natural resource.” This dissertation asserted that the first step towards valuing West Virginia’s people as a resource more important than coal was to listen directly to the concerns of coalfield residents about the human and environmental costs of coal. As this dissertation represented, the impacts associated with coal mining extend beyond the direct risk to 
miners through work related injuries. They include risk to families who lose water quality or have homes damaged by blasting, risk to communities living downstream from toxic slurry impoundments and massive denuded landscapes, and risk to the mountains and homeplaces of the Coal River Valley. Listening directly to coalfield residents reveals a great deal of solidarity regarding the need to address the safety of miners working to provide our nation with cheap electricity. Listening immediately reveals, however, divisive and bitter differences between residents about the costs and benefits of mountaintop removal coal mining.

The urging of a Coal River grandmother to remember that people of the coalfields have their own "hopes, families, dreams, just like anyone else outside of the coalfields" (CR \#2) must also be heeded. The discourse of resistance to mountaintop removal questions whether the costs of mountaintop removal on the "hopes, families, and dreams" on mountain communities are factored into the cost of cheap electricity at all. Across different discursive formations of gender, age, and livelihood, themes regarding the impacts of mountaintop removal on the landscape of participants and their families stand out clearly. A primary finding of this dissertation is that the way the subaltern discourse interprets the landscape contradicts both the environmental concerns of the "outsiders" and the economic concerns of “local miners”, law makers, and mining companies. Participants in Coal River, through interviews and through participatory mental mapping, clearly depict their homeland as much more than just an economic or environmental landscape. As Lorelei stated to the Governor, West Virginia is a mountain state, not an extraction state, and this dissertation argues that the mountain landscape is filled with communities and families, not just forest and mineral resources.

As the last relatively intact mountain in the watershed, the importance of Coal River Mountain is clearly stated at the beginning of this chapter: "It's the last mountain left intact that we can literally use to sustain our life here and to literally have something for our kids to be able to stay here. I think a lot of the residents here see that mountain as sort of like an Alamo. It's the last stand” (CR\#20). Participants clearly are concerned about increased flooding from mountaintop removal and the creation of valley fills of 
Coal River Mountain, and how this flooding could impact or destroy their homes. The loss of water quality through black water spills or other chemical or sediment contamination was another widely shared concern, as well as the danger to downstream communities from a slurry impoundment failure from the Brushy Fork Slurry Impoundment. Depending on the age group, social concerns such as the loss of community structure or the decrease in the quality of life for children were held unanimously. All of these concerns directly contradict the portrayal of the anti-MTR movement as constructed by outsiders bent on destroying local jobs and families.

Yet despite the universal nature of these concerns, the dominant discourse of coal continues to subjugate this discourse of resistance by claiming authority to "expert knowledge” and equating local knowledge with hearsay or ignorance. More specifically, the dynamics of the discourse of mountaintop removal pit "local miners" against “outsiders,” disempowering questions about risk and quality of life even more by associating those concerns with 'outsiders' uninformed with the daily sacrifice and dedication required to make a life in the southern coalfields.

My dissertation directly confronts this paradox - the local miner fighting for his/her job against outsider environmentalists - and shows it to be a fallacy. The subaltern discourse represented in this dissertation comes from a group of participants who live in the valley, some for many generations, and who are not again coal mining in general. The subaltern discourse is specific across discursive formations that local resistance is not again coal in general, despite the abusive and extractive history, but specifically against the practices of MTR. Considering the history of union organizing and community resistance in Coal River, it is illustrative of the power of King Coal that the dominant discourse continues to portray non-union coal companies as the insiders. Yet I argue that the power to define the discourse as between jobs and the environment, to decide what the two ideals are that are being balanced, has disempowered the subject position of the most important voice of resistance: the independent mountaineers of the coalfields. The rest of this chapter summarizes the overall findings and moves to conclusions. 


\section{8. a. Situating the Discourse of Resistance}

To begin, this dissertation had to situate the resistance to mountaintop removal coal mining within the broader conceptual themes that would guide the course of this study. The conceptual framework and literature review for this research pulled from diverse literatures including Foucault within geography, critical cartography and participatory GIS, and Appalachian political economy. Foucault's work on the relationships between knowledge, discourse and power were presented as the basis of the conceptual framework of this study due to my desire to highlight the power-knowledge relationships that discredit local voices of resistance. I gave an overview of the Foucauldian tools used for my conceptual framework as well as how the work of Foucault applies to mapping and geospatial technologies within geography. Foucault's archeological method and key Foucauldian terms such as discourse, discursive formations, and historical a priori were explained. Specific elements of Foucault's "archeological" method were introduced as an illustrative method to illustrate the dominant legal discourse of MTR. Using this Foucauldian framework, then, the subaltern discourse of resistance to MTR could be positioned as within a specific geographical and temporal emergence of the hegemonic, legal MTR discourse. Another virtue of this framework was the ability to approach and unearth power-knowledge relationships between the dominant and subaltern discourses of MTR that continue to subjugate the subaltern.

A methodology that could allow for transparent and power-conscious research methods was needed to gather the data to represent the discourse of resistance to mountaintop removal. Also, my methodology would need to be able to illustrate the place-based specialized knowledge of Coal River residents. Therefore, I drew from Critical GIS due to its concern with "power embedded in the production and use of technology" and a GIS that is "compatible with the emancipatory scholarship advanced by feminist researchers, post-structuralist scholars, Marxian scientists, and post-colonial thinkers” (Harvey et al, 2005, pg 1). This focus on power-knowledge relations within critical cartography / GIS, therefore, was an appropriate fit within the Foucauldian framework chosen for my study. Within critical cartography / GIS, I was drawn to authors such as Harley, Wood, Pickles 
and Crampton who integrated post-structuralist theory to see maps as constructed representations and sites of Foucault's power-knowledge. I saw applications in Wood's (1992) idea that "maps construct, not reproduce, the world," and that "the interest a map serves is often masked," to the masked power behind a permit map for surface mining. Wood's claim that these "hidden interests" could be revealed and then made to work for marginalized groups was described as a "manifesto" for counter mapping projects (Crampton and Krygier, 2006) and inspired my decision to chose participatory GIS to aid in representing the resistance to mountaintop removal.

Crampton (2001) draws upon Harley's work to suggest how his theories might translate into practice, and how Foucauldian power-knowledge can create spaces for the "possibilities of resistance." I drew upon Crampton's work connecting maps as sites of power-knowledge with Wood's proclamation that counter-mapping can be used to illustrate the "insurrection of subjugated knowledges" (Foucault, 1980, pg 81). Foucault gave two definitions of an "insurrection of subjugated knowledges," historical contents that had been buried or disguised as well as forms of knowledge that were disqualified or located low on the hierarchy: a "particular, local, regional knowledge” (Foucault, 1980, pg 82).

The potential revolutionary power that originally drew my attention to participatory GIS regarded the shifting of mapping power-knowledge from elites to subaltern perspectives in support of local social movements and advocacy. A PGIS methodology offers an avenue through which to integrate qualitative and quantitative methods and data (McClafferty, 2002; Kwan, 2002; Shuurman and Kwan, 2004; Abbot et al, 2008) with the goal of producing socially driven, inclusive research.

I facilitated a PGIS due to the importance of including qualitative data such as interviews and mental maps to represent the subaltern discourse of MTR in relation to larger powerknowledge regimes. These maps were incorporated into an online, multimedia website, JourneyUpCoalRiver.org, to be used for outreach and education. Additionally, residents can print out copies of the maps and use them locally to explain their concerns to their 
neighbors. I also chose PGIS due to my commitment to remove the barrier between the dichotomy of researcher/informant through the incorporation of participants into the power structures that can empower or marginalize. Elwood (2006) states that "a central tenet of PPGIS practice is its' commitment to incorporating local knowledge and representing multiple perspectives, but the ambiguities of the everyday practices that negotiate knowledge production in PPGIS illustrate the challenges of doing so” (pg 206). Applications such as PPGIS, CiGIS, and multimedia GIS could allow for productive inclusions of qualitative information such as pictures, video, oral history, and multiple forms of knowledge and spatial perceptions. Extensive literature review showed that communities could be empowered through PGIS using conflict resolution (Chapin, 2006; DeVera, 2005; Kyem, 2004), consensus building (DeVera, 2005), community interaction and networking (Harris and Weiner, 1998), formation of new leaders, use of "hidden interests” for marginalized groups (Wood, 1992), and increased access and participation in community and local resource planning (Aberly, 1993). However, I also found instances where PGIS could result in the loss of local control (McLafferty, 2005; Alcorn, 2000), generalization and abstraction of local issues when scale is “jumped” (Harris, 2006), cooption of data (Abbot et al, 1998), criminal prosecution (De Vera, 2005; Bujang, 2005), decrease of GRO performance due to time spent on PGIS (Sieber, 2000), privilege of expert data over local knowledge (Harris and Weiner, 1998), and legitimization of decisions that were not truly participatory (Harris and Weiner, 1998).

There was consensus, however, that the empowering or disempowering results of PGIS depended at least in part on the selection of culturally appropriate methods. Therefore, I turned to a third branch of literature to help situate the discourse of resistance within theories of poverty and culture in Appalachian Studies as well as outline the local social context for the selection of appropriate participatory methods: Appalachian Studies. To understand the context for subaltern and elite discourse within West Virginia, I first had to engage in the larger debates surrounding political economy and the evolving theories on culture and poverty in Appalachia. I presented a broad-brush overview of the progression of these theories with particular attention to the role of elites and patterns of absentee landownership in central Appalachia. Under the culture of poverty model, 
attention was put on the poor themselves instead of investigating the economic and political structures that both produced and then reproduced poverty. The internal colony model (Lewis et al, 1978; Eller, 1982; Rasmussen, 1994) introduced the political and economic aspects of absentee landowning patterns and the exploitation of local people by outside industry. Walls concludes by offering a variation of the internal colony model in which he proposed that Central Appalachia is best characterized as a peripheral region within an advanced capitalist society (1978).

Despite these steps forward in considering the political economy of Appalachia, these authors still largely portrayed Appalachia as homogenous. In both the internal colony and internal periphery models, all of Appalachia was considered to be part of the subaltern discourse disenfranchised by outside elites. Internal colony writers presented antebellum Appalachia as an isolated, subsistence farm culture lacking social stratification and ethnic differences. From this starting point, outside corporate interests came in and exploited Appalachian homogeneous "victims." Specific regional studies (Weise, 2001; Dunaway, 1996; Pudup et al, 1995; Mitchell, 1991; Dunn, 1988) focused on preindustrial Appalachia to provide a more realistic basis for academic discussion regarding the region's economic diversity as well as the role of local and outside elite in exploiting the Appalachia's natural resources. This shift in perspective on preindustrial Appalachia portrays Appalachians as becoming impoverished because they believed in the capitalist system, as opposed to earlier arguments that poverty was caused by Appalachian's disinclination and isolation from market systems.

My dissertation drew from Walls' internal periphery model to locate "subaltern" within the study area, but relied on recent scholarship to focus on the heterogeneous community of resistance and existence of multiple discursive formations within the discourse of MTR. The Foucauldian framework employed by this dissertation necessitated that unities, such as a singular discourse of resistance, be questioned. The use of subaltern to qualify the discourse of resistance in Coal River Valley allows for the existence of multiple discursive formations within the "history from below" at intersections between 
gender, age, and livelihood. Plainly put, my research focused on the voices of people concerned about MTR and allowed for different points of view regarding those concerns.

The voices of local residents concerned about mountaintop removal was now situated within a Foucauldian conceptual framework that emphasized power-knowledge relationships and placed the discourse within the Wall's internal periphery model. This "subaltern discourse" is illustrated using a participatory GIS methodology with an emphasis on inclusive and socially appropriate methods.

\section{8. b. Locating the Discourse within the Communities around Coal River Mountain}

This research focused on Coal River Valley as the geographical focus to investigate the physical impacts of mountaintop removal through the social concern of discourse originating from local residents. I chose the Coal River Mountain as the geographical surface of emergence for mountaintop removal and the communities surrounding the mountain as the source of qualitative information to represent the subaltern discourse for four reasons. Firstly, concerned residents in the communities surrounding Coal River Mountain had first-hand knowledge of the impacts of MTR due to their close proximity to two large MTR sites to the north and the west of the mountain. Secondly, Coal River Mountain was the last "mostly intact" mountain in the watershed, providing security and stability to residents impacted by blasting, flooding, and dust from neighboring MTR sites. Therefore, the potential loss of the protection of Coal River Mountain concerns residents across many different discursive lines. Thirdly, the combination of the previous factors has contributed to a rise in local resistance and organizing, allowing greater opportunities to access the subaltern discourse. And finally, considering the requirements of "time and trust" in building local relationships to support participatory research, I had established relationships with both community groups and local residents over a time period of six years prior to beginning this research. 
Using the internal periphery lens, the history of resource extraction within the case study area was highlighted as the historical a priori for the current use of surface mining and valley fill creation to extract coal. The Coal River Valley's wealth in coal and timber attracted a steady procession of people wishing to farm, hunt, mine, or harvest timber. Through the internal periphery lens, Coal River acted as an extraction zone to supply cheap natural resources to the dominant, core society. Much of the history of the Coal River valley showed conflicts between the people who controlled its natural resources, and the constant tensions around decisions to preserve or exploit the land and its people. The purchase of large areas of land by timber and mineral companies (Lewis, 1998; Rasmussen, 1994; Eller, 1982) seeking to provide much needed sources of fuel to the nation's industrial economy was highlighted. Although conventional strip mines had been operating in the Valley for close to 40 years, mountaintop removal did not become widespread in the valley until the 1980s, and produced larger scale impacts due to the methods of coal extraction and waste dispersal. Specifically, within the case study area, the permits for three mountaintop removal sites show that every headwater stream from Coal River Mountain will be filled with mining waste with the construction of eighteen valley fills. In response to the expansion of mountaintop removal, I also highlighted the challenges to this type of surface mining that sprung up across the coalfield through the grassroots groups of Coal River Wind, Pennies of a Promise, Kayford Mountain Heirs, Sludge Safety, and the non-violent direct action campaign of Climate Ground Zero.

I also situated my field work and research within the upwelling of direct non-violent civil disobedience to stop mountain top removal and raise awareness about the dangers of slurry impoundments, and the resulting tension within the community regarding this type of protest. Resistance in the form of union organizing and the formation of community groups within the case study area provided starting point for understanding some of the types of organizing and resistance within the case study area. Additionally, I immersed myself with literature and hands on experience regarding the importance of multiple livelihood strategies and community land use in understanding local concerns about MTR. 
While I understood that the culture of Coal River Valley was deeply connected to the use of the land and mountains for supplemental food, income, and community relationship, the intensity of that connection to land and home place still brought me to understand the first prominent theme within the subaltern discourse. This dissertation had originally sought to investigate the concerns of residents specifically regarding landscape change and use from mountaintop removal. However, local residents portrayed their landscape as a mountain landscape filled with families and communities, as opposed to a landscape for extraction of mineral resources or an environmental landscape for recreational purposes. The loss of Coal River Mountain represented the end of community access to one of the last mountains that could support recreational activities and multiple livelihood strategies for local residents. The use of the mountains by community members was important not only to strengthening communities and maintaining heritage, but also as a way to fight exploitation in both the cultural and material realms.

\section{8. c. Participatory Methods and Inclusive Research}

To understand the power-knowledge relationships subjugating the concerns of local residents, I drew on Foucault to develop my first research question: What are the legal discursive formations that define and allow the permitting of mountaintop removal (MTR) in the case study area? My Foucauldian framework requires an understanding of the conditions of possibility of a discourse; in this case, I chose to illuminate the legal and regulatory discourse that guided the permitting of MTR. Then I was able to proceed with my second research question: What are the subaltern discursive formations regarding the implementation of MTR in the case study area? . I draw from the literature on PGIS to situate the use of participatory maps as "insurrections of subjugated knowledges" (Foucault, 1980, p.81) within the "maps as social construction approach” (Harley, 1988; Wood, 1992; Pickles, 1995; Crampton, 2001) to address this question. The strength of this combination of PGIS methodologies and Foucauldian theory allowed for the conceptual placement of the subaltern discourse within a specific geographical and temporal emergence of the dominant discourse of MTR. The use of a PGIS approach to 
construct the subaltern discourse allowed me to create space for local residents in the case study area to provide "expert" data regarding their concerns and to play an active role in how their concerns and home place were represented in this research.

Residents in the Coal River Valley were not given meaningful opportunities, nor access to the "decision-making arena" (Barndt, 2002), regarding natural resource decisions around their homes. Therefore, it was essential to me to choose methods that emphasized local knowledge as 'expert' as well as context-specific data collection methods to draw out the subaltern discourse A primary goal of PGIS methodology is that research must do more than just describe or analyze social reality: it must work towards changing it. PGIS methodology emphasizes both the process (community organizing) as much as the actual product (the map) itself, as noted by the review of three PGIS case studies in Chapter Two. The emphasis on participatory mapping as opposed to just participatory methods derives from the geographical nature of mountaintop removal both in terms of its direct physical impact on the landscape and the location of communities impacted by the process. Although PGIS methodologies hold great potential to aid local empowerment, this study assumed that Coal River is a socially differentiated community in which differential access to resources may simultaneously empower and marginalize community members (Weiner et al, 2002).

I chose four data collection methods for this research: mini-archeology construction, base map construction, semi-structured interviews, and participatory mental mapping. My choice of appropriate methods was influenced by the importance of themes within the PGIS overview such as dis/empowerment of communities and individuals through the process, product, and long term outcome of PGIS research, legitimization by participation, the role of researcher/facilitator, and the importance of transparency and trust. The construction of a mini-archeology was the primary method used to collect data for my first research question. Applied to my dissertation, I applied Foucault's archeological method to understand how the legal discursive formations around MTR created the "conditions of possibility" for MTR to exist in the case study area. Semistructured interviews were the primary qualitative input to answer my second research 
question. The first round of "initial interviews" was semi-structured (Dunn, 2005) with room for open ended questions at the end. Questions focused on concerns regarding landscape change and alternative land use in the Coal River Valley. I used contacts with these initial gatekeepers to gain access to other informants through the snowball sampling method. Snowball, or chain sampling, identifies other potential participants from the connections of the original gatekeepers (Dunn, 2005). In this research, gatekeepers are people within the study area who are well connected with residents active within the discourse of resistance against MTR. Bias. However, as data collected to answer my second research question was not meant to be representative of the entire Coal River community, but rather of local residents resisting mountaintop removal, I chose it for this study. The construction of base maps was the first method used to address my second research question regarding subaltern discourse in the case study area. Due to the participatory methodology of this study, the construction of base-maps involved several stages to allow for greater transparency and participation. Chambers (1994a) listed and highly recommended participatory mental mapping as a data source for researchers working with marginalized groups. Participatory mental mapping was used to evoke the spatial discourse of landscape change in the valley.

\section{8. d. Unpacking the Original Construction of Mountaintop Removal}

My analysis began with the construction of a mini-archeology to elicit data for my first research question regarding the legal discourse of MTR. I drew from Foucault's archeological method to unpack the formation of MTR as an object using three dimensions: surfaces and temporalities of emergence, authorities of delimitation, and grids of specification. The first step focused on the original legal construction of MTR through two federal statues: the Surface Mining Control and Reclamation Act of 1977 and the Clean Water Act of 1972. Under SMCRA, the land must be restored to a condition that can support premining land use, must not present any "actual or probable 
hazard to public health or safety," nor any threat of water pollution. Companies are required to restore the mountain to "approximate original contour," although debate continues regarding how to do so, or apply for a Section C "AOC variance" which would allow the mountain to remain flattened if there is a "higher and better use.” Regarding the creation of valley fills, the CWA provides authorization for the Corps to issue 404 permits to discharge fill material in the "navigable waters of the United States" with the qualification that the discharge will not have an "unacceptable adverse effect on municipal water supplies,” fisheries, wildlife, or recreation areas.

The second step of my mini-archeology focused on the reconstruction of MTR through "rule-making" agencies that were given the authority by federal statutes to write the regulatory mechanisms that would govern the permitting of surface mining and valley fills. SMCRA is administered by the Office of Surface Mining (OSM), and the Clean Water Act is administered by the Environmental Protection Agency (EPA) and the U.S. Army Corps (Corps). OSM specifically regulated AOC variances and took steps towards defining what post mining land uses constituted better usage: industrial, commercial, agricultural, residential, and public facility. The process of defining and requiring that a surface mine site without an AOC variance was actually restored to AOC remains in debate today. The Corps proceeded to define "fill material" as excluding any "pollutant discharged into the water primarily to dispose of waste, therefore centering much of the debate regarding valley fill permitting around the definition of the word "fill." Additionally, the distinctions between general permits and individual permits continued to evolve.

In the final step, three surface mine permits on Coal River mountain were reviewed within the grids of dispersion outlined by the legal and regulatory formation of mountaintop removal. As defined by the WVDEP, the permitting agency for the surface mine permits, I discovered that none of these three permits were classified as mountaintop removal, despite the fact multiple seams are being accessed using explosives with the intent to place fill in neighboring hollows. None of the three surface mine permits had AOC variances, but the active site, Bee Tree, had been challenged already 
before the Surface Board regarding the AOC requirements that are in place for the reclamation plan. All three permits had forestland as a pre-mining land use, yet plan to replace the forest with wildlife habitat, a lower land use. Finally, all three permits had a variance for contemporaneous reclamation, allowing Marfork coal to post a 5,000 bond per acre in case reclamation is not finished. Despite the requirement that Marfork coal apply for CWA 404 individual permits for the 6 valley fills on the first permit, work has already on the Bee Tree permit. Marfork was able to dispose of overburden by using an "incidental boundary revision" on the neighboring permit, the Brushy Fork Slurry Impoundment, to dispose of overburden without going through the Clean Water Act. In fact, despite the regulatory definition of the Corps authority of the "waters of the United States," the surface mine board found that the Brushy Fork Impoundment was not within the jurisdiction of the Corps.

\section{8. e. The Mountaineer Meets Mountaintop Removal}

My second data analysis chapter moved to address my second research question regarding the discourse of resistance to MTR. The chapter began with an introduction to the fifty nine participants who participated. As one of the primary purposes of this research was to represent the perspectives of local residents, as opposed to "outsiders," regarding mountaintop removal, I made an effort to interview residents who had strong and often multi-generational connections with the land. All participants interviewed currently lived within the study area during the time of the interview. The average length of residency for participants was 44 years. Additionally, due to the history and importance of coal mining in the area, it was important to speak with residents who were familiar with the coal industry. 81\% of all participants had a family history of coal mining or had current family members working as either underground miners or strip miners. 
As expressed in the title of this chapter, "So go the mountains, so goes the mountaineer" (CR\#20), the traditions of community land use and multiple livelihood strategies meant that concerns about environmental impacts come bundled with numerous social concerns as well. Therefore, participant concerns grouped into two categories: impacts on the physical landscape, and the resulting social impacts on individuals, families, and communities. The highest concerns held by all residents regarding the impacts of MTR on the landscape included increased flooding (90\%), loss of water quality (69\%), slurry impoundment failure (68\%) and deforestation (54\%). The highest perceived social impacts included loss of community structure (92\%), blasting damage (71\%), loss of access to the mountain (71\%), destruction of home place (69\%), decreased quality of life for children (59\%), increased coal dust (54\%), dangerous traffic and roads (53\%) and loss of heritage / culture (53\%).

Not all residents were able to represent their concern initially, or at all, with specific problems. Some residents described the Coal River as a whole much greater than the sum of all its parts. A key finding was that outside of the concerns that were grouped into environment or social, a discursive formation of MTR as "total destruction” of all associated social and environmental values was revealed. Participants used phrases such as "unrepairable damage," "everything is gone," or "a wasteland as far as humanity is concerned" to describe the impacts of mountaintop removal. Participatory maps of flooding impacts, dangers from blow outs, and blasting impacts were introduced in the discussion of highest environmental impacts. I then moved to focus geographically on the concerns of residents living Horse Creek, Rock Creek, and Sycamore.

After a discussion of these concerns and related participatory maps, I investigated the subaltern discursive formations at intersections of gender, age, and means of subsistence. Thus far, my analysis had mostly focused on the 'unities' of concern held by the participants in this study. I moved to interpret the discursive formations found within data from interviews and participatory mapping to bring forward different formations within the subaltern discourse. When broken down by gender, participant concerns regarding impacts on the landscape are very similar. While men and women do seem to 
agree about the highest landscape concerns, their perspectives differ when we move on to the associated social impacts: women showed a higher concern for the decreased quality of life for their children, while men showed a higher concern for the loss of access to the mountain. The most interesting finding regarding age was that every single participant under the age of 40 requested that their interview be kept completely confidential. This age group also shared a 100\% concern about increased flooding, loss of community structure, deforestation, and decreased quality of life for children. In the group of participants within the ages of 40-59, the concern about blasting impacts on homes, destruction of the home place, and loss of heritage / culture was more elevated than within the under 40 age group. The 60+ age group is the only discursive formation thus far showing "loss of community structure" as the highest concern. This concern is understandable, as the older residents can remember the valley before MTR started and, as discussed in the review of this theme, often miss the tight knit relationships between family and community that existed before. Increased flooding, loss of access to the mountain, slurry impoundment failure, and destruction of home place were the other top concerns. Dangerous traffic and roads were significantly higher for participants over the age of 60 than in the other groups. When investigated by type of employment, this research yielded another interesting find: $52 \%$ of the participants who have worked or currently work for the coal industry cite the "loss of jobs" as an social impact of mountaintop removal: the percentage is even higher from the point of currently employed miners (67\%). Therefore, the participants in this study most closely connected with coal mining consider mountaintop removal to be hurting jobs in the area.

\section{8. f. Insurrections of Subjugated Knowledges}

Foucault stated that in order to do an "analysis of power... we must speak of powers and try to localize them in their historical and geographical specificity' (Crampton and Elden, 2007, pg 6). In my final data analysis chapter, I investigated the power-knowledge relationships between the dominant and subaltern discourses of MTR as represented thus 
far in this dissertation. My analysis proceeded in two steps to address the objectives of this study. First, to address the question of how dominant discursive formations continued to subjugate the subaltern discourse of MTR, I situated the subaltern discourse within the conditions of possibility created by the legal construction of MTR. I interpreted specific themes to address how the specialized forms of knowledge empowered within the dominant discourse work to discredit local knowledge and positioned the PGIS maps in relation to a permit map of the Bee Tree surface mine. A primary finding of this comparison was that residents looking online on the WVDEP site for local surface mines might be hampered by issues of access as well as lack of knowledge regarding what is missing on the maps. Participatory maps included information about what the land "holds," as opposed to just required data about the boundaries of land directly impacted by the surface mining and data on roads, streams, and towns.

Second, the chapter focused on where the subaltern perspective, as represented in the previous chapter, extended beyond the conditions of possibility constructed by the dominant discourse. This section unpacked where local knowledge addresses the impacts of MTR outside of the dominant legal discourse. The analysis of the relationship between the subaltern discourse of MTR in the Valley and the dominant discourse that created and permits MTR raised three possible spaces for the "possibilities of resistance” (Crampton, 2001, 236): the portrayal of the impacts of mountaintop removal as "total devastation,” the representation of local, multigenerational, mining-situated perspectives as expert knowledge, and the use of participatory research and counter mapping to provide tangible evidence and support this local, expert knowledge. In his 1980 afterward to Power/Knowledge, Colin Gordon theorizes on the ethical applications of Foucault's work: “For the recent eruptions of 'popular knowledge' and 'insurrections of subjugated knowledges' which he celebrates, what Foucault may have to offer is a set of possible tools, tools for the identification of the conditions of possibility which operate through the obviousness and enigmas of our present, tools perhaps also for the eventual modification of those conditions” (Foucault, 1980, pg 258). 
Applying Foucault, then, if local knowledge is privileged as expert, as stated in this dissertation, how could the subaltern discourse then relate back to the original statues in meaningful ways? Can the empowerment of local knowledge as expert be the "miniscule displacement" referenced above? And if so, perhaps the most important question is how can power-knowledge relationships between local residents and current authorities of delimitation be negotiated to empower and give meaningful access to concerned coalfield residents? If the dialogue of total destruction could be heard as "truth" by more local residents, could the origin of threat slowly begin to shift for pro-MTR miners from "outsider agitators" to the coal industry itself? This dissertation asserts that a possible space of resistance exists from which multi-generational residents with a past or current history of coal mining can directly address the impacts of mountaintop removal. The representation of concerns by local, multigenerational miners and their families directly questions the unity presented by the coal industry and in the media of "West Virginia miners” standing in solidarity against mountaintop removal against outsiders.

\section{8. g. Contributions and Additional Research}

This dissertation presents three major contributions. Firstly, it represents the first application of PGIS methodologies to southern West Virginia. At the beginning of this dissertation, that sounded like only an academic claim. However, after seeing the success of the participatory maps created thus far, other groups are beginning to use more participatory mapping methods as well. For example, the creation of Edwight watch, focused on monitoring the permits and boundaries on Cherry Pond mountain, will include the ability of local residents to contribute their "local" knowledge. Additionally, Coal River Mountain Watch is moving towards more similar projects that encourage citizen enforcement and use participatory mapping technologies to empower local knowledge to be recognized as expert knowledge, a space of resistance that I identified in this dissertation. 
Secondly, my dissertation is the first application of Foucault to the discourses of MTR. While highly technical at times and with some difficult vocabulary, the application of Foucault allowed for my third contribution: illuminating the spaces of "possibility of resistance” within the dominant discourse of MTR. These spaces of resistance will be shared with community groups working against MTR through a summary document created from this dissertation. Additional outcomes included written testimony regarding community concern about the location of Marsh Fork elementary and the creation of a participatory multimedia website, www.JourneyUpCoalRiver.org, through Aurora Lights. This website is based around an interactive map of the Coal River valley and contains interview segments, pictures, and lesson places for educators about the culture and history of the Coal River Valley. The website won the 2010 e-Appalachia website of the year award from the Appalachian Studies Association, and work has continued on the website through the include of a section on mapping community resources.

Unlike more quantitative research, this dissertation does not represent the actual flooding damage or changes in water quality, for example, caused by mountaintop removal. Instead, this dissertation looks at the impacts of mountaintop removal from a different perspective: not from the "tree hugger," not from the pro MTR miner, but from the perspective of Coal River residents who are concerned about changes in their families, communities, and their mountains. This research hopes to make a kaleidoscopic shift in perspective in the polarized debate regarding mountaintop removal by focusing on the concerns of ordinary people who live near mountaintop removal mines and valley fills. I hope that this dissertation can be used as a launching pad of ideas for scholars who want to design their research in line with community needs and concerns. Here are a few specific research areas that could address resident concern:

1. Quantitative and qualitative research is needed on the impacts of blasting on homes both within the required buffer areas as well as outside of the buffer zone.

2. Loss of community structure was a theme that was overwhelmingly held across discursive formations. Research is needed to draw more specific and further connections between mountaintop removal and the loss of community. 


\section{8. h. Conclusion}

I would like to know what's wrong with the elected officials in this state that's supposed to take care of the people. And there's not one thing, nothing, that they do. Absolutely nothing. They leave us here-I don't think they've even come and looked, at the destruction, the poison, what's going on, what they're doing to the people. They're tearing up your home, they run people out. This, at one time, was a large community, right here, where I live. And now, there's seven families here. And there was, oh good heavens, at least 150 wasn't there? (CR\#13)

As the dominant driver of landscape change in central Appalachia (Saylor, 2008), "mountaintop mining” or "mountaintop removal” is a controversial issue that has finally gained some access to debate at the national level. The environmental impacts of this form of surface mining and associated creation of valley fills are increasingly documented. In January of 2010, the peer-reviewed paper, “Mountaintop Mining Consequences,” was published in Science. More than a dozen scientists, including several members of the National Academy of Sciences, co-authored the paper. The authors offer the following conclusion:

Considering environmental impacts of MTM/VF, in combination with evidence that the health of people living in surface-mining regions of the central Appalachians is compromised by mining activities, we conclude that MTM/VF permits should not be granted unless new methods can be subjected to rigorous peer review and shown to remedy these problems. Regulators should no longer ignore rigorous science. (Palmer et al, 2010)

Yes, regulators need to listen to rigorous science that substantiates the claims of local residents that if the environmental impacts of mountaintop removal were internalized into the cost of producing electricity from coal, it would no longer be the cheapest source of electricity for the nation. Regulators need also listen to the concerns of local residents about the social impacts on their families and communities that are associated with landscape change and use from mountaintop removal coal mining. Although many of the social concerns can not be directly regulated by current statues and regulatory mechanisms, their existence outside of the conditions of possibility created through the 
original formation of MTR as an object does offer a possibility: a possibility of meaningful resistance again the ravages of this mining practice.

The original intent of both SMCRA and the CWA was to protect the public from the hazards and risks of surface mining and protect the nation's water supply from contamination and use as a disposal for rock and pollutants. The subaltern discourse plainly shows that the original intent of both these federal statues is not being followed on the ground in the Coal River Valley. The dominant discourse of coal continues to subjugate this discourse of resistance by claiming authority to "expert knowledge" and equating local knowledge with hearsay or ignorance. More specifically, the dynamics of the discourse of mountaintop removal pit "local miners" against "outsiders," disempowering questions about risk and quality of life even more by associating those concerns with 'outsiders' uninformed with the daily sacrifice and dedication required to make a life in the southern coalfields.

A primary finding of this dissertation is that the way the subaltern discourse interprets the landscape contradicts both the environmental concerns of the "outsiders" and the economic concerns of "local miners", law makers, and mining companies. Participants in Coal River clearly see their homeland as much more than just an economic or environmental landscape. While residents do share many environmental and economic concerns, their interpretation of changes in their landscape includes associated social concerns that can not be separated from the environmental concerns. Ironicly, this point brings us back to Senator Byrd's statement that West Virginia's people are its most important resource. The subaltern discourse clearly prioritizes the people of the coalfields as the highest resource, above the extractive or environmental resources; the people and their connection to their land, to their independent and sustainable way of life, and their right to raise their children in a safe and healthy way, as was done generations before them.

I argue that the dialogue of total devastation, if represented as expert knowledge by local, multigenerational, mining-situated families, has the potential to shift attention away from 
polarized debate and towards the experiences of the people who best understand the daily sacrifices required when living in an "extraction state.” I assert that the reason for framing the discourse of "total devastation" as one that originates outside of West Virginia is to maintain division within the community by asserting that environmentalists and treehuggers, not the coal industry, is the outside threat. If the dialogue of total destruction could be heard as "truth" by more local residents, could the origin of threat slowly begin to shift for pro-MTR miners from “outsider agitators” to the coal industry itself?

The subaltern discourse of resistance directly challenges the polarized portrayal of “outsiders” versus "local miners” in additional ways as well. Firstly, all of the participants in this study are local residents of Coal River, most of them come from mining families, and many of them are current or retired underground miners. The discourse of resistance illustrated in this dissertation is a local discourse that discredits the presentation of anti-MTR concerns as belonging only to "outsider agitating treehuggers” (OATS). The dominant claim that MTR is about providing good jobs to local residents is also unpacked by the finding that "job loss” as a result of MTR is a primary concern of current and retired miners. Local miners represented in this discourse clearly argue that they are not concerned about coal mining in general, (in fact they encouraged more underground mining, if done safely) but rather are concerned specifically about the practice of MTR.

This dissertation argues that "spaces of resistance" can be found by treating local knowledge as expert knowledge, and focusing on the representation of "total devastation" as the expert concerns of multigenerational residents with coal mining heritages. Situated in this way, the dominant discourse can not discredit these claims by associating them with outsiders. This dissertation also argues that participatory mapping projects have the potential to aid in the representation of local knowledge as expert knowledge. This change in perspective could be the 'miniscule displacement' that Foucault speaks of regarding the 'insurrection of subjugated knowledges.' 
To support the representation of local knowledge as expert, an opportunity presents itself for partnerships between non-profit organizations and students to work with community groups to illustrate this locally grounded reality about the true cost of mountaintop removal. It is my hope that this research will serve as a starting point for additional participatory projects that put the concerns and inclusion of coalfield residents as guiding methodological principles. 


\section{References}

Abbot, J., Chambers, R., Dunn, C., Harris, T., de Merode, E., Porter, G., Townsend, J., and D. Weiner. 1998. "Participatory GIS: Opportunity or oxymoron?" Participatory Learning \& Action PLA Notes (IIED, Sustainable Agriculture \& Rural Livelihoods), PLA 33, 27-34.

Aberly, D. 1993. Boundaries of Home: Mapping for local empowerment. Philadelphia, PA: New Society Press.

Alcorn, J. 2000. "Borders, rules and governance: Mapping to catalyze changes in policy and management.” Gatekeepers Series no. 91. IIED, London. www.iied.org/agri/gatkeep.htm

Appalachian Land Ownership Task Force. 1981. Land Ownership Patterns and Their Impacts on Appalachian Communities: A Survey of 80 Counties. Washington, DC: Appalachian Regional Commission.

Appleby, M.K. 1999. "Women and Revolutionary Relations: Community-Building in Appalachia.” In Neither Separate Nor Equal: Women, Race, and Class in the South, ed. B. E. Smith, 171-184. Philadelphia: Temple University Press.

Armstrong, M. P. and Ruggles, A. J. 2005. "Geographic information technologies and personal privacy.” Special issue: Critical GIS. Harvey, F., Kwan, M, and M. Pavlovskaya, eds. Cartographica 40(4), 63-73.

Aurora Lights. 2009. “Community Land Use in Coal River Valley,” Journey Up Coal River. http://auroralights.org/map_project/theme.php?theme=crm\&article=4. Accessed 5/15/10.

Barndt, M. 1998. "Public Participation GIS - Barriers to Implementation.” Cartography and Geographic Information System, Special Issue: Public Participation GIS. 25(2):105-112.

Batteau, A.W. 1990. The Invention of Appalachia. Tucson: University of Arizona Press.

Becker, J.S. 1998. Selling Tradition: Appalachia and the Construction of an American Folk, Chapel Hill: University of North Carolina Press.

Billings, D. 1974. "Culture and Poverty in Appalachia: A Theoretical Discussion and Empirical Analysis.” Social Forces. V53: 2., pgs 315-323.

Billings, D.B. and A. Tickamyer. 1993. “Uneven Development in Appalachia.” In Forgotten Places: Uneven Development in Rural America, ed. T. Lyson and W. Falk, 7-29. Lawrence: University Press of Kansas. 
Billings, D.B., Norman, G., and K. Ledford, eds. 1999. Back Talk from Appalachia: Confronting Stereotypes. Lexington: University Press of Kentucky.

Billings, D., and Blee, K. M. 2000. The Road to Poverty: The Making of Wealth and Hardship in Appalachia._Cambridge: Cambridge University Press.

Bone, W.D. 1994. The History of the Headwaters of Big Coal River in Southern West Virginia, 2 vols. Elkview, W.Va.

Boyer, J.C. 2008. "Reinventing the Appalachian Commons," in The Global Idea of 'the Commons'. Edited by Donald M. Nonini, 89-114. New York: Berghahn Books.

Bradford, R. 2008. "Site of plane crash will be stripped." September 6, Register Herald, www.register-herald.com/letters/x519102912/Our-Readers-Speak-Sunday-Sept-7$\underline{2008}$

Bujang, M. 2005. “A Community Initiative: Mapping Dayak’s Customary Lands in Sarawak.” Paper presented at the Regional Community Mapping Network Workshop, November 8 - 10, 2004, Diliman, Quezon City, Philippines.

Burns, S. 2007. Bringing Down the Mountains: The Impact of Mountaintop Removal on Southern West Virginia Communities. Morgantown: West Virginia University Press.

Braun, E.L. 1947. "Development of the Deciduous Forests of Eastern North America," Ecological Monographs, Vol. 17, No. 2, Ecological Society of America, p. 211219. http://www.jstor.org/stable/1943265

Caudill, L.M. 1963. Night comes to the Cumberlands: A biography of a depressed area. Boston: Little, Brown and Company.

Chambers, R., and G. Conway. 1992. Sustainable rural livelihoods: practical concepts for the 21st century. Brighton: Institute of Development Studies.

Chambers, R. 2006. "Participatory mapping and geographic information systems: Whose map? Who is empowered and who disempowered? Who gains and who loses?” EJISDC, 25(2), 1-11.

Chapin, M. 2006. "Mapping projects: identifying obstacles, finding solutions." Participatory Learning and Action 54: 93-97.

Cherniavsky, E. 1996. "Subaltern studies in a U.S. frame.” Boundary 2, Vol. 23, No. 2 (Summer), Duke University Press. pp. 85-110. http://www.jstor.org/stable/303808 
Chrisman, N. 2005. "Full circle: More than just social implications of GIS.” Special issue: Critical GIS. Harvey, F., Kwan, M, and M. Pavlovskaya, eds. Cartographica 40(4):23-35.

Coal River Mountain Watch. 2009. Retrieved October 15, 2009, from http://www.crmw.net.

Corbett, J., Rambaldi, G., Kyem, P., Weiner, D., Olson, R., Muchemi, J., McCall, M. and R. Chambers. 2006. IIED, Special Issue on "Mapping for change: Practice, technologies and communication." Participatory Learning and Action, 54: 1 -13, London.

Craig, W.J., Harris, T.M., and D. Weiner, eds. 2002. Community participation and geographic systems. New York, NY: Taylor and Francis.

Crampton, J.W. 2001. "Maps as social constructions: power, communication and visualization.” Progress in Human Geography, 25 (2), 235-252.

Crampton, J.W. and J. Krygier. 2006. “An Introduction to Critical Cartography.” In L. Harris and M. Harrower (Eds.), Special Issue: Critical Cartographies, ACME: An International E-Journal for Critical Geographies, 4 (1), 11-33.

Crampton, J.W. and S. Elden, Eds. 2007. Space, knowledge and power: Foucault and geography. Burlington: Ashgate.

Davis, C. 2008. "Preemptive Federalism or Regulatory Dismantlement? The Bush Administration's Implementation of the Federal Coal Mining Reclamation Program," Politics \& Policy, 36:3, pp. 400-418(19).

De Vera, D. 2005. "Mapping with communities in the Philippines: Rolling with the punches.” Presented during the PGIS conference in Nairobi, Kenya, Sept. 7-10.

Dix, K. 1988. What's a Coal Miner to Do? The Mechanization of Coal Mining. Pittsburgh: University of Pittsburgh Press. Pittsburgh Series in Social and Labor History.

Drew, C. 2003. "Transparency - Considerations for PPGIS research and development.” URISA Journal 15 (1):73-78

Dunaway, W.A. 1996. The First American Frontier: Transition to Capitalism in Southern Appalachia, 1700-1860. Chapel Hill: University of North Carolina Press.

Dunn, D. 1988. Cades Cove: The Life and Death of a Southern Appalachian Community 1818-1937. Knoxville: University of Tennessee Press.

Eades, R. 2000. "Brushy Fork Slurry Impoundment Final Report.” Prepared for the 
Ohio Valley Environmental Coalition, Dec., 8, 2000.

Eller, R.D. 1982. Miners, Millhands, and Mountaineers: Industrialization of the Appalachian South, 1880-1930. Knoxville: University of Tennessee Press.

Ellis, F. 1998. "Survey article: Household strategies and rural livelihood diversification." The Journal of Development Studies. 35(1): 1-38.

Elwood, S. 2006. "Negotiating Knowledge Production: The Everyday Inclusions, Exclusions, and Contradictions of Participatory GIS Research.” The Professional Geographer 58 (2):197-208.

Escobar, A. 1988. "Power and visibility: The invention and management of development in the Third World." Cultural Anthropology 3(4): 428-443.

Escobar, A. 1992. "Imagining a Post-Development Era? Critical Thought, Development and Social Movement." Social Text: Third World and Post-Colonial Issues, 31/32, pgs. 20-56. Duke University Press. http://www.jstor.org/stable/466217 Accessed: 26/08/2008 12:54.

Escobar, A. 1995. Encountering development: the making and unmaking of the Third World. New Jersey: Princeton University Press.

Ferrari, J., Lookingbill, T., McCormick, B., Townsend, P., and K. N. Eshleman. "Surface mining and reclamation effects on flood response of watersheds in the central Appalachian Plateau region.” Water Resources Research, Vol. 45. W04407.

Fisher, S.L. 2002. "Victim-Blaming in Appalachia: Cultural Theories and the Southern Mountaineers.” Appalachia: Social Context Past and Present. Bruce Ergood and Bruce Kuhre, eds, Third Edition. Dubuque: Kendall/Hunt, pp. 185-94.

Flynn, T.R. 2005. Sartre, Foucault, and Historical Reason, Vol. II: A Poststructuralist Mapping of History. Chicago: University of Chicago Press.

Fones-Wolf, K., and R. Lewis, eds. 2002. Transnational Appalachia: Ethnic communities and economic Change, 1840-1940. Morgantown: West Virginia University Press.

Foucault, M. 1970. The order of things: an archaeology of the human sciences. New York: Vintage.

Foucault, M. 1972. The archaeology of knowledge. London: Tavistock Publications.

Foucault, M. 1976. The history of sexuality, Vol 1. Paris: Gallimard. Translated by Robert Hurley. Harmondsworth: Penguin, 1978. 
Foucault, M., 1977. Discipline and punish. The Birth of the Prison, London: Penguin Books.

Foucault, M. 1980. Power / Knowledge. Harvester, Brighton.

Gaventa, J. 1980. Power and Powerlessness: Quiescence and Rebellion in an Appalachian Valley. Urbana: University of Illinois Press.

Guha, R. and G. C. Spivak. 1988. Selected subaltern studies. New York: Oxford University Press.

Halstead, Randy. Interviewed by Mary Hufford. October 26, 1995. The Library of Congress: American Memory Tending the Commons: Folklife and Landscape in Southern West Virginia. From the Library of Congress, http://memory.loc.gov/ammem/collections/tending/.

Hannah, M. 2007. "Formations of 'Foucault' in Anglo-American Geography: An Archeological Sketch.” In J. Crampton and S. Elden (Eds.), Space, knowledge and power: Foucault and geography (pp.83-106). Burlington: Ashgate Publishing. Pg 83-106.

Harley, J.B. 1988. "Maps, knowledge, and power.” In Cosgrove and Daniels (Eds.), The Iconography of Landscape: Essays on the Symbolic Representation, Design, and Use of Past Environment. Cambridge University Press.

Harley, J.B. 1989. “Deconstructing the map.” Cartographica 26, 1-20.

Harris, L.M., and H.D. Hazen. 2006. "Power of Maps: Counter Mapping for Conservation.” In Special Issue: Critical Cartographies, Harris, L., and Harrower, M., ACME: An International E-Journal for Critical Geographies, 4 (1), 99-130

Harris, T., and D. Weiner. 2002. "Implementing a Community-Integrated GIS: Perspectives from South African Fieldwork," In W. Craig, T. Harris, and D. Weiner (Eds.), Community Participation and Geographic Information Systems (pp. 246-258). London: Taylor and Francis.

Harris, T., and D. Weiner. 1996. "GIS and Society: the Social Implications of How People, Space, and Environment are Represented in GIS.” Scientific Rept. for Initiative 19 Specialist Meeting, South Haven, MN, March 1996. Santa Barbara, CA: NCGIA, Varenius Tech. Rept. No. 96-7. http://www.ncgia.ucsb.edu/Publications/Tech_Reports/96/96-7.PDF

Harris, T., and D. Weiner. 1998. "Empowerment, Marginalization and Community -Integrated GIS.” Cartography and Geographic Information Systems, 25(2): 6776. 
Harris, T. 2006. "Scale as Artifact: GIS, Ecological Fallacy, and Archaeological Analysis.” In Lock and Molyneaux (Eds.), Confronting Scale in Archaeology: Issues of Theory and Practice (pp. 39-53). New York: Springer.

Harvey, F., Kwan, M., and M. Pavlovskaya. 2005. "Introduction: Critical GIS.” In Harvey, F., Kwan, M, and M. Pavlovskaya (Eds.), Special issue: Critical GIS, Cartographica (pp. 1-3). 40(4).

Hayden, W. 2004. “Appalachian diversity: African-American, Hispanic/Latino, and other populations.” Journal of Appalachian Studies, Special Issue: Appalachia Counts. Region in 2000 Census, Vol. 10(3): 293-306.

Hechler, K. 2007. “Mountain Top Removal: Scourge of the People.” Published in Coal Country (2009) titled "How Congress Enabled Mountaintaintop Removal." Sierra Club Books.

Hendryx, M. and Ahern, M. 2009. Mortality in Appalachian Coal Mining Regions: The Value of Statistical Life Lost. Public Health Reports. July-August. Volume 124.

Hicks, R. 1998. Ecology and Management of Central Hardwood Forests. Wiley and Sons.

Hinsdale, M.A., Lewis, H.M., and S.M. Waller. 1995. It Comes From the People. Philadelphia: Temple University Press.

Hook, D. 2001. "Discourse, knowledge, materiality, history: Foucault and discourse analysis." Theory Psychology,11, pgs 521-547. http://tap.sagepub.com/cgi/content/abstract/11/4/521

Hufford, M. 2002. "Landscape and History at the Headwaters of the Big Coal River Valley: An Overview.” The Library of Congress: American Memory Tending the Commons: Folklife and Landscape in Southern West Virginia. From the Library of Congress, http://memory.loc.gov/ammem/collections/tending/

Kennedy, R.F. 2009. “A president breaks hearts in Appalachia.” The Washington Post, July 3, 2009. http://www.washingtonpost.com/wp-d yn/content/article/2009/07/02/AR2009070203022.html

Kindon, S. 2001. “Participatory action research.” In Hay (Ed.), Qualitative Research Methods in Human Geography (pp. 207-220). Second edition. Oxford: Oxford University Press.

Kingsolver, A.E. 1991. Tobacco, Toyota and subaltern development discourses: Constructing livelihood and community in rural Kentucky. Ph.D. Dissertation, University of Massachusetts. 
Kingston, R. 2007. "Public participation in local policy decision-making: the role of web based mapping.” The Cartographic Journal, 44(2), 138-144.

Kwan, M. 2002. "Feminist Visualization: Re-envisioning GIS as a Method in Feminist Geographic Research.” Annals of the Association of American Geographers, 92(4):645-661.

Kwan, M. 2002. "Is GIS for women? Reflections on the critical discourse in the 1990s." Gender, Place, and Culture. 9 (3): 271-79.

Kyem, P.A. 2002. Promoting local community participation in forest management through a PPGIS application in Southern Ghana. Community participation and geographic information systems. London: Taylor and Francis, pgs 218-231.

Latimer, M., and A.M. Oberhauser. 2004. "Exploring Gender and Economic Development in Appalachia.” Journal of Appalachian Studies, Special Issue: Appalachia Counts. Region in 2000 Census, Vol. 10(3): 269-291.

Lessa, I. 2006. "Discursive struggles within social welfare: Restaging teen motherhood.” British Journal of Social Work. 36: 283-298.

Lewis, R. L. 1987. Black coal miners in America: Race, class, and community conflict:1780-1980. Kentucky: The University Press of Kentucky.

Lewis, R. and D.B. Billings. 1997. “Appalachian Culture and Economic Development: A Retrospective View on the Theory and Literature,” Journal of Appalachian Studies 3(1): 3-42.

Lewis, R. 1998. Transforming the Appalachian Countryside: Railroads, Deforestation, and Social Change in West Virginia, 1880-1920. Chapel Hill: University of North Carolina Press.

Lewis, H.M., Johnson, L., and D. Haskins, eds. 1978. Colonialism in Modern America: The Appalachian Case. Boone, North Carolina.

Loeb, P. 2003. The Coalfield Communities of Southern West Virginia. Retrieved 6/10/10, from http://www.wvcoalfield.com/.

Macey, D. 1993. The Lives of Michel Foucault: A Biography. New York: Pantheon Books.

Maggard, S.W. 1987. “Women’s participation in the Brookside coal strike: Militance, class, and gender in Appalachia.” Frontiers, IX (3).

Marfork Coal Company, 2007. "Monitoring and emergency warning plan and procedures for the Brushy Fork Slurry Impoundment.” Oak Hill DEP. 
McCormick, B. C., Eshleman, K. N., Griffith, J.L., and P. A. Townsend. 2009.

"Detection of flooding responses at the river basin scale enhanced by land use change.” Water Resources Reseatch, Vol 45, W08401.

McLafferty, S. 2002. “Mapping women’s worlds: Knowledge, Power, and the bounds of GIS.” Gender, Place, and Culture. 9(3): 263-269.

McLafferty, S. 2005. "Women and GIS: Geospatial Technologies and Feminist Geographies.” Special issue: Critical GIS. Harvey, F., Kwan, M, and M. Pavlovskaya, eds. Cartographica 40(4).

Mitchell, R.D., ed. 1991. Appalachian Frontiers: Settlement, Society and Development in the Preindustrial Era. Lexington: University of Kentucky Press.

Negley, T. and K. Eshleman. 2006. "Comparison of stormflow responses of surfacemined and forested watersheds in the Appalachian Mountains, USA." Hydrological Processes. Vol. 20,16, published Online: 3 Apr 2006.

Oberhauser, A.M. and A.M.Turnage. 1999. “A Coalfield Tapestry: Weaving the Socioeconomic Fabric of Women's Lives.” In Neither Separate Nor Equal: Women, Race, and Class in the South, ed. B. E. Smith, 109-122. Philadelphia: Temple University Press.

Oberhauser, A.M. 1995. "Gender and Household Economic Strategies in Rural Appalachia.” Gender, Place and Culture 2(1): 51-70.

Osha, J. and D. Weiner. 2006. "Participatory GIS - A Paradigm Shift in Development?” Directions Magazine. www.directionsmag.com/article.php? article_id=2365\&trv=1.

Palmer, M., Bernhardt, E., Schlesinger, W., Eshleman, K., Foufoula-Georgius, E., Hendryx, M., Lemly, A., Likens, G., Loucks, O., Power, M., White, P., and P. Wilcock. 2010. “Mountaintop Mining Consequences.” Science 8 January 2010: Vol. 327. no. 5962.

Pavlovskaya, M. 2006. “Theorizing with GIS: a tool for critical geographies?” Environment and Planning. 38(11):2003-2020.

Pickles, J. 1995. Ground truth: The social implications of geographic information systems. Guilford Press, Kentucky.

Pudup, M.B, Billings, D.B., and A.L. Waller. 1995. Appalachia in the Making: The Mountain South in the Nineteenth Century. Chapel Hill: University of North Carolina Press. 
Quinn, H.P. 2007. Statement made before the United States House of Representatives Committee on Natural Resources, relating to $30^{\text {th }}$ anniversary review of SMCRA. July 25, 2007. Senior Vice president and General Counsel, National Mining Association.

Rambaldi, G., Chambers, R., McCall, M., and Fox, J. 2006. "Practical ethics for PGIS practitioners, facilitators, technology intermediaries, and researchers.” Participatory Learning and Action 54, 106-113.

Rasmussen, B. 1994. Absentee Landowning \& Exploitation in West Virginia, 17601920. Lexington: University Press of Kentucky.

Scott, S.L. 1995. Two sides to everything: The cultural construction of class consciousness in Harlan County, KY. New York: SUNY Press.

Semple, E.C. 1903. “The Influence of the Appalachian Barrier Upon Colonial History.” American History and its Geographic Conditions. New York: Houghton. Pgs 36-51.

Shapiro, T. 2010. Mountain Justice: Homegrown Resistance to Mountaintop Removal, for the Future of Us All. Oakland Press: AK Press.

Sieber, R. 2000. "Conforming (to) the Opposition: the Social Construction of Geographical Information Systems in Social Movements.” International Journal of Geographical Information Science, 14(8): 775-793.

Smith, N. 1992. "History and philosophy of geography: real wars, theory wars." Progress in Human Geography 16(2):257-271.

Taylor, E.M. 1992. “The Taxidermy of bioluminescence: Tracking "neighboring” practices in the coal-camps of West Virginia.” Anthropological Quarterly, 65 (3): 117-127.

Thompson, V.T. 1995. Our Thompson Heritage. Charleston: West Virginia Educational Services Print Shop.

Tickamyer, A.R. and C. Tickamyer. 1991. "Gender, family structure, and poverty in central Appalachia.” In B. Ergood and B. Kuhre (Eds.), Appalachia: Social Context Past and Present (pp.307-315). Dubuque, Iowa: Kendall/Hunt Publishing Company.

Trotter, J.W. Jr. 1990. Coal, class, and color: Blacks in Southern West Virginia, 19151932. Urbana: University of Illinois Press.

Waller, A.L. 1988. Feud: Hatfields, McCoys, and Social Change in Appalachia, 1860 1900. Chapel Hill: The University of North Carolina Press. 
Walls, D.S. 1978. “Internal Colony or Internal Periphery? A Critique of Current Models and an Alternative Formulation." Colonialism in Modern America: The Appalachian Case. H.M. Lewis, L. Johnson, and D. Askins, eds.

Ward, K. 2009. “Sen. Byrd: 'Coal Must Embrace the Future.”' Coal Tattoo: Mining's Mark on our World, The Charleston Gazette, Dec. 9. 2009. blogs.wvgazette.com/coaltattoo/2009/12/03/sen-byrd-coal-must-embrace-the-future/

Weiner, D., Harris, T., and W. Craig. 2002. "Community participation and geographic information systems.” In Craig, W.J., Harris, T.M., and D. Weiner (Eds.), Community participation and geographic systems. New York, NY: Taylor and Francis.

Weise, R.S. 2001. Grasping at Independence: Debt, Male Authority, and Mineral Rights in Appalachian Kentucky, 1850-1915. Knoxville: University of Tennessee Press, 2001.

Weller, J.E. 1965. “The Mountaineer in His Society.” Yesterday’s People. University Press of Kentucky.

Williams, J.A. 2001. West Virginia: A History. Morgantown: West Virginia University Press.

Wood, D. 1992. The power of maps. New York: Guilford Press.

Wood, D. 2003. “Cartography is dead (thank God!).” Cartographic Perspectives 45:4-7.

Wood, J. 1994. Raleigh County, West Virginia. Raleigh County Historical Society. BJW Printing and Office Supplies: Beckley, WV. 1994. 


\section{Appendix 1: Bee Tree Surface Mine Permit}

\begin{tabular}{|c|c|c|c|c|c|}
\hline \multicolumn{6}{|c|}{ (1) Permit } \\
\hline \multicolumn{3}{|c|}{ PERMITTEE } & \multicolumn{3}{|c|}{ MARFORK COAL COMPANY INC } \\
\hline \multicolumn{3}{|c|}{ DEP OFFICE } & \multicolumn{3}{|c|}{ OMR } \\
\hline \multicolumn{3}{|c|}{ PERMIT ID } & \multicolumn{3}{|c|}{ S301004 } \\
\hline \multicolumn{3}{|c|}{ ISSUE DATE } & \multicolumn{3}{|c|}{$07 / 11 / 06$} \\
\hline \multicolumn{3}{|c|}{ EXPIRATION DATE } & \multicolumn{3}{|c|}{$07 / 11 / 11$} \\
\hline \multicolumn{3}{|c|}{ FACILITY NAME } & \multicolumn{3}{|c|}{ Bee Tree Surface Mine } \\
\hline \multicolumn{3}{|c|}{ ORIGINIAL ACRES } & \multicolumn{3}{|c|}{1124} \\
\hline \multicolumn{6}{|c|}{ DISTURBED ACRES } \\
\hline \multicolumn{6}{|c|}{ RECLAIMED ACRES } \\
\hline \multicolumn{3}{|c|}{ CURRENT ACRES } & \multicolumn{3}{|c|}{1090} \\
\hline \multicolumn{6}{|c|}{ (1)Permit Status } \\
\hline \multicolumn{3}{|c|}{ ACTIVE YES/NO } & \multicolumn{3}{|l|}{$\mathrm{N}$} \\
\hline \multicolumn{3}{|c|}{ OPEN/CLOSED } & \multicolumn{3}{|l|}{$\mathrm{O}$} \\
\hline \multicolumn{3}{|l|}{ STATUS } & \multicolumn{3}{|l|}{ New } \\
\hline \multicolumn{3}{|c|}{ ACTIVITY ALLOWED } & \multicolumn{3}{|c|}{ Contour - Surface } \\
\hline \multicolumn{3}{|c|}{ ACTIVITY ALLOWED } & \multicolumn{3}{|c|}{ Highwall Miner - Surface } \\
\hline \multicolumn{3}{|c|}{ ACTIVITY ALLOWED } & \multicolumn{3}{|c|}{ Steep Slope - Surface } \\
\hline \multicolumn{6}{|c|}{ (5) Permit Activities } \\
\hline OFFICE & \begin{tabular}{|l|} 
ACRES \\
ADDED
\end{tabular} & $\begin{array}{r}\text { ACRES } \\
\text { DELETE }\end{array}$ & MILESTONE & DATE & COMMENT \\
\hline OMR & 0 & 0 & Revision & $07 / 10 / 08$ & $\begin{array}{l}\text { Permit } \\
\text { Revised }\end{array}$ \\
\hline OMR & 0 & 0 & \begin{tabular}{|l} 
Increment \\
Start
\end{tabular} & $09 / 12 / 08$ & \begin{tabular}{|l} 
Increment \\
Started
\end{tabular} \\
\hline OMR & 1 & 35 & \begin{tabular}{|l|} 
Incidental \\
Boundary \\
Revision
\end{tabular} & $11 / 20 / 08$ & \begin{tabular}{|l|} 
Incidental \\
Boundary \\
Revision
\end{tabular} \\
\hline OMR & 6 & 6 & \begin{tabular}{|l|} 
Incidental \\
Boundary \\
Revision
\end{tabular} & $11 / 03 / 09$ & \begin{tabular}{|l} 
Incidental \\
Boundary \\
Revision
\end{tabular} \\
\hline$\overline{\mathrm{OMR}}$ & 0 & 0 & Revision & $03 / 12 / 10$ & Permit \\
\hline
\end{tabular}




\begin{tabular}{|c|c|c|c|}
\hline & & \multicolumn{2}{|c|}{ Revised } \\
\hline \multicolumn{4}{|c|}{ (7) Land Uses } \\
\hline Premining Land Use & \multicolumn{2}{|c|}{ Fish and Wildlife Habitat/Recreation } & Acres: \\
\hline Premining Land Use & \multicolumn{2}{|c|}{ Previously Mined and Not Reclaimed } & Acres: \\
\hline Premining Land Use & \multicolumn{2}{|c|}{ Forestland } & Acres: \\
\hline Premining Land Use & \multicolumn{2}{|c|}{ Combined } & Acres: \\
\hline Postmining Land Use & \multicolumn{2}{|c|}{ Fish and Wildlife Habitat/Recreation } & Acres: \\
\hline Postmining Land Use & \multicolumn{2}{|c|}{ Forestland } & Acres: \\
\hline Postmining Land Use & \multicolumn{2}{|c|}{ Combined } & Acres: \\
\hline \multicolumn{4}{|c|}{ (5) Variances } \\
\hline Permit Variance & \multicolumn{3}{|c|}{ Contemporaneous reclamation variance } \\
\hline Permit Variance & \multicolumn{3}{|c|}{ In-stream drainage control } \\
\hline Permit Variance & \multicolumn{3}{|c|}{ Subsidence Control Plan } \\
\hline Permit Variance & \multicolumn{3}{|c|}{ Topsoil Substitutes } \\
\hline Permit Variance & \multicolumn{3}{|c|}{ Within 100 feet of a stream } \\
\hline \multicolumn{4}{|c|}{ (2) County / Quad } \\
\hline \multicolumn{2}{|l|}{ County: Raleigh } & \multicolumn{2}{|c|}{ Quad: WHITESVILLE } \\
\hline \multicolumn{2}{|l|}{ County: Raleigh } & \multicolumn{2}{|c|}{ Quad: DOROTHY } \\
\hline \multicolumn{4}{|c|}{ (46) Inspectable Units } \\
\hline \multicolumn{2}{|c|}{ INSPECTABLE UNIT CODE } & \multicolumn{2}{|l|}{ TYPE } \\
\hline \multicolumn{2}{|l|}{ ENTIRE } & \multicolumn{2}{|l|}{ Surface Coal Mine } \\
\hline \multicolumn{2}{|l|}{ VALLEY FILL 1} & \multicolumn{2}{|l|}{ Valley Fill } \\
\hline VALLEY FILL 3 & & Valley Fill & \\
\hline VALLEY FILL 6 & & Valley Fill & \\
\hline VALLEY FILL 5 & & Valley Fill & \\
\hline VALLEY FILL 4 & & Valley Fill & \\
\hline VALLEY FILL 2 & & Valley Fill & \\
\hline
\end{tabular}




\section{Appendix 2: Eagle No 2 Surface Mine Permit}

\begin{tabular}{|c|c|c|c|}
\hline \multicolumn{4}{|c|}{ (1) Permit } \\
\hline PERMITTEE & \multicolumn{3}{|c|}{ MARFORK COAL COMPANY INC } \\
\hline DEP OFFICE & \multicolumn{3}{|c|}{ OMR } \\
\hline PERMIT ID & \multicolumn{3}{|c|}{ S302805 } \\
\hline ISSUE DATE & \multicolumn{3}{|c|}{ 06/06/08 } \\
\hline EXPIRATION DATE & \multicolumn{3}{|c|}{ 06/06/13 } \\
\hline FACILITY NAME & \multicolumn{3}{|c|}{ Eagle No. 2 Surface Mine } \\
\hline ORIGINIAL ACRES & \multicolumn{3}{|c|}{2039.89} \\
\hline \multicolumn{4}{|l|}{ DISTURBED ACRES } \\
\hline \multicolumn{4}{|l|}{ RECLAIMED ACRES } \\
\hline \multicolumn{2}{|l|}{ CURRENT ACRES } & \multicolumn{2}{|c|}{2039.89} \\
\hline \multicolumn{4}{|c|}{ (1)Permit Status } \\
\hline ACTIVE YES/NO & & \multicolumn{2}{|l|}{$\mathrm{N}$} \\
\hline OPEN/CLOSED & & \multicolumn{2}{|l|}{$O$} \\
\hline \multicolumn{2}{|l|}{ STATUS } & \multicolumn{2}{|l|}{ New } \\
\hline \multicolumn{2}{|l|}{ ACTIVITY ALLOWED } & \multicolumn{2}{|l|}{ Area Mine - Surface } \\
\hline \multicolumn{2}{|l|}{ ACTIVITY ALLOWED } & \multicolumn{2}{|l|}{ Contour - Surface } \\
\hline \multicolumn{2}{|l|}{ ACTIVITY ALLOWED } & \multicolumn{2}{|l|}{ Highwall Miner - Surface } \\
\hline \multicolumn{2}{|l|}{ ACTIVITY ALLOWED } & Steep Slope - Surface & \\
\hline & & and Uses & \\
\hline Premining Land Use & Cor & & Acres: \\
\hline Premining Land Use & Fisl & Wildlife Habitat/Recreation & Acres: \\
\hline Premining Land Use & For & & Acres: \\
\hline Postmining Land Use & For & & Acres: \\
\hline Postmining Land Use & Cor & & Acres: \\
\hline Postmining Land Use & Fisl & Wildlife Habitat/Recreation & Acres: \\
\hline & & ariances & \\
\hline Permit Variance & Co-m & g of waters & \\
\hline Permit Variance & Conte & aneous reclamation variance & \\
\hline Permit Variance & Subsi & Control Plan & \\
\hline
\end{tabular}




\begin{tabular}{|c|c|c|}
\hline Permit Variance & \multicolumn{2}{|c|}{ Topsoil Substitutes } \\
\hline Permit Variance & \multicolumn{2}{|c|}{ Within 100 feet of a stream } \\
\hline \multicolumn{3}{|c|}{ (1) County / Quad } \\
\hline \multicolumn{3}{|c|}{ Quad: DOROTHY } \\
\hline \multicolumn{3}{|c|}{ (53) Inspectable Units } \\
\hline \multicolumn{2}{|c|}{ INSPECTABLE UNIT CODE } & TYPE \\
\hline \multicolumn{2}{|l|}{ ENTIRE } & Surface Coal Mine \\
\hline \multicolumn{2}{|l|}{ FILL NO. 4} & Valley Fill \\
\hline \multicolumn{2}{|l|}{ FILL NO. 6} & Valley Fill \\
\hline \multicolumn{2}{|l|}{ FILL NO. 5} & Valley Fill \\
\hline \multicolumn{2}{|l|}{ FILL NO. 2} & Valley Fill \\
\hline \multicolumn{2}{|l|}{ FILL NO. 1} & Valley Fill \\
\hline \multicolumn{2}{|l|}{ FILL NO. 3} & Valley Fill \\
\hline
\end{tabular}




\section{Appendix 3: Leather Leaf Pending Surface Mine Permit}

\begin{tabular}{|l|l|}
\hline \multicolumn{3}{|c|}{ SMA Application } \\
\hline DEP OFFICE ID & OMR \\
\hline NEW PERMIT ID & S300210 \\
\hline APPLICANT & $\begin{array}{l}\text { MARFORK COAL COMPANY } \\
\text { INC }\end{array}$ \\
\hline FACILITY NAME & Leather Leaf Surface Mine \\
\hline PERMIT_TYPE & Coal Surface Mine \\
\hline PROPOSED ACRES & 1,270.36 \\
\hline PERMIT TERM YEARS & 5.00 \\
\hline MSHA ID & Pending \\
\hline SOAP(Small Operator Assistance)? & N \\
\hline SOAP ACCOUNT ID & \\
\hline BONDING TYPE & Incremental Bonding \\
\hline $\begin{array}{l}\text { BLASTING INSURANCE } \\
\text { REQUIRED? }\end{array}$ & N \\
\hline \hline \multicolumn{3}{|c|}{$(\mathbf{4 )}$ Activities Allowed } \\
\hline Activity Allowed & Area Mine - Surface \\
\hline Activity Allowed & Contour - Surface \\
\hline Activity Allowed & Highwall Miner - Surface \\
\hline Activity Allowed & Steep Slope - Surface \\
\hline \hline \multicolumn{2}{|c|}{$\mathbf{( 2 )}$ Land Uses } \\
\hline Premining Land Use & Forestland \\
\hline Postmining Land Use & Forestland \\
\hline \multicolumn{2}{|c|}{ Contemporaneous reclamation variance } \\
\hline Application Variance & Acres: \\
\hline Application Variance & Subsidence Control Plan \\
\hline Application Variance & Topsoil Substitutes \\
\hline Application Variance & Within 100 feet of a stream \\
\hline \multicolumn{2}{|c|}{ Qunty / Quad } \\
\hline
\end{tabular}




\begin{tabular}{|l|l|}
\hline County: Raleigh & Quad: DOROTHY \\
\hline \hline \multicolumn{2}{|c|}{$(\mathbf{1})$ Inspectable Units } \\
\hline INSPECTABLE UNIT ID & ENTIRE \\
\hline TYPE & Surface Coal Mine \\
\hline CERTIFIED? & \\
\hline PERMANENT STRUCTURE? & \\
\hline
\end{tabular}




\section{Appendix 4: Questions for Semi-Structured Interviews}

1) What are the views of concerned residents on natural landscape change as a result of MTR within the study area thus far?

Do you have any concerns about how mountaintop removal (MTR) has affected the land here in Coal River? the water? the air?

(possible word choices: vegetation, plants, gardens, forest, trees)

2) Do you have any concerns about the impacts of the proposed mountaintop removal sites on Coal River Mountain?

3) How do concerned residents envision alternative land use within the valley?

If no more permits were granted for MTR, how would you like to see the land used?

3.a. What types of jobs would you like to see in place of jobs created by MTR?

3.b. Are there particular areas that you would like to see reclaimed?

(possible word choices: reforested, cleaned up) 


\section{Appendix 5: Quantitative Data of Participants in Case Study Area}

\begin{tabular}{|c|c|c|c|c|c|c|c|c|c|}
\hline $\begin{array}{c}\text { Coal } \\
\text { River } \\
\text { Resident } \\
\#\end{array}$ & Gender & $\begin{array}{l}\text { Age } \\
\text { Group }\end{array}$ & $\begin{array}{c}\text { Years of } \\
\text { Residency } \\
\text { in Coal } \\
\text { River }\end{array}$ & Residence & $\begin{array}{c}\text { Coal } \\
\text { Industry } \\
\text { Employment }\end{array}$ & Union & $\begin{array}{c}\text { Surface I } \\
\text { Underground }\end{array}$ & $\begin{array}{l}\text { Employed in } \\
\text { different } \\
\text { industry }\end{array}$ & $\begin{array}{l}\text { Family } \\
\text { history of } \\
\text { coal } \\
\text { mining }\end{array}$ \\
\hline 1 & $M$ & $50-59$ & $20-29$ & Rock Creek & Retired & Union & Surface & - & yes \\
\hline 2 & $\mathrm{~F}$ & $50-59$ & $50-59$ & Rock Creek & No & - & - & Full Time & yes \\
\hline 3 & $M$ & $40-49$ & $30-39$ & Naoma & No & - & - & Part Time & yes \\
\hline 4 & $\mathrm{~F}$ & $70-79$ & $20-29$ & Naoma & No & - & - & $\begin{array}{c}\text { Stay at Home } \\
\text { Mother }\end{array}$ & yes \\
\hline 5 & $\mathrm{~F}$ & $80-89$ & $80-89$ & Naoma & Retired & Union & Underground & - & yes \\
\hline 6 & $M$ & $60-69$ & $60-69$ & Horse Creek & No & - & - & $\begin{array}{l}\text { Retired Mine } \\
\text { Inspector }\end{array}$ & yes \\
\hline 7 & $\mathrm{~F}$ & $60-69$ & $30-39$ & Horse Creek & No & - & - & $\begin{array}{c}\text { Stay at Home } \\
\text { Mother }\end{array}$ & yes \\
\hline 8 & $M$ & $60-69$ & $60-69$ & Horse Creek & Current & Union & Underground & - & yes \\
\hline 9 & $\mathrm{~F}$ & $60-69$ & $60-69$ & Horse Creek & No & - & - & $\begin{array}{l}\text { Stay at Home } \\
\text { Mother }\end{array}$ & yes \\
\hline 10 & $M$ & $40-49$ & $30-39$ & Horse Creek & No & - & - & Part Time & yes \\
\hline 11 & $M$ & $50-59$ & $50-59$ & Naoma & Current & Union & Both & - & yes \\
\hline 12 & $M$ & $30-39$ & $20-29$ & Naoma & Current & $\begin{array}{l}\text { Non } \\
\text { Union }\end{array}$ & Underground & - & yes \\
\hline 13 & $\mathrm{~F}$ & $90-99$ & $90-99$ & Edwight & No & - & - & $\begin{array}{l}\text { Stay at Home } \\
\text { Mother and } \\
\text { Part Time } \\
\text { work }\end{array}$ & yes \\
\hline 14 & $M$ & $60-69$ & $60-69$ & Edwight & No & - & - & Retired & yes \\
\hline 15 & $M$ & $50-59$ & $50-59$ & Dameron & Retired & Union & Underground & - & yes \\
\hline 16 & $\mathrm{~F}$ & $40-49$ & $40-49$ & Dameron & No & - & - & Part Time & yes \\
\hline
\end{tabular}




\begin{tabular}{|c|c|c|c|c|c|c|c|c|c|}
\hline 17 & $\mathrm{M}$ & $60-69$ & $30-39$ & Hamlin & No & - & - & Full Time & yes \\
\hline 18 & M & $60-69$ & $30-39$ & Horse Creek & Retired & $\begin{array}{l}\text { Union } \\
\text { and } \\
\text { Salary }\end{array}$ & Underground & - & yes \\
\hline 19 & $\mathrm{~F}$ & $30-39$ & $30-39$ & Horse Creek & No & - & - & Full Time & yes \\
\hline 20 & $\mathrm{~F}$ & $50-59$ & $50-59$ & Rock Creek & No & - & - & Full Time & yes \\
\hline 21 & $M$ & $70-79$ & $70-79$ & Dry Creek & Retired & Union & Underground & & yes \\
\hline 22 & $\mathrm{M}$ & $40-49$ & $40-49$ & Rock Creek & No & - & - & Part Time & yes \\
\hline 23 & $\mathrm{M}$ & $40-49$ & $40-49$ & Dry Creek & Current & - & Surface & - & yes \\
\hline 24 & $M$ & $50-50$ & $30-39$ & Whitesville & No & - & - & Full Time & yes \\
\hline 25 & $\mathrm{M}$ & $70-79$ & 10 to 19 & Colcord & No & - & - & Retired & yes \\
\hline 26 & $\mathrm{~F}$ & $60-69$ & $30-39$ & Colcord & No & - & - & Retired & no \\
\hline 27 & $F$ & $60-69$ & $40-49$ & Sycamore & No & - & - & $\begin{array}{c}\text { Stay at Home } \\
\text { Mother }\end{array}$ & yes \\
\hline 28 & $\mathrm{M}$ & $70-79$ & $60-69$ & Colcord & Retired & Union & Underground & - & yes \\
\hline 29 & $\mathrm{~F}$ & $70-79$ & $70-79$ & Colcord & No & - & - & $\begin{array}{c}\text { Stay at Home } \\
\text { Mother }\end{array}$ & yes \\
\hline 30 & $\mathrm{M}$ & $50-59$ & $50-59$ & Pettry Bottom & Retired & Union & Underground & - & yes \\
\hline 31 & $\mathrm{M}$ & 70-79 & $70-79$ & Pettry Bottom & Retired & Union & Underground & - & yes \\
\hline 32 & $\mathrm{~F}$ & $60-69$ & $60-69$ & Pettry Bottom & No & - & - & $\begin{array}{c}\text { Stay at Home } \\
\text { Mother }\end{array}$ & yes \\
\hline 33 & $M$ & $70-79$ & $70-79$ & Sycamore & Retired & Union & Underground & & yes \\
\hline 34 & $F$ & $30-39$ & $0-9$ & Sycamore & No & - & - & $\begin{array}{c}\text { Stay at Home } \\
\text { Mother }\end{array}$ & yes \\
\hline 35 & $\mathrm{M}$ & $60-69$ & $60-69$ & Sycamore & No & - & - & Full Time & yes \\
\hline 36 & $\mathrm{~F}$ & $50-59$ & $0-9$ & Sycamore & No & - & - & Part Time & yes \\
\hline 37 & $\mathrm{~F}$ & $30-39$ & $0-9$ & Sycamore & No & - & - & $\begin{array}{c}\text { Stay at Home } \\
\text { Mother }\end{array}$ & yes \\
\hline 38 & $\mathrm{M}$ & $60-69$ & 10 to 19 & Horse Creek & Quit & Union & Underground & Part Time & no \\
\hline
\end{tabular}




\begin{tabular}{|c|c|c|c|c|c|c|c|c|c|}
\hline 39 & $\mathrm{M}$ & $70-79$ & $60-69$ & Horse Creek & Retired & Union & Underground & - & no \\
\hline 40 & $\mathrm{M}$ & $60-69$ & $60-69$ & Horse Creek & No & - & - & Retired & yes \\
\hline 41 & $\mathrm{M}$ & $50-59$ & $40-49$ & Naoma & Current & Union & Underground & - & yes \\
\hline 42 & $\mathrm{M}$ & $60-69$ & $60-69$ & Peachtree & No & - & - & Part Time & no \\
\hline 43 & $\mathrm{~F}$ & $20-29$ & $0-9$ & Pettry Bottom & No & - & - & $\begin{array}{c}\text { Stay at Home } \\
\text { Mother }\end{array}$ & yes \\
\hline 44 & $M$ & $20-29$ & $20-29$ & Pettry Bottom & No & - & - & Part Time & yes \\
\hline 45 & $\mathrm{M}$ & $50-59$ & $50-59$ & Pettry Bottom & Retired & Union & Underground & $\begin{array}{l}\text { retired, non } \\
\text { coal }\end{array}$ & no \\
\hline 46 & $\mathrm{~F}$ & $50-59$ & $20-29$ & Rock Creek & No & - & - & Full Time & yes \\
\hline 47 & $\mathrm{M}$ & $50-59$ & $50-59$ & Rock Creek & Retired & Union & Underground & - & yes \\
\hline 48 & $\mathrm{M}$ & $60-69$ & $60-69$ & Rock Creek & Retired & Union & Underground & - & yes \\
\hline 49 & $\mathrm{M}$ & $50-59$ & $20-29$ & $\begin{array}{l}\text { Girl Scout } \\
\text { Camp }\end{array}$ & No & - & - & Disability & yes \\
\hline 50 & $\mathrm{M}$ & $60-69$ & $60-69$ & Rock Creek & No & - & - & Disability & no \\
\hline 51 & $\mathrm{M}$ & $50-59$ & $50-59$ & Naoma & No & - & - & Part Time & no \\
\hline 52 & $\mathrm{M}$ & $30-39$ & $30-39$ & Horse Creek & No & - & - & Full Time & yes \\
\hline 53 & $\mathrm{M}$ & $40-49$ & 10 to 19 & Horse Creek & No & - & - & Full Time & no \\
\hline 54 & $\mathrm{M}$ & $60-69$ & $20-29$ & Edwight & No & - & - & Part Time & yes \\
\hline 55 & $\mathrm{M}$ & $50-59$ & 10 to 19 & Colcord & Current & Union & both & - & no \\
\hline 56 & $\mathrm{~F}$ & $60-69$ & $50-59$ & Colcord & No & - & - & Part Time & no \\
\hline 57 & $\mathrm{M}$ & $50-59$ & $50-59$ & Colcord & Current & Union & Underground & - & yes \\
\hline 58 & $\mathrm{~F}$ & $50-59$ & $50-59$ & Colcord & No & - & - & Retired & yes \\
\hline 59 & $\mathrm{M}$ & $70-79$ & $0-9$ & Rock Creek & No & - & - & Retired & no \\
\hline 60 & $\mathrm{~F}$ & $40-49$ & 10 to 19 & Pettry Bottom & No & - & - & $\begin{array}{c}\text { Stay at Home } \\
\text { Mother }\end{array}$ & yes \\
\hline
\end{tabular}

